\title{
Identification and functional characterisation of oncogenic pathway signatures in malignant Lymphoma
}

\author{
Doctoral Thesis \\ In partial fulfilment of the requirements for the degree \\ "Doctor rerum naturalium (Dr. rer. nat.)" \\ in the Molecular Medicine Study Program \\ at the Georg-August University Göttingen
}

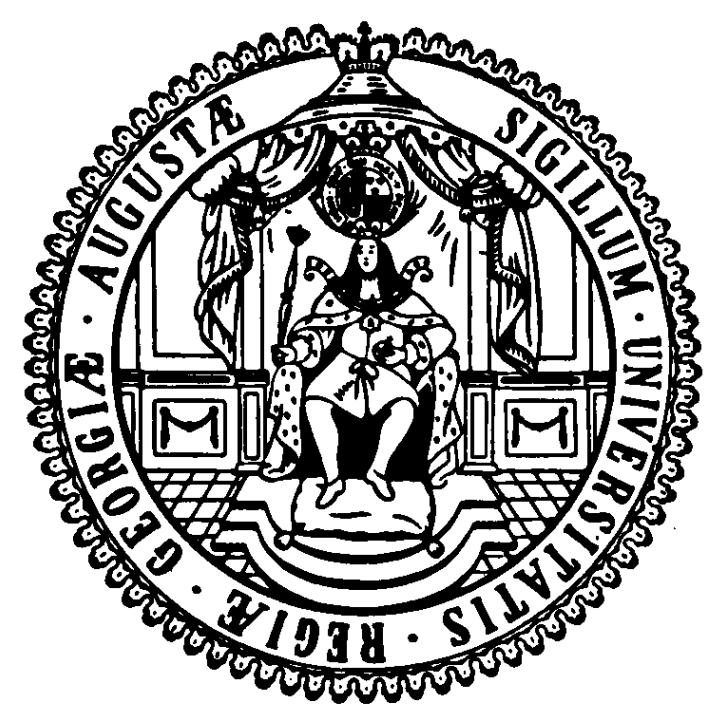

Graduate School 1034

submitted by Alexandra Schrader

born in Soest

Göttingen, 2011 



\section{Thesis Committee}

Prof Dr. Dieter Kube (Supervisor)

E-Mail

dkube@med.uni-goettingen.de

Phone

0049-551-391537

Postal Address

Universitätsmedizin Göttingen

Zentrum Innere Medizin

Abteilung Hämatologie und Onkologie

Robert-Koch-Straße 40

37075 Göttingen

\section{Prof Dr. Heidi Hahn}

E-Mail

hhahn@gwdg.de

Phone

0049-551-39-14010

Postal Address

Universitätsmedizin Göttingen

Zentrum Hygiene und Humangenetik

Institut für Humangenetik

Heinrich-Düker-Weg 12

37073 Göttingen

Prof Dr. Martin Oppermann

E-Mail

mopperm@gwdg.de

Phone

0049-551-395822

Postal Address

Universitätsmedizin Göttingen

Zentrum Hygiene und Humangenetik

Abteilung Zelluläre und Molekulare Immunologie

Humboldtallee 34

37073 Göttingen

Date of Disputation:

22.09.2011 



\section{Affidavit}

By this I declare that I independently authored the presented thesis:

\section{"Identification and functional characterisation of oncogenic pathway signatures in malignant Lymphoma"}

and that I did not use other auxiliary means than indicated. Paragraphs that are taken from other publications, by wording or by sense, are marked in every case with a specification of the literary source.

Furthermore I declare that I carried out the scientific experiments following the principles of Good Scientific Practice according to the valid "Richtlinien der Georg-August-Universität Göttingen zur Sicherung guter wissenschaftlicher Praxis".

Alexandra Schrader

Göttingen, July 2011 

Table of Contents

\begin{tabular}{|c|c|}
\hline \multirow{2}{*}{\multicolumn{2}{|c|}{ Abstract }} \\
\hline & \\
\hline \multicolumn{2}{|r|}{ List 0 tables. } \\
\hline \multicolumn{2}{|r|}{ Abbreviations } \\
\hline 1 & Introduction \\
\hline 1.1 & Burkitt Lymphoma (BL) \\
\hline 1.1 .1 & 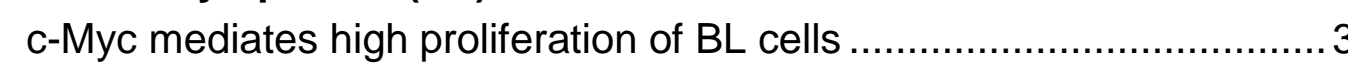 \\
\hline 1.1 .2 & The c-Myc target gene network affects $15 \%$ of all genes....................... 3 \\
\hline 1.1 .3 & Gene expression profiling has enabled the molecular diagnosis of $\mathrm{BL} . .4$ \\
\hline 1.1 .4 & $\begin{array}{l}\text { The microenvironmental factor BAFF might play a role for the survival o } \\
\mathrm{BL} \text { cells }\end{array}$ \\
\hline 1.1 .5 & Treatment strategy in $\mathrm{BL}$ \\
\hline 1.2 & 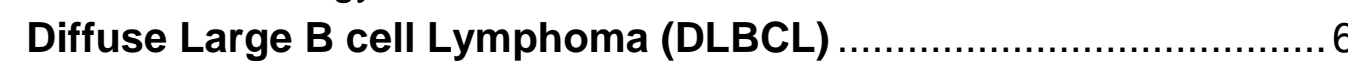 \\
\hline 1.2 .1 & $\begin{array}{l}\text { DLBCL are characterised by a complex karyotype involving the } \\
\text { translocation of BCL6. }\end{array}$ \\
\hline 1.2.2 & $\begin{array}{l}\text { DLBCL is characterised by a high aberrant activity of survival signals } \\
\text { including NF-KB. }\end{array}$ \\
\hline 1.2 .3 & Global gene expression profiling identified subgroups of DLBCL $\ldots \ldots \ldots . .7$ \\
\hline 1.2 .4 & 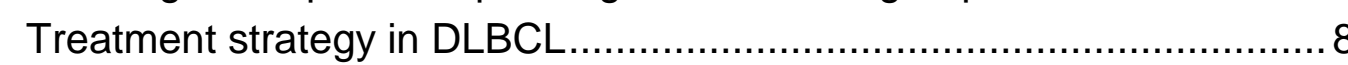 \\
\hline 1.3 & B cell Development and the Germinal Centre Reaction ................. 9 \\
\hline 1.4 & B cells are dependent on microenvironmental survival signals $\ldots . .11$ \\
\hline 1.4 .1 & $\begin{array}{l}\text { Nuclear factor of kappa B light polypeptide gene enhancer in B-cells } \\
\text { signalling }\end{array}$ \\
\hline 1.4 .2 & 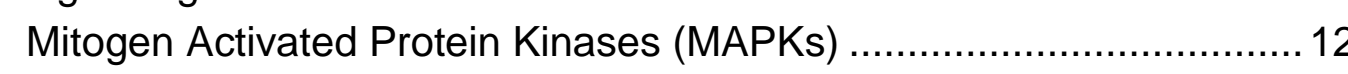 \\
\hline 1.4 .3 & $\begin{array}{l}\text { BCR activation triggers a variety of signalling pathways including } \\
\text { Calcium signalling, NF-KB, PIJK/AKT and MAPK activation } \ldots \ldots \ldots \ldots \ldots . . . . .13\end{array}$ \\
\hline 1.4 .4 & Toll like receptor mediated activation of NF-KB and MAPK signals......13 \\
\hline 1.4 .5 & 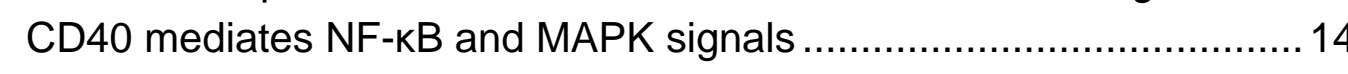 \\
\hline 1.4.6 & $\begin{array}{l}\text { B cell activating factor of the TNF superfamily (BAFF/ TNFSF13B) car } \\
\text { activate distinct TNF receptors that trigger noncanonical NF-KB and } \\
\text { MAPK signalling }\end{array}$ \\
\hline 1.4 .7 & IL21 signals via IL21R mediated STAT1 and STAT3 activity .............. 16 \\
\hline \multicolumn{2}{|r|}{ Aim of the Study } \\
\hline 2 & 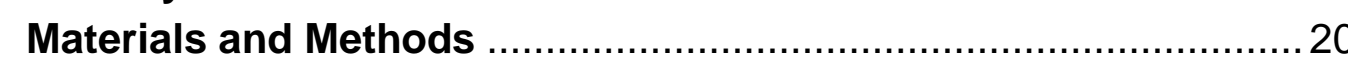 \\
\hline 2.1 & Biological Material ........................... \\
\hline 2.2 & Consumable supplies...................... \\
\hline 2.3 & 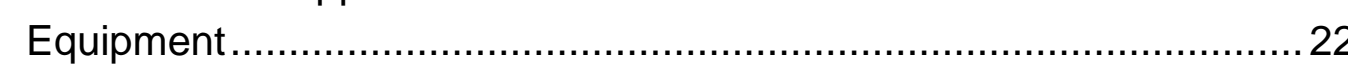 \\
\hline 2.4 & 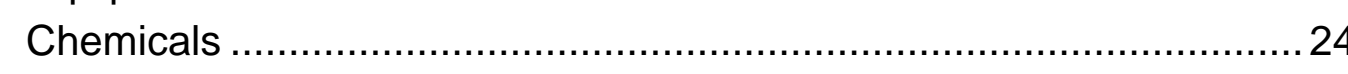 \\
\hline 2.5 & 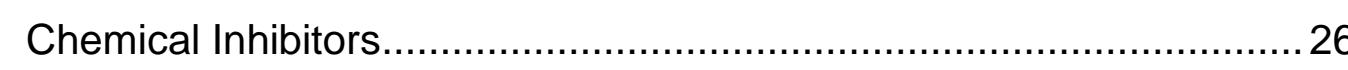 \\
\hline 2.6 & 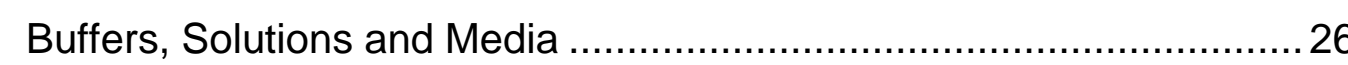 \\
\hline 2.7 & Plasmids \\
\hline
\end{tabular}




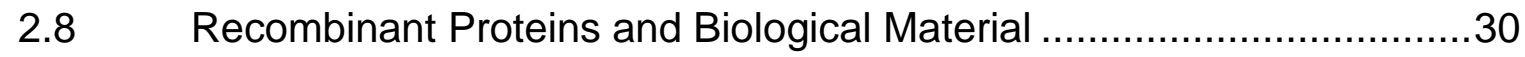

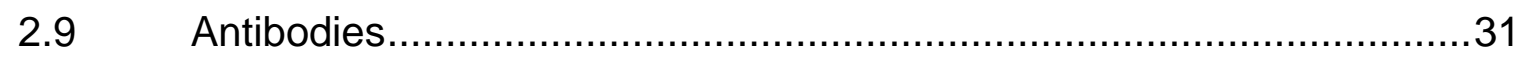

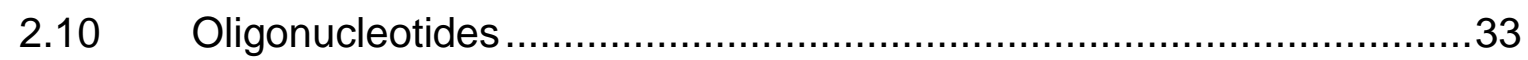

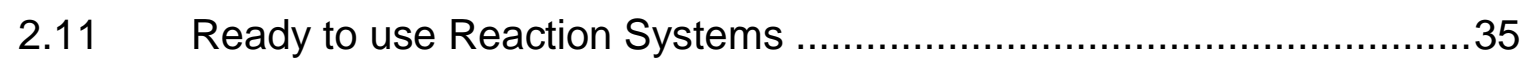

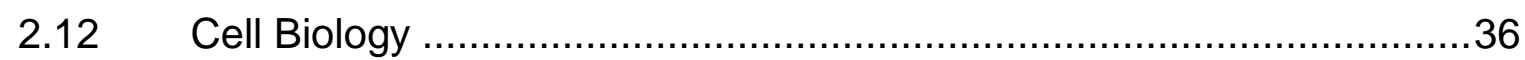

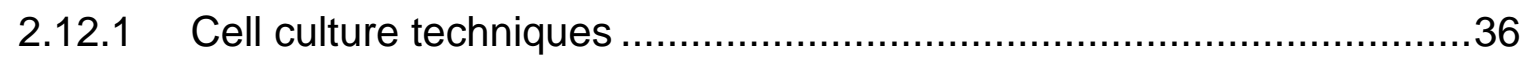

2.12.2 Isolation of Tonsillar Mononuclear Cells from human primary tissue ....36

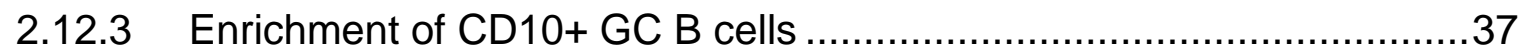

2.12.4 Transfection of $\mathrm{CD} 10^{+} \mathrm{B}$ cells via non-viral DNA transfer.....................37

2.12.5 Activation of $B$ cells with soluble stimulating factors ............................38

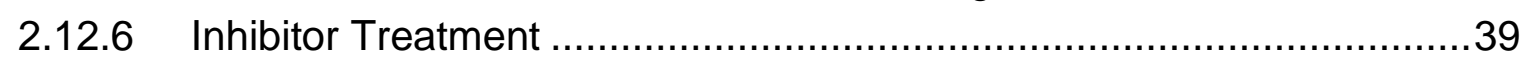

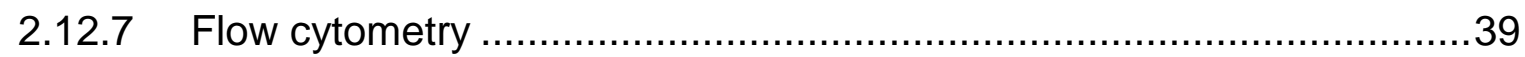

2.12.8 Characterisation of cell populations via flow cytometry ........................40

2.12.9 Preparative FACS of transfected CD10 ${ }^{+}$cells .....................................40

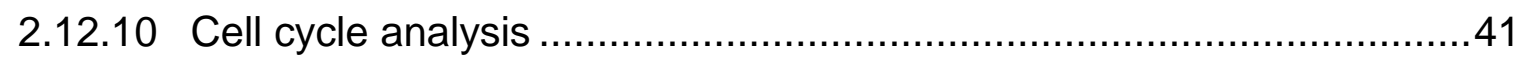

2.12.11 Synchronisation of BL cells using Thymidine treatment ......................42

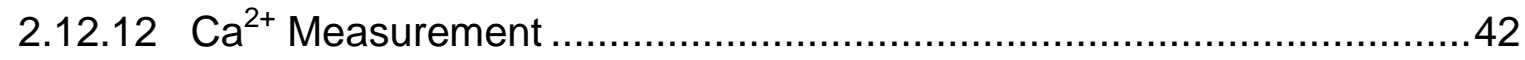

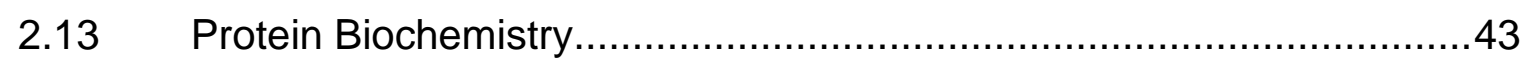

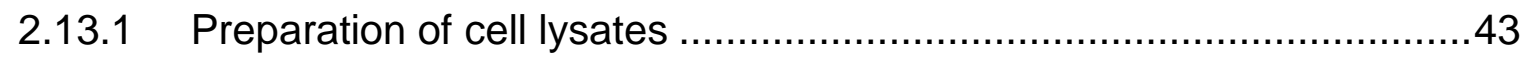

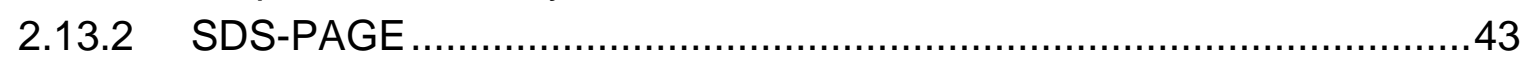

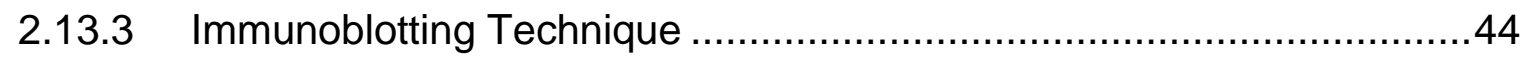

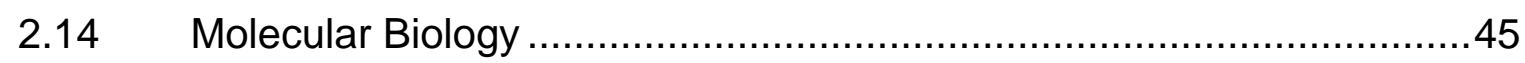

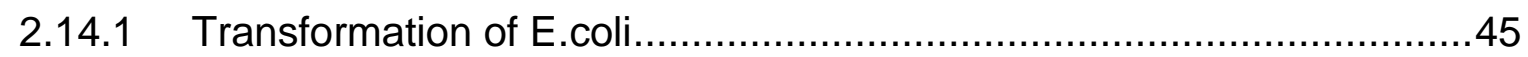

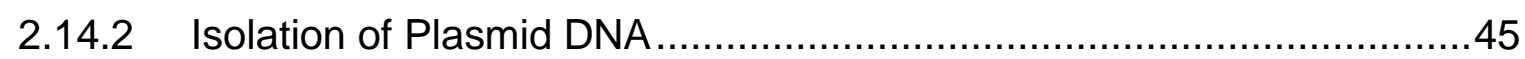

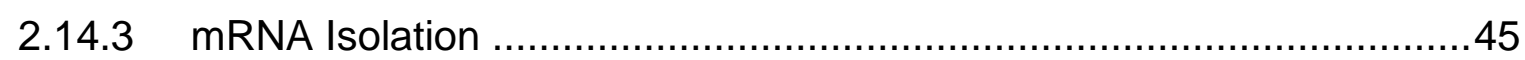

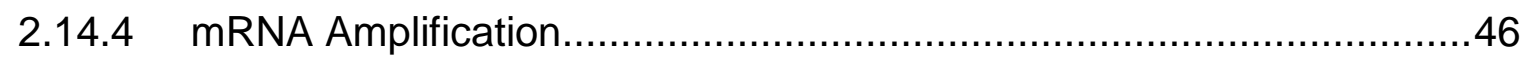

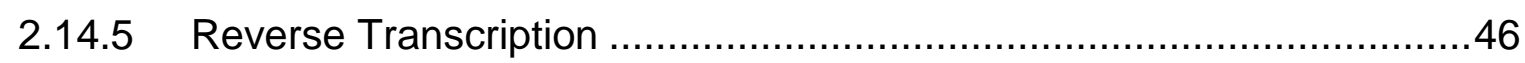

2.14.6 Transcript quantification via qRT-PCR (quantitative Real Time Polymerase Chain Reaction) .................................................... 47

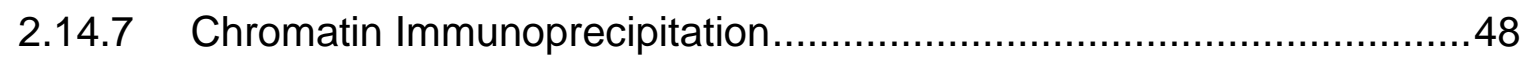

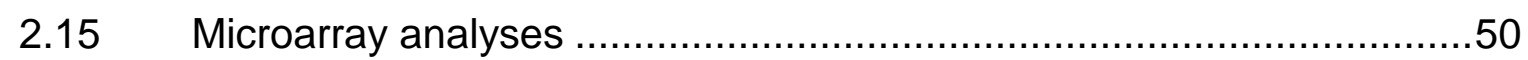

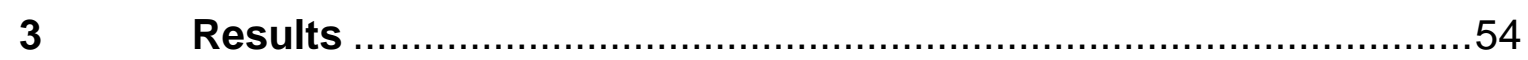

3.1 High c-Myc activity is an independent negative prognostic factor for diffuse large $B$ cell lymphomas .............................................54

3.1.1 Overexpression of C-Myc in primary human GC B cells ......................54

3.1.2 Ectopic c-Myc expression triggers a tumour like expression profile in primary GC B cells.....................................................................56

3.1.3 Very high expression of C-Myc target genes is a hallmark of molecular

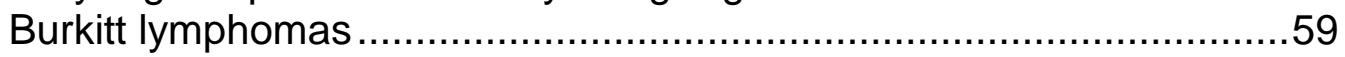

3.1.4 High expression of c-Myc inducible genes in the group of non-mBL and intermediate lymphomas is associated with shorter overall survival.....65 
3.2 Activation of BL cells with B cell specific microenvironmental factors triggers global changes in gene expression patterns useful to define pathway activity in individual lymphoma 68

3.2.1 anti-IgM, CD40L, IL21, BAFF and LPS stimulation activate an individual, partially overlapping pattern of pathways upon stimulation of Burkitt Lymphoma cells 69

3.2.2 Global changes in gene expression profile through specific in vitro BL cell stimulation............................................................................ 72

3.2.3 Distinct stimuli induce the differential expression of overlapping as well as specific target genes ................................................................ 75

3.2.4 Investigation of differential gene expression using qRT-PCR …..........79

3.2.5 Stimulation mediated gene expression changes in lymphoma precursor cells

3.2.6 Activated expression of DUSP2, DUSP5, DUSP10 and DUSP22 through BCR is dominantly mediated by ERK activation in contrast to MYC activation that is dominantly involves PI3K. 84

3.2.7 rhBAFF stimulation induces differential p38 signals in cell lines of distinct lymphoma entities independent of BAFF receptor expression. 86

3.2.8 Individual aNHL gene expression profiles exhibit a high similarity to the gene expression profiles of in vitro stimulated BL cells, if globally changed genes are considered for this comparison.............................90

3.3 Identification of pathway activities in aNHL using stimulation mediated gene expression changes detected by guided clustering .94

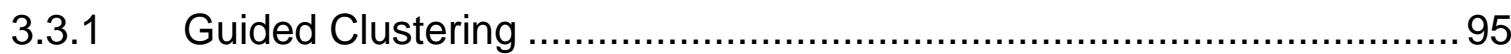

3.3.2 CD40 and BCR mediated pathway activity is continuously increasing in aggressive NHL samples .............................................................96

3.3.3 mBLs are characterised by a missing BCR.1 and a high c-Myc activity 100

3.3.4 The expression of some BCR.1 cluster genes is decreased upon inhibition of c-Myc in BL cell lines................................................. 101

3.3.5 Changes in BUB1B gene expression in response to BCR crosslink are mediated by altered c-Myc binding to the BUB1B locus.................... 103

3.3.6 Prolongation of the G2 phase of the cell cycle in BL cells after BCRx 105

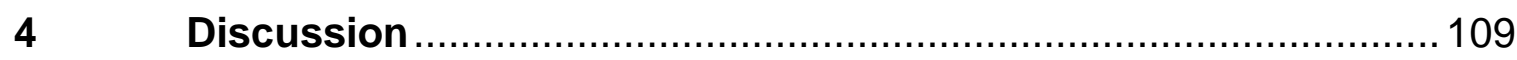

4.1 High c-Myc activity is an independent negative prognostic marker for

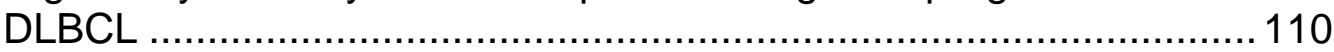

4.2 Identification and characterisation of pathway activities in $\mathrm{aNHL} \ldots \ldots . .113$

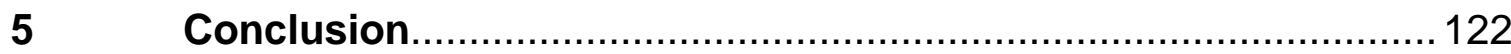

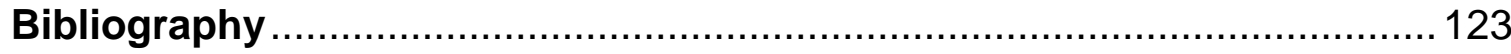

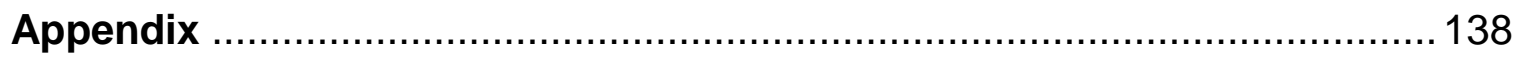





\section{Abstract}

B cell aggressive non-Hodgkin lymphomas (aNHL) represent a heterogeneous group of lymphatic malignancies comprising Burkitt Lymphoma (BL) and Diffuse Large $\mathrm{B}$ cell lymphoma (DLBCL). aNHL have to be treated with high dose chemotherapy regimen. Still $20 \%$ of $B L$ and $40 \%$ of DLBCL patients do not achieve a complete remission to the so far best treatment. BL cells are characterised by a simple karyotype and an aberrant c-Myc activity that is associated with very high proliferative index of lymphoma cells. DLBCLs are characterised by a complex karyotype and are very heterogeneous in respect to their underlying oncogenic deregulation. Most DLBCL cases harbour a genetic aberration involving BCL6 as well as constitutive active NF-KB signalling. So far largely descriptive approaches have been followed to achieve a better understanding of lymphoma biology based on gene expression profiling of aNHL. These include the description of a molecular diagnosis for $\mathrm{BL}$, the $\mathrm{mBL}$ signature, as well as the identification of DLBCL subgroups (ABC/GCB). In this study new gene expression patterns holding information about $B$ cell relevant oncogenic pathways were identified. These can be used to infer on the activity of deregulated pathways in malignant lymphoma based on their gene expression profiles. A c-Myc signature was described that comprises genes which are co-regulated with MYC in lymphoma precursor cells as well as in aNHL. Using the expression of these genes as a surrogate marker for c-Myc activity (c-Myc index), it was found that high c-Myc activity is an independent negative prognostic factor for DLBLC. To identify functionally important clusters of genes, affected by $B$ cell specific paracrine survival stimuli, the gene expression changes of a $B L$ cell line in response to $B C R$ and $C D 40$ activation as well as Interleukin 21 (IL21), B cell activating factor (BAFF) and Lipopolysaccharide (LPS) stimulation were elucidated. Using the new approach "guided clustering" a gene cluster inhibited upon BCR stimulation (BCR.1) was identified among others. The activity of the BCR.1 gene cluster is negatively correlated with the c-Myc index. The BCR.1 cluster, associated with differences in the expression of cell cycle regulatory factors, provides an explanation for the high chromosomal complexity in a subgroup of DLBCL cases. The gene clusters identified here can help to obtain a better understanding of the biology of so far unclassifiable lymphoma. 


\section{List of figures}

Figure

Page

Figure 1-1 Simplified scheme of the Germinal Centre Reaction. The naïve antigen primed $B$ cell enters secondary lymphatic organs and form a Germinal Centre (GC). GC B cells proliferate in the dark zone. After undergoing somatic hypermutation the cells enter the light zone and affinity maturation of the BCR occurs. Therefore B cells are in close contact with $T$ helper cells and Follicular Dendritic Cells (FDCs), which mediate the needed survival signals via paracrine stimulation of maturing B cells. Subsequent to positive selection and class switch recombination the differentiated $B$ cells leave the $\mathrm{GC}$ as memory or plasma cells. Figure taken from (Küppers 2005).

Table 2-1 Cell lines. 20

Table 2-2 Consumables .21

Table 2-3 Equipment 22

Table 2-4 Chemicals 24

Table 2-5 Chemical Inhibitors .26

Table 2-7 Vectors 30

Table 2-8 Recombinant Proteins .30

Table 2-9 Antibodies 31

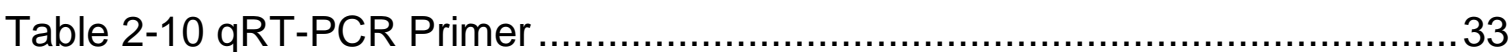

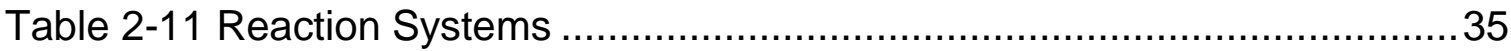

Table 2-12 Amount of plasmid DNA used for transfection.................................38

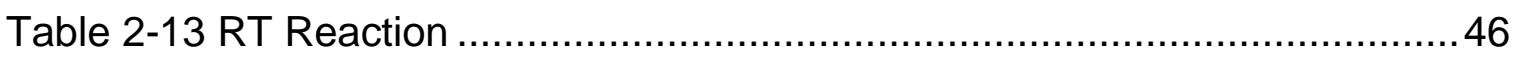

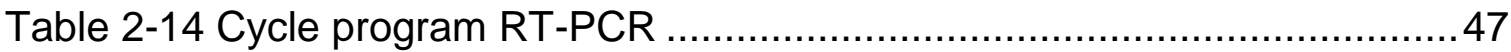

Table 2-15 Reaction Mix and Cycling Program PCR ChIP................................50 
Figure 3-1 Expression of c-Myc in primary human germinal centre $B$ cells. A Flow cytometric analysis of $\mathrm{CD} 10^{+}$tonsillar $\mathrm{B}$ cells transfected with pcDNA3.1 (upper row) or c-Myc (lower row) together with pMACS $\triangle$ LNGFR stained with Hoechst Dye to perform live gating. B CD10 and NGFR staining. CD10 ${ }^{+}$and $\triangle \mathrm{LNGFR}^{+}$, Hoechst negative cells were collected for RNA isolation (see respective gating). C Detection of $\mathrm{C}-\mathrm{Myc}$ and b-actin in transfected $\mathrm{CD} 10^{+}$tonsillar $\mathrm{B}$ cells by immunoblot analysis. D Real-time RT-PCR of the relative quantity of c-Myc in C-Myc-expressing and non-expressing GC B cells. All samples were analysed in triplicates and are presented as $2^{-\triangle A C T}$ values compared to vector control. $\mathrm{E}$ Multidimensional Scaling (MDS) based on the transcriptional fold-changes of the top $200 \mathrm{c}-\mathrm{Myc}$ responsive genes. The plot is a two dimensional visualization (dimension 1 and dimension 2) of the differences between the tonsils with respect to the transcriptional changes induced by c-Myc. F Shown are the transcriptional levels of c-Myc (y-axis) measured by HGU133 Plus 2.0 Affymetrix microarrays in 8 tonsils (x-axis). Each tonsil is represented by a dark green bar and light green bar indicating a pair of transfection experiments (dark green: empty control vector, light green c-Myc expression vector). The scale of the expression data (y-axis) obtained from microarray normalization (variance stabilization) is equivalent to the natural logarithm of the true fold-change: An increase by one unit corresponds to a fold change of $e^{1}$. 55

Figure 3-2 Gene set enrichment analysis (GSEA) of c-Myc responsive genes. Genes were ranked by their correlation with expression levels of MYC in decreasing order from the most positively correlated to most negatively correlated genes. GSEA enrichment scores (y-axis of the top panel) are plotted against the gene list ranked by correlation with MYC. A GSEA revealed a strong enrichment of a known c-Myc signature among the genes most correlated with c-Myc in our analysis. This is indicated by the sharp increase in the GSEA enrichment score to the left of the graph and a decrease to the right B In contrast, a known CD40 signature is enriched among the genes negatively correlated with c-Myc. This is indicated by the gradual decrease of the GSEA enrichment score to the left of the graph, and a sharp increase to the right. C GSEA revealed an enrichment of a CANCER NEOPLASTIC META UP gene set which comprises genes that are 
upregulated in tumour cells relative to matching normal tissue cells across many tumour entities. For a detailed list of Gene Sets please see Table 3-1.

Figure 3-3 FZD7 expression is high in lymphoma precursor cells but reduced in lymphoma cells and negatively correlated to MYC-gene expression. FZD7 and MYC gene expression was assessed using qRT-PCR. Ct values were normalized to $\mathrm{B} 2 \mathrm{~m}$ expression and $\Delta \Delta \mathrm{Ct}$ values were calculated compared to respective gene expression in MC116 lymphoma cells. T99, T96, T97, T98, T101 and T102 represent different preparations of tonsilar B cells purified by CD10 MACS. All other analysed samples represent different lymphoma cell lines. 64

Figure 3-4 Stratification of NHL patients in $\mathrm{mBL}$ and non $\mathrm{mBL}$ by expressing c-Myc in GC B cells. Each row in the heatmaps represents a gene and each column represents a microarray sample. The expression levels for each gene were standardized to a mean value of 0 and a standard deviation of 1 , and are represented according to a color scale; yellow and blue indicate high and low expression, respectively. A Heatmaps of genes expressed in GC B cells that show a correlation to MYC in tonsillar samples and $220 \mathrm{NHL}$ samples (Hummel, Bentink et al. 2006). B Heatmap of gene expression levels of the same genes plotted in (A) this time in $220 \mathrm{NHL}$ samples (Hummel, Bentink et al. 2006) recently classified as $\mathrm{mBL}$, non-mBL or intermediate cases. This classification is colour coded in the top bar (green: mBL, red: non-mBL, grey: intermediate). The patients are arranged according to c-Myc index (increasing from left to right). ...65

Figure 3-5 High expression of c-Myc index genes in the group of non-mBL and intermediate lymphomas is associated with shorter overall survival A Boxplots of the level of the c-Myc index (y-axis) in NHL lymphomas classified as non-mBL, intermediate and $\mathrm{mBL}$ (x-axis). B Boxplots of the level of the c-Myc expression index (y-axis) in NHL lymphomas classified as MYC-negative, MYC-complex and MYC-simple (x-axis). Statistical significance of the differences was tested using ANOVA. (C\&D) Kaplan Meier plots of the overall survival of non-mBL and intermediate patients stratified by the c-Myc expression index $\mathrm{C} 88$ non-mBL and intermediate patients samples (MMML) were stratified based on the level of their c-Myc expression index into tumours of very low, low, medium and high c-Myc activity. Patients with a tumour of high c-Myc activity have the shortest overall 
survival (grey continuous line). D 157 DLBCL patients of the data set published by Dave and colleagues (LLMPP) were grouped as in (C). Patients with high c-Myc index showed shorter overall survival. Statistical significance of the differential survival of these groups was tested using the log rank test.

Figure 3-6 Different pathways activated by IL21, CD40L, anti-IgM (BCRx), BAFF and LPS in human Burkitt Lymphoma cells. BL2 cells were incubated with IL-21 (100ng/ml), CD40L $(200 \mathrm{ng} / \mathrm{ml})$, anti $\mathrm{lgM} F(\mathrm{ab})_{2}$ fragments $(1.3 \mu \mathrm{g} / \mathrm{ml})$, BAFF $(100 \mathrm{ng} / \mathrm{ml})$ and LPS $(1 \mu \mathrm{g} / \mathrm{ml}))$ for indicated time points. A The activation of calcium signalling was detected using a $\mathrm{Ca}^{2+}$ sensitive fluorophor in combination with flowcytometric analyses. BL2 cells were loaded with indo1 and $\mathrm{Ca}^{2+}$ influx was measured directly after the stimulation. BCRx $(1.3 \mu \mathrm{g} / \mathrm{ml})$ induced an immediate $\mathrm{Ca}^{2+}$ accumulation in the cytoplasm as indicated by the increased Indo-1 fluorescence. B BL2 cells stimulated for $30 \mathrm{mins}$ as indicated above. The activation of canonical NF-KB signalling was visualized by immunoblot of IKBa. C BL2 cells were stimulated for distinct time points (6hrs for CD40L and LPS, 3hrs for BCRx, 9hrs for BAFF and 2hrs for IL21 stimulation) as described in above. The activation of noncanonical NF-KB signalling was detected monitoring the p52 cleavage product of 100 by immunoblot. D BL2 cells stimulated for $5 \mathrm{mins}$ as indicated above. The activation of ERK was shown through immunoblot analyses of phosphorylated ERK1/2. E BL2 cells were stimulated for 30mins as indicated in above. The activation of p38 was detected through detection of phosphorylated p38 via immunoblot. F In vitro kinase assay to investigate the activation of JNK in BL2 cells (Kutz, Reisbach et al. 2008). These data were kindly provided by A. Ulrich and A. Kieser. G BL2 cells were stimulated for distinct time points (6hrs for CD40L and LPS, 3hrs for BCR, 9hrs for BAFF and 2hrs for IL21 stimulation) as described in above. The activation of PI3K/AKT signalling was detected using immunoblot detection of phosphorylated AKT1. H\&I BL2 cells were stimulated for $30 \mathrm{mins}$ as indicated above. The activation of STAT1/STAT3 was detected through the verification of phosphorylated STAT1/STAT3 via immunoblot......... 71

Figure 3-7 Identification of anti-IgM (BCRx), CD40L, IL-21, BAFF and LPS regulated genes in $B L$ cells using microarrays. BL2 cell were stimulated as described in Figure 3-6 with $A$ anti IgM F(ab) ${ }_{2}$ fragment (3hrs), B CD40L (6hrs), C 
IL21 (2hrs), D BAFF (9hrs) and E LPS (6hrs). RNAs from these cells were used to perform whole genome gene expression profiling on Affymetrix HGU-133 plus 2.0 microarray chips. These heatmaps show the TOP 100 most highly changed genes (adj. p-value $\leq 0.05$ ) in response to each stimulus. As distinct microarray chips were used for the microarray analyses of cell perturbation and patient samples (Affymetrix HGU-133A and HGU-133 plus2.0), the list of TOP100 genes had to be adapted to be able to transfer the resulting genes to patient data (see below for additional details). Therefore the lists were shortened since not all probesets were present on both array platforms (BCRx (74 genes), sCD40L (71 genes), rhBAFF (77 genes), rhIL21 (77 genes) and LPS (66 genes)). Each row in the heatmaps represents a gene and each column represents a microarray sample. Yellow and blue indicate high and low expression, respectively. .74

Figure 3-8 Overview of high responsive overlapping and stimulus specific genes upregulated in response to BCRx, CD40L, rhBAFF and rhIL21. The lists of genes showing the highest differential expression in response to stimulation (see Appendix table A2, A3, A4, A5) were compared. This comparison was made using VENNY (Oliveros 2007). Genes upregulated in response to BAFF stimulation are represented in the blue ellipsoid $(\mathrm{BCR}=$ yellow, CD40L $=$ green, IL21 = red). The overlaps of the gene lists are represented by overlaps of the respective ellipsoids. The number of genes in the respective overlap is indicated.

Figure 3-9 Overview of high responsive overlapping and stimulus specific genes downregulated in response to BCRx, CD40L, rhBAFF and rhIL21. The lists of genes showing the highest differential expression in response to stimulation (see Appendix table A2, A3, A4, A5) were compared. This comparison was made using VENNY (Oliveros 2007). For a detailed description see Figure 3-8 78

Figure 3-10 qRT-PCR analyses of the expression of a selection of genes after respective stimulation. BL2 cells were stimulated as described in Figure 3-7. One representative experiment out of two is shown. All samples were analysed in triplicates. Results are presented as $2^{-\Delta \Delta C T}$ or $\Delta C T$ values, relative to abl housekeeper expression and compared to unstimulated control. N.E. = Not Expressed $(\triangle \mathrm{Ct}>10)$ A ID1 B ICAM1 C CD58. D DUSP2 E DUSP5 (basal $\triangle \mathrm{Ct}>$ 
10) F DUSP10 G DUSP22 H MYC I CXCL10 J SLAMF7 (basal $\triangle \mathrm{Ct}>10$ ) $\mathrm{K}$ RGS1 (basal $\Delta \mathrm{Ct}>10$ ). 80

Figure 3-11 Expression of ICAM1, DUSP2, DUSP5, DUSP10, DUSP22 and MYC, SLAMF7 in CD10+ germinal centre B cells in response to SCD40L, BCRx, rhIL21 and rhBAFF stimulation CD10+ B cells from distinct tonsillar preparations (T96, T97, T98, T99, T101, T102) were stimulated with 100ng/ml rhlL21, 200ng/ml sCD40L, $1.3 \mu \mathrm{g} / \mathrm{ml}$ anti $\operatorname{lgM} /$ anti $\operatorname{lgG} \mathrm{F}(\mathrm{ab})_{2}$ fragments and rhBAFF for 3hrs. Effects are depicted as $\Delta \Delta \mathrm{Ct}$ values normalized to $\beta 2 \mathrm{~m}$ expression and relative to the unstimulated control ( $\mathrm{NE}=$ not expressed). The statistical significance of the differences in gene expression was calculated for each gene and stimulation separately, using the two paired t-test. A ICAM1 expression in affected by CD40 ( $p=0.0005)$ and IL21 ( $p=0.0186)$. B DUSP2 expression is affected by BCRx $(p=0.0209)$ and IL21 $(p=0.0138)$ C DUSP5 expression is affected by BCRx $(p=0.0378)$. D DUSP10 expression is affected by BCRx $(p<0.0001)$. E DUSP22 expression is highly variable and not affected by any stimulation. F MYC expression is affected by BCRx $(p=0.0101)$ and CD40 $(p=0.0306)$. G SLAMF7 expression is affected by BCRx $(p=0.0006)$.

Figure 3-12 Pathways involved in the regulation of DUSP5, DUSP2 and DUSP10 as well as MYC in response to BCRx in BL cells. BL2 cells were pre-incubated with specific pathway inhibitors for 3hrs (for detailed information see Methods section chapter 2.12.6). $1.3 \mu \mathrm{g} / \mathrm{ml}$ anti-lgM $\mathrm{F}(\mathrm{ab})_{2}$ fragments were added respectively and cells were harvested after additional $3 \mathrm{hrs}$ for qRT-PCR. A-D Expression of DUSP2, DUSP5 and DUSP10 and MYC. Results are presented as $2^{-\triangle \triangle C T}$ values, relative to abl housekeeper expression and compared to unstimulated DMSO control. As DUSP5 expression (B) is below detectable levels in unstimulated probes, only $\triangle \mathrm{Ct}$ values of stimulated probes relative to DMSO control were compared. One representative experiment out of three biological replicates is shown 85

Figure 3-13 rhBAFF stimulation induces differential p38 signals in cell lines of distinct lymphoma entities despite comparable receptor equipment A BL2, Ramos, BL16, SuDHL4 and SuDHL6 cells were stimulated with $100 \mathrm{ng} / \mathrm{ml}$ rhBAFF for 30 mins. p38 activity was detected using an anti pp38 specific 
antibody. B BL2, SuDHL4 and SuDHL6 cells were stimulated as described in A for 9 and $24 \mathrm{~h}$ respectively. Activation of the noncanonical NF-kB pathway was detected using an antibody that detects p100/p52 NFKB2. C\&D Surface expression of BAFF-R and TACI was detected on BL2, Ramos, BL16, SuDHL4 and SUDHL6 cells using flow cytometry. D Mean fluorescence intensities of BAFF-R and TACI stained cells are compared. E Expression of BAFF-R, TACI and BCMA mRNA was investigated in BL2, Ramos, SuDHL4 and SuDHL6 cells using qRT-PCR. $\triangle \mathrm{Ct}$ values were calculated using beta2m expression as housekeeper (NE = not expressed).

Figure 3-14 Expression of stimulus regulated genes in aNHL. The TOP100 most highly responding genes upon stimulation of BL2 with A rhBAFF, B sCD40L, C anti-lgM $F(a b)_{2}$, D rhlL21, fragments, E LPS and (see tables A2-A6 in the appendix) were investigated for their expression in the gene expression profiles of 220 aNHL lymphoma cases (Hummel, Bentink et al. 2006). aNHL cases were ordered from left to right according to the similarity of gene expression to the stimulated status of BL2 cells. The Heatmaps display the expression of target genes (columns) across 220 lymphoma samples (rows). The colour bar above the heatmaps marks $\mathrm{mBL}$ in red, non-mBL in green and intermediate lymphoma in yellow. Furthermore the affiliation of samples to ABC/GCB DLBCL subgroups and the presence of an IG-MYC translocation in encoded in a bar on top of the map (see legend for colour coding). Relative gene expression is encoded with yellow (high expression) and blue (low expression). .93

Figure 3-15 Comparison of the patient groups that show a gene expression profile of stimulus effected genes most closely to the activated gene expression profile of BL2 cells 55 aNHL samples that show the highest similarity regarding their gene expression profile to the stimulated BL cells in response to CD40L, BCRx, IL21 and BAFF stimulation were compared using Venn Diagrams as

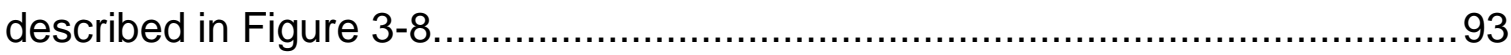

Figure 3-16 (legend see next page) .99

Figure 3-16 Guided clustering identifies four major clusters of genes regulated by BCR activation and CD40L stimulation. Each row in the heatmaps represents a 
gene and each column represents a microarray sample. Yellow and blue indicate high and low expression. left panel: Heatmaps show the gene expression of the respective cluster genes in stimulated BL2 cells compared to control. right panel: Heatmaps show the expression of respective cluster genes in gene expression profiles of tumour samples from 175 intermediate and non-mBL aNHL patients. The patient samples are ordered according to rising BCR.1/CD40.1 index from left to right (symbolized by the red bars). The colour coded bar on top of the heatmaps represents the affiliation of patients to ABC / GCB DLBCL subgroups (orange $=A B C$ tumour sample, blue $=G C B$ tumour sample and grey $=$ unclassifiable sample). A The gene expression of BCR.1 and BCR.2 cluster genes is depicted. B The gene expression of CD40.1 and CD40.2 cluster genes is displayed. 100

Figure 3-17 The BCR.1 index is inversely correlated with the c-Myc index. A\&B Correlation coefficients of Pathway Activation Indices in a cohort of $220 \mathrm{aNHL}$ cases. c-Myc index genes, BCR.1, BCR.2, CD40.1 and CD40.2 gene clusters were used to calculate the respective PAls in gene expression profiles of 220 aNHL diagnosed as $\mathrm{mBL}$ (red), non-mBL (green) and intermediate lymphoma (yellow) by Hummel and colleagues (Hummel, Bentink et al. 2006). The parallel activity was estimated plotting the indices against each other and calculating the respective correlation coefficient. A coefficient close to one indicates highly correlated index activities and a high number of lymphoma expressing both gene clusters in an activated state. 102

Figure 3-18 Expression of BCR.1 cluster genes is downregulated by BCR activation and C-Myc inhibition in Burkitt Lymphoma cell lines. A-F BL2 and Ramos cell were pretreated for 3h with $60 \mu \mathrm{M}$ 10058-F4 c-Myc inhibitor or left untreated (DMSO). Cells were stimulated for additional 3h with anti $\operatorname{lgM} F(a b) 2$ fragment $(1.3 \mu \mathrm{g} / \mathrm{ml})$. qRT-PCR analyses were performed using SYBR green. Foldchanges were calculated using the $\Delta \Delta \mathrm{Ct}$ method. One representative experiment of three replicates is shown. 104

Figure 3-19 ChIP of c-Myc reveals a change in c-Myc abundance at the Bub1B promoter upon BCR activation. Chromatin IPs were performed using antibodies directed against IgG as negative control, against C-Myc and against acetylated 
histone $\mathrm{H} 3$ as positive control (marker for active transcription). To check for c-Myc binding a fragment was amplified that encompasses the previously described E-box in intron 1 of the Bub1B gene (Menssen, Epanchintsev et al. 2007). The lower lane shows a shorter exposure time to infer on differences in acetyl Histone $\mathrm{H} 3$ binding.................................................................... 105

Figure 3-20 (legend see next page) 108

Figure 3-20 Activation of the BCR leads to a prolonged G2 phase in BL cell lines A \& B Asynchronous growing BL2 and Ramos cells were treated with $1.3 \mu \mathrm{g} / \mathrm{ml}$

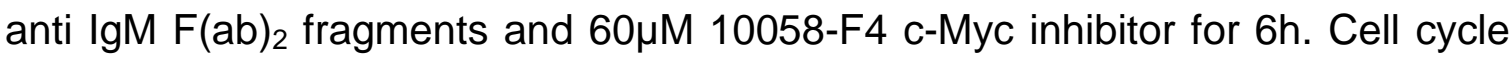
distribution of cells was measured using Nicolletti buffer and FACS based analyses of the DNA content of the nuclei. C Ramos cells were synchronised in G2 cell cycle phase using 2 rounds of thymidine $(2 \mathrm{mM})$ treatment. After removing the Thymidine (Oh) the cells started to pass through the cell cycle. Cell cycle distributions were measured over a time course of $0 \mathrm{~h}$ up to $8 \mathrm{~h}$ using Nicoletti technique. The $24 \mathrm{hrs}$ time point was measured separately. One out of three representative experiments is shown.

Table A 1 Gene Set Enrichment Analysis of c-Myc responsive genes. Gene set enrichment analysis (GSEA) of the resulting ranked gene list was performed using the Java implementation of GSEA obtained from http://www.broadinstitute.org/gsea/. The ES (Enrichment Score) is given, which is the primary result of the gene set enrichment analysis and reflects the degree to which a gene set is overrepresented in a ranked list of genes. Gene sets are displayed in the order of the NES (Normalized Enrichment Score) which accounts for differences in gene set sizes and correlations between the gene set and the expression dataset. The NOM p-value (Nominal p-value) is a statistical measure for the significance of the enrichment of one single gene set. The FDR q-value (False Discovery Rate) is adjusted for multiple testing. 138

Table A 3 CD40 responsive genes This table shows the effects of SCD40L on the most variable genes. 100 probesets with the highest differential expression were selected from all significantly regulated genes. Probesets that were array specific 
and not spotted on the HG U133 plus, which was used for the evaluation of aNHL samples, were discarded and excluded from further analysis.

Table A 4 BCR responsive genes. This table shows the effects of BCRx on the most variable genes. 100 probesets with the highest differential expression were selected from all significantly regulated genes. Probesets that were array specific and not spotted on the HG U133 plus, which was used for the evaluation of aNHL samples, were discarded and excluded from further analysis.

Table A 5 LPS responsive genes This table shows the effects of LPS on the most variable genes. 100 probesets with the highest differential expression were selected from all significantly regulated genes. Probesets that were array specific and not spotted on the HG U133 plus, which was used for the evaluation of aNHL samples, were discarded and excluded from further analysis 144

Table A 7 Cluster genes identified by guided clustering 146 


\section{List of tables}

Table

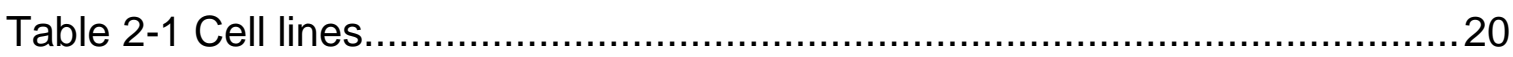

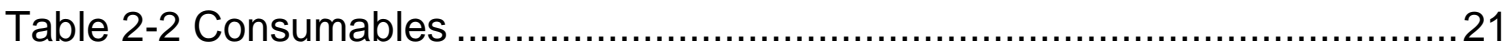

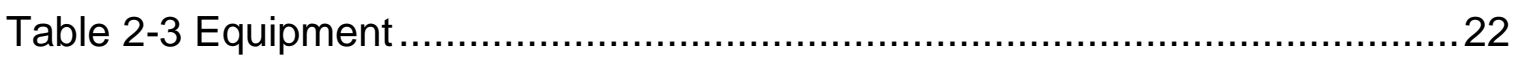

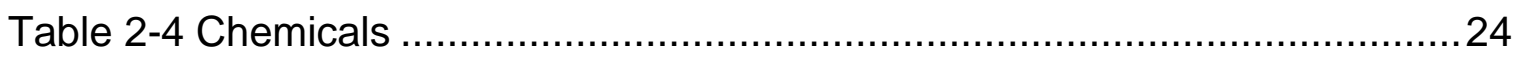

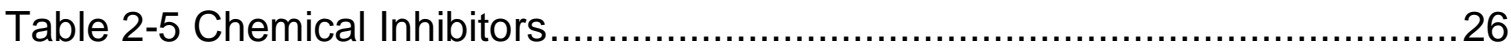

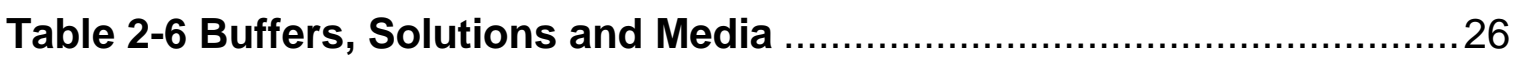

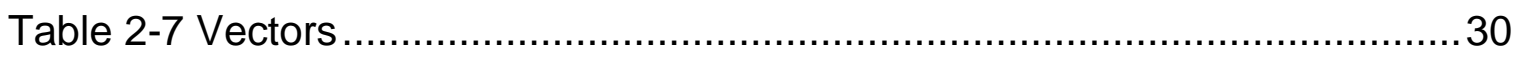

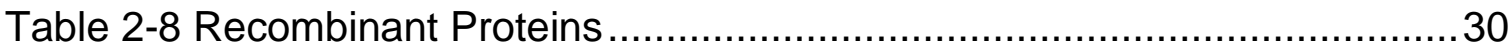

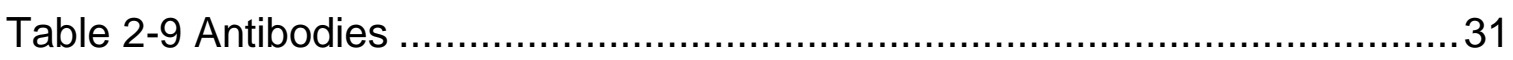

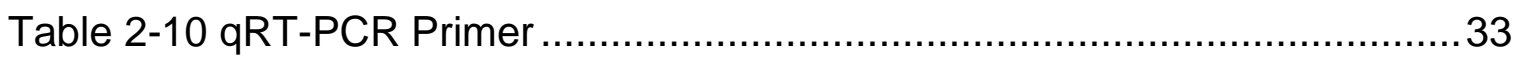

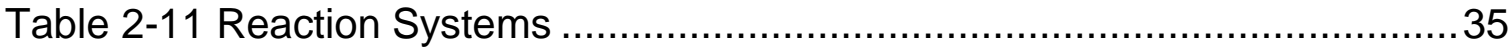

Table 2-12 Amount of plasmid DNA used for transfection.................................38

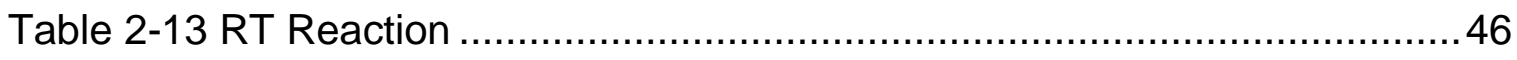

Table 2-14 Cycle program RT-PCR ……......................................................

Table 2-15 Reaction Mix and Cycling Program PCR ChIP................................50

Table 3-1 Top 100 genes correlated with $M Y C$ in GC B cells and aNHL: The c-Myc index. Genes that are correlated with MYC in primary transfected GC B cells as well as in gene expression profiles of aNHL are listed below. Genes are ordered according to assumed cellular functions and the calculated t-scores. The Pearson Correlation for being expressed in correlation with $M Y C$ is also given for each gene. .60 


\section{Abbreviations}

\begin{tabular}{|c|c|}
\hline Abbreviation & Denotation \\
\hline ABC-like & Activated B cell like \\
\hline Amp & Ampicilin \\
\hline aRNA & antisense RNA \\
\hline $\mathrm{BCR}$ & B Cell Receptor \\
\hline $\mathrm{BL}$ & Burkitt Lymphoma \\
\hline BR & Basic Region \\
\hline CD & Cluster of Diffrentiation \\
\hline cDNA & complementary DNA \\
\hline CIN & Chromosomal Instability \\
\hline CSR & Class Switch Recombination \\
\hline CT & Cycle Threshold \\
\hline CTD & C-Terminal-Domain \\
\hline $\mathrm{ddH}_{2} \mathrm{O}$ & Water, double-distilled \\
\hline DLBCL & Diffuse Large B Cell Lymphoma \\
\hline DNA & desoxyribonucleic acid \\
\hline DTT & dithiothreitol \\
\hline EBV & Epstein Barr Virus \\
\hline E. coli & Escherichia coli \\
\hline ECL & enhanced chemiluminescence \\
\hline EDTA & ethylenediaminetetraacetic acid \\
\hline et al. & Lat.: et alteri \\
\hline FACS & Fluorecense Activated Cells Sorting \\
\hline FBS & Fetal Bovine Serum \\
\hline FDC & Follicular Dendritic Cell \\
\hline
\end{tabular}




\begin{tabular}{|c|c|}
\hline Abbreviation & Denotation \\
\hline FITC & Fluoreszeinthiocyanat \\
\hline FSC & Forward Scatter \\
\hline GC & Germinal Centre \\
\hline GCB-like & Germinal Centre B cell like \\
\hline GFP & Green Fluorescent Protein \\
\hline HEPES & 4-(2-hydroxyethyl)-1-piperazineethanesulfonic acid \\
\hline HLH & Helix-loop-Helix \\
\hline HRP & horseradish peroxidase \\
\hline IG & Immunoglobulin \\
\hline IVT & In Vitro Transcription \\
\hline $\mathrm{kDa}$ & kilo-Dalton \\
\hline LB & Luria Bertani \\
\hline LLMPP & Lymphoma/Leukemia Molecular Profiling Project \\
\hline LNGFR & Low Affinity Nerve Growth Factor Receptor \\
\hline LPS & Lipopolysacharide \\
\hline LZ & Leucine Zipper \\
\hline MACS ${ }^{\mathrm{TM}}$ & Magnetic Activated Cell Sorting \\
\hline MALT & Mucosa Associated Lymphoid Tissue \\
\hline $\mathrm{mBL}$ & Molecular Burkitt Lymphoma \\
\hline miRNA & micro RNA \\
\hline mRNA & messenger RNA \\
\hline MMML & Molecular Mechanisms of Malignant Lymphoma \\
\hline NF-kB & $\begin{array}{l}\text { Nuclear factor of kappa B light polypeptide gene } \\
\text { enhancer in B-cells }\end{array}$ \\
\hline aNHL & aggressive Non-Hodgkin Lymphoma \\
\hline PAGE & Polyacrylamide-Gelelectrophoresis \\
\hline
\end{tabular}




\begin{tabular}{ll}
\hline Abbreviation & Denotation \\
\hline PAP & Pathway Activation Pattern \\
PBS & Phosphate Buffered Saline \\
PE & Phycoerythrin \\
PI & Propidium lodide \\
PMSF & phenylmethylsulfonylfluoride \\
qRT-PCR & Quantitative Reverse Transcriptase - Polymerase \\
RNA & Chain Reaction \\
RNAi & ribonucleic acid \\
RPM & RNA interference \\
RT & rounds per minute \\
SDS & roomtemperature \\
siRNA & Sodium-Dodecyl-Sulfate \\
SSC & small interfering RNA \\
TAE & Side Scatter \\
TBS & Tris-Acetate-EDTA \\
TEMED & Tris Buffered Saline \\
TMC & TolN,N',N'-Tetramethylethylendiamin \\
Tris & Tonsillar Mononuclear Cell \\
Tween & World Health Organisation \\
VDJ & \\
WHO & Triple of acceleration of gravity $\left(\mathrm{g}=9.80665 \mathrm{~m} / \mathrm{s}^{2}\right)$ \\
\hline & \\
\hline &
\end{tabular}





\section{Introduction}

The demographic change approves living circumstances and humans life expectancies. Cancer has become a leading cause of death worldwide. According to the World Health Organization (WHO) cancer accounted for 7.6 million deaths (13\% of all) worldwide in 2008 (Ferlay J 2010). It was the biologist Theodor Heinrich Boveri (1862-1915) who first hypothesised that a tumour might arise from one single cell that was not able to separate chromosomes accurately during mitosis (Boveri 1907). Based on his studies with sea urchins he stated: "We may [...] regard it as probable that individual chromosomes have different properties in vertebrates too, and it is this assumption that forms the basis of the tumour hypothesis I have put forward. A malignant tumour cell is [...] a cell with a specific abnormal chromosome constitution." (Boveri 2008). Today it is widely accepted that cancer is a genetic disease and that the deregulation of protooncogenes and tumour suppressor genes is the fundamental basis of cellular transformation. The accumulation of multiple independent genetic alterations induce a deregulation of cell signalling pathways crucial for the control of cell growth, cell proliferation, apoptosis, and cell fate. In addition to cell intrinsic genetic aberrations the effects of the tumour environment on the growth of malignant cells has emerged as being particularly important (Hanahan and Weinberg 2011).

The term lymphoma refers to a heterogeneous group of malignancies that originate from $B$ or $T$ lymphocytes. Most of the lymphomas have a $B$ cell origin (95\%). B cell lymphoma arise from differentiating B cells during the process of the germinal centre reaction (reviewed in (Küppers 2005). One discriminates two major groups of $B$ cell lymphomas: Hodgkin Lymphoma and Non-Hodgkin Lymphoma (NHL). According to the WHO the Age-World-Standardized incidence rate (ASR (W)) the incidence for NHL was 5.1 new cases per 100000 persons in 2008. NHL comprises many different types of $B$ cell lymphomas, which can be divided into aggressive (fast-growing) and indolent (slow-growing) types (Jaffe, Harris et al. 1998). B cell aggressive non-Hodgkin lymphomas (aNHL) is a heterogonous group of malignancies that comprises Burkitt's Lymphoma and Diffuse Large B cell lymphoma (DLBCL) (Good and Gascoyne 2008). aNHL have 
to be treated with high dose chemotherapy regimens. Despite current treatment advancements still $20 \%$ of $\mathrm{BL}$ and $40 \%$ of DLBCL patients do not achieve a complete response to the so far best treatment regimen. (Yustein and Dang 2007; Friedberg and Fisher 2008; Kahl 2008; Perkins and Friedberg 2008; de Jong and Balague Ponz 2011). A better understanding of aNHL biology and the oncogenic pathway activities that underlie the heterogeneity of aNHL will allow the development of an improved treatment strategy for patients at risk and a better individualized therapy for all patients. Recently major procedings have been made regarding the characterisation of aNHL based on their tumour gene expression profiles. These transcriptomic gene expression studies allowed the establishment of a molecular diagnosis for BL as well as the discovery of two major subgroups of DLBCL that are indeed different on functional level with respect to their oncogenic dependency (Alizadeh, Eisen et al. 2000; Dave, Fu et al. 2006; Hummel, Bentink et al. 2006). Nervertheless these subgroups still comprise very heterogeneous lymphomas that probably depend on the deregulation of so far uncharacterised pathways.

\section{$1.1 \quad$ Burkitt Lymphoma (BL)}

The Burkitt Lymphoma (BL) was first characterised by Denis Burkitt in 1958 as the most prevalent childhood lymphoma mostly localised at the jaw (Burkitt 1958). It is an aggressive form of $\mathrm{B}$ cell $\mathrm{NHL}$ and accounts for $2 \%$ of all lymphoma cases (Küppers 2005). The BL appears in different variants. The endemic form of $B L$ is found in equatorial Africa and is associated with an Epstein-Barr-Virus infection (Rasti, Falk et al. 2005; McNally and Parker 2006). In European areas and in Northern America the sporadic and the immunodeficiency associated forms of BL are predominant (reviewed in (Yustein and Dang 2007). The histology of $\mathrm{BL}$ is characterised by monomorphic medium sized $\mathrm{B}$ cells that are highly proliferative and silent with respect to NF-KB and JAK-STAT signals. The tumour has a so called "starry sky" appearance, that is based on the high number of interspersed macrophages in-between the tumour cells (O'Conor, Rappaport et al. 1965). 


\subsection{1 c-Myc mediates high proliferation of BL cells}

$\mathrm{BL}$ are characterised by a specific genetic aberration, the translocation of the proto-oncogene MYC into one of the immunoglobulin gene loci. BL cells have a simple karyotype with a low number of additional chromosomal aberrations (Hummel, Bentink et al. 2006). The genetic aberration involving MYC is regarded as the central event leading to lymphoma genesis of BL (Dalla-Favera, Bregni et al. 1982; Taub, Kirsch et al. 1982). In BL cells the translocated allele of MYC is highly expressed whereas the normal allele is usually silent (Eick and Bornkamm 1989).

c-Myc is a Helix-Loop-Helix (HLH) leucine zipper transcription factor which mediates its function only as heterodimer with its HLH partner Max (Adhikary and Eilers 2005). The c-Myc/Max dimer binds specifically to the E-Box sequence in the DNA (consensus "CANNTG") (Blackwell, Kretzner et al. 1990). High c-Myc activity can factors mediate a high proliferative signal on the one hand and induce apoptosis in the absence of survival on the other hand (Dang, O'Donnell et al. 2006). Thus the extremely high proliferative potential of BL cells can be explained by their aberrant c-Myc activity. One mechanism how high levels of c-Myc can mediate cell cycle progression was explained by the activation of Cyclin D2 (CCND2). Increased presence of CCND2 leads to the sequestration of cyclin dependent kinase (CDK) inhibitor p27 in Cyclin D2-CDK4 complexes. p27 is degraded via the proteasome and release of the Cyclin E - CDK4 complex from p27 leads to promotion of the cell cycle (Pelengaris, Khan et al. 2002). Furthermore, c-Myc target genes that play a role in cell cycle regulation are CDC2 (cdc2 Kinase, also known as cdk1), CCNA2 (Cyclin A2), CCND3 (Cyclin D3) (http://www.myccancergene.org), as well as MAD2 and BUB1B (Menssen, Epanchintsev et al. 2007).

\subsubsection{The c-Myc target gene network affects $15 \%$ of all genes}

Among the c-Myc targets, regulators of cell metabolism, cell-cycle control and proliferation are prominent. (Schuhmacher et al., 2001; Cole and Cowling, 2008) c-Myc is proposed to affect a context dependent large network of genes comprising up to $15 \%$ of the whole genome (Dang, O'Donnell et al. 2006). Three 
major experimental approaches have been used to investigate the actual processes that accompany the deregulated expression of c-Myc: (i) c-Myc overexpression in cell lines or transgenic mice, (ii) respective knockouts or knockdowns of c-Myc or (iii) c-Myc driven chromatin immunoprecipitation in cells with aberrant c-Myc expression in order to identify respective target genes. c-Myc overexpression in mouse $B$ cells can induce the formation of lymphomas (Adams et al., 1985; Kovalchuk et al., 2000; Chesi et al., 2008) While expression in B-cell progenitors or naïve $B$ cells leads to lymphoma cells of the earlier differentiation stage. Ectopic expression during later stages of B-cell development mostly leads to plasmacytoma. (Adams et al., 1985; Kovalchuk et al., 2000; Adams et al., 1983; Chesi et al., 2008). Despite the compelling number of investigations to understand the role of $\mathrm{C}-\mathrm{Myc}$ in $\mathrm{B}$ cell transformation no data available on the potential of c-Myc expression in human lymphoma precursor cells. Recent data demonstrated that c-Myc expression in normal GC B cells is, if at all existing, rather low (Martinez-Valdez et al., 1996; Shaffer et al., 2001; Klein et al., 2003). A first attempt to identify direct c-Myc target genes in primary human GC B cells was not successful, as the effects of $\mathrm{C}-\mathrm{Myc}$ on the gene expression profiles of $B$ cells were rather low and variable between the distinct biological replicates (M.Sc. Thesis A. Schrader).

\subsubsection{Gene expression profiling has enabled the molecular diagnosis of BL}

Recently several approached were utilized to describe and functionally characterise aNHL cases on the basis of gene expression profiles. Hummel and colleagues (Hummel, Bentink et al. 2006) achieved a clear discrimination of BL from other mature aggressive B-cell lymphoma. Using the gene expression profiles of 220 aNHL tumours they developed a molecular classifier for the diagnosis of $\mathrm{BL}$ : the $\mathrm{mBL}$ signature (58 genes). This gene signature was used to established a continuous index of 'Burkitt likeness' (I) that enables the classification of aNHL into either molecular Burkitt lymphoma $(\mathrm{mBL})(\mathrm{l}>0.95)$, non-mBL $(\mid<0.05)$ or intermediate lymphomas $(0.95>1>0.05)$. Most intermediate lymphomas and non-mBL display DLBCL morphology, while $\mathrm{mBL}$ includes cases with and without classical BL morphology. Whereas most mBLs harbour a deregulated c-Myc expression as a consequence of an IG-MYC translocation, the 
majority of non mBLs does not carry IG-MYC translocations, but has other genetic abnormalities (reviewed by (Küppers and Dalla-Favera 2001). Although heterogeneous, the intermediate cases are enriched for those with IG-MYC or non-IG-MYC aberrations on a background of a complex karyotype. The separation of NHL into these different molecular subtypes might be clinically important; cases with the $\mathrm{mBL}$ signature and a cytogenetic so called 'MYCsimple' status have a favourable outcome, whereas those with $M Y C$ breakpoints but lacking a $\mathrm{mBL}$ signature have a poor outcome. This study by Hummel and colleagues was published "Back to Back" with a paper from an American consortium (LMPP), which as well established a gene expression signature that discriminates BL from DLBCL (Dave, Fu et al. 2006). Dave and colleagues additionally performed a c-Myc knockdown in a DLBCL cell line with a gene expression close to activated B cells (OCl-Ly10). The combination of C-Myc target genes defined in this vein with large-scale gene expression profiling of lymphoma samples allowed to discriminate to a certain extend between lymphoma subtypes. It is not clear whether these target genes are affected by $\mathrm{c}-\mathrm{Myc}$ already in lymphoma precursor cells or to which extend the $\mathrm{mBL}$ signature itself might be maintained by c-Myc itself.

\subsubsection{The microenvironmental factor BAFF might play a role for the survival of BL cells}

The role of BAFF for the survival of BL cells was investigated by Ogden and colleagues. They showed in vitro that IL10 activated macrophages can rescue BL cells from apoptosis by secreting BAFF (He, Chadburn et al. 2004; Ogden, Pound et al. 2005). Furthermore Saito and colleagues showed that BAFF can inhibit Rituximab as well as BCR triggered apoptosis in a human hairy cell leukemia cell line (Saito, Miyagawa et al. 2008). Nevertheless it still remains elusive whether BL TAMs indeed mediate BAFF signals in the primary tumour and how the BL cells respond in detail to BAFF stimulation.

\subsubsection{Treatment strategy in BL}

$\mathrm{BL}$ is treated with intensive high dose regimens of chemotherapy comparable to the B-ALL scheme. This chemotherapy includes cyclophosphamide, vincristine, 
doxorubicin, and high-dose methotrexate (Yustein and Dang 2007; Perkins and Friedberg 2008). Using comparable therapeutic regimens long-term remission can be achieved in approximately $50 \%$ of patients. If the disease is not treated it follows a rapid clinical course and can be lethal within several months. Although it is a curable disease, many patients do not achieve complete remission or they relapse.

\subsection{Diffuse Large B cell Lymphoma (DLBCL)}

DLBCL is the most common lymphoma entity, since it constitutes about $30-40 \%$ of all aNHL (Friedberg and Fisher 2008). Diffuse Large B cell lymphoma (DLBCL) is a very heterogeneous disease. In contrast to a relatively high uniformity of BL, DLBCL comprises B cell tumours that morphological differ and very often are misdiagnosed (Küppers 2005; Friedberg and Fisher 2008). This led to the assumption of the existence of a diversity of oncogenic events underlying these lymphomas. DLBCL tumours are composed of large B cells with a very high percentage of tumour infiltrate. In about $80 \%$ of DLBCL cases the tumour cells resemble centroblasts. Apart from this centroblastic type of DLBCL, one differentiates the immunoblastic type of DLBCL (10\% of the cases) that shows more than $90 \%$ immunoblasts, the T-Cell-Rich/Histiocyte-Rich variant, the anaplastic type and the rare plasmablastic variant.

\subsubsection{DLBCL are characterised by a complex karyotype involving the translocation of BCL6}

DLBCL tumours present with complex chromosomal aberrations (Dave, Nelson et al. 2002; lqbal, Gupta et al. 2007). These include in 35\% of cases a translocation of the proto-oncogene BCL6. Bcl6 is a transcription repressor that is highly expressed during germinal centre reaction and was found to be essential for germinal centre formation (Dent, Shaffer et al. 1997; Fukuda, Yoshida et al. 1997; Ye, Cattoretti et al. 1997). Further genetic aberrations found in DLBCL include for example the translocation of MYC to one of the IGH or IGL gene loci (Weiss, Warnke et al. 1987; Ladanyi, Offit et al. 1991; Baron, Nucifora et al. 1993; Ye, Rao et al. 1993). The high prevalence of chromosomal aberration in DLBCL is 
likely a result of an elevated chromosomal instability (CIN). CIN is a frequently observed phenomenon in cancers in general. The aneuploidy resulting from CIN is likely to be induced by a faulty progression of cells trough the spindle assembly checkpoint in early M phase (Li, Fang et al. 2009).

\subsubsection{DLBCL is characterised by a high aberrant activity of survival signals including NF-KB}

High NF-KB activity is a hallmark of subsets of DLBCL (Davis, Brown et al. 2001; Feuerhake, Kutok et al. 2005; Lam, Davis et al. 2005; Ngo, Davis et al. 2006). This aberrant activity can be mediated for example by loss of function mutations in IKBa (Inhibitor of NF-KB) (Thomas, Wickenhauser et al. 2004) or by mutations in CARD11, necessary for the activation of NF-kB (Lenz, Davis et al. 2008). Furthermore it has been shown that the aberrant activity of the B cell receptor (BCR) is of high relevance for the acquired survival property of DLBCL cells. Chen and colleagues described a Syk dependent tonic active BCR signalling in DLBCL cell lines and primary tumours. Aiming at therapy of DLBCL with Syk inhibitor, this group showed that cell lines depend on tonic BCR signalling: They undergo apoptosis in response to Syk inhibitor (R406) treatment (Chen, Monti et al. 2008). Furthermore it has been shown in vitro that there are subgroups of DLBCL that depend on constitutive active JAK-STAT signalling (Ding, Yu et al. 2008; Lam, Wright et al. 2008). Based on the heterogeneity of DLBCL it is likely that other, so far unidentified pathways are involved in the maintenance of the transformed phenotype of DLBCL.

\subsubsection{Global gene expression profiling identified subgroups of DLBCL}

Regarding the microarray based investigation of the heterogeneity of DLBCLs four major studies were conducted. Alizadeh and colleagues developed a sub stratification for DLBCL established on their similarity to distinct differentiation stages of normal $B$ cells $(A B C=$ Activated $B$ Cell like and $G C B=$ Germinal Centre B Cell like) (Alizadeh et al. 2000). This study helped to underline the aberrant signalling properties of DLBCL. Based on gene expression profiling it was found that Activated B cell like DLBCL show a high aberrant activity of NF-KB signalling (Lam, Davis et al. 2005). Monti and colleagues identified three 
distinct subtypes of DLBCLs based on their gene expression profiles (Monti, Savage et al. 2005). They described the characteristics of the distinct gene expression profiles as being associated with (i) "oxidative phosphorylation", (ii) "B cell receptor/proliferation" and (ii) with "host inflammatory response". These attempts to investigate gene expression profiles of malignant lymphoma have a rather descriptive character. In $2009 \mathrm{Ci}$ and colleagues developed a gene expression profiling based method to infer on Bcl6 activity in primary DLBCL lymphoma (Ci, Polo et al. 2009). Using a Bcl6 driven ChIP-on-Chip assay they defined a group of 1361 target genes in GC B cells and in DLBCL cell lines respectively. They observed that BCL6 target genes are favourably repressed in GCB-type DLBCLs and in the group of BCR type DLBCLs as described by Monti and colleagues (Monti, Savage et al. 2005). In contrast to that Bentink and colleagues used the gene expression data established from ectopic expression of eight oncogenes (including $M Y C, R A S, S R C, B$-catenin and E2F3) in primary human epithelial cells (Bild, Yao et al. 2006) to model gene modules. These could be used to identify aberrant oncogenic pathway activity in aNHL gene expression profiles (Bentink, Wessendorf et al. 2008). Single gene modules, representing the activity of a defined proto-oncogene, were combined to patterns of oncogene activity called PAPs (Pathway Activation Patterns). BL is characterised by a specific PAP (mBL-PAP). DLBCL can be characterised by four prominent combinations of gene module activities (PAP1-PAP4). One PAP has been defined that comprises aNHLs which cannot be allocated to one of the major PAPs (mindL (molecular individual lymphoma) PAP). The mindL PAP can be used to describe most of the lymphoma which are characterised as "intermediate" by the $\mathrm{mBL}$ index. So far the pathway activities are not defined that underline these lymphoma.

\subsubsection{Treatment strategy in DLBCL}

DLBCL tumours are treated with high dose CHOP therapy. This therapy includes Cyclophosphamid, ㅂydroxydaunorubicin (Doxorubicin), Vincristin (ㅁncovin®) and Prednisolon. On top Rituximab, a monoclonal antibody against the B cell specific marker CD20, has further improved the therapy success (R-CHOP) (reviewed in 
(Coiffier 2005; Kahl 2008). Nevertheless still $40 \%$ of DLBCL patients do not achieve a complete response to this therapy.

\subsection{B cell Development and the Germinal Centre Reaction}

$B L$ and DLBCL arise from germinal centre B cells (GC B cells) reviewed in (Küppers 2005). B lymphocytes, as part of the adaptive immune response, function as effectors of immune defence. To achieve optimal antigen recognition $B$ cells undergo a strictly regulated maturation process. Maturing B lymphocytes are probably the cells showing the highest dependency on their surrounding microenvironment. The proliferation and survival of activated B cells in secondary lymphatic organs is greatly reliant on paracrine signalling by $\mathrm{T}$ cells and follicular dendritic cells. Depending on the antigen affinity of activated B cells, $T$ cells and dendritic cells decide about the fate of the $B$ cell. Positive selection of the right $B$ cell clone promotes proliferation and survival, whereas negative selection leads to the death of the cell (reviewed in (Klein and Dalla-Favera 2008). Since these signalling pathways are critical for survival and proliferation of $B$ cells it is not surprising that their deregulation can lead to the transformation of B lymphocyte during the GC-reaction.

During early B cell development in the bone marrow the B cell precursor rearranges IG-heavy and IG-light chain genes. This leads first to the expression of the surrogate $B$ cell receptor and finally to the equipment of the $B$ cell with $a$ functional $B$ cell receptor (BCR). Mature naïve $B$ cells leave the bone marrow and can then be activated by antigen binding to the BCR. Upon BCR activation various signalling pathways are activated including Calcium signalling, PI3K/AKT, NF-KB and MAPK signals (described in detail in Chapter 1.4). Subsequently, activated B cells migrate to secondary lymphatic organs, where they undergo clonal expansion and further differentiation to memory or plasma cells (Figure 11) (Osmond 1990). 


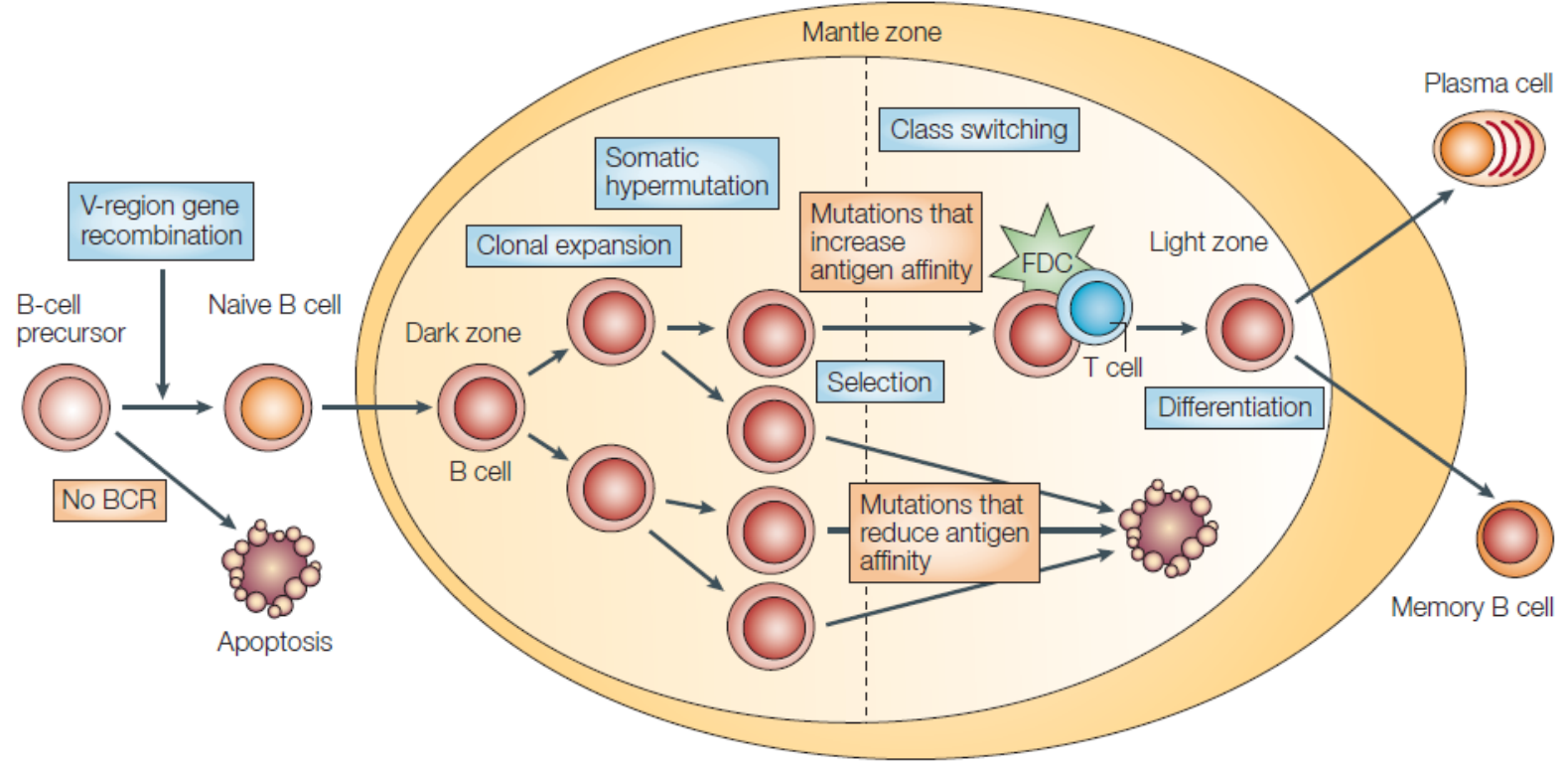

Figure 1-1 Simplified scheme of the Germinal Centre Reaction. The naïve antigen primed B cell enters secondary lymphatic organs and form a Germinal Centre (GC). GC B cells proliferate in the dark zone. After undergoing somatic hypermutation the cells enter the light zone and affinity maturation of the BCR occurs. Therefore B cells are in close contact with $T$ helper cells and Follicular Dendritic Cells (FDCs), which mediate the needed survival signals via paracrine stimulation of maturing $B$ cells. Subsequent to positive selection and class switch recombination the differentiated $B$ cells leave the GC as memory or plasma cells. Figure taken from (Küppers 2005).

During the physiological GC reaction B lymphocytes are selected for an optimal antigen recognition property. First antigen primed B cells enter secondary lymphatic organs and form germinal centres. Germinal centre B cells express the characteristic surface marker CD10 (Klein, Tu et al. 2003). Within the germinal centre distinct regions can be described: a dark zone, a light zone and the surrounding marginal zone. Within the dark zone B cells (centroblasts) proliferate and undergo somatic hypermutation (SHM). SHM is a process leading to mutations in the variable regions of immunoglobulin genes. These modifications are required for the affinity maturation of the BCR. During the process of the GC reaction $B$ cells stay in close contact with $T$ cells and antigen presenting follicular dendritic cells (FDC). These bystander cells supply the maturating B cells with important survival signals including for example CD40L and IL21 expressed by CD4+ $T$ cells (see chapter 1.4. for further description). Cells accumulating mutations that increase antigen affinity receive survival signals, provided by $T$ 
cells and FDCs (Figure 1-1). If a cell encounters mutations that lead to a lower antigen affinity or defective immunoglobulins it usually undergoes apoptosis. During SHM DNA strand brakes in the immunoglobulin loci are induced. This process involves the AID (activation induced deaminase) (Muramatsu, Kinoshita et al. 2000). SHM induced DNA strand breaks are necessary for genetic changes including deletions or insertions, which display up to $6 \%$ of the genetic alterations in SHM. After selection for antigen affinity germinal centre B lymphocytes, then called centrocytes, can switch the class of immunoglobulins they produce. This switch depends on the antigen and respective specific additional signals. During this process of class-switch-recombination (CSR) DNA double strand breaks are employed to achieve a new combination of the variable hypermutated VDJ gene elements with genes encoding for a different heavy chain (Rajewsky 1996). Centrocytes further differentiate to plasma- and memory B cells and leave the germinal centre.

\subsection{B cells are dependent on microenvironmental survival signals}

One can discriminate B cell intrinsic signalling, that is not dependent on surrounding micro-environmental cells on the one hand and paracrine signalling that is mediated by the microenvironment of the $B$ cell. Central players of intrinsic $B$ cell survival signalling include of course the engagement of the $B$ cell receptor with its specific antigen and furthermore the recognition of non-self molecules by receptors of the innate immune response, the Toll like receptors (TLRs). Important paracrine signals include the $\mathrm{T}$ cell mediated co stimulatory activation of CD40. Furthermore IL21 and BAFF function in the sustained survival of activated B cells within the GC (Küppers 2005; D'Orlando, Gri et al. 2007; Khan 2009; Konforte, Simard et al. 2009). In the following paragraphs a brief overview will be given about pathways activated by these factors and the distinct mechanisms employed for the respective pathway activations. As NF-kB and MAPK signals are central to most of the considered stimuli, they will be explained in more detail. 


\subsubsection{Nuclear factor of kappa B light polypeptide gene enhancer in B-cells signalling}

NF-kB signalling includes two main processes: canonical and noncanonical pathway (reviewed in (O'Dea and Hoffmann). Canonical and noncanonical NF-kB differ in the mode of activation and the utilised NF-kBs. The transcription factors of the NF-KB family include RelA (p65), Rel (c-Rel), and RelB, p50 (the processed form of NFKB1), p50 (the processed active form of p105) or p52 (the processed form of $\mathrm{p} 100$ ). The distinct NF-KBs form homo or heterodimers to bind to DNA and act as transcription factors. In the inactive state of the pathway NF-KBs are sequestered in the cytoplasm. Upon activation of IKK (IKB kinase), for example via the CBM complex, IKB proteins (Inhibitor of NF-KB) IKBa, IKBß and IKBY (NEMO) become phosphorylated and are as a consequence proteasomally degraded. This leads to the release of NF-KB dimers and their translocation into the nucleus (Baldwin 1996; Karin and Ben-Neriah 2000). Noncanonical NF-kB signalling is activated upon the proteasomal cleavage of the inactive proform of NFKB2, p100, to the active form p52. This cleavage is induced upon phosphorylation of $\mathrm{p} 100$ by NIK (NF-KB inducing kinase).

\subsubsection{Mitogen Activated Protein Kinases (MAPKs)}

MAPKs comprise ERK/MAPK1, p38a (MAPK14) and JNK (Jun terminal kinase / MAPK8). In the following paragraph the activation of p38a (further referred to as p38) will be illustrated as one example for the activation of a MAPK. The primary step in the MAPK cascade is the phosphorylation of MAP3Ks, which can be mediated for example by TNF receptor associated factors like (TRAF2, TRAF3 or TRAF6). Upon activation of MAP3Ks, which include TAK1 or Tpl2, these trigger the phosphorylation and subsequent activation of MAP2Ks. In the case of p38 activation these are MKK4, MKK3 and MKK6. MKK4, MKK3 and MKK6 can the phosphorylated and thereby activate p38. The activation of p38 leads to the phosphorylation and activation of downstream effectors like MAPKKAPK2/5 and subsequently ATFs or CREB, which regulated the transcription of respective target genes. Furthermore, a number of specific serine/threonine phosphatases, tyrosine specific phosphatases and dual specificity phosphatases (DUSPs) have 
been identified as negative regulators of the MAPK cascade (Keyse 2000; Saxena and Mustelin 2000; Keyse 2008).

\subsubsection{BCR activation triggers a variety of signalling pathways including Calcium signalling, NF-KB, PI3K/AKT and MAPK activation}

Upon antigen recognition BCRs cluster in lipid rafts on the cell surface (Yang and Reth 2010). The BCR itself lacks intracellular signalling domains. Therefore the Igs are linked to CD79A (immunoglobulin-associated alpha) and CD79B (immunoglobulin-associated beta), which mediate the activation of downstream signalling (Reth 1989; Sanchez, Misulovin et al. 1993; Cambier 1995). BCR activation leads to the activation of a variety of signalling pathways including calcium signalling, PI3K/AKT, NF-KB and MAPK signals reviewed in (Wang and Clark 2003).

BCR activation triggers Scr kinases that subsequently lead to the activation of downstream kinases like BTK (Brutons Tyrosine kinse) and PLCY2 (Phospholipase CY2). PLCY2 activity leads to the hydrolysis of $\mathrm{PIP}_{2}$ (phosphatidyl inositol-4,5-bisphosphate) to $\mathrm{IP}_{3}$ (inositol-1,4,5-trisphosphate) and DAG (diacylglycerol). The rise of intracellular $\mathrm{IP}_{3}$ levels is leads to the release of $\mathrm{Ca}^{2+}$ from the endoplasmatic reticulum and thereby to the activation of Calcineurin and the transcriptionfactor NFAT (nuclear factor of activated T cells). Furthermore PI3K (phosphoinositol 3-kinase) pathway is turned on upon antigen recognition and triggers the phosphorylation and activation of AKT1. Additionally BCR activation triggers MAPK signals (JNK/ERK/p38). These comprise the activation of Ras-Raf-MEK and finally ERK as well as p38 (MAPK14) and JNK. The activation of NF-KB via BCR is triggered via the formation of the so called CBM (CARMA1BCL-10-MALT1) complex, which subsequently leads to the activation of NF-KB (Ruland, Duncan et al. 2001; Wang, You et al. 2002; Egawa, Albrecht et al. 2003; Ruland, Duncan et al. 2003; Bidere, Ngo et al. 2009).

\subsubsection{Toll like receptor mediated activation of NF-KB and MAPK signals}

The recognition of bacterial lipopolysaccharides (LPS) via Toll like receptor 4 (TLR-4) is part of the innate immune response (Medzhitov, Preston-Hurlburt et al. 1997; Poltorak, He et al. 1998). TLR-4 belongs to the family of pattern recognition 
receptors (PRRs). TLR-4 specifically recognizes Lipopolysaccharide (LPS), which is a component of the cell wall of Gram-negative bacteria (Poltorak, He et al. 1998; Hoshino, Takeuchi et al. 1999). The activation of TLR-4 leads to the recruitment of the adaptor protein MyD88 (Kawai, Adachi et al. 1999). This activation has been shown to trigger the activation of NF-KB and MAPK signalling (p38 and JNK) via TRAF6 and TAK1 (reviewed in (Palsson-McDermott and O'Neill 2004; Doyle and O'Neill 2006). It has been shown for some lymphomas that the constant activation of transformed $\mathrm{B}$ cells by a persisting microbial antigen is essential for lymphoma growth. This chronic activation can lead for example to the development of MALT lymphomas as a consequence of chronic Helicobacter pylori infection (Zucca, Bertoni et al. 1998; Farinha and Gascoyne 2005).

\subsubsection{CD40 mediates NF-KB and MAPK signals}

CD40/TNFRSF5 belongs to the family of TNF receptors. The similarity of the large family of TNF receptors is mainly expressed by their trimetric clustering upon ligand binding (Locksley, Killeen et al. 2001). CD40 is activated via its specific ligand CD40L/CD154 that is expressed either on the surface of or as soluble form by CD4+ T helper cells (Armitage, Fanslow et al. 1992; Graf, Korthauer et al. 1992; Hollenbaugh, Grosmaire et al. 1992; Lederman, Yellin et al. 1992). The stimulation of B cells by $T$ helper cells via CD40L is regarded as the "classical" co-stimulatory signal or "help" mediating positive selection of the right B cell clone during immune response (Foy, Shepherd et al. 1993; Van den Eertwegh, Noelle et al. 1993; Foy, Laman et al. 1994). Upon binding of CD40L the receptor trimerizes and a so called "cytokine receptor-assembled signalling complex" (Matsuzawa, Tseng et al. 2008) is formed. It has been proposed that this complex constitutes of TRAF2 (TNF receptor-associated factor 2) and TRAF3 (TNF receptor-associated factor 3), UBE2N (bendless-like ubiquitin conjugating enzyme), c-IAP1 and c-IAP2 (cellular inhibitor of apoptosis proteins 1 and 2), IKKY (NEMO) and MEKK1 (mitogen-activated protein kinase (MAPK) kinase kinase). MEKK1 is needed for the activation of MAPK signalling via JNK and p38 and IKK activated canonical and noncanonical NF-KB signalling. In addition to the interaction of TRAF2 and TRAF3 with CD40 (Hu, O'Rourke et al. 
1994; Cheng, Cleary et al. 1995; Rothe, Sarma et al. 1995; Sato, Irie et al. 1995), it has also been shown that additional members of the TRAF family bind to the intracellular part of CD40. These include TRAF5 and TRAF6 (Ishida, Mizushima et al. 1996; Ishida, Tojo et al. 1996). TRAF6 leads to the activation of JNK and p38 probably trough TAK1 (Matsuzawa, Tseng et al. 2008).

The functionality of CD40 signals for lymphoma cells have extensively been studied in vitro. It has been shown by several groups that CD40 activation can have positive effects on cell survival and cell proliferation. This includes for example the rescue of $\mathrm{BL}$ and DLBCL cells from apoptosis or BCR induced growth arrest as well as the induction of proliferation of lymphoma cells by CD40 ligation (Santos-Argumedo, Gordon et al. 1994; An and Knox 1996; Wang, Grand et al. 1996; Mackus, Lens et al. 2002; Hristov, Knox et al. 2005; Pham, Tamayo et al. 2005).

\subsubsection{B cell activating factor of the TNF superfamily (BAFF/ TNFSF13B) can activate distinct TNF receptors that trigger noncanonical NF-KB and MAPK signalling}

The homeostasis of mature B cells is essentially dependent on B cell Activating Factor of the TNF family (BAFF), also named BLys/ TALL-1/ TNFSF13B (Moore, Belvedere et al. 1999; Shu, Hu et al. 1999; Schiemann, Gommerman et al. 2001; Mackay, Sierro et al. 2005). An overexpression of BAFF has been shown to induce severe $B$ cell hyperplasia and autoimmune diseases (reviewed in (Mackay, Sierro et al. 2005; Mackay and Leung 2006). BAFF is expressed by T cells and macrophages either in a membrane bound form or as soluble factor, which is proteolytically cleaved from the cell surface (reviewed in (Bossen and Schneider 2006)). Like other members of the TNF family BAFF occurs as homotrimer. It has been shown that 20 of these trimers can oligomerize to a capsule like structure composed of 60 BAFF proteins (Liu, Hong et al. 2003). BAFF can activate three distinct types of receptors of the TNF receptor superfamily. These include the BAFF-R (BAFF-Receptor/BR3/TNFRSF13C), TACI (transmembrane activator and CAML interactor/TNFRSF13B) and BCMA (B Cell Maturation Antigen/TNFRSF17). Dependent on the quaternary structure of BAFF the ligand shows differing affinities to these receptors (reviewed in (Dillon, Gross et al. 
2006)). Trimeric BAFF predominantly binds to and activates BR3. The stimulation of BR3 leads primarily to the activation of the noncanonical NF-kB pathway via a degradation of TRAF3 by TRAF2, which in turn mediates the accumulation of NIK (MAPK14). NIK induces the activation of NF-kB2 by phosphorylation induced proteasomal cleavage of p100 to the active form p52 (Claudio, Brown et al. 2002; Bossen and Schneider 2006; Gardam, Sierro et al. 2008; Vallabhapurapu, Matsuzawa et al. 2008). The BAFF 60mer has a higher affinity to TACl and BCMA. The activation of TACI leads to the recruitment of TRAF2 and TRAF6 and the activation of canonical NF-KB signalling, whereas BCMA activation has been shown to trigger NF-KB and MAPK signalling (Gross, Johnston et al. 2000; Hatzoglou, Roussel et al. 2000).

Expression of BAFF and BAFF receptors has been detected in lymphoma sections (Rodig, Shahsafaei et al. 2005) and seems to be associated with a bad prognosis for aNHL (DLBCL) patients (Novak, Grote et al. 2004). This is in line with the observation that aNHL patients can show elevated serum levels of BAFF protein (Briones, Timmerman et al. 2002). Autocrine BAFF signalling was shown for CLL, multiple myeloma, DLBCL, MCL and BL cells (He, Chadburn et al. 2004; Novak, Darce et al. 2004; Novak, Grote et al. 2004). Currently an monoclonal antibody directed against human BAFF (belimumab; Lymphostat-B) (Baker, Edwards et al. 2003) is tested in $2^{\text {nd }}$ Phase clinical trials regarding its performance in the therapy of a autoimmune disease (rheumatoid arthritis and SLE) (Ding and Jones 2006). It is discussed that BAFF activity interacts with tonic BCR signalling in a way that the BCR signal leads to the increased expression of NFKB2/p100 which is needed for BR3 signalling (Stadanlick, Kaileh et al. 2008).

\subsubsection{IL21 signals via IL21R mediated STAT1 and STAT3 activity}

IL-21 has been identified as potent B cell activator and plasma cell differentiationinducer (reviewed in (Ettinger, Sims et al. 2005; Davis, Skak et al. 2007; Ettinger, Kuchen et al. 2008). The cytokine IL21 is produced by activated CD4+ T cells and NK cells (Parrish-Novak, Dillon et al. 2000; Harada, Magara-Koyanagi et al. 2006; Coquet, Kyparissoudis et al. 2007). IL21 signals through a heterodimeric receptor comprised of the IL-21 receptor (IL-21R) and the common gamma chain of the IL-2 receptor family (Spolski and Leonard 2008). After binding of IL-21 to 
the receptor, JAK1 (Janus-activated kinase 1) and JAK3 (Janus-activated kinase 3) are autophosphorylated. As a results from that STAT1 and STAT3 (signal transducer and activator of transcription 1/3) become phosphorylated and thereby activated. This leads to their subsequent translocation to the nucleus and the change of STAT target gene expression (Asao, Okuyama et al. 2001; Zeng, Spolski et al. 2007). In addition to the activation of STATs by IL21R, the receptor can also trigger the activation of MAPK and PI3K/AKT signalling (Zeng, Spolski et al. 2007; Fuqua, Akomeah et al. 2008).

Regarding the effects of IL21 stimulation on BL or DLBCL so far no data exist. It has been shown for follicular lymphoma $(F L)$ that these cells exhibit a high IL-21 receptor expression and that the activation of lymphoma cells via IL21 induces apoptosis (Akamatsu, Yamada et al. 2007). 


\section{Aim of the Study}

The recent molecular classification of aggressive Non-Hodgkin Lymphoma (NHL) based on global gene expression analyses of individual lymphomas is a major step forward to understand the clinical heterogeneity of aggressive NHL. These transcriptome based analyses aimed to identify oncogenic events in order to describe new biomarkers or elucidate potential targets for individualized therapies of aNHL. An improved understanding of the heterogeneity of pathway deregulation in aggressive NHL is essential to obtain a better prediction of the clinical outcome and treatment responses of aNHL patients.

The heterogeneity of aggressive NHL is fundamentally characterised by differences in proliferative potential and chromosomal complexity of Diffuse Large B Cell Lymphoma and Burkitt Lymphoma (BL). MYC is the classical oncogene described for BL. However, it was found that $M Y C$ is also genetically altered in some non-mBL on a background of additional chromosomal aberrations.

So far the analyses of $\mathrm{NHL}$ gene expression profiles contributed to a molecular classification defining two major subgroups: "molecular Burkitt lymphoma (mBL)" and "non-molecular Burkitt lymphoma (non-mBL)". Apart from candidate gene approach driven investigations the characterisation of primary aggressive NHL using global gene expression analyses is so far largely descriptive. A discrimination of Diffuse Large B C Lymphoma into "Activated B Cell (ABC)-like" and "Germinal Centre B cell (GCB)-like" subtypes was achieved. The so far described molecular classifications differ in the degree of heterogeneity within the defined NHL subgroups. The subgroup of ABC Diffuse Large B Cell Lymphoma for example comprises largely heterogeneous lymphoma cases. Based on in vitro experiments it was concluded that $A B C$ lymphoma are mainly characterised by activated NF-KB and JAK-STAT signals. Regardless these advancements numerous open questions still need to be answered.

- Is there deregulated c-Myc activity in non-mBL lymphoma? Is there any c-Myc activity detectable in non-mBL independent of the genetic MYC abberations? Is this potential c-Myc activity of prognostic relevance for non-mBL patients? 
- Is it possible to identify novel pathway activities in malignant lymphoma by transferring gene expression data from in vitro perturbations of BL cells to lymphoma gene expression profiles? Can quantitative differences of pathway activities, reflected in gene expression profiles of lymphoma, be detected?

- Which deregulated pathways, apart from NF-KB and JAK-STAT, underlie the heterogeneity of aggressive NHL? Is it possible to draw conclusions on cell cycle deregulation or chromosomal complexity of aggressive aNHL based on the identified pathway activities.

In order to answer these questions, this study aims to identify and characterise new gene expression patterns that hold information about relevant oncogenic pathway activities. The identification of these patterns was aspired using perturbation experiments in primary lymphoma precursor cells and lymphoma cell lines. In order to improve the knowledge about the deregulated processes in aggressive NHL this study focuses on two distinct approaches: (i) the effect of ectopic expression of the proto-oncogene MYC in lymphoma precursor cells and (ii) perturbations of $B$ cell lines by $B$ cell specific paracrine stimuli. 


\section{$2 \quad$ Materials and Methods}

\subsection{Biological Material}

\section{Primary material}

Primary material of human tonsils from paediatric patients was obtained with informed consent and ethical approval (Ref No.06/Q2702/50) from tonsillectomies performed in the Children's Hospital Birmingham, UK (surgeon: Michael Kuo).

\section{Cell lines}

The cell lines that were used in this work are listed in table 2-1.

Table 2-1 Cell lines

\begin{tabular}{|c|c|c|c|}
\hline Cell line & Source & Distributor & Reference \\
\hline BL2 & $\begin{array}{l}\text { B cell, Burkitt Lymphoma } \\
\text { (EBV negative) }\end{array}$ & DSMZ & $\begin{array}{l}\text { (Nilsson and Ponten 1975; Kube, Platzer et } \\
\text { al. 1995) }\end{array}$ \\
\hline BL16 & $\begin{array}{l}\text { B cell, Burkitt Lymphoma } \\
\text { (EBV positive) }\end{array}$ & $\begin{array}{l}\text { Coriell } \\
\text { Institute for } \\
\text { Medical } \\
\text { Research }\end{array}$ & (Bernheim, Berger et al. 1983) \\
\hline BL41 & $\begin{array}{l}\text { B cell, Burkitt Lymphoma } \\
\text { (EBV negative) }\end{array}$ & DSMZ & (Lenoir, Vuillaume et al. 1985) \\
\hline BL70 & $\begin{array}{l}\text { B cell, Burkitt Lymphoma } \\
\text { (EBV negative) }\end{array}$ & DSMZ & (Lenoir, Vuillaume et al. 1985) \\
\hline DG75 & $\begin{array}{l}\text { B cell, Burkitt Lymphoma } \\
\text { (EBV negative) }\end{array}$ & DSMZ & (Ben-Bassat, Goldblum et al. 1977) \\
\hline HT & $\begin{array}{l}\text { B cell, Diffuse Large B cell } \\
\text { lymphoma (GCB) }\end{array}$ & DSMZ & (Beckwith, Longo et al. 1990) \\
\hline MC116 & $\begin{array}{l}\text { B cell, lymphoma } \\
\text { undifferentiated }\end{array}$ & DSMZ & (Magrath, Freeman et al. 1980) \\
\hline Ramos & B cell, Burkitt Lymphoma & DSMZ & (Klein, Giovanella et al. 1975) \\
\hline SuDHL4 & $\begin{array}{l}\text { B cell, Diffuse Large B cell } \\
\text { lymphoma (GCB) }\end{array}$ & DSMZ & (Epstein, Herman et al. 1976) \\
\hline SuDHL5 & $\begin{array}{l}\text { B cell, Diffuse Large B cell } \\
\text { lymphoma (GCB) }\end{array}$ & DSMZ & (Epstein, Levy et al. 1978) \\
\hline
\end{tabular}


Materials and Methods

\begin{tabular}{|l|l|l|l|}
\hline SuDHL6 & $\begin{array}{l}\text { B cell, Diffuse Mixed Small } \\
\text { and Large B cell lymphoma } \\
\text { (GCB) }\end{array}$ & DSMZ & (Epstein, Herman et al. 1976) \\
\hline OCI-Ly1 & $\begin{array}{l}\text { B cell, Diffuse Large B cell } \\
\text { lymphoma (GCB) }\end{array}$ & $\begin{array}{l}\text { University } \\
\text { Health } \\
\text { Network } \\
\text { (Toronto, } \\
\text { Canada) }\end{array}$ & (Epstein, Levy et al. 1978) \\
\hline OCI-Ly3 & $\begin{array}{l}\text { B cell, Diffuse Large B cell } \\
\text { lymphoma (ABC) }\end{array}$ & $\begin{array}{l}\text { Health } \\
\text { Network } \\
\text { (Toronto, } \\
\text { Canada) }\end{array}$ & (Tweeddale, Jamal et al. 1989) \\
\hline OCI-Ly7 & $\begin{array}{l}\text { Bniversity } \\
\text { Bymphoma (GCB) }\end{array}$ & $\begin{array}{l}\text { University } \\
\text { Health } \\
\text { Network } \\
\text { (Toronto, } \\
\text { Canada) }\end{array}$ & (Chang, Blondal et al. 1995) \\
\hline
\end{tabular}

\section{Bacteria}

Escherichia coli (E. coli) TOP10 (Invitrogen, Darmstadt GER) were used for the transformation and amplification of plasmid DNA.

\subsection{Consumable supplies}

Table 2-2 Consumables

\begin{tabular}{|c|c|}
\hline Consumable & Manufacturer \\
\hline ABI PRISM® 384-Well Clear Optical Reaction Plate & Applied Biosystems, Foster City USA \\
\hline ABI PRISM® Optical Adhesive Covers & Applied Biosystems, Foster City USA \\
\hline Cell culture flasks & Sarstedt, Nümbrecht GER \\
\hline Cryo Box & Nunc, Wiesbaden GER \\
\hline Cryotubes & Nunc, Wiesbaden GER \\
\hline Diethylaminoethyl-Cellulose & Whatman $\circledast$, International Ltd UK \\
\hline Electroporation Cuvettes & Eurogentec, Cologne GER \\
\hline FACS tubes & $\begin{array}{l}\text { Becton Dickinson Labware, Franklin Lakes, NJ, } \\
\text { USA }\end{array}$ \\
\hline
\end{tabular}


Materials and Methods

\begin{tabular}{|c|c|}
\hline Falcon Tubes $15 \mathrm{ml}$ & Sarstedt, Nümbrecht GER \\
\hline Falcon Tubes $50 \mathrm{ml}$ & Sarstedt, Nümbrecht GER \\
\hline Filter Tips, $10 \mu \mathrm{l}, 100 \mu \mathrm{l}, 1000 \mu \mathrm{l}$ & Starlab, Ahrensburg GER \\
\hline Micro Touch Examination Gloves & Ansell, München Germany \\
\hline MACS ${ }^{\mathrm{TM}}$ MS columns & Miltenyi-Biotech, Surrey UK \\
\hline MACS $^{\top M}$ pre separation filters & Miltenyi-Biotech, Surrey UK \\
\hline Nucleofection cuvettes & Amaxa-biosystems, Cologne GER \\
\hline Pasteurpipettes & Sarstedt, Nümbrecht GER \\
\hline Pipette Tips (wo filters) & Sarstedt, Nümbrecht GER \\
\hline Reactiontubes $1.5 \mathrm{ml}$ & Sarstedt, Nümbrecht GER \\
\hline Reactiontubes $2.0 \mathrm{ml}$ & Sarstedt, Nümbrecht GER \\
\hline Serological pipettes $5 \mathrm{ml}$ & Sarstedt, Nümbrecht GER \\
\hline Serological pipettes $10 \mathrm{ml}$ & Sarstedt, Nümbrecht GER \\
\hline Serological pipettes $25 \mathrm{ml}$ & Sarstedt, Nümbrecht GER \\
\hline Tissue culture dish & Sarstedt, Nümbrecht GER \\
\hline Tissue culture plates, 6 well & Nunc, Wiesbaden GER \\
\hline Tissue culture plates, 24 well & Nunc, Wiesbaden GER \\
\hline
\end{tabular}

\subsection{Equipment}

Table 2-3 Equipment

\begin{tabular}{|l|l|}
\hline Instrument & Manufacturer \\
\hline 3130 Genetic Analyzer & Applied Biosystems, Foster City USA \\
\hline 96-Well Plate Septa & Applied Biosystems, Foster City USA \\
\hline ABI PRISM 7900HT & Applied Biosystems, Foster City USA \\
\hline Accu-jet & Brand, Hamburg GER \\
\hline Amaxa Nucleofector ${ }^{\text {TM } I I}$ & Amaxa-biosystems, Cologne GER \\
\hline
\end{tabular}


Materials and Methods

\begin{tabular}{|c|c|}
\hline Instrument & Manufacturer \\
\hline Biofuge Pico & Heraeus Instruments, Hanau GER \\
\hline Biofuge Primo $\mathrm{R}$ & Heraeus Instruments, Hanau GER \\
\hline Biorupter & Diagnode, Liège, Belgium \\
\hline Consort E734 Power Supply & Schütt Labortechnik, Göttingen GER \\
\hline CAT RM 5 horizontal roller & CAT M Zipperer, Staufen GER \\
\hline Centrifuge 5451D & Eppendorf, Hamburg GER \\
\hline FACSscan flow cytometer & Becton Dickinson, Heidelberg GER \\
\hline Hera freeze $-80^{\circ} \mathrm{C}$ freezer & Heraeus Instruments, Hanau GER \\
\hline IKA KS 260 shaker & IKA, Staufen GER \\
\hline IKAMAG RCT magnetic stirrer & IKA, Staufen GER \\
\hline Incubator Galaxy R & RS Biotech, Irvine Scotland, UK \\
\hline Incubator Cytoperm & Heraeus Instruments, Hanau GER \\
\hline Incudrive incubator & Schütt Labortechnik, Göttingen GER \\
\hline LAS-4000 Image Reader & Fujfilm, Düsseldorf GER \\
\hline Leitz DM IL inverse fluorescence microscope & Leica, Wetzlar GER \\
\hline MACS ${ }^{\mathrm{TM}}$ Separator & Miltenyi-Biotech, Surrey UK \\
\hline Microflow Laminar Downflow Workstation & Bioquell, England \\
\hline Microcoolcentrifuge 1-15k & Sigma, Munich GER \\
\hline Multifuge $3 \mathrm{~L}-\mathrm{R}$ & Heraeus Instruments, Hanau GER \\
\hline MoFlow® High-Performance Cell Sorter & Dako, Stockport UK \\
\hline NanoDrop ${ }^{\mathrm{TM}}$ & $\begin{array}{l}\text { ND-1000 UV/Vis-Spektralphotometer, Wilmington } \\
\text { IISA }\end{array}$ \\
\hline Neubauer Counting Chamber Improved & Lo Labor Optik, Friedrichsdorf GER \\
\hline Power Pac 300 Power Supply & Bio-Rad, München GER \\
\hline Reax2 shaker & Heidolph, Schwabach GER \\
\hline Sunrise $^{\mathrm{TM}}$ Microplate Reader & Tecan, Crailsheim GER \\
\hline Televal 31 inverse light optical microscope & Zeiss, Jena GER \\
\hline
\end{tabular}


Materials and Methods

\begin{tabular}{|l|l|}
\hline Instrument & Manufacturer \\
\hline Thermocycler Mastercycler & Eppendorf, Hamburg GER \\
\hline Thermocycler 60 & Biomed, Theres GER \\
\hline Thermocycler T3000 & Biometra, Goettingen GER \\
\hline Thermomixer Compact & Eppendorf, Hambrug GER \\
\hline Vortex Genie 2 & Schütt Labortechnik, Göttingen GER \\
\hline Vienna Superautomatica & Saeco, Eigeltingen GER \\
\hline Water bath & Köttermann Labortechnik, Hänigsen GER \\
\hline
\end{tabular}

\subsection{Chemicals}

\section{Table 2-4 Chemicals}

\begin{tabular}{|c|c|}
\hline Chemical & Manufacturer \\
\hline Agarose & Sigma-Aldrich, Munich GER \\
\hline Acrylamid/Bisacrylamid $40 \%$ & BioRad, Munich GER \\
\hline Ammonium persulphate & Sigma-Aldrich, Munich GER \\
\hline Bradford solution & RothiQuant-Roth, Karlsruhe GER \\
\hline Bromphenol Blue & Sigma-Aldrich, Munich GER \\
\hline BSA & Serva, Heidelberg GER \\
\hline DMSO & Sigma-Aldrich, Munich GER \\
\hline Ethanol (100\%) & J.T. Baker, Deventer NL \\
\hline Ethidiumbromid & Sigma-Aldrich, Munich GER \\
\hline EDTA & Riedel-de Haën, Seelze GER \\
\hline FACS Flow & Becton Dickinson, Heidelberg GER \\
\hline Full Range Rainbow Molecular Weight & GE Healthcare, Munich GER \\
\hline Formaldehyde & Sigma-Aldrich, Munich GER \\
\hline Glycerol & Roth, Karlsruhe GER \\
\hline Glycin & Roth, Karlsruhe GER \\
\hline
\end{tabular}


Materials and Methods

\begin{tabular}{|c|c|}
\hline Chemical & Manufacturer \\
\hline HEPES & Sigma-Aldrich, Munich GER \\
\hline Hydrogen Peroxide & Sigma-Aldrich, Munich GER \\
\hline Indo-1-AM & Invitrogen/Molecular Probes, Karlsruhe GER \\
\hline Isopropanol & Sigma-Aldrich, Munich GER \\
\hline Methanol $100 \%$ (p.a.) & J.T. Baker, Deventer NL \\
\hline Milk powder & Roth, Karlsruhe GER \\
\hline Nonidet P-40 & Sigma-Aldrich, Munich GER \\
\hline Phosphatase inhibitor Phospho- STOP & Roche, Mannheim GER \\
\hline Pluronic acid F-127 & Sigma-Aldrich, Munich GER \\
\hline PMSF & Sigma-Aldrich, Munich GER \\
\hline Protein A Sepharose & GE Healthcare, Munich GER \\
\hline Propidium iodide & Sigma-Aldrich, Munich GER \\
\hline Proteaseinhibitor-Mix Complete $^{\mathrm{TM}}$ & Santa Cruz biotechnology, Heidelberg GER \\
\hline SDS & Merck, Darmstadt, GER \\
\hline Sodiumchloride & Merck, Darmstadt, GER \\
\hline Sodiumdeoxycholat & Merck, Darmstadt, GER \\
\hline Sodiumvanadat & Sigma-Aldrich, Munich GER \\
\hline Spectra Multicolor Broad Range & Fermentas, Frankfurt GER \\
\hline TEMED & Sigma-Aldrich, Munich GER \\
\hline Trisbase & Sigma-Aldrich, Munich GER \\
\hline Trypanblue $0.4 \%$ in PBS & GIBCO BRL, Life Technologies, Eggenstein GER \\
\hline Tween-20 & Merck, Darmstadt GER \\
\hline Thymidine (cell culture grade) & Sigma-Aldrich, Munich GER \\
\hline Water HPLC grade & Merck, Darmstadt GER \\
\hline
\end{tabular}




\subsection{Chemical Inhibitors}

The following chemical inhibitors were used for the inhibition of specific pathway components.

Table 2-5 Chemical Inhibitors

\begin{tabular}{|l|l|l|}
\hline Description & Manufacturer & $\begin{array}{l}\text { Final } \\
\text { concentration }\end{array}$ \\
\hline 10058F4 (c-Myc) & Sigma-Aldrich, Munich GER & $60 \mu \mathrm{M}$ \\
\hline 5Z-7-oxozeaenol (TAK1) & Calbiochem/Merck, Darmstadt, GER & $100 \mathrm{nM}$ \\
\hline IKK2 inhibitor VIII & Calbiochem/Merck, Darmstadt, GER & $7 \mu \mathrm{M}$ \\
\hline Ly294002 (PI3K) & Calbiochem/Merck, Darmstadt, GER & $10 \mu \mathrm{M}$ \\
\hline SB203580 (p38/MAPK14) & Sigma-Aldrich, Munich GER & $2 \mu \mathrm{M}$ \\
\hline SP600125 (JNK) & Calbiochem/Merck, Darmstadt, GER & $10 \mu \mathrm{M}$ \\
\hline U0126 (ERK1/2) & Sigma-Aldrich, Munich GER & $10 \mu \mathrm{M}$ \\
\hline VIVIT (NFAT) & Sigma-Aldrich, Munich GER & $2.5 \mu \mathrm{M}$ \\
\hline
\end{tabular}

\subsection{Buffers, Solutions and Media}

Commonly used buffers solutions and media are summarized below.

Table 2-6 Buffers, Solutions and Media

\begin{tabular}{|l|l|}
\hline Liquid & Receipt / Manufacturer \\
\hline $2 x$ SDS loading dye & $\begin{array}{l}4 \% \text { SDS } \\
0.12 \text { M Tris-HCl }(\mathrm{pH} 6.8) \\
200 \mathrm{mM} \text { DTT } \\
\text { Pipette Tip of } 1 \% \text { BromphenolBlue }\end{array}$ \\
\hline 4 X loading buffer Roti®-Load & Roth, Karlsruhe GER \\
\hline AnxV binding buffer & 10 mM HEPES/NaOH pH 7.4, $140 \mathrm{mM} \mathrm{NaCl,5} \mathrm{mM} \mathrm{CaCl}$ \\
\hline autoMACS ${ }^{\text {TM }}$ buffer & Miltenyi-Biotech, Surrey UK \\
\hline
\end{tabular}




\begin{tabular}{|c|c|}
\hline autoMACS ${ }^{\mathrm{TM}}$ buffer plus & $\begin{array}{l}\text { autoMACS }{ }^{\text {TM }} \text { buffer supplemented with: } \\
100 \mathrm{U} / \mathrm{ml} \text { penicillin }+ \\
100 \mu \mathrm{g} / \mathrm{ml} \text { streptomycin, Sigma-Aldrich, Dorset UK } \\
10 \mu \mathrm{g} / \mathrm{ml} \text { ciprofloxacin, Bayer Cambridge UK } \\
0.25 \%(\mathrm{v} / \mathrm{v}) \text { BSA Miltenyi-Biotech, Surrey UK }\end{array}$ \\
\hline $\begin{array}{l}\text { Cell culture medium I } \\
\text { (cell lines - BL) }\end{array}$ & $\begin{array}{l}\text { RPMI-1640 (PAA, Pasching AUS) } \\
\text { 10\% (v/v) FBS (Sigma-Aldrich, Munich GER) } \\
200 \mathrm{U} / \mathrm{ml} \text { Penicilin + } \\
200 \mu \mathrm{g} / \mathrm{ml} \text { Streptomycin + } \\
4 \mathrm{mM} \text { L-Glutamine (Sigma-Aldrich, Munich GER) } \\
50 \mu \mathrm{M} \alpha \text {-Thiolglycerol (), } 20 \mathrm{nM} \text { BCS, } 1 \mathrm{mM} \text { Sodium pyruvat }\end{array}$ \\
\hline $\begin{array}{l}\text { Cell culture medium II } \\
\text { (cell lines - DLBCL) }\end{array}$ & 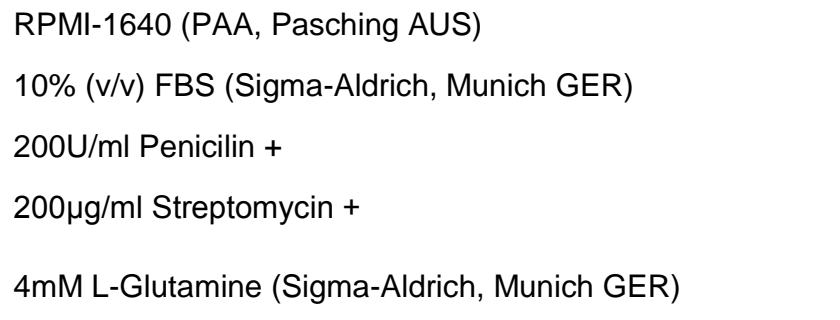 \\
\hline Cell culture medium III & $\begin{array}{l}\text { IMDM (PAA) } \\
\text { 10\% (v/v) FBS (Sigma-Aldrich, Munich GER) } \\
200 \mathrm{U} / \mathrm{ml} \text { Penicilin + } \\
200 \mu \mathrm{g} / \mathrm{ml} \text { Streptomycin + } \\
4 \mathrm{mM} \text { L-Glutamine (Sigma-Aldrich, Munich GER) } \\
\text { OCl-Ly3 cells were cultivated with 20\% FBS }\end{array}$ \\
\hline $\begin{array}{l}\text { Cell culture medium IV } \\
\text { (primary cell isolation) }\end{array}$ & $\begin{array}{l}\text { RPMI } 1640 \text { (GIBCO, Paisley UK) } \\
100 \mathrm{U} / \mathrm{ml} \text { penicillin } \\
100 \mu \mathrm{g} / \mathrm{ml} \text { streptomycin (Sigma-Aldrich, Dorset UK) } \\
10 \mu \mathrm{g} / \mathrm{ml} \text { ciprofloxacin (Bayer, Newbury UK) }\end{array}$ \\
\hline $\begin{array}{l}\text { Cell culture medium V } \\
\text { (primary cell cultivation) }\end{array}$ & $\begin{array}{l}\text { Cell culture medium IV + } \\
10 \%(v / v) \text { FBS (Sigma-Aldrich, Dorset UK) }\end{array}$ \\
\hline ChIP Puffer & $\begin{array}{l}30 \mathrm{ml} 5 \mathrm{M} \mathrm{NaCl} \\
10 \mathrm{ml} 500 \mathrm{mM} \text { EDTA (pH 8) } \\
50 \mathrm{ml} 1 \mathrm{M} \text { Tris (pH 8) } \\
50 \mathrm{ml} 10 \% \text { NP-40 } \\
100 \mathrm{ml} 10 \% \text { Triton-X-100 } \\
\text { Add } 1000 \mathrm{ml} \text { bidest } \mathrm{H}_{2} \mathrm{O} \\
\text { plus Roche Protease inhibitor cocktail }\end{array}$ \\
\hline
\end{tabular}


Materials and Methods

\begin{tabular}{|c|c|}
\hline ECL Western Blotting Detection Kit & GE Healthcare, Munich GER \\
\hline EDTA cell culture grade & 0.5 M, Sigma-Aldrich, Munich GER \\
\hline \multirow[t]{2}{*}{ FACS buffer } & $1 \times$ PBS \\
\hline & $0.5 \%(w / v) B S A$ \\
\hline FACS flow & Becton Dickinson (Heidelberg GER) \\
\hline \multirow[t]{2}{*}{ Freezing medium } & 90\% (v/v) FBS (Biochrom, Berlin GER) \\
\hline & $10 \%(v / v)$ DMSO (Sigma-Aldrich, Munich GER) \\
\hline Krebs-Ringer solution $\quad$ (+ Calcium) & $\begin{array}{l}10 \mathrm{mM} \text { HEPES, pH 7.0, } 140 \mathrm{mM} \mathrm{NaCl}, 4 \mathrm{mM} \mathrm{KCl} \text {, } \\
1 \mathrm{mM} \mathrm{MgCl}, 10 \mathrm{mM} \text { glucose, } 1 \mathrm{mM} \mathrm{CaCl} 2\end{array}$ \\
\hline LB-agar & $1.5 \%(w / v)$ Agar in LB-medium \\
\hline \multirow[t]{3}{*}{ LB-Medium } & $0.5 \%(w / v)$ Sodium Chloride \\
\hline & $0.5 \%(\mathrm{w} / \mathrm{v})$ Yeast Extract \\
\hline & $1 \%(w / v)$ Bacto-Trypton \\
\hline \multirow[t]{5}{*}{ Laemmli buffer $(2 x)$} & 187.5 mM Tris/HCl pH 6.8 \\
\hline & $6.0 \%(w / v)$ SDS \\
\hline & $30.0 \%(v / v)$ Glycerin \\
\hline & 0.01\% (w/v) Bromphenolblue \\
\hline & $10 \%$ (v/v) B-Mercaptoethanol \\
\hline Lymphoprep $^{\mathrm{TM}}$ ficoll solution & Axis-Shield, Liverpool UK \\
\hline \multirow[t]{3}{*}{ Nicoletti buffer } & $0.1 \%(w / v)$ Sodium Citrate \\
\hline & $0.1 \%(v / v)$ TritonX-100 \\
\hline & $50 \mu \mathrm{g} / \mathrm{ml}$ propidium iodide \\
\hline \multirow[t]{5}{*}{ PCR buffer (10x) for qRT } & 750 mM Tris- $\mathrm{HCl} \mathrm{pH} 8.8$ \\
\hline & 200 mM Ammonium sulfate (Merck, Darmstadt \\
\hline & GER) \\
\hline & $0.1 \%$ Tween-20 \\
\hline & in depc water (DEPC by Roth, Karsruhe GER) \\
\hline PBS & $137 \mathrm{mM} \mathrm{NaCl}$ \\
\hline \multirow[t]{2}{*}{ (Phosphate Buffered Saline) } & 10 mM Phosphate \\
\hline & 2.7 mM KCl, pH 7.4. \\
\hline PBS pH 7.4 (cell culture grade) & Lonza, Verviers BEL \\
\hline
\end{tabular}




\begin{tabular}{|c|c|}
\hline Ponceau-S & $\begin{array}{l}5 \%(\mathrm{v} / \mathrm{v}) \text { glacial acetic acid } \\
0.5 \%(\mathrm{w} / \mathrm{v}) \text { Ponceau-S }\end{array}$ \\
\hline ReBlot plus mild & Millipore, Schwalbach/Ts. GER \\
\hline RIPA buffer & $\begin{array}{l}\text { 1x PBS pH } 7.4 \\
1 \%(\mathrm{v} / \mathrm{v}) \text { Igepal } \\
0.5 \%(\mathrm{w} / \mathrm{v}) \text { Sodium-deoxycholat } \\
\mathrm{mg} / \mathrm{ml} \text { PMSF (solved in isopropanol) } \\
1 \mathrm{mM} \text { Soduim-Orthovanadat } \\
\text { Complete-Solution ( } 40 \mu \mathrm{l} \text { stocksolutiuon for } 1 \mathrm{ml} \text { RIPA; } \\
\text { stocksolution: } 1 \text { tablet for } 1.5 \mathrm{ml} \mathrm{H}_{2} \mathrm{O} \text {, Roche, Grenzach GER) }\end{array}$ \\
\hline Running buffer (1x): & $\begin{array}{l}\text { 25mM Tris-Base } \\
\text { 192mM Glycin } \\
34.67 \mathrm{mM} \text { SDS }\end{array}$ \\
\hline Separation Gel Mix & $\begin{array}{l}31.3 \text { \% (v/v) Acrylamid/Bis Solution (40 \%) } \\
332 \text { mM Tris Base, pH 8,9 } \\
3.33 \text { mM EDTA }\end{array}$ \\
\hline Stacking Gel Mix & $\begin{array}{l}15 \%(\mathrm{v} / \mathrm{v}) \text { Acrylamid/Bis Solution (40\%) } \\
125 \mathrm{mM} \text { Tris Base } \mathrm{pH} 6.8 \\
0.1 \%(\mathrm{w} / \mathrm{v}) \text { SDS } \\
5 \mathrm{mM} \text { EDTA }\end{array}$ \\
\hline $\begin{array}{l}\text { Solution } 1 \text { Chemiluminescence - } \\
\text { Luminol }\end{array}$ & $\begin{array}{l}100 \text { mM Tris/HCl pH } 8.8 \\
2.5 \text { mM Luminol (Sigma-Aldrich, Munich GER) } \\
4 \text { mM 4-IPBA (Sigma-Aldrich, Munich GER) }\end{array}$ \\
\hline $\begin{array}{l}\text { Solution } 2 \text { Chemiluminescence - } \\
\text { Peroxide }\end{array}$ & $\begin{array}{l}100 \mathrm{mM} \text { Tris/HCl pH } 8.8 \\
10.6 \mathrm{mM} \mathrm{H}_{2} \mathrm{O}_{2}\end{array}$ \\
\hline SybrGreenMix & $\begin{array}{l}\text { 1x PCR buffer; } 3 \mathrm{mM} \mathrm{MgCl} 2 \text { (Primetech LTD, Minsk Belarus); } \\
1: 80000 \text { SybrGreen (Roche, Grenzach Germany); } 0.2 \mathrm{mM} \\
\text { dNTP each (Primetech LTD, Minsk Belarus); } 20 \mathrm{U} / \mathrm{ml} \mathrm{taq} \\
\text { polymerase (Primetech LTD, Minsk } \\
\text { Belarus), } 0.25 \% \text { TritonX-100 (Roth, Karlsruhe Germany), } 0.5 \\
\text { mM trehalose (Roth, Karlsruhe Germany) in depc water }\end{array}$ \\
\hline TAE (10x) & $\begin{array}{l}\text { 400mM Tris } \\
0.01 \mathrm{M} \text { EDTA }(\mathrm{pH} 8.3)\end{array}$ \\
\hline TBS (1x) & $\begin{array}{l}\text { 20mM Tris-Base, } \\
137 \mathrm{mM} \text { Sodium Chloride }(\mathrm{pH} 7.6)\end{array}$ \\
\hline
\end{tabular}




\begin{tabular}{|l|l|}
\hline TBS-T & $1 \times$ TBS \\
& $0.1 \%(v / v)$ Tween-20 \\
\hline Transferpuffer (1x): & $25 \mathrm{mM}$ Tris-Base \\
& $192 \mathrm{mM}$ Glycin \\
& $15 \%(\mathrm{v} / \mathrm{v}) \mathrm{MeOH}$ \\
\hline
\end{tabular}

\section{$2.7 \quad$ Plasmids}

Vectors used for the non-viral DNA transfer are summarized in table 2-7 below.

Table 2-7 Vectors

\begin{tabular}{|l|l|l|}
\hline Name & Description & Source \\
\hline pcDNA3.1 & Control vector & Invitrogen, Karlsruhe GER \\
\hline pcDNA3.1-myc & C-Myc expression vector & $\begin{array}{l}\text { kindly povided by Georg Bornkamm } \\
\text { (Hörtnagel, Mautner et al. 1995) }\end{array}$ \\
\hline pMAX-GFP & GFP control & Amaxa-biosystems, Cologne GER \\
\hline pMACS- $\Delta$ LNGFR & $\begin{array}{l}\text { LLNGFR expression } \\
\text { vector }\end{array}$ & Miltenyi-Biotech, Surrey UK \\
\hline
\end{tabular}

\subsection{Recombinant Proteins and Biological Material}

The following recombinant proteins were used for the stimulation of $\mathrm{BL}$ and DLBCL cell lines as well as primary $B$ cells.

Table 2-8 Recombinant Proteins

\begin{tabular}{|c|c|}
\hline Description & Manufacturer \\
\hline goat anti human IgM $\mathrm{F}(\mathrm{ab})^{2}$ fragment (\#109006129) & $\begin{array}{l}\text { Jackson ImmunoResearch / Dianova, } \\
\text { Hamburg GER }\end{array}$ \\
\hline $\begin{array}{l}\text { goat anti human } \lg M \text { / anti } \lg G \quad F(a b)^{2} \text { fragment } \\
\text { (\#109226044) }\end{array}$ & $\begin{array}{l}\text { Jackson ImmunoResearch / Dianova, } \\
\text { Hamburg GER }\end{array}$ \\
\hline Lipopolysaccharide from E. coli 055:B5 (\#62326 ) & Sigma-Aldrich, Munich GER \\
\hline rhBAFF (\#2149-BF-10 ) & $\begin{array}{l}\text { R\&D systems, Wiesbaden-Nordenstadt } \\
\text { GER }\end{array}$ \\
\hline rhIL21 (\#11340213) & ImmunoTools, Friesoythe GER \\
\hline sCD40L (\#ABC159) & AutogenBioclear, Calne, Wiltshire UK \\
\hline
\end{tabular}




\section{$2.9 \quad$ Antibodies}

Antibodies used for immunoblotting, cell sorting and cell characterisation and Chromatin-Immunoprecipitation are summarized below.

Table 2-9 Antibodies

\begin{tabular}{|c|c|c|c|}
\hline Antibody & \multicolumn{2}{|l|}{ Source } & Working Dilution \\
\hline \multicolumn{4}{|l|}{ Flow cytometry } \\
\hline Anti CD3-PE & $\begin{array}{l}\text { BD Biosciences } \\
\text { Oxford UK }\end{array}$ & Pharmingen, & $1: 20$ in FACS buffer \\
\hline Anti CD8-FITC & $\begin{array}{l}\text { BD Biosciences } \\
\text { Oxford UK }\end{array}$ & Pharmingen, & $1: 20$ in FACS buffer \\
\hline Anti CD10-PE & \multicolumn{2}{|c|}{ eBioscience, San Diego USA } & $1: 20$ in FACS buffer \\
\hline Anti CD19-FITC & \multicolumn{2}{|c|}{ Becton Dickinson, Oxford UK } & $1: 20$ in FACS buffer \\
\hline Anti CD20-FITC & \multicolumn{2}{|c|}{ Becton Dickinson, Oxford UK } & 1:20 in FACS buffer \\
\hline Anti CD27-FITC & \multicolumn{2}{|c|}{ Becton Dickinson, Oxford UK } & $1: 20$ in FACS buffer \\
\hline Anti CD38-FITC & \multicolumn{2}{|c|}{$\begin{array}{l}\text { Immunotech/BC, Buckinghamshire } \\
\text { UK }\end{array}$} & 1:20 in FACS buffer \\
\hline Anti CD77-FITC & \multicolumn{2}{|l|}{$\begin{array}{l}\text { BD Biosciences } \\
\text { Oxford UK }\end{array}$} & $1: 20$ in FACS buffer \\
\hline Anti CD267-FITC (TACI) & \multicolumn{2}{|l|}{ Oxford UK } & $1: 20$ in FACS buffer \\
\hline Anti CD268-PE (BR-3) & \multicolumn{2}{|l|}{$\begin{array}{l}\text { BD Biosciences } \\
\text { Oxford UK }\end{array}$} & $1: 20$ in FACS buffer \\
\hline Anti IgD-FITC & \multicolumn{2}{|l|}{$\begin{array}{l}\text { BD Biosciences } \\
\text { Oxford UK }\end{array}$} & $1: 20$ in FACS buffer \\
\hline Anti IgM-FITC & \multicolumn{2}{|l|}{$\begin{array}{l}\text { BD Biosciences } \\
\text { Oxford UK }\end{array}$} & 1:20 in FACS buffer \\
\hline Anti IgG-FITC & \multicolumn{2}{|l|}{ Oxford UK } & $1: 20$ in FACS buffer \\
\hline $\begin{array}{l}\text { Isotype control } \\
\text { antibodies, mouse lgG } \\
\text { FITC }\end{array}$ & \multicolumn{2}{|l|}{$\begin{array}{l}\text { BD Biosciences } \\
\text { Oxford UK }\end{array}$} & $\begin{array}{l}1: 20 \text { in FACS buffer1:20 in FACS } \\
\text { buffer }\end{array}$ \\
\hline $\begin{array}{l}\text { Isotype control } \\
\text { antibodies, mouse lgG PE }\end{array}$ & \multicolumn{2}{|c|}{ eBioscience, San Diego USA } & 1:20 in FACS buffer \\
\hline $\begin{array}{l}\text { Isotype control } \\
\text { antibodies, mouse lgG PE }\end{array}$ & \multicolumn{2}{|l|}{$\begin{array}{l}\text { BD Biosciences } \\
\text { Oxford UK }\end{array}$} & $1: 20$ in FACS buffer \\
\hline
\end{tabular}


Materials and Methods

\begin{tabular}{|c|c|c|}
\hline \multicolumn{3}{|l|}{ ChIP } \\
\hline $\begin{array}{l}\text { anti c-Myc for ChIP (N- } \\
262)\end{array}$ & Santacruz, Heidelberg GER & $2 \mu \mathrm{g} / \mathrm{IP}$ \\
\hline $\begin{array}{l}\text { anti acH3 for ChIP (06- } \\
599)\end{array}$ & Millipore, Schwalbach GER & $2 \mu \mathrm{g} / \mathrm{IP}$ \\
\hline $\begin{array}{l}\text { anti IgG for ChIP } \\
(\text { ab46540) }\end{array}$ & abcam, Cambridge UK & $2 \mu \mathrm{g} / \mathrm{IP}$ \\
\hline \multicolumn{3}{|l|}{ Immunoblot } \\
\hline $\begin{array}{l}\text { mouse monoclonal anti } \boldsymbol{\alpha}- \\
\text { tubulin }(\# 05-829)\end{array}$ & Upstate/Millipore, Schwalbach GER & $1: 5000$ in $3 \%$ milkpowder in TBS-T \\
\hline $\begin{array}{l}\text { rabbit anti p-AKT } \\
(\text { Ser473) (\#9271) }\end{array}$ & $\begin{array}{l}\text { Cell Signalling/ New England } \\
\text { Biolabs, Frankfurt am Main GER }\end{array}$ & $1: 1000$ in $3 \%$ BSA in TBS-T \\
\hline $\begin{array}{l}\text { rabbit anti pan AKT } \\
(\# 100-401-401)\end{array}$ & Rockland via BioMol, Hamburg GER & $1: 1000$ in $5 \%$ BSA in TBS-T \\
\hline $\begin{array}{l}\text { rabbit anti pan } \mathbf{A K T} \\
(\# 9272)\end{array}$ & $\begin{array}{l}\text { Cell Signalling/ New England } \\
\text { Biolabs, Frankfurt am Main GER }\end{array}$ & $1: 1000$ in $3 \%$ BSA in TBS-T \\
\hline rabbit anti p-p38 (\#9211) & $\begin{array}{l}\text { Cell Signalling/ New England } \\
\text { Biolabs, Frankfurt am Main GER }\end{array}$ & $1: 1000$ in $3 \%$ BSA in TBS-T \\
\hline rabbit anti p38 (\#9212) & $\begin{array}{l}\text { Cell Signalling/ New England } \\
\text { Biolabs, Frankfurt am Main GER }\end{array}$ & $1: 1000$ in $3 \%$ BSA in TBS-T \\
\hline $\begin{array}{l}\text { rabbit anti p-STAT1 } \\
\text { (Tyr701) (\#9171) }\end{array}$ & $\begin{array}{l}\text { Cell Signalling/ New England } \\
\text { Biolabs, Frankfurt am Main GER }\end{array}$ & $1: 1000$ in $3 \%$ BSA in TBS-T \\
\hline rabbit anti STAT1 (\#9172) & $\begin{array}{l}\text { Cell Signalling/ New England } \\
\text { Biolabs, Frankfurt am Main GER }\end{array}$ & $1: 1000$ in $3 \%$ BSA in TBS-T \\
\hline $\begin{array}{l}\text { rabbit anti p-STAT3 } \\
\text { (Ser727) (\#9134) }\end{array}$ & $\begin{array}{l}\text { Cell Signalling/ New England } \\
\text { Biolabs, Frankfurt am Main GER }\end{array}$ & $1: 1000$ in $3 \%$ BSA in TBS-T \\
\hline rabbit Anti STAT3 (\#9132) & $\begin{array}{l}\text { Cell Signalling/ New England } \\
\text { Biolabs, Frankfurt am Main GER }\end{array}$ & $1: 1000$ in $3 \%$ BSA in TBS-T \\
\hline $\begin{array}{l}\text { rabbit anti p-STAT5 } \\
(\# 9351)\end{array}$ & $\begin{array}{l}\text { Cell Signalling/ New England } \\
\text { Biolabs, Frankfurt am Main GER }\end{array}$ & $1: 1000$ in $3 \%$ BSA in TBS-T \\
\hline $\begin{array}{l}\text { mouse anti STAT5 } \\
(\# 610191)\end{array}$ & BD, Heidelberg GER & $1: 1000$ in $3 \%$ BSA in TBS-T \\
\hline $\begin{array}{l}\text { rabbit anti p-STAT6 } \\
(\text { Y641) (\#9361) }\end{array}$ & $\begin{array}{l}\text { Cell Signalling/ New England } \\
\text { Biolabs, Frankfurt am Main GER }\end{array}$ & $1: 1000$ in $3 \%$ BSA in TBS-T \\
\hline $\begin{array}{l}\text { mouse anti STAT6 (S-20) } \\
\text { X (\#611291) }\end{array}$ & BD, Heidelberg GER & $1: 1000$ in $3 \%$ milkpowder in TBS-T \\
\hline $\begin{array}{l}\text { rabbit anti p100/p52 } \\
(\# 4882)\end{array}$ & $\begin{array}{l}\text { Cell Signalling/ New England } \\
\text { Biolabs, Frankfurt am Main GER }\end{array}$ & $1: 1000$ in $3 \%$ BSA in TBS-T \\
\hline
\end{tabular}


Materials and Methods

\begin{tabular}{|l|l|l|}
\hline $\begin{array}{l}\text { rabbit anti lkappaBalpha } \\
\text { (44D4) (\#4812) }\end{array}$ & $\begin{array}{l}\text { Cell Signalling/ New England } \\
\text { Biolabs, Frankfurt am Main GER }\end{array}$ & $1: 1000$ in 3\% BSA in TBS-T \\
\hline $\begin{array}{l}\text { Anti mouse HRP } \\
\text { polyclonal goat (D1609) }\end{array}$ & Santa Cruz, Heidelberg GER & $1: 5000$ in 3\% milkpowder in TBS-T \\
\hline $\begin{array}{l}\text { Anti rabbit HRP } \\
\text { polyclonal goat (E1710) }\end{array}$ & Santa Cruz, Heidelberg GER & $1: 1000$ in 3\% BSA in TBS-T \\
\hline
\end{tabular}

\subsection{Oligonucleotides}

The primers used for SYBR Green qRT-PCR are listed in table 2-10.

Table 2-10 qRT-PCR Primer

\begin{tabular}{|c|c|}
\hline Gene & Oligonucleotide \\
\hline $18 \mathrm{~S}$ ribosomal RNA & $\begin{array}{l}\text { fwd 5'-AACTTTCGATGGTAGTCGCCG-3' } \\
\text { rev 5'-GGATGTGGTAGCCGTTTCTCAG-3' }\end{array}$ \\
\hline$A B L$ & $\begin{array}{l}\text { fwd 5'-AGCCTGGCCTACAACAAGTTCTC-3' } \\
\text { rev 5'-GACATGCCATAGGTAGCAATTTCC-3' }\end{array}$ \\
\hline AURKA & $\begin{array}{l}\text { fwd 5'-ATCCTGAGGAGGAACTGGCATC-3' } \\
\text { rev 5'-GTCTTCCAAAGCCCACTGCC-3' }\end{array}$ \\
\hline beta2 microglobulin ( $(32 \mathrm{~m})$ & $\begin{array}{l}\text { fwd 5'-CTATCCAGCGTACTCCAAAGATTCA-3' } \\
\text { rev 5'-TCTCTGCTGGATGACGTGAGTAAA-3' }\end{array}$ \\
\hline BAFF & $\begin{array}{l}\text { fwd 5'-AAGACCTACGCCATGGGACATC-3' } \\
\text { rev 5'-TCTTGGTATTGCAAGTTGGAGTTCA-3' }\end{array}$ \\
\hline BAFF-R & $\begin{array}{l}\text { fwd 5'-GGAGTTTGGTGTGCTTGCCTT-3' } \\
\text { rev 5'-TAGTGCCCCAGCCTTTTGAAG-3' }\end{array}$ \\
\hline BCMA & $\begin{array}{l}\text { fwd 5'-AATGCGATTCTCTGGACCTGTT-3' } \\
\text { rev 5'-CCAGGAGACCTGATCCTGTGTT-3' }\end{array}$ \\
\hline BIRC5 & $\begin{array}{l}\text { fwd 5'-CAAGGACCACCGCATCTCTACA-3' } \\
\text { rev 5'-CTCGGCCATCCGCTCC-3' }\end{array}$ \\
\hline BUB1B & $\begin{array}{l}\text { fwd 5'-CTCAGCATCAAGAAGCTGAGCC-3' } \\
\text { rev 5'-GGAGGTGCTTGCAACCGAG-3' }\end{array}$ \\
\hline
\end{tabular}


Materials and Methods

\begin{tabular}{|c|c|}
\hline CD58 & $\begin{array}{l}\text { fwd 5' - CTTGAGTCTCTTCCATCTCCCA-3' } \\
\text { rev 5'- AAGTCCTCGATGGCTGTTGTAA-3' }\end{array}$ \\
\hline CXCL10 & $\begin{array}{l}\text { fwd 5'- CCATTCTGATTTGCTGCCTTATCT-3' } \\
\text { rev 5'-GAGAGAGGTACTCCTTGAATGCCA-3' }\end{array}$ \\
\hline$M Y C$ (tonsils) & $\begin{array}{l}\text { fwd 5'-GCAGAGGAGCAAAAGCTCATT-3' } \\
\text { rev 5'-TGATTGCTCAGGACATTTCTGT-3' }\end{array}$ \\
\hline$M Y C$ var2 (cell lines) & $\begin{array}{l}\text { fwd 5'-AAGAGGGTCAAGTTGGACAGTTGC-3' } \\
\text { rev 5'-TTTCGGTTGTTGCTGATCTGTCT-3' }\end{array}$ \\
\hline DUSP2 & $\begin{array}{l}\text { fwd 5'-GTACTTCCTGCGAGGAGGCTTC -3' } \\
\text { rev 5'-AGGAGCCCTGGAGTCGGAG -3' }\end{array}$ \\
\hline DUSP5 & $\begin{array}{l}\text { fwd 5'- CAGCCACACGGCTGACATTAG-3' } \\
\text { rev 5'-GAGATCCCAGCCTCACAGTGG -3' }\end{array}$ \\
\hline DUSP10 & $\begin{array}{l}\text { fwd 5'- CATTGAGGAAGCTCACCAGTGTG-3' } \\
\text { rev 5'- CGAGTGTGCTTCATCAAGTAAGCGA-3' }\end{array}$ \\
\hline DUSP22 & $\begin{array}{l}\text { fwd 5'-CCATCAGTATCGGCAGTGGC-3' } \\
\text { rev 5'-AGAACTTCAGAATTCCTGGAGCG -3' }\end{array}$ \\
\hline FZD7 & $\begin{array}{l}\text { fwd 5'- GCCACACGAACCAAGAGGAC-3' } \\
\text { rev 5'- GGCGCATACATGGAGCATAAG-3' }\end{array}$ \\
\hline ICAM1 & $\begin{array}{l}\text { fwd 5'-TTCACAATGACACTCAGCGGTC -3' } \\
\text { rev 5'- AGTGCAAGCTCCCAGTGAAATG-3' }\end{array}$ \\
\hline ID1 & $\begin{array}{l}\text { fwd 5'-CCTCAACGGCGAGATCAGC-3' } \\
\text { rev 5'-ATGCGATCGTCCGCAGG -3' }\end{array}$ \\
\hline Lef1 & $\begin{array}{l}\text { fwd 5' - TAATGCACGTGAAGCCTCAGC-3' } \\
\text { rev 5'- TTAATGTGAGGTCTTTTTGGCTCC-3' }\end{array}$ \\
\hline $\mathrm{TACl}$ & $\begin{array}{l}\text { fwd 5'-CCATTTGCAACCATCAGAGCC-3' } \\
\text { rev 5'-ATGGAGGCACAGCTGATGCAGT-3' }\end{array}$ \\
\hline
\end{tabular}


Materials and Methods

\begin{tabular}{|c|c|}
\hline TMEM97 & $\begin{array}{l}\text { fwd 5' - CTGCTGAAGTGGTATGCTAAGGAGTT-3' } \\
\text { rev 5'- TGAGGAAGGCATACGTTGCAA-3' }\end{array}$ \\
\hline PBK-TOPK & $\begin{array}{l}\text { fwd 5'- GGTGTTATTACTGACAAGGCAGACATATT-3' } \\
\text { rev 5'- AATGTGTGGAATCGATAAAGTCATCAT-3' }\end{array}$ \\
\hline PARP2 & $\begin{array}{l}\text { fwd 5'- GGAATCTTGAGCCATGGGCTT-3' } \\
\text { rev 5'- GAGCAGCAGTCCTGTATTCTTTAGGC-3' }\end{array}$ \\
\hline RGS1 & $\begin{array}{l}\text { fwd 5'- GAATGGATATGAAAGCATACCTGAGATC-3' } \\
\text { rev 5'- CCATTGCATTACTTCAGCAGCA-3' }\end{array}$ \\
\hline SlamF7 & $\begin{array}{l}\text { fwd 5'- GAGCAGCAGTCCTGTATTCTTTAGGC-3' } \\
\text { rev 5'- GCTGCTGACCCTGTGAGCTG-3' }\end{array}$ \\
\hline ChIP Bub1B & $\begin{array}{l}\text { fwd 5'- GACACGGCCTGGTAGGTAAT-3' } \\
\text { rev 5'- GCAGCCTTCTTCGCTTTG-3' }\end{array}$ \\
\hline
\end{tabular}

\subsection{Ready to use Reaction Systems}

The following ready to use reaction systems were utilized in this work.

Table 2-11 Reaction Systems

\begin{tabular}{|l|l|}
\hline Description & Manufacturer \\
\hline EndoFree® Plasmid Maxi Kit & Fa. Qiagen, Hilden \\
\hline ExpressArt@ mRNA Amplification Kit & AmpTec, Hamburg GER \\
\hline $\begin{array}{l}\text { PathDetect@ in Vivo Signal Transduction Pathway trans- } \\
\text { Reporting Systems }\end{array}$ & Stratagene/Agilent, Waldbronn GER \\
\hline RNA Isolation Kit & Machery+Nagel, Düren GER \\
\hline Rneasy® Mini Kit & Qiagen, Hilden GER \\
\hline SuperscriptII TM RT Kit & Invitrogen, Karlsruhe GER \\
\hline SignalBoostTM Immunoreaction Enhancer Kit & Calbiochem via Merck, Darmstadt GER \\
\hline
\end{tabular}




\subsection{Cell Biology}

\subsubsection{Cell culture techniques}

Burkitt Lymphoma cell lines were cultivated in cell culture medium I (for details concerning media supplements please refer to table 2.6 Buffers, Solutions and Media) at $37^{\circ} \mathrm{C}, 5 \% \mathrm{CO}_{2}$ and splitted every second day in a ratio depending on observed cell proliferation (cell densitiy: $0.3 \times 10^{5} / \mathrm{ml}-1 \times 10^{6} / \mathrm{ml}$ ). All DLBCL cell lines, apart from OCl-Ly1, OCl-Ly3 and OCl-Ly7, were cultivated in cell culture medium II in a cell density of $5 \times 10^{5} / \mathrm{ml}-1 \times 10^{6} / \mathrm{ml}$. OCl cells were cultivated in cell culture medium III supplemented with 10\% FBS for OCI-Ly1 and OCI-Ly7 and with $20 \%$ FBS for OCl-Ly3 cells. Cells were counted in PBS $0.4 \%(\mathrm{w} / \mathrm{v})$ Trypanblue using a Neubauer counting chamber. Primary tonsillar mononuclear cells were isolated using cell culture medium IV and cultivated in cell culture medium $\mathrm{V}$ in a cell density of $1 \times 10^{6} / \mathrm{ml}$.

To cultivate cells from a frozen aliquot, thawed cells were washed with $10 \mathrm{ml}$ of the respective cell culture medium (centrifugation $250 \mathrm{xg}, 7 \mathrm{mins}$ at RT). The cell pellet was resuspended in $5-10 \mathrm{ml}$ medium and cells were incubated at $37^{\circ} \mathrm{C}, 5 \%$ $\mathrm{CO}_{2}$. To freeze cells, approximately $1 \times 10^{7}$ cells were sedimented as described above and resuspended in 500 $\mu$ freezing medium. Cells were frozen in cryo boxes containing isopropanol to obtain a constant cooling of approximately $1^{\circ} \mathrm{C} / \mathrm{min}$.

\subsubsection{Isolation of Tonsillar Mononuclear Cells from human primary tissue}

Primary tonsillar tissue was kept in PBS on ice after tonsillectomy. The tonsillar cells were extracted by mincing the tonsil in cell culture medium IV. The Tonsillar Mononuclear Cells (TMCs) were separated via density gradient centrifugation. Therefore the Lymphoprep ${ }^{\mathrm{TM}}$ solution was overlaid with the cell suspension and centrifugation was performed at $400 \times \mathrm{g}, 30 \mathrm{~min}$ at RT without break. The interphase containing the TMCs was collected. TMCs were washed once with cell culture medium IV and a second time with autoMACS ${ }^{\mathrm{TM}}$ buffer plus. 


\subsubsection{Enrichment of CD10+ GC B cells}

Cell enrichment was performed by an indirect labelling of the GC B cell marker CD10 on the cell surface with an antibody coupled to magnetic beads (MACS ${ }^{\mathrm{TM}}$ MicroBeads). The magnetic sorting was performed using MACS ${ }^{\mathrm{TM}}$ columns placed in a MACS ${ }^{\mathrm{TM}}$ Separator, a strong permanent magnet. Thereby the MACS $^{\text {TM }}$ Column provides a magnetic field which retains labelled cells. Elution was achieved by removing the column from the magnet and rinsing the column with buffer.

TMCs were counted and resuspended in autoMACS ${ }^{\mathrm{TM}}$ buffer plus $\left(1 \times 10^{8} \mathrm{cells} / \mathrm{ml}\right)$. Cells were stained with anti CD10-PE antibody (diluted 1:50) for $15 \mathrm{~min}$ at $4^{\circ} \mathrm{C}$. Cells were washed with autoMACS ${ }^{\mathrm{TM}}$ buffer plus (centrifugation $300 \mathrm{xg}, 10 \mathrm{mins}, 4^{\circ} \mathrm{C}$ ). Staining with anti-PE microbeads was performed in a dilution of $1: 5$ in $100 \mu$ l autoMACS ${ }^{\text {TM }}$ buffer plus containing $1 \times 10^{7}$ cells for 15 mins at $4^{\circ} \mathrm{C}$. Cells were washed with 50x volume of autoMACS ${ }^{\mathrm{TM}}$ buffer plus and resuspended in autoMACS ${ }^{\mathrm{TM}}$ buffer plus $\left(1 \times 10^{8}\right.$ cells/500 $\left.\mu \mathrm{l}\right)$. CD10 ${ }^{+}$cells were enriched using LS MACS ${ }^{\mathrm{TM}}$ separation columns (Miltenyi-Biotech, Surrey UK) topped with pre-separation filters (Miltenyi-Biotech, Surrey UK). After the equilibration of the columns and filters with $500 \mu$ lautoMACS ${ }^{\text {TM }}$ buffer plus in the magnetic field, $1 \times 10^{8}$ cells in $500 \mu$ l autoMACS ${ }^{\text {TM }}$ buffer plus were given onto the column. The columns were washed with $3 \mathrm{ml}$ autoMACS ${ }^{\mathrm{TM}}$ buffer plus three times. The first washing step was executed through the pre-separation filter. Elution was performed with $5 \mathrm{ml}$ autoMACS ${ }^{\mathrm{TM}}$ buffer plus. An aliquot of CD10+ enriched cells was stored at $4^{\circ} \mathrm{C}$ for cell characterisation by flow cytometry.

\subsubsection{Transfection of $\mathrm{CD} 10^{+} \mathrm{B}$ cells via non-viral DNA transfer}

The $\mathrm{CD} 10^{+}$cells were transfected by nucleofection using Human B Cell Nucleofector ${ }^{\circledR}$ Kit and the Amaxa Nucleofector ${ }^{\circledR}$ II device. The following vectors were used: pcDNA3.1, pcDNA3.1-myc and pMACS-ALNGFR (please refer to table 1-6). pcDNA3.1-myc was used for the transfection of the MYC. This construct was kindly provided by Georg Bornkamm (Hörtnagel, Mautner et al. 1995). The $\triangle$ LNGFR expression plasmid was cotransfected in all reactions to sort the cells for DNA uptake. 
$1 \times 10^{7}$ cells in $100 \mu$ l Nucleofection solution $B$ were mixed with specific amounts of plasmid DNA. Cells were transfected in a nucleofection cuvette using the U-15 nucleofection program. For the exact amounts of plasmid DNA please refer to values in table $2-12$.

Table 2-12 Amount of plasmid DNA used for transfection

\begin{tabular}{|l|l|l|}
\hline transfection reaction & control & MYC \\
\hline plasmid & pcDNA3.1 & pcDNA3.1-myc \\
\hline amount & $7 \mu \mathrm{g}$ & $7 \mu \mathrm{g}$ \\
\hline pMACS- $\triangle$ LNGFR & $3 \mu \mathrm{g}$ & $3 \mu \mathrm{g}$ \\
\hline
\end{tabular}

Transfected cells were cultivated at $37^{\circ} \mathrm{C}, 5 \% \mathrm{CO}_{2}$ for $12 \mathrm{~h}$ in a concentration of $0.5 \times 10^{7}$ cells $/ \mathrm{ml}$ in cell culture medium III and further processed for the preparative FACS. To test protein levels and expression of introduced genetic material $1 \times 10^{7}$ transfected cells were sedimented (10mins, 3000rpm, $4^{\circ} \mathrm{C}$ ) and washed with PBS containing $1 \mathrm{mM}$ Sodium orthovanadate. Samples were frozen at $-20^{\circ} \mathrm{C}$ as dry pellets.

\subsubsection{Activation of $B$ cells with soluble stimulating factors}

Primary B cells - $1 \times 10^{6}$ fresh CD10 $B$ cells were resuspended in cell culture medium $\mathrm{V}$ containing $10 \mathrm{mM}$ HEPES $\left(1 \times 10^{6} \mathrm{cells} / \mathrm{ml}\right)$ and supplemented with sCD40L $(200 \mathrm{ng} / \mathrm{ml})$, anti human lgM/lgG $\mathrm{F}(\mathrm{ab})_{2}(1.3 \mu \mathrm{g} / \mathrm{ml})$, rhlL21 $(100 \mathrm{ng} / \mathrm{ml})$, rhBAFF $(100 \mathrm{ng} / \mathrm{ml}$ and $200 \mathrm{ng} / \mathrm{ml})$ or LPS $(1 \mu \mathrm{M})$. Cells were incubated at $37^{\circ} \mathrm{C}$, $5 \% \mathrm{CO}_{2}$ for $3 \mathrm{hrs}$ for microarray analyses. Cells were harvested (10mins, $300 \mathrm{xg}$, $4^{\circ} \mathrm{C}$ ) and washed with PBS containing $100 \mathrm{mM}$ sodium orthovanadate. Samples were frozen at $-80^{\circ} \mathrm{C}$ and RNA was isolated with the RNeasy Kit (Qiagen).

B cell lymphoma cell lines - For the stimulation of lymphoma cell lines, cells were counted and seeded at a concentration of $3 \times 10^{5} \mathrm{cell} / \mathrm{s} / \mathrm{ml}$ in fresh cell culture medium I $16 \mathrm{~h}$ prior to the experiment. Next day $1 \times 10^{6}$ cells were resuspended in fresh cell culture medium I containing $10 \mathrm{mM}$ HEPES $\left(1 \times 10^{6} \mathrm{cells} / \mathrm{ml}\right)$ and supplemented with SCD40L $(200 \mathrm{ng} / \mathrm{ml})$, anti human $\operatorname{lgM} F(a b)_{2}(1.3 \mu \mathrm{g} / \mathrm{ml})$, 
rhlL21 $(100 \mathrm{ng} / \mathrm{ml})$, rhBAFF $(100 \mathrm{ng} / \mathrm{ml}$ and $200 \mathrm{ng} / \mathrm{ml})$ or LPS $(1 \mu \mathrm{g} / \mathrm{ml})$. Cells were incubated at $37^{\circ} \mathrm{C}, 5 \% \mathrm{CO}_{2}$ for 5 mins, 15 mins or 30 mins (signalling analyses via WB) or for longer timepoints (sCD40L (6h), anti human $\operatorname{lgM} / \lg F \mathrm{~F}(\mathrm{ab})_{2}(3 \mathrm{~h})$, rhIL21 (2h), rhBAFF (9h) or LPS (6h)) for microarray analyses. Cells were harvested (10mins, $\left.300 \mathrm{xg}, 4^{\circ} \mathrm{C}\right)$ and washed with PBS containing $1 \mathrm{mM}$ Sodium orthovanadate. Samples for protein analyses were frozen at $-20^{\circ} \mathrm{C}$ as dry pellets and subsequently lysed in supplemented RIPA buffer. Samples for microarray analyses were frozen at $-80^{\circ} \mathrm{C}$ and RNA was isolated with the RNeasy Kit (Qiagen). For the detection of pathway activities in response to stimulation the BL cells were serum starved (16h) prior to stimulation.

\subsubsection{Inhibitor Treatment}

For cell cycle analyses and analyses of BCR.1 gene expression, BL2 cells were treated with $60 \mu \mathrm{M}$ of the c-Myc inhibitor 10058-F4 in cell culture medium I for 16hrs prior to $3 \mathrm{~h} / 6 \mathrm{~h} / 9 \mathrm{~h}$ of B cell receptor stimulation (scheme $16 \mathrm{~h}+3 \mathrm{~h} / 6 \mathrm{~h} / 9 \mathrm{~h}$ ).

For the gene expression analyses of MYC and DUSPs, BL2 cells were seeded $16 \mathrm{~h}$ prior to the experiment in a cell density of $3 \times 10^{5}$ cells $/ \mathrm{ml}$ in cell culture medium I containing $0.5 \%$ FCS. Next day $1 \times 10^{6}$ cells $/ \mathrm{ml}$ in cell culture medium I containing $0.5 \%$ FCS were treated with 100nM 5Z-7-oxozeaenol (TAK1 inhibitor), $7 \mu \mathrm{M}$ IKK2 inhibitor, 10 $\mu \mathrm{M}$ Ly294002 (PI3K inhibitor), $2 \mu \mathrm{M}$ SB203580

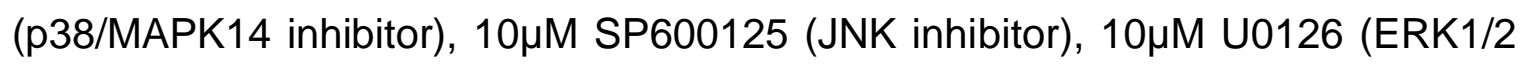

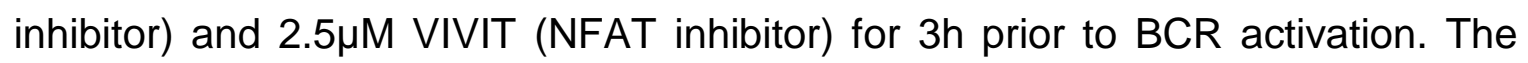
stimulation was performed for another $3 \mathrm{~h}$ (scheme $3 \mathrm{~h}+3 \mathrm{~h}$ ). The cells were harvested at $300 \mathrm{xg}, 10 \mathrm{mins} 4^{\circ} \mathrm{C}$, washed with PBS containing $1 \mathrm{mM}$ sodium orthovanadate and stored at $-80^{\circ} \mathrm{C}$ as dry pellets. To check for pathway activity via WB additional timepoints were harvested $(3 \mathrm{~h}+30 \mathrm{~min})$.

\subsubsection{Flow cytometry}

Flow cytometry is based on the detection of fluorescence which is emitted by a single cell flowing through a liquid stream. A laser beam of a specific wavelength is directed onto the stream of fluid. A number of detectors are aimed at the point where the stream passes through the light beam; one in line with the light beam 
(Forward Scatter or FSC) and several vertical to it (Side Scatter (SSC)) and one or more fluorescent detectors. Each cell that passes through the laser beam scatters the light. Fluorescent dyes bound to a cell can be excited and the emitted light can be detected. This combination of scattered and fluorescent light is collected by the distinct detectors. FSC correlates with the cell volume and SSC depends on the inner complexity (granularity) of the cell. Fluorescein (FITC absorption maximum at $494 \mathrm{~nm}$; emission maximum of $521 \mathrm{~nm}$ ) and Phycoerythrin (PE - absorption maximum at $495 \mathrm{~nm}$; emission maximum at $575 \mathrm{~nm}$ ) were used as fluorescent dyes coupled to specific antibodies. To adjust the detectors for the "spillover" of one fluorescence signal into the wrong channel, compensation can be performed. FITC, for example, is primarily green but fluorescein also has a significant yellow component to the fluorescence, which appears in the PE channel (Loken, Parks et al. 1977). Compensation can therefore be used to subtract a fraction of the FITC signal from the PE signal (FL1-FL2).

\subsubsection{Characterisation of cell populations via flow cytometry}

For the characterisation of cell populations approximately $6.5 \times 10^{6}$ cells were used. The $\mathrm{CD} 10^{+}$enriched cell population was stained with antibodies against CD27, CD38, CD77, IgM, IgD, IgG and BAFF-R / TACl (see Table 2.9 antibodies). Staining of cells was carried out as follows: $45 \mu$ cell suspension was supplemented with $5 \mu$ lantibody (1:10 in 50 $\mu$ lautoMACS ${ }^{\text {TM }}$ buffer plus). The cells were incubated at $4^{\circ} \mathrm{C}$ for $15 \mathrm{mins}$ then washed with $1 \mathrm{ml}$ autoMACS buffer plus. Cells were resuspended in $300 \mu \mathrm{l}$ autoMACS ${ }^{\mathrm{TM}}$ buffer plus $(0.1 \mu \mathrm{g} / \mathrm{ml} \mathrm{PI})$ for the measurement. Data analyses were performed using CellQuest ${ }^{\mathrm{TM}}$ (Becton Dickinson, Oxford UK) and FlowJo ${ }^{\mathrm{TM}}$ (Treestar, USA) software.

\subsubsection{Preparative FACS of transfected $\mathrm{CD}_{10}{ }^{+}$cells}

To optimize sensitivity and compensation of the FACS sorter, untransfected TMCs were stained with antibodies labelled with fluorescent dyes that were used for the sorting process (CD10-PE; CD19-FITC). Isotype control IgG monoclonal mouse antibodies coupled to FITC were used to control for the non-specific binding of antibodies directed against cell surface antigens. Cells were cotransfected with a $\Delta$ LNGFR expression plasmid that encodes a truncated form 
of the membranous Nerve Growth Factor Receptor. The expression of this surface marker only on transfected cells enables to sort for them by a staining with an anti $\triangle$ LNGFR-FITC coupled antibody (Kube and Vockerodt 2001). Cells were stained as described above. Antibodies for the controls were used in a dilution of $1: 10$ in $50 \mu$ l autoMACS ${ }^{\mathrm{TM}}$ buffer. The cell suspensions were spiked with propidium iodide $(\mathrm{PI} 0.1 \mu \mathrm{g} / \mathrm{ml})$ or Hoechst Dye (1:100 dilution) (Sanofi Aventis, Frankfurt GER) to ensure selection of viable cells. The cells were stained with a $\triangle$ LNGFR-FITC antibody in a dilution of 1:10 in $250 \mu$ l autoMACS ${ }^{\mathrm{TM}}$ buffer

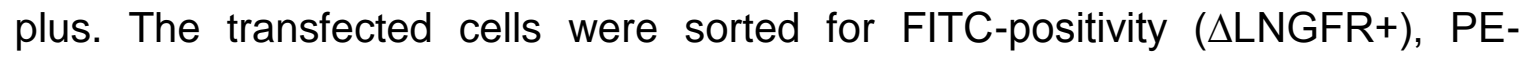
positivity $\left(\mathrm{CD} 10^{+}\right)$and propidium iodide / Hoechst negativity (viability) with the help of MoFlow ${ }^{\circledR}$ High-Performance Cell Sorter (Dako, Stockport UK). Sorted cells were collected into 500 $\mu$ PBS and stored on ice. RNA isolation was performed immediatly.

\subsubsection{Cell cycle analysis}

The cell cycle analysis was performed on the basis of analysing the DNA content in the nuclei of the cells by propidium iodide staining and followed by flow cytometric analyses. Therefore an $200 \mu$ l of the cellsuspension was sedimented (250 x g, 10min, RT) and the pellet was resuspended in 500 $\mu$ l hypotonic Nicoletti solution (Nicoletti, Migliorati et al. 1991). This buffer leads to the destruction of the cell membrane due to hypotonic stress, whereas the nucleus stays intact. Propidium iodide respectively DNA content of the nuclei was determined by flow cytometry. Distribution of the cells according to the phase of the cell cycle was performed with the help of FlowJo ${ }^{\text {TM }}$ (Treestar, Ashland USA) software according to Dean-Jett-Fox (Fox 1980) and by CellQuest ${ }^{\mathrm{TM}}$ (Becton Dickinson, Oxford UK) software. The nuclei of viable cells show three characteristic distributions in the flow cytometric analysis based on their differing DNA content. By this analysis method one can discriminate the cell cycle phases G1, S und G2. Furthermore nuclei from apoptotic cells show an even smaller amount of DNA as cells in the G1 phase and are therefore summarized in the group of SubG1 events. 


\subsubsection{Synchronisation of BL cells using Thymidine treatment}

The treatment of cells with $2 \mathrm{mM}$ Thymidine can be used to achieve a cell cycle arrest in S/G2 phase. An overexposure of cells to Thymidine leads to an inhibition of Thymidine kinase which is necessary for DNA synthesis and thereby to an arrest of cells in the S/G2 phase (Stolz, Ertych et al. 2010).

\subsubsection{2 $\mathrm{Ca}^{2+}$ Measurement}

The calcium signalling response in Burkitt Lymphoma cells was measured using flow cytometry and the $\mathrm{Ca}^{2+}$-sensitive fluorophore Indo-1. Indo-1 (Indo-1-AM) is an uncharged molecule. It can passively diffuse through the plasma membrane. Lipophilic groups are cleaved intracellularly, resulting in a charged molecule which is trapped in the cell due to an altered membrane permeabilization potential. The fluorescence emission maximum of Indo-1 shifts from $475 \mathrm{~nm}$ (Indo-blue) without $\mathrm{Ca}^{2+}$ to $400 \mathrm{~nm}$ (Indo-violet) after $\mathrm{Ca}^{2+}$ binding (excitement at $350 \mathrm{~nm})$. Cell loading with the fluorophore is facilitated by the surfactant polyol Pluronic F-127.

To analyse $\mathrm{Ca}^{2+}$ signalling $1 \times 10^{6}$ cells were harvested at $300 \times \mathrm{xg}, 4^{\circ} \mathrm{C}, 5 \mathrm{~min}$. The cells were resuspended in $700 \mu \mathrm{l}$ of cell culture medium I containing $5 \%$ FCS. The cells were loaded with Indo- 1 for $25 \mathrm{~min}$ at $30^{\circ} \mathrm{C}$. Subsequently, the cell suspension was diluted with $700 \mu$ l of the corresponding prewarmed medium containing $10 \%$ FCS. The cells were incubated for $10 \mathrm{~min}$ at $37^{\circ} \mathrm{C}$ and washed twice with $\mathrm{Ca}^{2+}$ containing Krebs-Ringer solution. The cells were resuspended in $\mathrm{Ca}^{2+}$-containing Krebs-Ringer solution and kept at $20^{\circ} \mathrm{C}$ until measurement. The ratio Indo-violet/Indo-blue was measured using LSR II (Becton Dickinson). After $30 \mathrm{~s}$, stimulation was performed with $1.3 \mu \mathrm{g} / \mathrm{ml}$ anti $\operatorname{lgM} F\left(a b^{\prime}\right) 2$ fragment. The $\mathrm{Ca}^{2+}$ mobilization profiles were analysed using FlowJo software. 


\subsection{Protein Biochemistry}

\subsubsection{Preparation of cell lysates}

Cells were sedimented $\left(10 \mathrm{mins}, 3000 \mathrm{rpm}, 4^{\circ} \mathrm{C}\right)$ and washed with PBS containing $100 \mathrm{mM}$ Sodium orthovanadate. Samples were frozen at $-20^{\circ} \mathrm{C}$ as dry pellets until further investigation.

To prepare protein lysates cell pellets were thawed on ice. Cell lysis was carried out by resuspending the cell pellet in RIPA buffer (Table 2.6) and incubating the cell suspensions on ice for $30 \mathrm{mins}$. The cell lysates were centrifuged to sediment the residual cell debris (15mins, $13.000 \mathrm{rpm}, 4^{\circ} \mathrm{C}$ ). The supernatant was transferred into a new reaction tube. The protein concentrations were examined by Bradford assay (Bradford 1976) with the help of a ready to use Bradford solution and photometric quantification of protein concentrations was performed.

\subsubsection{SDS-PAGE}

Protein samples in SDS (sodium dodecyl sulphate) containing Laemmli buffer are negatively charged and thus can be separated by size in an electric field using polyacrylamide gelelectrophoresis (PAGE).

Separation of proteins via gel electrophoresis was performed with two different systems. For the investigation of C-Myc expression in transfected GC B cells ready to use gradient gels (Invitrogen, Paisley UK) were utilized in the Xcell Surelock $^{\mathrm{TM}}$ chamber (Invitrogen, Paisley UK). The Biorad System (BioRad, München GER) was applied to investigate the activation of signalling pathways. SDS-PAGE gels were used in a concentration of $10 \%$ and $12.5 \%$ for the separation gel and $5 \%$ for the stacking gel.

Immediately after pouring the separation gel, it was covered by $100 \%$ isopropanol to obtain a smooth surface of the gel and to protect it from drying out. After polymerization the stacking gel was prepared and poured on top of the separation gel after removing the isopropanol. Differing amounts of protein were used. The exact values are indicated in the depiction of the immunoblot. The protein probe was supplemented with $4 \mathrm{x}$ loading buffer Roti®-Load, denaturized 
for $5 \mathrm{mins}$ at $95^{\circ} \mathrm{C}$ and loaded on the gel. The gels were run at a current of $20 \mathrm{~mA}$ for $15 \mathrm{mins}$ to ensure proper entering of the probes into the stacking gel. For separation the current was fixed at $40 \mathrm{~mA}$ in both systems. If the protein concentration was too low to achieve an appropriate amount of protein the whole lysate was loaded onto the gel. For protein size determination the Fullrange rainbow $^{\mathrm{TM}}$ marker was used.

\subsubsection{Immunoblotting Technique}

For further analysis, the proteins separated by SDS-PAGE were transferred onto a nitrocellulose membrane using the western blot technique. The stacking gel was separated from the gel. The nitrocellulose membrane was equilibrated in aqua dest. for $1 \mathrm{~min}$. Membrane and the whatman papers were well soaked in transfer buffer prior to arranging them in a pile as follows: Cathode (-); 2 whatman papers; polyacrylamid gel; nitrocellulose membrane; 2 whatman papers; Anode (+). The gel was blotted onto a nitrocellulose membrane (Hybond ${ }^{\mathrm{TM}}$ C extra, GE Healthcare, München GER) with the help of the Tank Blot System (BioRad, München, Deutschland) in case of BioRad Gels and with Xcell Surelock ${ }^{\mathrm{TM}}$ blotting system (Invitrogen, Paisley UK) in case of invitrogen gradient gels.

The blotting was carried out in transfer buffer at a voltage of $100 \mathrm{~V}$, a current of max. $300 \mathrm{~mA}$ and a power of $300 \mathrm{~W}$ for $4 \mathrm{~h}$. The membrane was washed with TBS-T buffer and blocked with 5\% milk powder or 5\% BSA in TBS-T for $1 \mathrm{~h}$ at RT. The staining with primary antibodies was carried out by incubation of the membrane in antibody dilution over night at $4^{\circ} \mathrm{C}$. The membrane was washed three times for $10 \mathrm{mins}$ with TBS-T and staining with secondary antibodies for $1 \mathrm{~h}$ at RT was performed. The membrane was washed three times $10 \mathrm{mins}$ with TBS$\mathrm{T}$ and the membrane was incubated with ECL-Enhanced Chemiluminescence solution or sel-made ECL (see list of Buffers) for $1 \mathrm{~min}$ at RT. The detection was performed with the help of Hyperfilm ${ }^{\mathrm{TM}}$ ECL (GE Healthcare, München GER) light sensitive films and Hypercasette ${ }^{\mathrm{TM}}$ (GE Healthcare, München GER) and with the chemiluminescence camera "LAS-4000 Image Reader" (Fujifilm, Düsseldorf GER). The development of films was performed with Protec Optimax X-Ray Film Processor (Maco, Hamburg GER). 


\subsection{Molecular Biology}

\subsubsection{Transformation of E.coli}

E.coli bacteria were cultivated in LB medium at $37^{\circ} \mathrm{C}$ shaking. The bacteria were used for the amplification of plasmid DNA. Therefore the DNA was induced by transformation of the bacteria. Stocks of competent bacteria were stored at $-80^{\circ} \mathrm{C}$ and thawed on ice. 100ng plasmid DNA was mixed with $25 \mu \mathrm{l}$ competent cells. After incubation on ice for $30 \mathrm{mins}$ cells underwent a heatshock for $1 \mathrm{~min}$ at $42^{\circ} \mathrm{C}$. The bacteria were again incubated on ice for 10 mins immediately after the heatshock. Cells were incubated shaking for $1 \mathrm{~h}$ in $1 \mathrm{ml}$ LB medium without antibiotics. To select positively transformed cells $100 \mu \mathrm{l}$ bacteria suspension was plated on LB agar plates containing $100 \mu \mathrm{g} / \mathrm{ml}$ Ampicillin and plates were incubated at $37^{\circ} \mathrm{C}$ for $16 \mathrm{~h}$. To amplify the bacteria a pre culture was inoculated (2ml LB Medium containing antibiotics) and incubated at $37^{\circ} \mathrm{C}$ for at least $6 \mathrm{~h}$. With the help of this pre culture a larger culture was inoculated $(150 \mathrm{ml}$ LB medium containing antibiotics) and a cryoculture was established $(40 \%(\mathrm{v} / \mathrm{v})$ glycerol-stock) and stored at $-80^{\circ} \mathrm{C}$.

\subsubsection{Isolation of Plasmid DNA}

$150 \mathrm{ml}$ bacterial culture was incubated at $37^{\circ} \mathrm{C}$ shaking for $16 \mathrm{~h}$. Isolation of plasmids was performed with the EndoFree Plasmid Maxi Kit (Qiagen, Hilden). The precipitated DNA was resolved in endotoxin free water and DNA concentrations were measured photometrically.

\subsection{3 mRNA Isolation}

cell lines - The RNA was isolated with the help of the RNeasy ${ }^{\circledR}$ mini Kit (Qiagen) or the RNA isolation Kit (Machery + Nagel). RNA was eluted with $30 \mu \mathrm{l}-40 \mu \mathrm{l}$ RNAse free water. Concentrations were measured by NanoDrop ${ }^{\mathrm{TM}}$ measurement.

primary GC B cells - The sorted cells were spinned down (10min, 3000rpm, $4^{\circ} \mathrm{C}$ ) and resuspended in $100 \mu \mathrm{l}$ RLT-buffer (RNeasy ${ }^{\circledR}$ microkit) supplemented with $1 \mu \mathrm{l}$-carrier solution (ExpressArt ${ }^{\circledR}$ ). Lysed cells were stored at $-80^{\circ} \mathrm{C}$ until 
further processing. Samples were thawed on ice and isolation of RNA was performed using the RNeasy ${ }^{\circledR}$ microkit, following manufacturer's instructions. The elution was performed twice with $14 \mu \mathrm{l}$ RNAse free water (RNeasy $\AA^{\circledR}$ microkit).

\subsection{4 mRNA Amplification}

To obtain enough RNA of sorted GC B cells the RNA was amplified. RNA was isolated and amplified to be used for microarray analyses and transcript quantification with the help of qRT-PCR. It was described that the amplification process itself does not interfere with the reproducibility of gene regulations estimated by microarray analyses (Puskas, Zvara et al. 2002). Three rounds of amplification of cellular mRNA were performed with the help of ExpressArt $\circledast$ mRNA Amplification Kit from AmpTec according to manufacturer's instructions. The success of the RNA amplification was supervised by analysing the amplification products with the help of agarose gel electrophoresis. The concentrations of antisense aRNAs were determined by NanoDrop ${ }^{\mathrm{TM}}$ measurement. Test IVT was performed with the Ambion Mega Script ${ }^{\circledR}$ Kit.

\subsubsection{Reverse Transcription}

The reverse transcription of RNA from the amplification process was performed with SuperscriptIII ${ }^{\mathrm{TM}}$ RT Kit using 500ng aRNA. For the cDNA synthesis from $1 \mu \mathrm{g}$ RNA of cell lines SuperscriptII ${ }^{\text {TM }}$ RT Kit was utilized. RT reactions were prepared as follows:

Table 2-13 RT Reaction

\begin{tabular}{|l|l|}
\hline Probe reaction Mix & Mastermix \\
\hline $11 \mu \mathrm{l}$ RNA (500ng respectively $1 \mu \mathrm{g})$ & $4 \mu \mathrm{l} 5 \mathrm{x}$ buffer \\
\hline $1 \mu \mathrm{l}$ random primer $(100 \mathrm{ng} / \mu \mathrm{l})$ & $1 \mu \mathrm{l}$ DDT $(0.1 \mathrm{M})$ \\
\hline $1 \mu \mathrm{l}$ dNTPs $(10 \mathrm{mM})$ & $1 \mu \mathrm{l}$ RNAse out \\
\hline$\rightarrow$ incubation 5 mins at $65^{\circ} \mathrm{C}$ & $1 \mu \mathrm{l}$ superscript II / III \\
\hline$\rightarrow$ on ice & \\
\hline $\begin{array}{l}13 \mu \mathrm{l} \text { probe reaction Mix }+7 \mu \mathrm{l} \text { Mastermix } \\
\text { Incubation } 50^{\circ} \mathrm{C} 1 \mathrm{~h} \\
70^{\circ} \mathrm{C} 15 \mathrm{mins} \\
4^{\circ} \mathrm{C}\end{array}$ \\
\hline
\end{tabular}




\subsubsection{Transcript quantification via qRT-PCR (quantitative Real Time - Polymerase Chain Reaction)}

SYBR $B$ Green is an asymmetrical cyanine dye that binds to double stranded DNA. The resulting DNA-dye-complex absorbs blue light $\left(\lambda_{\max }=488 \mathrm{~nm}\right)$ and emits green light $\left(\lambda_{\max }=522 \mathrm{~nm}\right)$ (Zipper, Brunner et al. 2004). This attribute can be used for the detection of double stranded PCR products over the time of the PCR reaction. The number of PCR cycles at which a significant exponential increase in fluorescence is detected is directly correlated with the number of copies of DNA template present in the reaction. This value is called the Cycle Threshold (Ct).

Transcript quantification was performed with Fast SYBRß Green (Applied Biosystems, Foster City USA) and a self made SYBR Green Mix (see section Materials). ABI PRISM 7900HT sequence detection system (Applied Biosystems) was used to carry out the PCR reaction and the fluorescence detection. For each real time PCR reaction with the SYBR Green Mix from Applied Biosystems, a $10 \mu$ reaction volume was used with $5 \mu$ Fast SYBR® Green Master Mix (containing all ingredients needed for the PCR) an amount of cDNA that corresponds to 10ng RNA utilized for the cDNA synthesis and $0.3 \mathrm{pmol} / \mu \mathrm{l}$ forward and reverse primer. PCR reactions were performed using a 348 well plate sealed with an optical adhesive foil.

Table 2-14 Cycle program RT-PCR

\begin{tabular}{|l|l|l|}
\hline Initial denatutaion & $95^{\circ} \mathrm{C} 20 \mathrm{~s}$ & \\
\hline Deanturation & $95^{\circ} \mathrm{C} 1 \mathrm{~s}$ & \\
\hline Annealing/Extension & $60^{\circ} \mathrm{C} 20 \mathrm{~s}$ & 55 cycles \\
\hline \multirow{3}{*}{ Dissociation stage } & $95^{\circ} \mathrm{C} 15 \mathrm{~s}$ & \multirow{2}{*}{} \\
\cline { 2 - 2 } & $60^{\circ} \mathrm{C} 15 \mathrm{~s}$ & \\
\cline { 2 - 2 } & $95^{\circ} \mathrm{C} 15 \mathrm{~s}$ & \\
\hline
\end{tabular}

The relative expression values for each gene were estimated by normalizing the actual CT values, calculated as means of three independent triplets, to CT values of a housekeeping gene:

$\Delta \mathrm{CT}=\mathrm{CT}$ gene of interest $-\mathrm{CT}$ housekeeping gene 
The $\triangle \mathrm{CT}$ values can then be compared in-between the control and modified samples by calculating $\Delta \Delta \mathrm{CT}$ :

$\Delta \Delta \mathrm{CT}=\Delta \mathrm{CT}$ modified sample $-\Delta \mathrm{CT}$ control

$\Delta \triangle \mathrm{CT}$ is a relative measurement and gives the value for the differences of cycles after the amplicon of the gene of interest can be detected in samples of control transfected cells vs. modified cells. On the basis of $\triangle \Delta C T$ the change of gene expression can be calculated as fold change: fold change $=1 /\left(2^{\Delta \Delta C T}\right)$

For this study $32 \mathrm{~m}$ was chosen as a housekeeping gene. The primers for the qRT-PCR reactions were designed on the basis of mRNA sequences published on the NCBI homepage (http://www.ncbi.nlm.nih.gov/sites/entrez/) with the help of PrimerExpress ${ }^{\mathrm{TM}}$ software (Applied Biosystems, Foster City USA). They were tested for specificity with BLAST (http://www.ncbi.nlm.nih.gov/blast/Blast.cgi).

\subsubsection{Chromatin Immunoprecipitation}

Chromatin-Immunoprecipitation (ChIP) can be used to detect DNA binding of transcription factors to specific sites on the genome. Therefore DNA and bound proteins are crosslinked using formaldehyde. DNA is sheared using ultrasound and the protein DNA complexes are subsequently used for immunoprecipitation of the protein of interest using specific antibodies. In a last step the co-precipitated DNA can be released from the proteins and used for PCR to detect whether specific loci have been co-precipitated. The protocol was performed as follows: $10 \mathrm{ml}$ of $1 \times 10^{6} \mathrm{BL} 2$ cells $/ \mathrm{ml}$ were stimulated with $1.3 \mu \mathrm{g} / \mathrm{ml}$ anti-lgM $\mathrm{F}(\mathrm{ab})_{2}$ fragments for 3hrs or left untreated as control (stimulations were performed in triplicate). Cells were sedimented and resuspended in $8 \mathrm{ml}$ PBS containing $1.42 \%$ formaldehyde (in PBS) and incubated for $15 \mathrm{~min}$ at room temperature. Subsequently the formaldehyde was quenched by adding $1 \mathrm{ml}$ 1.25M Glycine (incubation for $5 \mathrm{~min}$ at room temperature). Cells were washed twice with ice-cold PBS. Cells were resuspended in $1 \mathrm{ml}$ cool IP-buffer + , mixed by pipetting up and down several times, and centrifuged at $12.000 \mathrm{~g}$ for $1 \mathrm{~min}$ at $4^{\circ} \mathrm{C}$. The supernatant was discarded. The nuclear pellet was washed once with 1 $\mathrm{ml}$ IP-buffer + and sedimented $\left(12.000 \mathrm{~g}, 1 \mathrm{~min} ., 4^{\circ} \mathrm{C}\right)$. The supernatant was discarded and the pellet resuspended in $250 \mu \mathrm{I}$ IP-buffer + . Samples were 
sonicated using the Biorupter device from Diagnode for $3 \times 10$ minutes with fresh ice-water (Settings: $10 \mathrm{sec}$ on/off duty time at high power). Protein A Sepharose was blocked by adding $15 \mathrm{ml}$ of IP buffer containing $0.5 \mathrm{~g}$ BSA and $100 \mu \mathrm{l}$ of salmon sperm DNA for $16 \mathrm{~h}$ at $4^{\circ} \mathrm{C}$. The swollen sepharose was washed with IPbuffer (centrifuge $2 \mathrm{~min}$ at $1000 \mathrm{~g}$ ). 1 volume of IP buffer + was added to the sepharose. For pre-clearing $80 \mu \mathrm{l}$ blocked sepharose was added to sheared and diluted chromatin and incubated for $1 \mathrm{~h}$ at $4^{\circ} \mathrm{C}$. Sepharose was sedimented at $12.000 \mathrm{~g}, 10 \mathrm{~min}, 4^{\circ} \mathrm{C}$ and the supernatant was transferred to a new tube. $50 \mu \mathrm{l}$ of each precleared lysate was used for every IP (anti c-Myc, anti acH3, anti IgG control and Input control). $50 \mu \mathrm{l}$ extract was diluted using $450 \mu \mathrm{l} \mathrm{IP-buffer.} 2 \mu \mathrm{g}$ antibody was added to each sample and incubated at $4^{\circ} \mathrm{C}$ overnight. In parallel $1 \mu \mathrm{l}$ of GlycoBlue (glycogen) and $100 \mu \mathrm{l} 100 \%$ ethanol was added to input DNA samples. These were placed at $-20^{\circ} \mathrm{C}$ overnight. $30 \mu$ of protein $\mathrm{A}$ - sepharose was added to each sample and probes were incubated at $4^{\circ} \mathrm{C}$ for 2 hours. In parallel input DNA in $\mathrm{EtOH}$ was centrifuged at $4^{\circ} \mathrm{C}, 12.000 \mathrm{~g}$ for $20 \mathrm{~min}$ and the DNA pellet was washed once with $500 \mu \mathrm{l} 70 \% \mathrm{EtOH}$. The pellet was air dried. ChIP immune complexes (sepharose beads) were washed 6 times with $1 \mathrm{ml}$ cold IP-buffer. Centrifugation was performed at $2.000 \mathrm{~g}, 4^{\circ} \mathrm{C}$, for $2 \mathrm{~min}$. To release DNA from protein immune complexes 100 $\mu$ l 10\% (wt/vol) Chelex 100 slurry was added to the washed beads and to the Input DNA pellet. Samples were mixed and heated to $95^{\circ} \mathrm{C}$ for $10 \mathrm{~min}$. After boiling $2 \mu \mathrm{l}$ of $20 \mu \mathrm{g} / \mu \mathrm{l}$ proteinase $\mathrm{K}$ was added to the cooled samples. Incubation was performed at $55^{\circ} \mathrm{C}$ for 30 min on a thermal mixer (shaking at $1000 \mathrm{rpm}$ ). Proteinase $\mathrm{K}$ was inactivated by incubating samples at $95^{\circ} \mathrm{C}$ for 10 minutes. Samples were centrifuged at $12.000 \mathrm{~g}$ for $1 \mathrm{~min}$ at $4^{\circ} \mathrm{C}$ and the supernatant $(70 \mu \mathrm{l})$ was transferred to a new tube. Samples were stored at $-20^{\circ} \mathrm{C}$ until PCR reactions were performed. BuB1B PCR was performed using the following cycle protocol: 
Table 2-15 Reaction Mix and Cycling Program PCR ChIP

\begin{tabular}{|c|c|}
\hline 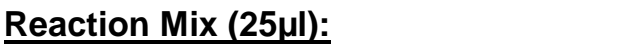 & Cycling Protocol: \\
\hline $1 \mu l$ DNA & Primary Denaturation: $5 \mathrm{~min}$ at $95^{\circ} \mathrm{C}$ \\
\hline 2.5 $\mu \mathrm{l}$ 10x buffer (Primetech, Belarus) & Primary Annealing: $3 \mathrm{~min}$ at $60^{\circ} \mathrm{C}$ \\
\hline $1.5 \mu \mathrm{l} 25 \mathrm{mM} \mathrm{MgCl}_{2}$ (Primetech, Belarus) & Primary Elongation: $3 \mathrm{~min}$ at $72^{\circ} \mathrm{C}$ \\
\hline $0.1 \mu \mathrm{l} \mathrm{Taq} \mathrm{(0.5} \mathrm{U)} \mathrm{(Primetech,} \mathrm{Belarus)}$ & Denaturation: $5 \mathrm{~min}$ at $95^{\circ} \mathrm{C}$ \\
\hline $0.5 \mu \mathrm{l}$ dNTPs (10mM) & Annealing: $3 \mathrm{~min}$ at $56^{\circ} \mathrm{C}$ \\
\hline $18.4 \mu \mathrm{l} \mathrm{H}_{2} \mathrm{O}$ & Elongation: $3 \mathrm{~min}$ at $72^{\circ} \mathrm{C}$ \\
\hline $0.5 \mu \mathrm{l}$ fwd Primer & Final Elongation: $3 \mathrm{~min}$ at $72^{\circ} \mathrm{C}$ \\
\hline $0.5 \mu \mathrm{l}$ rev Primer & \\
\hline
\end{tabular}

\subsection{Microarray analyses}

cDNA was labelled for microarray hybridization with the help of a labelling IVT reaction. The labelling IVT was performed with the help of Affymetrix GeneChip $\AA$ IVT Labelling Kit (Affymetrix, High Wycombe UK). Fragmentation and hybridization of labelled aRNA on Human Genome U133A 2.0 Arrays (Affymetrix, High Wycombe UK) was performed by the group around M. Hummel, Charité Berlin, as part of the MMML project. Microarray raw data were sent to Rainer Spang and Katharina Meyer, Insitute of Functional Genomics, University Regensburg for statistical analyses.

Differential gene expression - Data analysis was performed using the statistical computing environment $\mathrm{R}$ and the life-science related extension Bioconductor (http://www.bioconductor.org). The expression values were background corrected and normalized using the robust multi-array average function from the affy package for c-Myc expression data (Huber, von Heydebreck et al. 2002). Normalized probe intensities were summarized to probeset expression levels using robust additive model as implemented in the RMA approach (Irizarry, Hobbs et al. 2003). For the analyses of stimulation data, the expression values were background corrected and normalized using a variance stabilization method (vsn). Gene expression levels were estimated by fitting an additive model employing a median polish routine. Given the normalized 
cell line data from the platform „HG-U133plus2“ and the normalized Patient data from the platform "HG-U133A" the probe sets from both platforms were intersected. Thus it is possible to change between patient and cell line data without losing genes, previously found on one of the data sets.

Multidimensional Scaling - To explore the coherence of the transcriptional response of the tonsillar B-cells to ectopic c-Myc expression multidimensional scaling was used. Differences in gene-per-gene expression levels between control and c-Myc transfection experiments were computed separately for each tonsil (11 tonsils) by subtracting the expression levels in the control sample from those in the c-Myc transfected sample (log ratio). The top 200 genes showing the highest absolute average log ratios across the tonsils were selected. Euclidean distances between the tonsils based on the log ratios of the top 200 genes were computed and embedded into 2 dimensions for using multidimensional scaling.

c-Myc index - A c-Myc gene signature (c-Myc index) was derived from genes responding to $M Y C$ expression in both tonsillar B-cells and lymphomas. An integrated gene expression analysis of 220 clinical lymphoma samples and the tonsillar B cell data set was performed. For each gene the Pearson correlation coefficient of its expression across the tonsils compared to that of $M Y C$ (Affymetrix probeset 202431_s_at) was calculated. The same calculation was performed separately across the lymphomas. Genes were ranked by a weighted average of the correlation coefficients in lymphomas and tonsils with twice as much weight on tonsils. Expression levels of negatively correlated genes were first multiplied by minus one. The expression levels of the top 100 genes was subsequently averaged to a single index. This index is a single number per lymphoma sample reflecting the expression of c-Myc target genes in each sample. Similarly, a truncated c-Myc index was generated that aggregates the expression of all genes in the intersection of the 100 index genes and the genes present on the microarray platform used in the study of Dave and co-workers (Dave, Fu et al. 2006).

Stimulation mediated uniquely regulated genes: To identify genes that are uniquely influenced by only one of the stimuli and not affected by any of the other utilized stimuli, the mean of the control gene expression values was subtracted 
from the gene expression values of stimulated samples, resulting in values that solely represent the reaction caused by the stimulation. The gene vectors were correlated to a binary vector. This binary vector includes a "1" only the one stimulation that was investigated to solely regulate genes. The genes were ordered according to the calculated absolute Pearson correlation coefficient. From these two genesets all genes showing a false discovery rate smaller than 0.5 within the genelist calculted by limma were selected. The genes were discretisized, in a way that gene values having an FDR smaller than 0.5 within a stimulation were set to one and otherwise to zero.

Pathway Activation Clusters - The identification of pathway activation clusters was performed using a newly developed bioinformatical approach named Guided Clustering (Maneck, Schrader et al. 2011). This algorithm identifies specific groups of genes (clusters) which fulfil 2 criteria at the same time: (i) They are differentially expressed in the guiding dataset (e.g. stimulated vs. unstimulated BL2 cells) and (ii) they show differential expression across distinct lymphoma samples. Thereby one identifies genes which can be used as potential surrogate marker for pathway activity in lymphoma samples. Using the guided clustering approach genes were searched that are differentially expressed among lymphoma samples and as well specifically regulated by one of the utilized stimuli and not affected by the others. Therefore guided clustering was combined with the vector based approach described above.

To infer on gene cluster activity in lymphoma patients, an index value was calculated per gene cluster per lymphoma sample. This index value is calculated by first finding a reference gene that best reflects the set of genes. Then all other genes are turned in the direction of the reference gene. That means if there are genes anti correlated to the reference gene, they are multiplied by minus one. After that, all expression values were averaged using a standard additive model and fitted with a median polish procedure resulting in one value per sample, which includes the overall effect and the sample effect. The index values of genes that were down regulated by a stimulus were multiplied by minus one to enable the interpretation of the indices as absence or presence of stimulation. 
GO KEGG and GSEA - Gene set enrichment analysis (GSEA) of ranked gene list was performed using the Java implementation of GSEA obtained from http://www.broadinstitute.org/gsea/. GSEA was conducted in the mode for preranked gene lists on the $\mathrm{C} 2$ set of curated gene signatures from the Molecular Signature Database (MSigDB). GO and KEGG pathway enrichment analyses were performed using the gokeggLister method implemented in the package compdiagTools.

Survival Analyses - The prognostic impact of the c-Myc index was evaluated after exclusion of patients with $\mathrm{mBL}$ by splitting the remaining lymphomas into groups based on the quartiles of the c-Myc index, i.e. they were split into groups of very low, low, medium, high and very high c-Myc target expression. Survival within the groups was assessed by multivariate Cox regression analysis with patient age (>60 years), Ann Arbor stage, presence of cytogenetically detectable $M Y C$ aberrations and the presence of an activated $B$ cell $(A B C)$ like lymphoma signature as confounding factors. Cases that could not be assigned an $A B C$ or GCB (germinal centre B cell) label were excluded. In addition, a log-rank test was performed to assess the significance of the survival differences between the groups of lymphomas induced by the c-Myc index. The differences of the c-Myc index in different groups of lymphomas were assessed by ANOVA. 


\section{$3 \quad$ Results}

\subsection{High c-Myc activity is an independent negative prognostic factor for diffuse large $B$ cell lymphomas}

Gene expression profiling has recently enabled the reclassification of aggressive Non Hodgkin lymphomas (aNHL) into distinct subgroups. In BL aberrant c-Myc activity results from IG-MYC translocations. However, MYC aberrations are not limited to BLs and then have a negative prognostic impact. In this study it was investigated to which extend aberrant c-Myc activity plays a functional role in other aNHL and whether it is independent from MYC translocations. Based on a combined microarray analysis of human germinal centre (GC) B cells transfected with a c-Myc expression vector and 220 aNHLs cases, a 'c-Myc index' was developed (Schrader, Bentink et al. 2011).

\subsubsection{Overexpression of c-Myc in primary human GC B cells}

The transcriptional consequences of overexpressing c-Myc in human GC B cells, as the presumed progenitors of $B L$ and $D L B C L$, were studied first. For this purpose human tonsillar CD10+ B cells were isolated and cotransfected with either a c-Myc expression plasmid or a control plasmid together with a vector

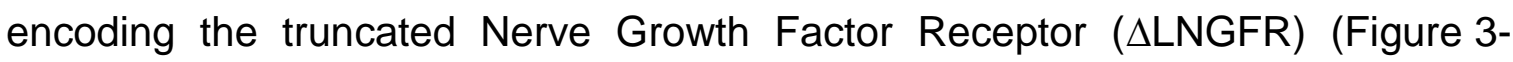
1 A\&B) as previously described (Vockerodt, Morgan et al. 2008; Vrzalikova, Vockerodt et al. 2011). 12 hours after transfection, viable (PI-) cells expressing CD10 and $\triangle$ LNGFR were sorted by FACS (Figure 3-1B). This was repeated on 11 separate GC B cell preparations (T15, T16, T17, T21, T28, T29, T51, T55, T56, T57, T58). High c-Myc expression was confirmed in transfected cells. In contrast, control cells showed virtually undetectable levels of endogenous c-Myc. One representative experiment is shown in Figure 3-1 C\&D. In a next step microarray analyses were performed using Affymetrix HG U133 plus 2.0 chip. 
A
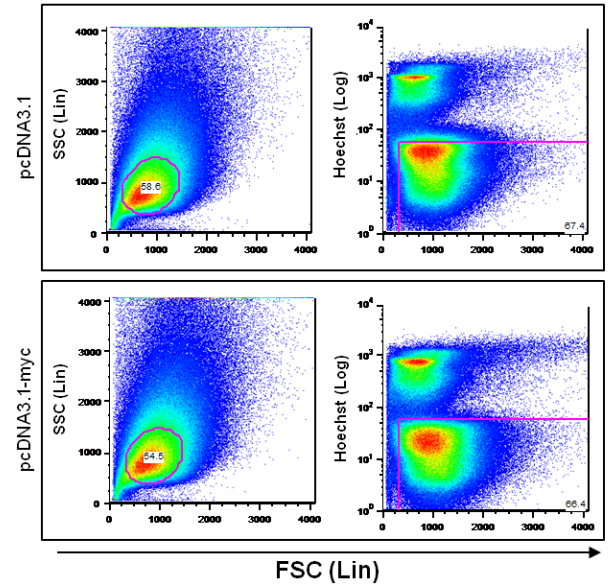

C

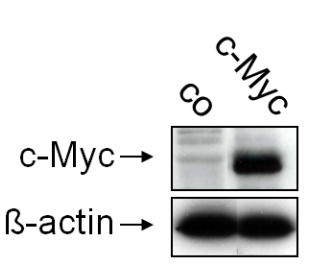

D

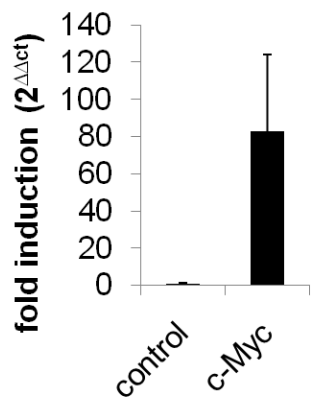

B

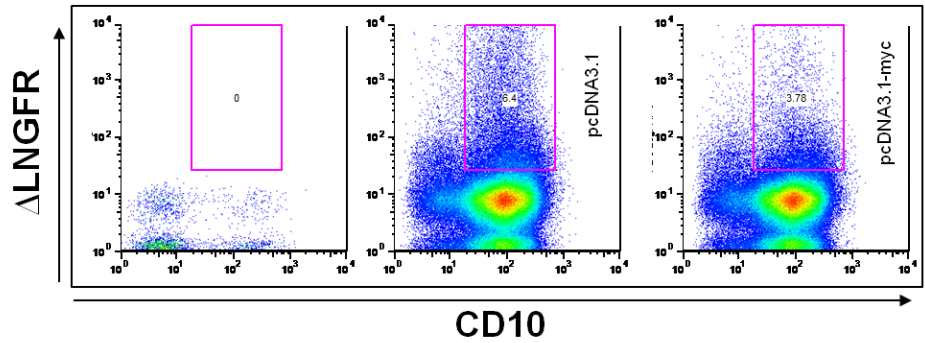

$E$

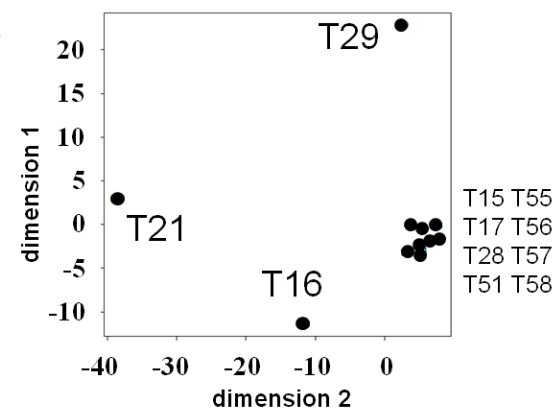

$\mathrm{F}$

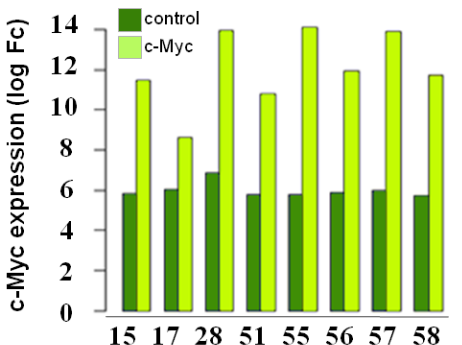

Figure 3-1 Expression of c-Myc in primary human germinal centre B cells. A Flow cytometric analysis of $\mathrm{CD} 10^{+}$tonsillar B cells transfected with pcDNA3.1 (upper row) or c-Myc (lower row) together with pMACS $\triangle$ LNGFR stained with Hoechst Dye to perform live gating. B CD10 and NGFR staining. CD10 ${ }^{+}$and $\triangle \mathrm{LNGFR}^{+}$, Hoechst negative cells were collected for RNA isolation (see respective gating). C Detection of C-Myc and b-actin in transfected CD10 ${ }^{+}$tonsillar B cells by immunoblot analysis. D Real-time RT-PCR of the relative quantity of c-Myc in c-Myc-expressing and non-expressing GC B cells. All samples were analysed in triplicates and are presented as 2 $\triangle \triangle C T$ values compared to vector control. E Multidimensional Scaling (MDS) based on the transcriptional fold-changes of the top $200 \mathrm{c}-M y c$ responsive genes. The plot is a two dimensional visualization (dimension 1 and dimension 2) of the differences between the tonsils with respect to the transcriptional changes induced by c-Myc. F Shown are the transcriptional levels of c-Myc (yaxis) measured by HGU133 Plus 2.0 Affymetrix microarrays in 8 tonsils (x-axis). Each tonsil is represented by a dark green bar and light green bar indicating a pair of transfection experiments (dark green: empty control vector, light green c-Myc expression vector). The scale of the expression data (y-axis) obtained from microarray normalization (variance stabilization) is equivalent to the natural logarithm of the true fold-change: An increase by one unit corresponds to a fold change of $e^{1}$.

To visualize the global response to c-Myc overexpression, the gene expression data was embedded in a two dimensional plane using multiple scaling based on the fold changes of 200 genes with highest average fold-changes between c-Myc overexpressing and control cells across the 11 preparations (Figure 3-1 E). The distances between samples reflect similarity in the response to c-Myc 
overexpression rather than any similarity between individual expression profiles. While most tonsils formed a tight cluster indicating a coherent response to c-Myc overexpression, T16, T21 and T29 did not and were removed from further analysis. Consistent with the data shown in Figure 3-1 C\&D, the microarray analyses revealed increased c-Myc expression in transfected cells (Figure 3-1 F). However, when compared across all tonsils the average fold changes of the top 200 c-Myc target genes (selected by absolute values of the log fold-change) were small (maximum 4.9 fold). As the effects of c-Myc were rather small, a customized approach was used to extract the information about c-Myc regulated genes from these data.

\subsubsection{Ectopic c-Myc expression triggers a tumour like expression profile in primary GC B cells.}

To analyse the genes co-regulated with $M Y C$ an integrated analysis combining two gene expression data sets was performed: CD10 lymphoma precursor cells (data set 1) and 220 aNHL samples (data set 2). This patient cohort of $220 \mathrm{aNHL}$ cases was firstly published by the MMML (Mechanisms of Malignant Lymphoma) consortium (Hummel, Bentink et al. 2006). Within this study a molecular diagnosis of Burkitt Lymphoma, based on the gene expression profiles of these 220 aNHL samples, was developed. According to this so called "index of Burkitt likeness" the patient cohort comprises $45 \mathrm{BL}$ cases, 127 non-mBL cases (of these more than $80 \%$ are DLBCL) and 48 unclassifiable so called intermediate cases. All analyses of aNHL microarray samples presented in the following paragraphs were, unless stated otherwise, performed using this study group.

Using this combinatory approach a ranked list of c-Myc-dependent genes was generated. This list comprises genes which are co-regulated with $M Y C$ in lymphoma precursor cells as well as in the gene expression profiles of malignant lymphoma. Genes were ranked by a weighted average of the correlation coefficients in lymphomas and tonsils with twice as much weight on tonsils. Highly ranked genes thus show a strong response to ectopic c-Myc expression in GC B cells and coherent regulation in lymphomas. It is important to note that these genes show consistent behaviour in both data sets and are not simply differentially expressed between normal and tumour cells (Table 3-1). 
Gene set enrichment analysis (GSEA) was used to characterise the ranked list of genes (Subramanian, Tamayo et al. 2005). A significant enrichment of C-Myc target genes previously defined from studies on non lymphoid tissues was found. This is exemplified in Figure 3A by the sharp increase in the GSEA enrichment score to the left of the graph and a decrease to the right. 344 gene sets were found to be significantly (FDR $q<0.25$ ) enriched in genes that are positively correlated with MYC and 52 gene sets enriched in genes which are negatively correlated with MYC. Within the list of 20 gene sets that were most significantly enriched in MYC positively correlated genes, 5 were pre-defined c-Myc target gene sets (Figure 3-2 A). This is indicated by the gradual decrease of the GSEA enrichment score to the left of the graph, and a sharp increase to the right. For a detailed list of Gene Sets please see Table A1 in the Appendix. Furthermore, gene sets representing known c-Myc functions like cell cycle regulation or serum response were also enriched in MYC positively correlated gene sets. Also in line with previous observations, MYC expression was associated with a depletion of gene sets that are described as NF-KB regulated based on gene expression in CD40 ligand stimulated BL cells (Figure 3-2 B). These results support recent observations of an inverse correlation between MYC expression and NF-KB signalling in lymphomas (Schlee, Holzel et al. 2007; Klapproth, Sander et al. 2009). Most importantly, a significant enrichment of genes from a set called 'CANCER NEOPLASTIC META UP' was observed. This gene set comprises genes that are upregulated in tumour cells relative to matching normal tissue cells across many tumour entities (Figure 3-2 C). This suggests that the c-Myc index includes genes that are reflecting essential transcriptional features of neoplastic transformation. 


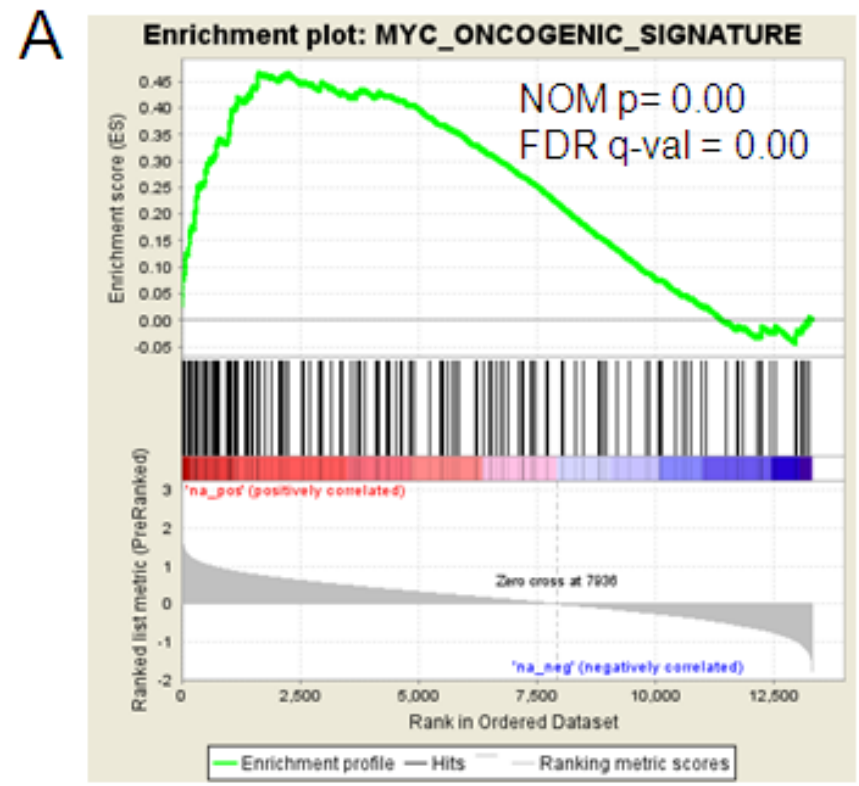

B Enrichment plot: BASSO_GERMINAL_CENTER_CD40_UP
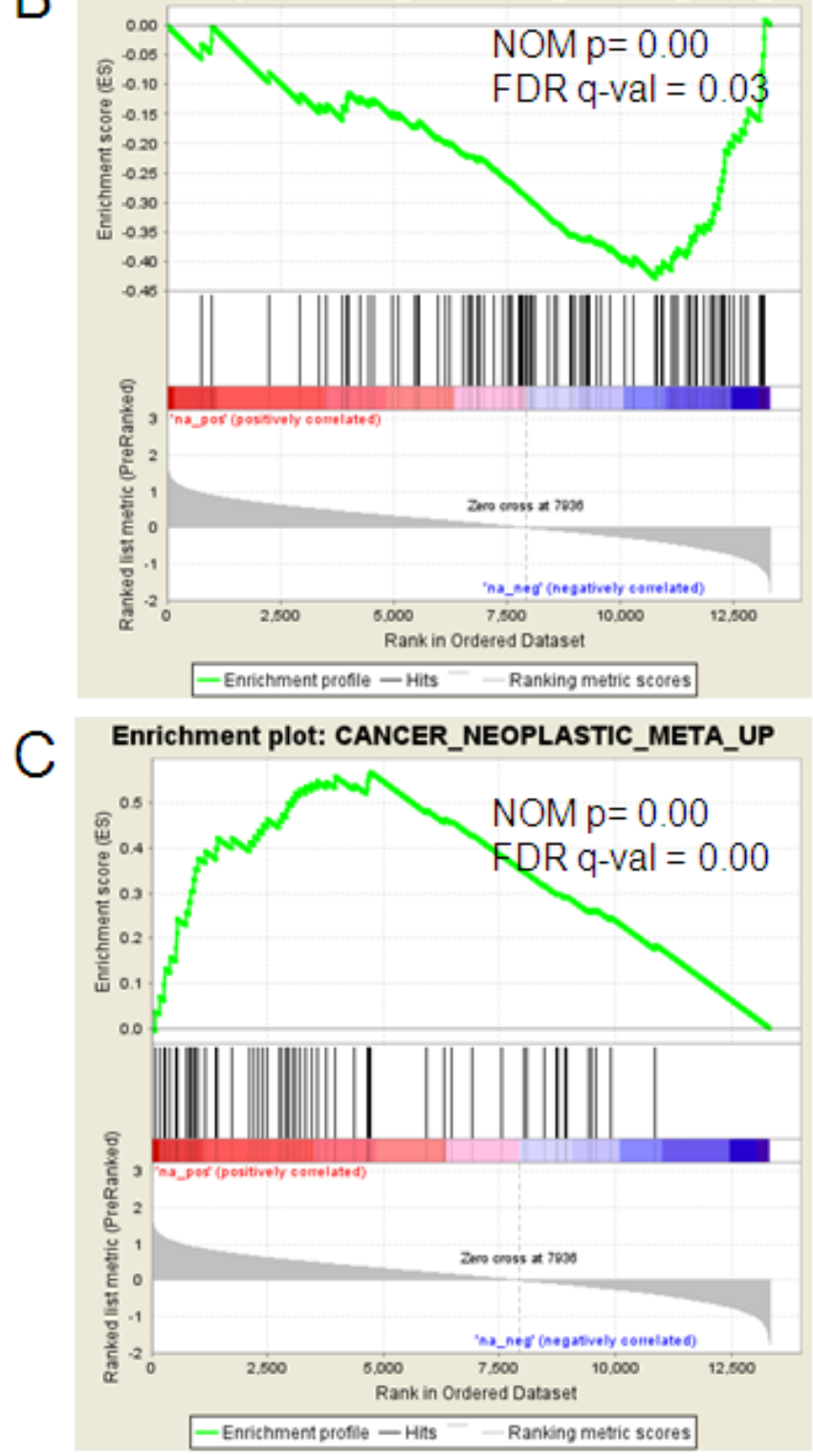

Figure 3-2 Gene set enrichment analysis (GSEA) of c-Myc responsive genes. Genes were ranked by their correlation with expression levels of $M Y C$ in decreasing order from the most positively correlated to most negatively correlated genes. GSEA enrichment scores (y-axis of the top panel) are plotted against the gene list ranked by correlation with MYC. A GSEA revealed a strong enrichment of a known c-Myc signature among the genes most correlated with c-Myc in our analysis. This is indicated by the sharp increase in the GSEA enrichment score to the left of the graph and a decrease to the right $\mathbf{B}$ In contrast, a known CD40 signature is enriched among the genes negatively correlated with c-Myc. This is indicated by the gradual decrease of the GSEA enrichment score to the left of the graph, and a sharp increase to the right. C GSEA revealed an enrichment of a CANCER NEOPLASTIC META UP gene set which comprises genes that are upregulated in tumour cells relative to matching normal tissue cells across many tumour entities. For a detailed list of Gene Sets please see Table 3-1. 
Manual inspection of the top 100 MYC correlated genes defining the c-Myc-index, revealed many of them to be involved in functions known to be modulated by c-Myc (Table 3-1 and Table A1 in the Appendix). The observed genes can be grouped to cellular activities as cell cycle regulation and proliferation, transcriptional regulation, chromatin remodelling and DNA-repair, cell metabolism and stress response, regulation of RNA processing and translation as well as cytokines, cell cell communication and intracellular signalling components or drug resistance. Genes involved in cell cell communication show a negative correlation with $M Y C$, including the NF-kB target ICAM1/CD54 and the 'frizzled' receptor gene family member FZD7 as part of the Wnt pathway. To test exemplarily for the reverse correlation of $F Z D 7$ and $M Y C$ expression in lymphoma cell lines as well as in CD10+ germinal center B cells from tonsils qRT-PCR analyses were performed. MYC expression was found to be high in BL cell lines DG75, BL2, BL70 and Ramos, but also in cell lines MC116 and OCI-Ly1 and SuDHL4. In these cells FZD7 expression is detected only at low amounts or is absent (Figure 3-3, page 64). In contrast cell lines OCl-Ly3, HT, OCI-Ly7, SuDHL6 show the opposite pattern. All analysed CD10+ cells from tonsils are clearly characterised by a nearly undetectable $M Y C$ expression but high for FZD7. Thus we conclude that there is an inverse correlation between $M Y C$ and $F Z D 7$ expression reflecting the described c-Myc index.

\subsubsection{Very high expression of c-Myc target genes is a hallmark of molecular Burkitt lymphomas}

In a next step the expression of $M Y C$ co regulated genes was investigated in two independent data sets of aNHL samples. These include the previously mentioned cohort of 220 cases published by Hummel and colleagues and the dataset published by the LLMPP consortium (Dave, Fu et al. 2006). The expression levels of 100 genes in our ranked list were aggregated into a single c-Myc index score for each lymphoma sample (Figure 3-4 A\&B page 65, Table A1). The c-Myc index was used as a surrogate marker of c-Myc activity, which is robust to random fluctuations of individual gene expression measures. The c-Myc index measures the extent to which an individual lymphoma expresses genes that are responsive to c-Myc. 
Results

Table 3-1 Top 100 genes correlated with $M Y C$ in GC B cells and aNHL: The c-Myc index. Genes that are correlated with MYC in primary transfected GC B cells as well as in gene expression profiles of aNHL are listed below. Genes are ordered according to assumed cellular functions and the calculated t-scores. The Pearson Correlation for being expressed in correlation with $M Y C$ is also given for each gene.

\begin{tabular}{|c|c|c|c|c|}
\hline Probeset ID & $\begin{array}{l}\text { Cellular } \\
\text { activity/gene } \\
\text { name }\end{array}$ & Gene name & $\begin{array}{l}\text { MYC } \\
\text { correl } \\
\text { ation }\end{array}$ & $\begin{array}{c}t \\
\text { score }\end{array}$ \\
\hline \multicolumn{5}{|c|}{ metabolism } \\
\hline 204290_s_at & ALDH6A1 & aldehyde dehydrogenase 6 family, member $A 1$ & 0.52 & 3.64 \\
\hline 209092_s_at & GLOD4 & glyoxalase domain containing 4 & 0.51 & 2.81 \\
\hline 203150_at & RABEPK & Rab9 effector protein with kelch motifs & 0.60 & 2.68 \\
\hline 221551_x_at & ST6GALNAC4 & $\begin{array}{l}\text { ST6 (alpha-N-acetyl-neuraminyl-2,3-beta-galactosyl-1,3)-N- } \\
\text { acetylgalactosaminide alpha-2,6-sialyltransferase } 4\end{array}$ & 0.53 & 1.82 \\
\hline 201892_s_at & IMPDH2 & IMP (inosine monophosphate) dehydrogenase 2 & 0.54 & 1.79 \\
\hline 210868_s_at & ELOVL6 & $\begin{array}{l}\text { ELOVL family member } 6 \text {, elongation of long chain fatty acids } \\
\text { (FEN1/Elo2, SUR4/Elo3-like, yeast) }\end{array}$ & 0.49 & 1.61 \\
\hline 208700_s_at & TKT & transketolase & 0.53 & 1.52 \\
\hline 211715_s_at & $\mathrm{BDH} 1$ & 3-hydroxybutyrate dehydrogenase, type 1 & 0.56 & 1.49 \\
\hline 216659_at & LOC1720 & dihydrofolate reductase pseudogene & -0.51 & -2.47 \\
\hline 213572_s_at & SERPINB1 & serpin peptidase inhibitor, clade B (ovalbumin), member 1 & -0.59 & -4.48 \\
\hline 208949_s_at & LGALS3 & lectin, galactoside-binding, soluble, 3 & -0.52 & -4.99 \\
\hline \multicolumn{5}{|c|}{ Cytokines / cell cell interaction } \\
\hline 209591_s_at & $\begin{array}{l}\text { BMP7 (BMP } \\
\text { signalling) }\end{array}$ & bone morphogenetic protein 7 & 0.56 & 2.23 \\
\hline 209100_at & $\begin{array}{l}\text { IFRD2 (Growth } \\
\text { factor receptor) }\end{array}$ & interferon-related developmental regulator 2 & 0.51 & 1.94 \\
\hline 37408_at & $\begin{array}{l}\text { MRC2 (Migration } \\
\text { and ECM } \\
\text { interaction) }\end{array}$ & mannose receptor, C type 2 & -0.49 & -1.76 \\
\hline 221378_at & CER1 & $\begin{array}{l}\text { cerberus } 1 \text {, cysteine knot superfamily, homolog (Xenopus } \\
\text { laevis), BMP antagonist }\end{array}$ & -0.51 & -1.76 \\
\hline 211287_x_at & $\begin{array}{l}\text { CSF2RA (Growth } \\
\text { factor receptor) }\end{array}$ & $\begin{array}{l}\text { colony stimulating factor } 2 \text { receptor, alpha, low-affinity } \\
\text { (granulocyte-macrophage) }\end{array}$ & -0.50 & -2.09 \\
\hline 203175_at & $\begin{array}{l}\text { RHOG (G protein } \\
\text { coupled Signals) }\end{array}$ & ras homolog gene family, member $\mathrm{G}$ (rho $\mathrm{G}$ ) & -0.49 & -2.50 \\
\hline 210904_s_at & $\begin{array}{l}\text { IL13RA1 } \\
\text { (JAK/STAT } \\
\text { signalling) }\end{array}$ & interleukin 13 receptor, alpha 1 & -0.51 & -2.85 \\
\hline
\end{tabular}


Results

\begin{tabular}{|c|c|c|c|c|}
\hline 221958_s_at & $\begin{array}{l}\text { GPR177 (G protein } \\
\text { coupled Signals) }\end{array}$ & G protein-coupled receptor 177 & -0.54 & -3.03 \\
\hline 202637_s_at & $\begin{array}{l}\text { ICAM1 (cell } \\
\text { adhesion and NF- } \\
\text { kapppaB signalling) }\end{array}$ & intercellular adhesion molecule 1 & -0.51 & -3.33 \\
\hline 208302_at & HMHB1/HLA-HB1 & $\begin{array}{l}\text { histocompatibility (minor) HB-1, CTL-response, expressed in } \\
\text { EBV-positive B cells }\end{array}$ & -0.50 & -3.50 \\
\hline 203706_s_at & $\begin{array}{l}\text { FZD7 (Wnt } \\
\text { signalling) }\end{array}$ & frizzled homolog 7 (Drosophila) & -0.49 & -4.55 \\
\hline \multicolumn{5}{|c|}{ cell cycle / proliferation } \\
\hline 221965_at & MPHOSPH9 & M-phase phosphoprotein 9 & 0.49 & 2.79 \\
\hline 203847_s_at & AKAP8 & A kinase (PRKA) anchor protein 8 & 0.49 & 2.45 \\
\hline 200955_at & IMMT & $\begin{array}{l}\text { inner membrane protein, mitochondrial (mitofilin), proliferation } \\
\text { induced }\end{array}$ & 0.53 & 2.14 \\
\hline 201970_s_at & NASP & nuclear autoantigenic sperm protein (histone-binding) & 0.51 & 2.09 \\
\hline 201856_s_at & ZFR & zinc finger RNA binding protein & 0.50 & 1.62 \\
\hline 212899_at & CDC2L6 & cell division cycle 2-like 6 (CDK8-like) & -0.59 & -4.09 \\
\hline \multicolumn{5}{|c|}{ mRNA processing / translation regulation / stability } \\
\hline 200014_s_at & HNRNPC & heterogeneous nuclear ribonucleoprotein $\mathrm{C}$ (C1/C2) & 0.49 & 3.79 \\
\hline 211787_s_at & EIF4A1 & eukaryotic translation initiation factor $4 \mathrm{~A}$, isoform 1 & 0.56 & 3.03 \\
\hline 201530_x_at & (2 probesets) & & 0.53 & 2.17 \\
\hline 208835_s_at & CROP & $\begin{array}{l}\text { cisplatin resistance-associated overexpressed protein / } \\
\text { splicosome }\end{array}$ & 0.54 & 2.59 \\
\hline 217810_x_at & LARS & leucyl-tRNA synthetase & 0.53 & 2.34 \\
\hline 208765_s_at & HNRNPR & heterogeneous nuclear ribonucleoprotein $\mathrm{R}$ & 0.52 & 2.24 \\
\hline 208766_s_at & (2 probesets) & & 0.55 & 2.22 \\
\hline 211930_at & HNRNPA3 & heterogeneous nuclear ribonucleoprotein A3 & 0.50 & 2.19 \\
\hline 213614_x_at & EEF1A1 & eukaryotic translation elongation factor 1 alpha 1 & 0.51 & 1.96 \\
\hline 215963_x_at & RPL3P7 & ribosomal protein L3 pseudogene 7 & 0.49 & 1.77 \\
\hline 200005_att & EIF3D & eukaryotic translation initiation factor 3 , subunit $D$ & 0.49 & 1.20 \\
\hline \multicolumn{5}{|c|}{ stress response } \\
\hline 201841_s_at & HSPB1 & heat shock $27 \mathrm{kDa}$ protein 1 & 0.49 & 4.00 \\
\hline 215792_s_at & DNAJC11 & DnaJ (Hsp40) homolog, subfamily C, member 11 & 0.63 & 2.47 \\
\hline
\end{tabular}


Results

\begin{tabular}{|c|c|c|c|c|}
\hline 211969_at & HSP90AA1 & heat shock protein $90 \mathrm{kDa}$ alpha (cytosolic), class A member 1 & 0.55 & 2.22 \\
\hline \multicolumn{5}{|c|}{ Intracellular Signalling } \\
\hline \multicolumn{5}{|c|}{ transcription factors / regulators / scaffolds } \\
\hline 212945_s_at & MGA & MAX gene associated & 0.64 & 5.15 \\
\hline 213584_s_at & CREBZF & CREB/ATF bZIP transcription factor & 0.56 & 4.76 \\
\hline 209750_at & NR1D2 & $\begin{array}{l}\text { nuclear receptor subfamily } 1 \text {, group } \mathrm{D} \text {, member } 2 / \mathrm{RORa} \\
\text { response associated }\end{array}$ & 0.49 & 3.30 \\
\hline 205446_s_at & ATF2 & activating transcription factor 2 & 0.57 & 3.22 \\
\hline 206912_at & FOXE1 & forkhead box E1 (thyroid transcription factor 2) & 0.51 & 2.92 \\
\hline 203150_at & RABEPK & Rab9 GTPase effector protein with kelch motifs & 0.60 & 2.68 \\
\hline $\begin{array}{l}\text { 210543_s_at } \\
\text { 208694_at }\end{array}$ & $\begin{array}{l}\text { PRKDC } \\
\text { (2 pobesets) }\end{array}$ & $\begin{array}{l}\text { protein kinase, DNA-activated, catalytic polypeptide (DNA } \\
\text { repair / gene transcription) }\end{array}$ & $\begin{array}{l}0.59 \\
0.51\end{array}$ & $\begin{array}{l}1.95 \\
1.62\end{array}$ \\
\hline 218406_x_at & NENF & neuron derived neurotrophic factor/activator of Erk/AKt & -0.51 & -2.20 \\
\hline 203349_s_at & ETV5 & ets variant 5 & -0.56 & -2.26 \\
\hline 215228_at & NHLH2 & nescient helix loop helix 2/bHLHa34 & -0.53 & -2.85 \\
\hline 35254_at & TRAFD1 & TRAF-type zinc finger domain containing 1 & -0.49 & -3.66 \\
\hline 209785_s_at & PLA2G4C & $\begin{array}{l}\text { phospholipase A2, group IVC (cytosolic, calcium- } \\
\text { independent) produces precursors of signalling molecules }\end{array}$ & -0.59 & -5.78 \\
\hline \multicolumn{5}{|c|}{ phosphatases } \\
\hline 216181_at & SYNJ2 & synaptojanin 2/inositol-polyphosphate-5- phosphatase & 0.55 & 2.31 \\
\hline 219264_s_at & PPP2R3B & $\begin{array}{l}\text { protein phosphatase } 2 \text { (formerly } 2 \mathrm{~A} \text { ), regulatory subunit B", } \\
\text { beta }\end{array}$ & 0.51 & 1.73 \\
\hline 203030_s_at & PTPRN2 & protein tyrosine phosphatase, receptor type, N polypeptide 2 & -0.51 & -3.34 \\
\hline 204015_s_at & DUSP4 & dual specificity phosphatase 4 & -0.55 & -3.53 \\
\hline \multicolumn{5}{|c|}{ Chromatin remodelling / DNA-repair } \\
\hline 41386_i_at & JMJD3 & jumonji domain containing 3 , histone lysine demethylase & 0.52 & 3.93 \\
\hline 217815_at & SUPT16H & $\begin{array}{l}\text { suppressor of Ty } 16 \text { homolog (S. cerevisiae)/FACT complex } \\
\text { part }\end{array}$ & 0.53 & 1.94 \\
\hline 200957_s_at & SSRP1/FACT & structure specific recognition protein 1 & 0.59 & 1.84 \\
\hline 201115_at & POLD2 & polymerase (DNA directed), delta 2 , regulatory subunit $50 \mathrm{kDa}$ & 0.58 & 1.82 \\
\hline 201072_s_at & SMARCC1 & $\begin{array}{l}\text { SWI/SNF related, matrix associated, actin dependent } \\
\text { regulator of chromatin, subfamily c, member } 1\end{array}$ & 0.49 & 1.73 \\
\hline
\end{tabular}


Results

\begin{tabular}{|l|l|l|c|c|}
\hline 218788_s_at & SMYD3 & $\begin{array}{l}\text { SET and MYND domain containing 3 histone } \\
\text { methyltransferase }\end{array}$ & 0.49 & 1.45 \\
\hline 209731_at & NTHL1 & nth endonuclease III-like 1 (E. coli) & 0.53 & 1.15 \\
\hline 40446_at & PHF1 & PHD finger protein 1/polycomb protein & -0.53 & -2.17 \\
\hline 211373_s_at & PSEN2 & presenilin 2 (Alzheimer disease 4) & -0.55 & -3.53 \\
\hline
\end{tabular}

\section{Drug resistance}

\begin{tabular}{|l|l|l|c|c|}
\hline 212282_at & TMEM97 & transmembrane protein 97 & 0.53 & 1.97 \\
\hline 213485_s_at & ABCC10 & ATP-binding cassette, sub-family C (CFTR/MRP), member 10 & -0.52 & -2.58 \\
\hline
\end{tabular}

\section{Other}

\begin{tabular}{|c|c|c|c|c|}
\hline 220459_at & MCMЗAPAS & MCM3AP antisense RNA (non-protein coding) & 0.52 & 3.00 \\
\hline 50314_i_at & C20orf27 & chromosome 20 open reading frame 27 & 0.64 & 2.91 \\
\hline $\begin{array}{l}\text { 210157_at } \\
214173 \text { _x_at }\end{array}$ & $\begin{array}{l}\text { C19orf2 (2 } \\
\text { probesets) }\end{array}$ & chromosome 19 open reading frame 2 & $\begin{array}{l}0.59 \\
0.50\end{array}$ & $\begin{array}{l}2.62 \\
1.44\end{array}$ \\
\hline $\begin{array}{l}\text { 65472_at } \\
221878 \text { at }\end{array}$ & $\begin{array}{l}\text { C2orf68 } 2 \\
\text { probesets }\end{array}$ & chromosome 2 open reading frame 68 & $\begin{array}{l}0.51 \\
0.51\end{array}$ & $\begin{array}{l}2.54 \\
2.50\end{array}$ \\
\hline 218437_s_at & LZTFL1 & leucine zipper transcription factor-like 1 & 0.50 & 2.20 \\
\hline 204559_s_at & LSM7 & $\begin{array}{l}\text { LSM7 homolog, U6 small nuclear RNA associated (S. } \\
\text { cerevisiae) }\end{array}$ & 0.56 & 1.82 \\
\hline 220736_at & SLC19A3 & solute carrier family 19 , member 3 & -0.52 & -2.00 \\
\hline 220297_at & BTBD7 & BTB (POZ) domain containing 7 & -0.49 & -2.02 \\
\hline 206573_at & KCNQ3 & $\begin{array}{l}\text { potassium voltage-gated channel, KQT-like subfamily, } \\
\text { member } 3\end{array}$ & -0.54 & -2.20 \\
\hline 220519_s_at & LIM2 & lens intrinsic membrane protein $2,19 \mathrm{kDa}$ & -0.49 & -2.22 \\
\hline 215770_at & LOC100133572 & similar to seven transmembrane helix receptor & -0.55 & -2.22 \\
\hline 217783_s_at & YPEL5 & yippee-like 5 (Drosophila) & -0.51 & -2.23 \\
\hline 206299_at & FAM155B & family with sequence similarity 155 , member $B$ & -0.51 & -2.32 \\
\hline 215754_at & SCARB2/CD36L2 & scavenger receptor class $\mathrm{B}$, member 2 & -0.50 & -2.46 \\
\hline 219106_s_at & KBTBD10 & kelch repeat and BTB (POZ) domain containing 10 & -0.51 & -2.47 \\
\hline 203242_s_at & PDLIM5 & PDZ and LIM domain 5 & -0.53 & -2.56 \\
\hline 220476_s_at & C1orf183 & chromosome 1 open reading frame 183 & -0.50 & -2.59 \\
\hline 210135_s_at & SHOX2 & short stature homeobox 2 & -0.53 & -2.87 \\
\hline 218765_at & SIDT2 & SID1 transmembrane family, member 2 & -0.49 & -3.00 \\
\hline 205138_s_at & UST & uronyl-2-sulfotransferase & -0.50 & -3.56 \\
\hline
\end{tabular}


Results

\begin{tabular}{|l|l|l|c|c|}
\hline 215734_at & C19orf36 & chromosome 19 open reading frame 36 & -0.55 & -3.75 \\
\hline 218945_at & C16orf68 & chromosome 16 open reading frame 68 & -0.50 & -4.56 \\
\hline 217220_at & NA & & -0.60 & -4.25 \\
\hline 212806_at & NA & & -0.52 & -3.10 \\
\hline 220875_at & NA & & -0.51 & -2.23 \\
\hline 220713_at & NA & & 0.49 & 3.64 \\
\hline 217166_at & NA & & 0.52 & 1.72 \\
\hline
\end{tabular}

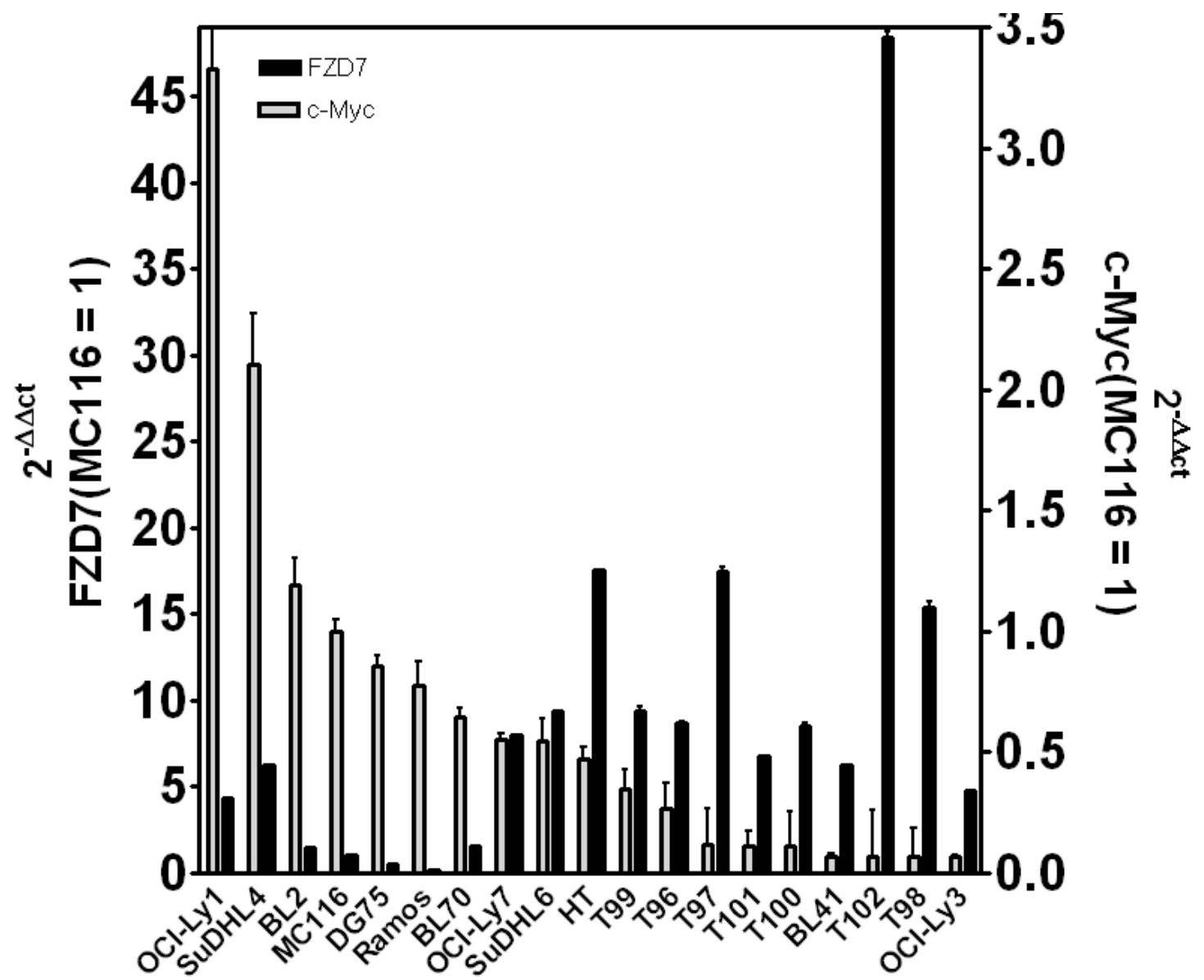

Figure 3-3 FZD7 expression is high in lymphoma precursor cells but reduced in lymphoma cells and negatively correlated to MYC-gene expression. FZD7 and MYC gene expression was assessed using qRT-PCR. Ct values were normalized to $32 \mathrm{~m}$ expression and $\Delta \Delta \mathrm{Ct}$ values were calculated compared to respective gene expression in MC116 lymphoma cells. T99, T96, T97, T98, T101 and T102 represent different preparations of tonsilar B cells purified by CD10 MACS. All other analysed samples represent different lymphoma cell lines. 
A

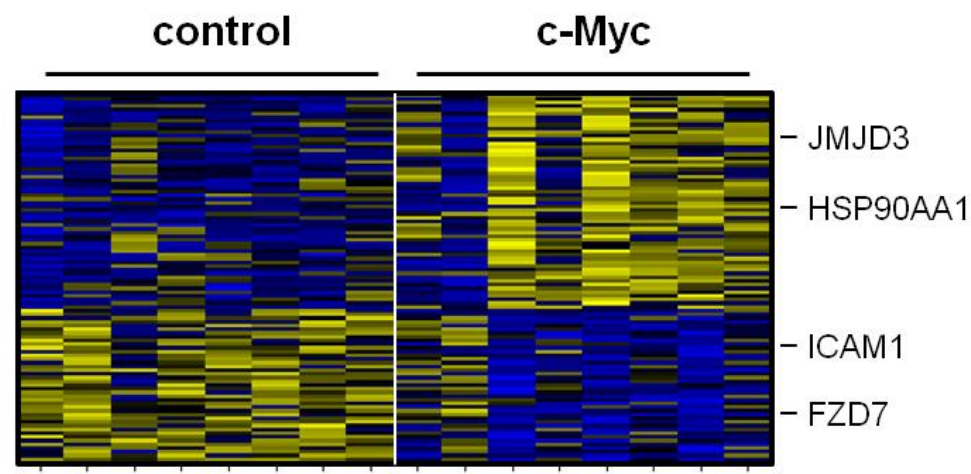

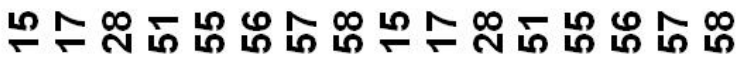

B

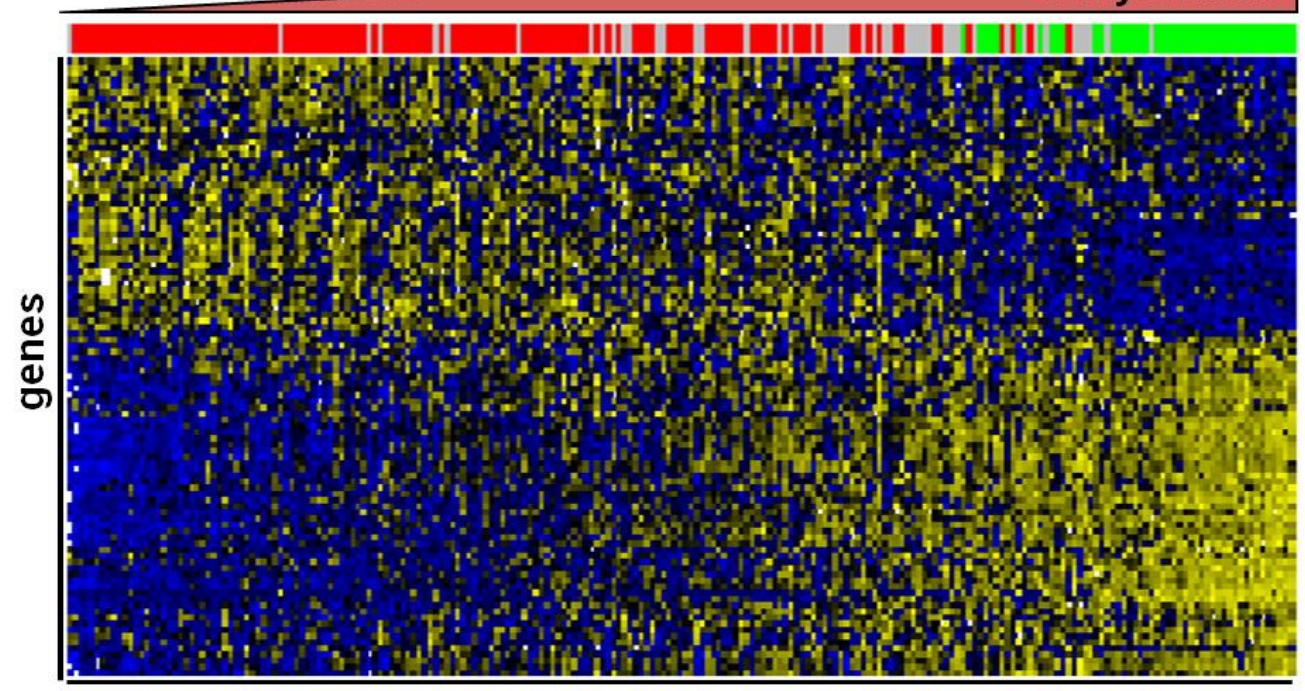

aNHL tumours (MMML cohort)

Figure 3-4 Stratification of NHL patients in $\mathrm{mBL}$ and non $\mathrm{mBL}$ by expressing c-Myc in GC B cells. Each row in the heatmaps represents a gene and each column represents a microarray sample. The expression levels for each gene were standardized to a mean value of 0 and a standard deviation of 1 , and are represented according to a color scale; yellow and blue indicate high and low expression, respectively. A Heatmaps of genes expressed in GC B cells that show a correlation to MYC in tonsillar samples and $220 \mathrm{NHL}$ samples (Hummel, Bentink et al. 2006). B Heatmap of gene expression levels of the same genes plotted in (A) this time in $220 \mathrm{NHL}$ samples (Hummel, Bentink et al. 2006) recently classified as $\mathrm{mBL}$, non-mBL or intermediate cases. This classification is colour coded in the top bar (green: $\mathrm{mBL}$, red: non-mBL, grey: intermediate). The patients are arranged according to c-Myc index (increasing from left to right).

\subsubsection{High expression of c-Myc inducible genes in the group of non-mBL} and intermediate lymphomas is associated with shorter overall survival

Analyses of the c-Myc index across the lymphoma subgroups of $220 \mathrm{aNHL}$ specimens revealed that mBLs consistently showed a higher c-Myc index than 
did non-mBLs. This is in line with the assumption that the IG-MYC translocation and the resulting aberrant $M Y C$ expression is the major contributor to the malignant phenotype of BL (Figure 3-5 A\&B; see also Figure 3-4 B). Furthermore, other groups of lymphomas defined by their genetic background also show significantly different c-Myc activities. Thus, Figure 3-5 B shows that on average, cases without MYC aberrations show the lowest c-Myc index. In contrast, the c-Myc index is higher in cases harbouring MYC breakpoints in a background of other complex genetic aberrations and is consistent with a contribution of c-Myc to the pathogenesis of these tumours. The c-Myc induced gene expression pattern is also expressed in lymphoma classified as non-molecular BL.

In the study group of aNHL cases analysed here (MMML cohort) $80 \%$ of non$\mathrm{mBL}$ and intermediate cases consisted of DLBCLs. All molecularly defined non$\mathrm{mBL}$ and intermediate lymphomas were ranked according to their c-Myc index and classified into four equally sized groups which were defined as c-Myc very low, low, medium and high. The Kaplan Meier curves in Figure 3-5 C demonstrate a poorer overall survival for patients with non-mBL and intermediate lymphomas that display a high c-Myc index. Significance of the differences between groups was calculated using the log rank test.

Moreover, multivariate Cox regression analysis accounting for the established risk factors of age, Ann Arbor stage, and the ABC/GCB status revealed that the effect of a C-Myc index classified as high on survival was independent of these factors ( $n=88$; hazard ratio for death: $4.2 ; 95 \% \mathrm{Cl}: 1.5-10.1 ; P=0.0014$ ). To test if the poorer outcome of patients with high c-Myc index tumours can be explained just by the presence of a MYC break, which has been shown to be associated with shorter overall survival (Hummel, Bentink et al. 2006), the MYC break was included as additional factor in the Cox model. In this model a high c-Myc index is associated with a 3.4 fold increased risk of earlier death, independent of a MYC break in these lymphomas ( $n=86$; high c-Myc index: hazard ratio for death: 3.4; 95\% Cl: 1.4-8.3; $P=0.008)$. 
A

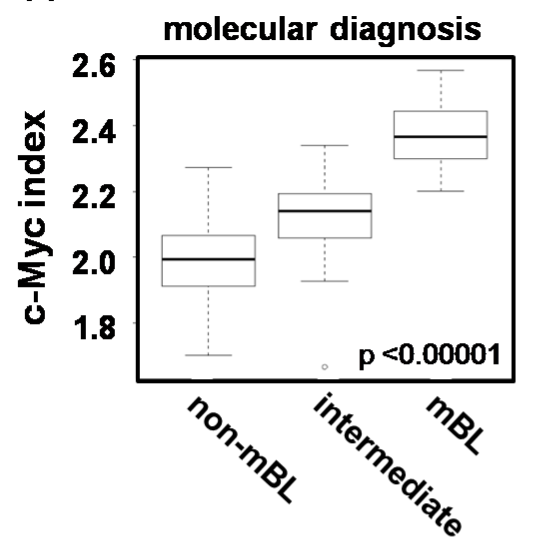

C

MMML survival (non-mBL and intermediate GCB/ABC, $n=88$ )

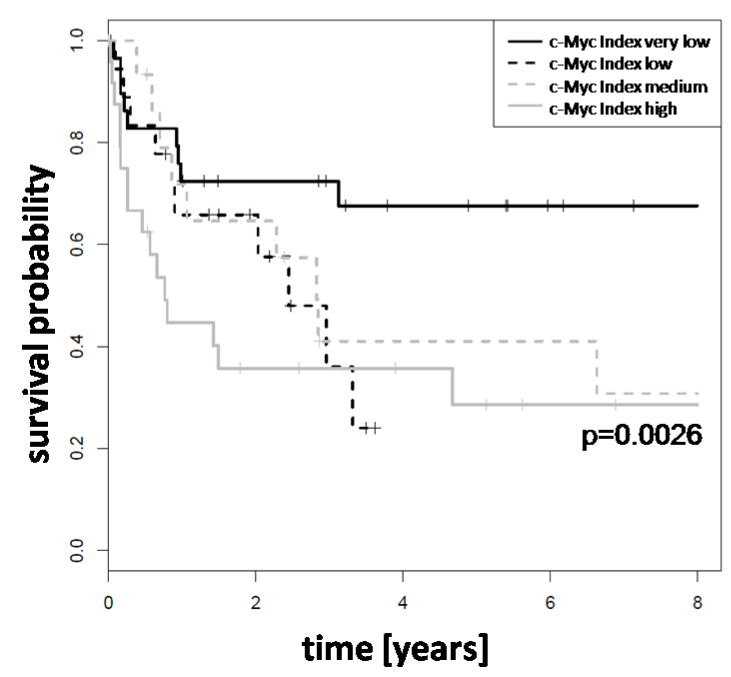

B

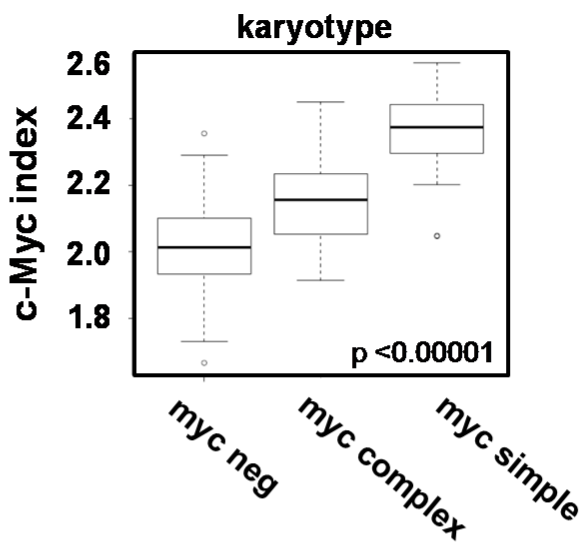

D

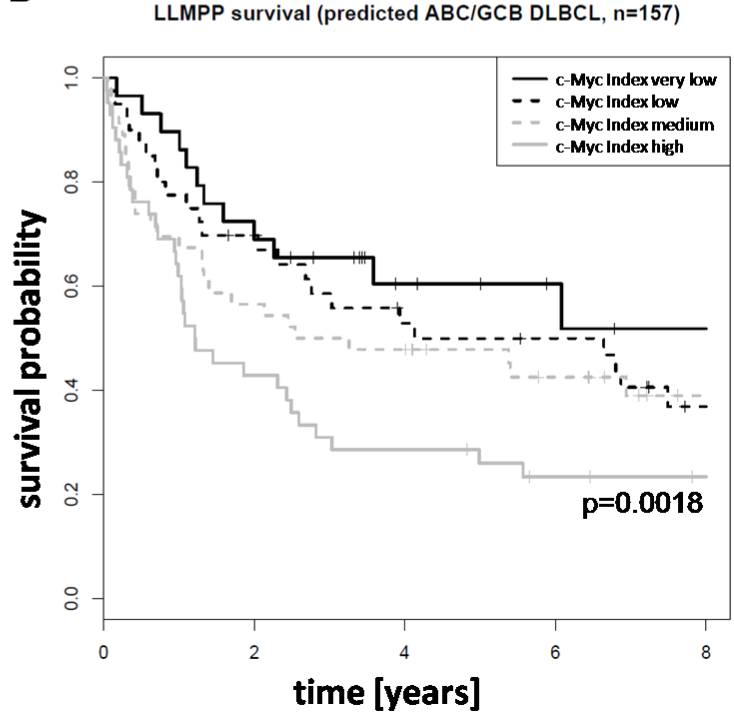

Figure 3-5 High expression of c-Myc index genes in the group of non-mBL and intermediate lymphomas is associated with shorter overall survival A Boxplots of the level of the c-Myc index ( $y$-axis) in NHL lymphomas classified as non-mBL, intermediate and $\mathrm{mBL}(\mathrm{x}-$ axis). B Boxplots of the level of the c-Myc expression index (y-axis) in NHL lymphomas classified as $M Y C$-negative, $M Y C$-complex and $M Y C$-simple (x-axis). Statistical significance of the differences was tested using ANOVA. (C\&D) Kaplan Meier plots of the overall survival of non$\mathrm{mBL}$ and intermediate patients stratified by the c-Myc expression index C 88 non-mBL and intermediate patients samples (MMML) were stratified based on the level of their C-Myc expression index into tumours of very low, low, medium and high c-Myc activity. Patients with a tumour of high c-Myc activity have the shortest overall survival (grey continuous line). D 157 DLBCL patients of the data set published by Dave and colleagues (LLMPP) were grouped as in (C). Patients with high c-Myc index showed shorter overall survival. Statistical significance of the differential survival of these groups was tested using the log rank test.

The finding that a high c-Myc index was associated with shorter survival was confirmed in a subgroup of DLBCL patients $(n=157)$ of the dataset published by Dave and colleagues (LLMPP). Since these data were generated on a different array platform, a truncated c-Myc index build from signature genes that are 
present on both arrays was used for this analysis. Patients with DLBCL displaying a high c-Myc index were shown to have a significantly shorter overall survival ( $n=157$; hazard ratio for death: 2.0; 95\% Cl: 1.0-3.8; $P=0.045$ ) (Figure 3-5 D).

These results point to an important deregulated function for c-Myc in non-mBL cases, which is not necessarily dependent on the c-Myc translocation, but possibly on other mechanisms that have not been identified so far. The newly described c-Myc index comprises genes that are affected in a variety of tumours compared to normal tissue. This supports the view that aberrant c-Myc expression in GC B cells triggers a tumour like expression pattern. As expected, the c-Myc index is very high in $\mathrm{mBL}$, but more importantly also high within other aNHL. It constitutes a negative prognostic marker independent of established risk factors and of the presence of a MYC translocation.

\subsection{Activation of BL cells with B cell specific microenvironmental factors} triggers global changes in gene expression patterns useful to define pathway activity in individual lymphoma

The microenvironment is a dominant factor for most B cell lymphoma. An improved understanding of signalling modules or their effectors that might play a role in tumour-microenvironment interaction are important to understand elements potentially involved in cell transformation. It is likely that immune response associated signals like $B$ cell receptor activation, innate antigen LPS stimulation or co stimulatory signals mediated via CD40L, B cell activating factor (BAFF) and Interleukin 21 (IL21) are specific mediators in B cell transformation. These stimuli were used to identify modules of genes which can then be utilized to infer on the respective stimulus activity in gene expression profiles of aNHL tumours. In pretests performed in the group of D. Kube it was observed that gene expression changes induced by $\mathrm{CD} 40 \mathrm{~L}$ in $\mathrm{BL}$ cells are probably useful to describe pathway activities in aNHL.

In the present study additional stimuli were utilized that are capable of activating overlapping (e.g. NF-KB) as well as specific pathways (e.g. JAK-STAT signalling) and thereby mimic oncogenic activities. To infer on the global response of 
lymphoma cells the major patterns of gene expression changes in response to the different stimulations were investigated in vitro and subsequently used to identify respective patterns in primary lymphoma.

\subsection{1 anti-IgM, CD40L, IL21, BAFF and LPS stimulation activate an individual, partially overlapping pattern of pathways upon stimulation of Burkitt Lymphoma cells}

The BL cell line BL2 was stimulated in triplicate using anti-lgM antibody to achieve BCR activation (BCRx), recombinant human CD40 ligand (CD40L), recombinant human BAFF (BAFF), recombinant human IL21 (IL21) and LPS to achieve TLR4 activation. To describe the effects of these stimuli on the BL cell line the activation of the following pathways was determined: $\mathrm{Ca}^{2+}$ influx, NF-KB signalling (canonical and noncanonical), MAPK signalling (ERK, p38, JNK), PI3K/AKT signals and JAK/STAT signalling via STAT1 and STAT3. The activation of pathways was monitored using flow cytometry based measurement of $\mathrm{Ca}^{2+}$ influx, immunoblots specifically detecting phosphorylation of key pathway components and a kinase assay for the detection of JNK activity. This kinase assay was performed as follows: BL2 cells were transfected with a JNK-HA expression construct. After 24hrs the cells were stimulated with the respective agent for $30 \mathrm{mins}$ and subsequently harvested. Cell lysates were incubated with recombinant c-Jun in presence of radioactive phosphor. The induced kinase activity could be verified by detecting phosphorylated c-Jun.

As shown in Figure 3-6 anti IgM treatment of $B L$ cells induces a strong calcium signal. This is expressed by a sharp increase of intracellular $\mathrm{Ca}^{2+}$ levels after 5 seconds of anti-lgM stimulation. The $\mathrm{Ca}^{2+}$ influx was measured using a specific fluorescent dye that changes the spectrum of emitted light upon binding to $\mathrm{Ca}^{2+}$ and flow cytometric analysis of stained cells (Figure 3-6 A). CD40L, BAFF, LPS or IL21 are unable to induce a $\mathrm{Ca}^{2+}$ influx. The activation of NF-KB pathways was detected by monitoring the reduced leves of the NF-KB inhibitor IKBa as marker for canonical NF-KB activity. The cleavage of the p100 (NFKB2) precursor to the p52 form is monitored as marker for noncanonical NF-kB activity. In contrast to effective induction of $\mathrm{Ca}^{2+}$ signals, the activation of the canonical and noncanonical NF-kB pathway in response to BCRx is only marginal, whereas 
CD40L strongly activates noncanonical NF-KB (Figure 3-6 B \& C). The MAPKs p38 (pp38), JNK (p-c-Jun) and ERK (p-ERK) are all activated upon BCR crosslink (Figure 3-6 D-F). Furthermore BCRx leads to the activation of the PI3K/AKT pathways as detected by phosphorylation of AKT upon 30 minutes of anti-lgM stimulation (Figure 3-6 G).The stimulation of BL2 cells with CD40L leads to the activation of canonical and noncanonical NF-KB pathways (Figure 3-6 B \& C). Furthermore an activation of p38 and JNK MAPKs can be detected (Figure 3-6 $E \& F)$. In contrast to BCRx an activation of ERK upon CD40L stimulation is not detectable (Figure 3-6 D). BAFF treatment is associated with a low activation of canonical NF-kB signalling (Figure 3-6 B) and as well a low activation of the noncanonical NF-kB pathway (Figure 3-6 C). Nevertheless the p38 pathway is induced comparable to BCR crosslink and CD40 activation (Figure 3-6 E). Activation of the PI3K/AKT pathway, as described already for BAFF stimulation (Badr, Borhis et al. 2008), cannot be observed in BL2 cells (Figure 3-6 G). The incubation of BL2 cells with LPS is accompanied with the activation of the canoncial NF-KB pathway but with a delayed kinetic when compared to CD40L (data not shown). An activation of p38 by LPS can only be observed under serum deprivation (Figure 3-6 E). The stimulation of BL2 cells with IL21 is associated with the activation of the STAT1 and STAT3 pathway as shown by the respective phosphorylation of STAT1 and STAT3 (Figure 3-6 H\&I). STAT5 and STAT6 were found to be activated to a lesser extend (data not shown). An activation of ERK by IL21, as published by Fuqua and colleagues, cannot be observed in BL2 cells (Figure 3-6 G) (Fuqua, Akomeah et al. 2008).

These results show that the $B L$ cell line $B L 2$ is in general responsive to each of the utilized stimuli and that overlapping as well as specific signalling pathways are activated upon stimulation. Overlapping pathways include for example the activation of p38 by BCRx and CD40L. Furthermore, noncanonical NF-KB is activated by CD40L and to lesser extent by BAFF. The activation of JNK is limited to CD40L and BCRx. Pathways that are specifically activated by one stimulus include the activation of $\mathrm{Ca} 2+, \mathrm{ERK}$ and $\mathrm{PI} 3 \mathrm{~K}$ by BCRx or the activation of JAK-STAT signalling by IL21. Nevertheless this analysis cannot represent the complete pattern of activated pathways as not all possible time points could be captured for each pathway in response to each stimulus. 
A

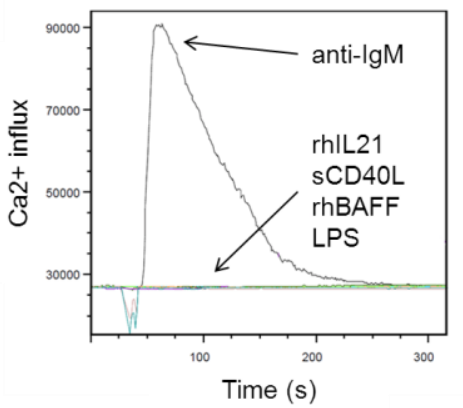

B

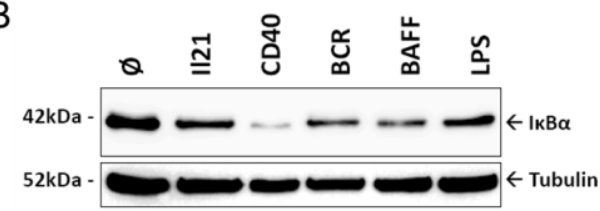

C
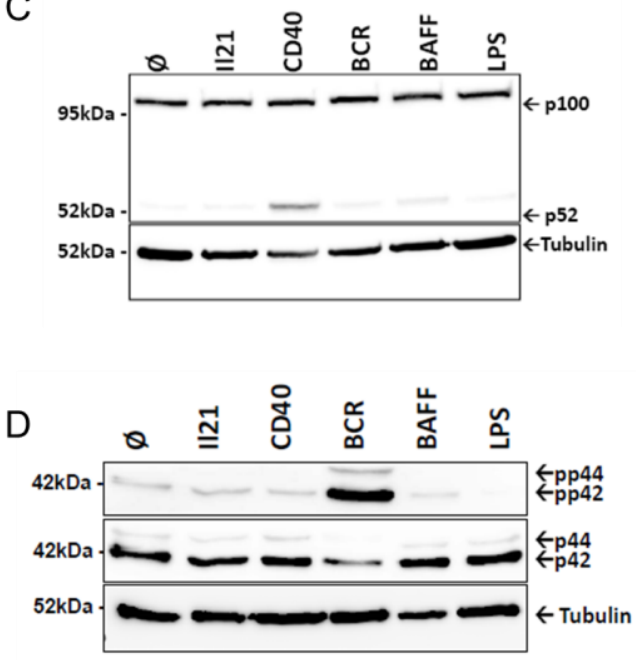

$\mathrm{E}$
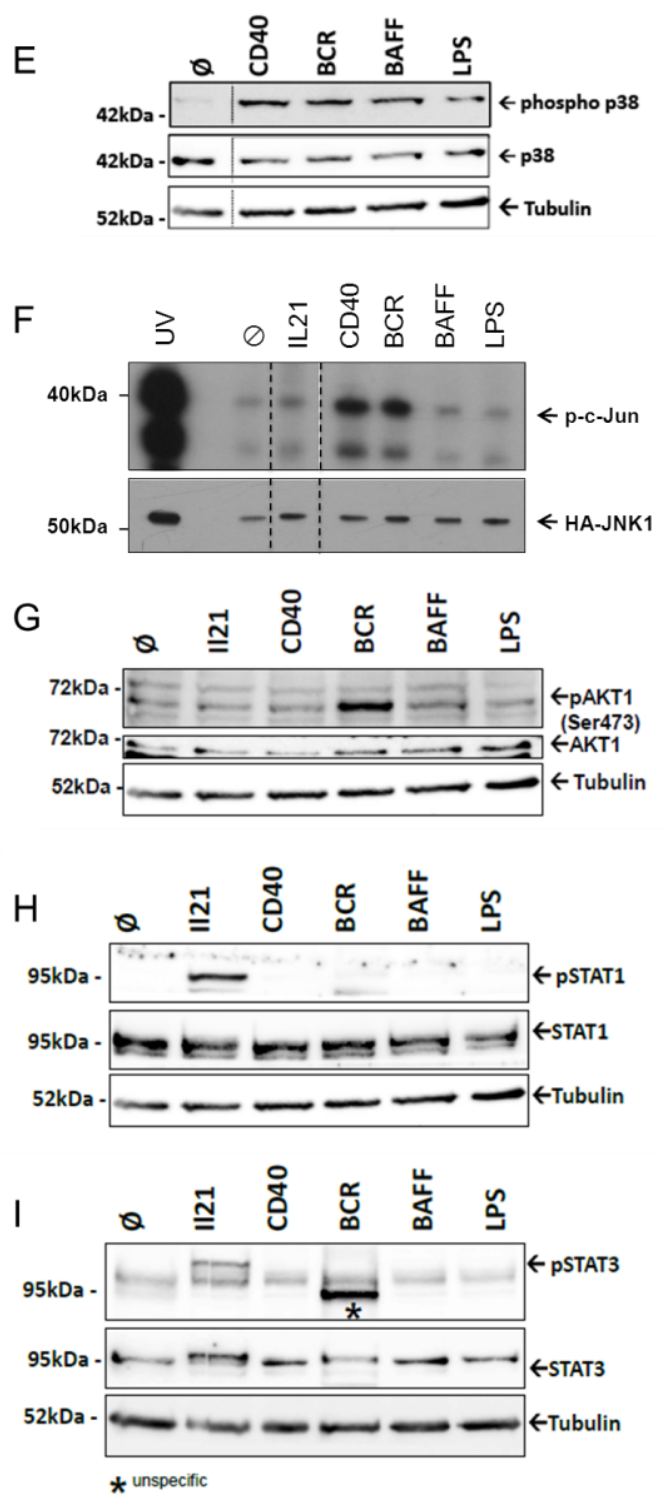

Figure 3-6 Different pathways activated by IL21, CD40L, anti-IgM (BCRx), BAFF and LPS in human Burkitt Lymphoma cells. BL2 cells were incubated with IL-21 (100ng/ml), CD40L $(200 \mathrm{ng} / \mathrm{ml})$, anti $\mathrm{lgM} F(a b)_{2}$ fragments $(1.3 \mu \mathrm{g} / \mathrm{ml})$, BAFF $(100 \mathrm{ng} / \mathrm{ml})$ and LPS $\left.(1 \mu \mathrm{g} / \mathrm{ml})\right)$ for indicated time points. A The activation of calcium signalling was detected using a $\mathrm{Ca}^{2+}$ sensitive fluorophor in combination with flowcytometric analyses. BL2 cells were loaded with indo1 and $\mathrm{Ca}^{2+}$ influx was measured directly after the stimulation. BCRx $(1.3 \mu \mathrm{g} / \mathrm{ml})$ induced an immediate $\mathrm{Ca}^{2+}$ accumulation in the cytoplasm as indicated by the increased Indo-1 fluorescence. B BL2 cells stimulated for 30 mins as indicated above. The activation of canonical NF-kB signalling was visualized by immunoblot of IKBa. C BL2 cells were stimulated for distinct time points (6hrs for CD40L and LPS, 3hrs for BCRx, 9hrs for BAFF and 2hrs for IL21 stimulation) as described in above. The activation of noncanonical NF-KB signalling was detected monitoring the p52 cleavage product of $\mathrm{p} 100$ by immunoblot. D BL2 cells stimulated for $5 \mathrm{mins}$ as indicated above. The activation of ERK was shown through immunoblot analyses of phosphorylated ERK1/2. E BL2 cells were stimulated for 30 mins as indicated in above. The activation of p38 was detected through detection of phosphorylated p38 via immunoblot. $\mathbf{F}$ In vitro kinase assay to investigate the activation of JNK in BL2 cells (Kutz, Reisbach et al. 2008). These data were kindly provided by A. Ulrich and A. Kieser. G BL2 cells were stimulated for distinct time points (6hrs for CD40L and LPS, 3hrs for BCR, 9hrs for BAFF and 2hrs for IL21 stimulation) as described in above. The activation of $\mathrm{PI} 3 \mathrm{~K} / \mathrm{AKT}$ signalling was detected using immunoblot detection of phosphorylated AKT1. H\&I BL2 cells were stimulated for $30 \mathrm{mins}$ as indicated above. The activation of 
STAT1/STAT3 was detected through the verification of phosphorylated STAT1/STAT3 via immunoblot.

\subsubsection{Global changes in gene expression profile through specific in vitro BL cell stimulation}

To investigate the gene expression changes that are induced by the distinct stimuli in a global way, gene expression profiling was performed. Therefore for every stimulus the time points were chosen individually. Based on the above described activation of different pathways (3.2.1) and literature based analysis the utilized stimulation periods were defined in the following way: (i) Harvest cells as early as possible to avoid autocrine effects of mediated by the induced expression of cytokines in response to respective stimuli and (ii) Harvest cells as late as possible to get a transcriptional response strong enough to be detected using whole genome microarrays. As CD40L, LPS and BAFF have been described to activate noncanonical NF-kB, longer time points (6hrs for CD40L and LPS, 9hrs for BAFF) were selected in this case. These were pretested. For $\mathrm{BCRx}$ and IL21, which mainly induce short term active signals, shorter time points were chosen (3hrs for BCRx and 2hrs for IL21). Probes were hybridized onto Affymetrix HG U133 plus 2.0 microarrays using three independent biological experiments. Data were analysed with support from K. Meyer/R. Spang from Regensburg. Genes which show a significant (adj. $p$ value $\leq 0.05$ ) change compared to unstimulated cells were considered.

The stimulation of BL2 cells trough BCRx lead to the differential expression of 6596 genes. In the following the alterations of gene expressions are given as absolute logarithmic fold changes ( $\log \mathrm{FC}$ ). Of these 3039 were upregulated with the highest absolute fold change of 5.5. 3557 genes showed significantly lower expression in response to BCRx with the highest absolute fold change of 2.7. This is the strongest response observed in this study. Activation of CD40 with CD40L alters the expression of 1194 genes (689 upregulated ( $\log F C=1.8$ ); 496 downregulated $(\log F C=2.0))$. Stimulation of BL2 cells with IL21 induced the differential expression of 902 genes. Of these 463 genes were upregulated with a maximal absolute fold change of 3.15. 439 genes were found to be significantly downregulated in response to IL21 treatment $(\log F C=1.936)$. BAFF stimulation 
significantly affected 129 genes. Of these 89 genes were upregulated with a maximal absolute fold change of $5(\log F C=0.8)$. In response to BAFF the expression of 39 genes is significantly inhibited $(\log F C=2.1)$. Activation of $B L$ cells with LPS induced the differential expression of 283 genes. Of these 114 genes are upregulated with a logFC of 1.1 and 169 show a reduced expression in response to LPS with a logFC of 1.9.. The genes differentially expressed with the highest fold changes were summarized in a heatmap (Figure 3-7). This dataset comprises a highly comprehensive amount of data. Therefore only specific differentially expressed genes will be considered for the detailed description in the following paragraph.

The effects of a prolonged CD40L stimulation (24hrs) on Ramos BL cells have been investigated previously by Basso and colleagues. They thereby obtained information suitable to mirror potential CD40 associated processes in the course of the germinal centre reaction (Basso, Klein et al. 2004). The group around Basso used an older version of arrays and thus identified a lower number of differentially expressed genes. Nevertheless they identified comparable global changes in gene expression in response to CD40L stimulation of BL cells. This is for example expressed by the regulation of the same target genes (e.g. ICAM1, CD58, DUSP2 and ID1). This indicates that some genes are affected at earlier time points but are still detectable at later time points.

Furthermore in the study presented here it was observed that BCRx, CD40L and IL21 stimulation induce the largest changes in global gene expression profiles in BL2 cells. This observation is in line with the study of Zhu and colleagues from 2004 (Zhu, Hart et al. 2004). They investigated the gene expression changes in mouse splenic $B$ cells in response to the stimulation with CD40L, LPS, BCRx, BAFF and 29 additional single ligands. Zhu and colleagues as well identified $\mathrm{BCRx}$ as the most potent inducer of gene expression changes. In contrast to the marginal effects of LPS on the global gene expression profile of BL cells, Zhu and colleagues observed a change in gene expression in response to LPS that is comparable to anti-lgM treatment. This could be explained by the distinct cell systems used. Zhu and colleagues used primary mouse B cells whereas the presented study focuses on the effects of the distinct stimuli on lymphoma cells. 


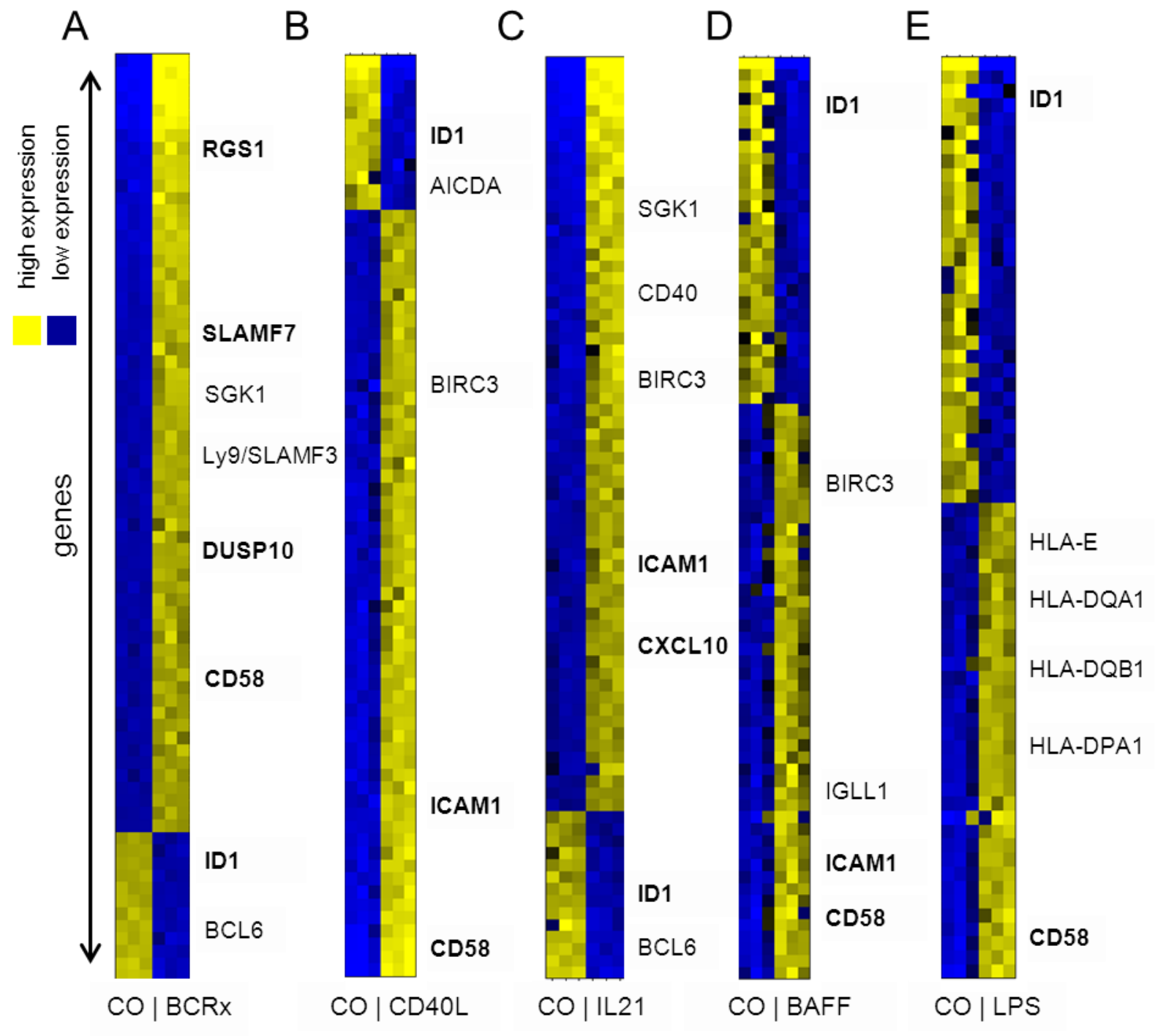

Figure 3-7 Identification of anti-IgM (BCRx), CD40L, IL-21, BAFF and LPS regulated genes in BL cells using microarrays. BL2 cell were stimulated as described in Figure 3-6 with $\mathbf{A}$ anti $\operatorname{lgM~F}(\mathrm{ab})_{2}$ fragment (3hrs), B CD40L (6hrs), C IL21 (2hrs), D BAFF (9hrs) and E LPS (6hrs). RNAs from these cells were used to perform whole genome gene expression profiling on Affymetrix HGU-133 plus 2.0 microarray chips. These heatmaps show the TOP 100 most highly changed genes (adj. p-value $\leq 0.05$ ) in response to each stimulus. As distinct microarray chips were used for the microarray analyses of cell perturbation and patient samples (Affymetrix HGU$133 \mathrm{~A}$ and HGU-133 plus2.0), the list of TOP100 genes had to be adapted to be able to transfer the resulting genes to patient data (see below for additional details). Therefore the lists were shortened since not all probesets were present on both array platforms (BCRx (74 genes), sCD40L (71 genes), rhBAFF (77 genes), rhIL21 (77 genes) and LPS (66 genes)). Each row in the heatmaps represents a gene and each column represents a microarray sample. Yellow and blue indicate high and low expression, respectively. 


\subsubsection{Distinct stimuli induce the differential expression of overlapping as well as specific target genes}

As shown in chapter 3.2.1 BL2 cells activate overlapping as well as specific signalling pathways upon stimulation. Overlapping pathways include for example the activation of $\mathrm{p} 38$ by $\mathrm{BCRx}$ and $\mathrm{CD} 40 \mathrm{~L}$, the activation of noncanonical NF-KB by CD40L and to lesser extent by BAFF. Furthermore JNK is commonly activated by CD40L and BCRx. Pathways that are specifically activated by one stimulus include for example the activation of $\mathrm{Ca2+}$, ERK and PI3K by BCRx or the activation of JAK-STAT signalling by IL21. Corresponding to this observation in the following paragraph differentially expressed genes which are specifically affected only by one of the stimuli as well as differentially expressed genes which are regulated in response to more than one stimulus will be analysed in more detail. Therefore the lists of genes showing the highest differential expression (see table A2- A6 in the Appendix) in response to BCRx, CD40L, IL21 and BAFF were compared. To allow an overview of genes that are affected on high levels in response to the stimulation the lists of the TOP regulated genes were used for a comparison using Venny (Oliveros 2007) (Figure 3-8 and 3-9). As BCRx, CD40L and IL21 stimulation affect a significantly higher number of genes some of the considered overlapping / specific genes could not be depicted in the utilized Venn Diagrams for all stimuli.

BL2 cells upregulate the expression of ICAM1 in response to all utilized stimuli (Figure 3-8 and supplementary tables 1-5). ICAM1 has been described as classical NF-KB target as well as a STAT1 target gene (Audette, Larouche et al. 2001; Klapproth, Sander et al. 2009). BCRx affected genes furthermore include for example like $C D 58$. $C D 58$ expression is as well upregulated in response to CD40L, BAFF, LPS stimulation, but not affected by IL21 stimulation (Figure 3-8). Genes upregulated by BCR activation as well include several factors involved in negative feedback loops, necessary for shutting down specific pathways. These include DUSP1, DUSP2, DUSP5, DUSP10, DUSP16 and DUSP22 (Figure 3-8, supplementary table 1), that can dephosphorylate and thereby inhibit MAPKs (Keyse 2008). It can be observed that CD40 and LPS stimulation as well mediate the upregulation of DUSP22 (supplementary tables $2 \& 5$ ). Interestingly a high 
overlap can be observed comparing the lists of genes affected by BCRx and IL21 stimulation. IL21 stimulation for example as well induces the upregulation of DUSP2 expression (Figure 3-8).

Additionally genes have been identified that are upregulated solely by one of the utilized stimuli. BCRx specifically affects genes which are involved in other feedback regulatory mechanisms. One of the strongest upregulated genes in response to BCRx is RGS1 (Figure 3-8), which encodes a factor that can diminish the signalling activity of G-protein coupled receptors by binding to activated, GTP-bound G-alpha subunits (Blumer 2004). Factors that negatively regulate NF-KB signalling like TNFAIP3/A20 are as well upregulated in response to BCRx (supplementary table 1). Interestingly IL21 stimulation upregulates the expression of BCL3 which is a negative modulator of NF-KB signalling (Figure 38) (Zhang, Didonato et al. 1994). Thus IL21 could probably affect NF-kB signalling mediated by other stimuli.

Remarkably SLAMF7 is found to be strongly upregulated upon BCR activation. SLAMF7 is a lymphocyte cell surface signalling molecule which has been shown to be transcriptionally upregulated in response to anti-IgM treatment of Ramos cells and to induce proliferation and autocrine cytokine signalling in human $B$ lymphocytes (Lee, Mathew et al. 2007) (Figure 3-8). The chemokine CXCL10 is upregulated in response to rhIL21 stimulation (Figure 3-8). CXCL10 has been implicated in the regulation of the host immune response to the tumour (Wendel, Galani et al. 2008). 


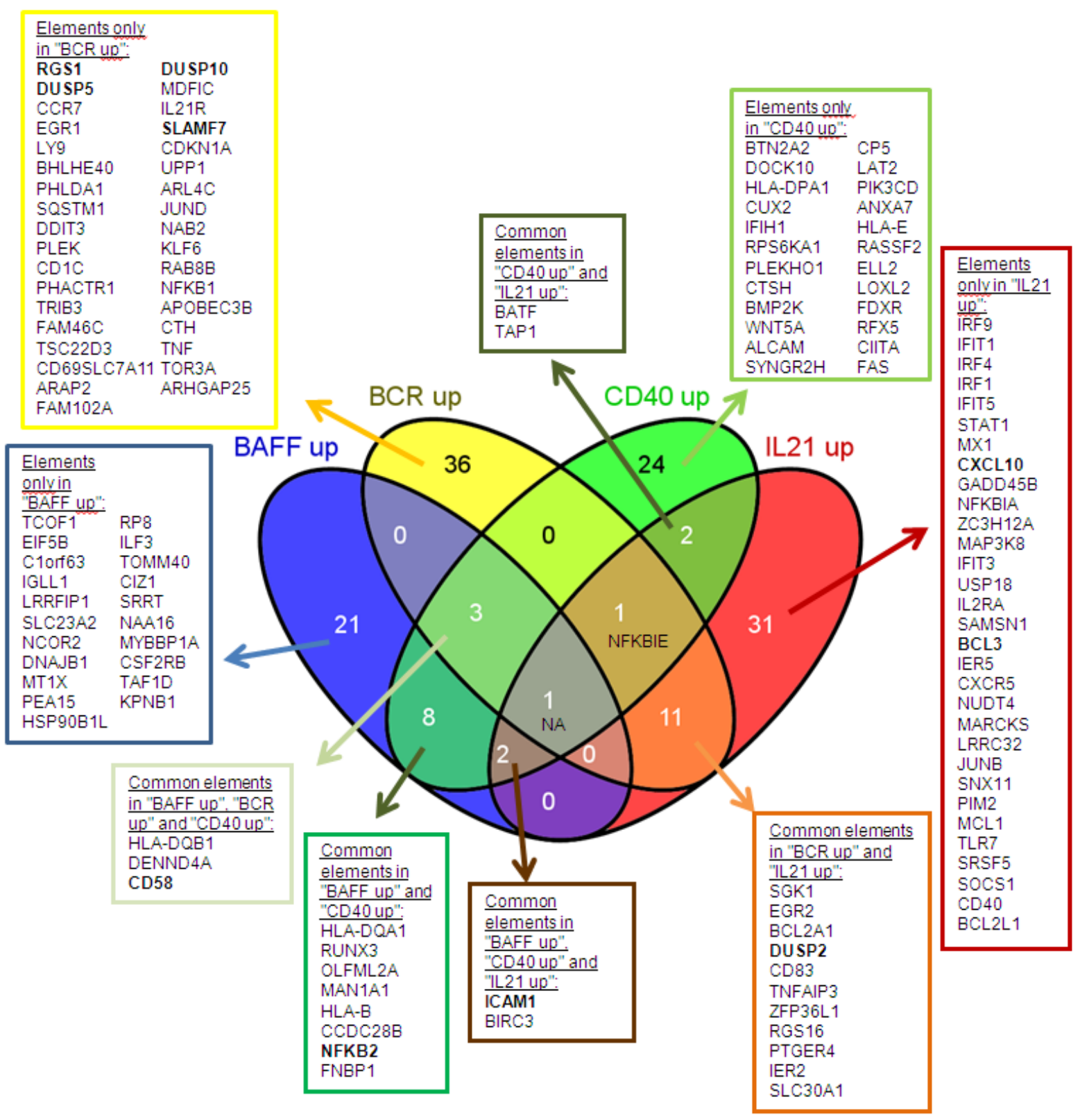

Figure 3-8 Overview of high responsive overlapping and stimulus specific genes upregulated in response to BCRx, CD40L, rhBAFF and rhIL21. The lists of genes showing the highest differential expression in response to stimulation (see Appendix table A2, A3, A4, A5) were compared. This comparison was made using VENNY (Oliveros 2007). Genes upregulated in response to BAFF stimulation are represented in the blue ellipsoid $(\mathrm{BCR}=$ yellow, CD40L $=$ green, IL21 = red). The overlaps of the gene lists are represented by overlaps of the respective ellipsoids. The number of genes in the respective overlap is indicated.

Generally fewer genes are found to be negatively affected in response to the respective stimulation (Figure 3-9). These include for example the inhibition of ID1, ID3 and ID4 expression by all of the utilized stimuli. Furthermore the inhibition BCL6 expression can be observed in response to BCR activation or 
rhIL21 stimulation (Figure 3-9). Interestingly, the expression of MYC was found to be inhibited in response to the activation of the BCR and will be analysed in more detail in the next paragraphs (supplementary table 1).

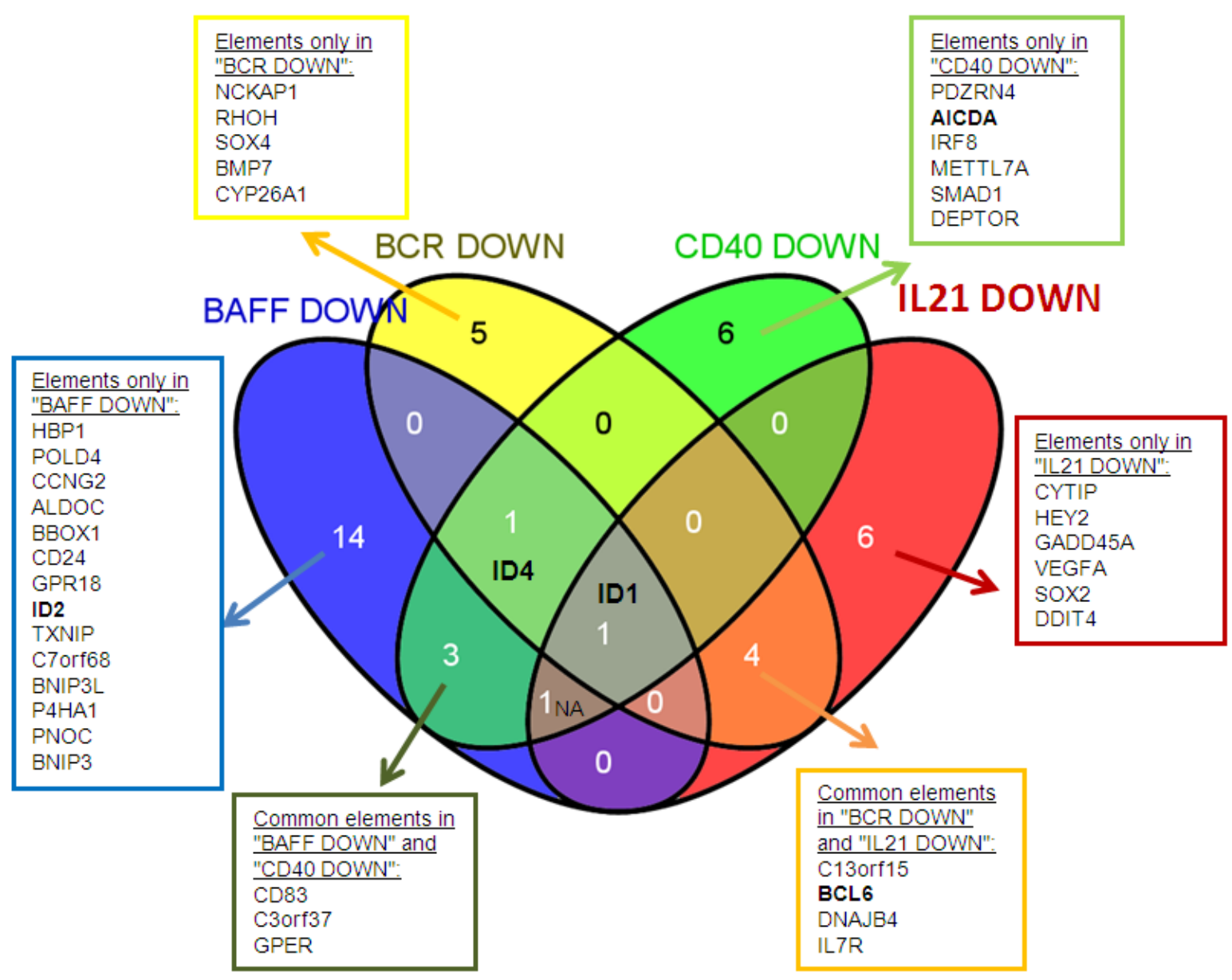

Figure 3-9 Overview of high responsive overlapping and stimulus specific genes downregulated in response to BCRx, CD40L, rhBAFF and rhIL21. The lists of genes showing the highest differential expression in response to stimulation (see Appendix table A2, A3, A4, A5) were compared. This comparison was made using VENNY (Oliveros 2007). For a detailed description see Figure 3-8.

Furthermore it was observed that distinct stimuli change the expression of the same gene in a different way. The expression of AICDA for example, is inhibited upon BCRx and CD40L stimulation, but activated upon IL21 stimulation (Figure 3-9 and supplementary tables $1 \& 3$ ). Thus is seems to be that the capacity of BL cells to undergo somatic hypermutations can be modulated by paracrine factors. 


\subsubsection{Investigation of differential gene expression using qRT-PCR}

The regulation of a set of genes presented above was investigated using qRT-PCR of two independent stimulations (Figure 3-10 A-K). Stimulation was performed as described for the microarray experiments.

It was observed that ID1 expression is strongly inhibited in response to all utilized stimuli thus supporting the microarray analyses (Figure 3-10 A). It was found that ICAM1 expression is activated by all utilized stimuli. The IL21 stimulation has the highest impact on ICAM1 activation suggesting a dominant function for JAK/STAT signalling for the regulation of this gene (Figure 3-10 B). CD58 is activated dominantly by $\mathrm{CD} 40 \mathrm{~L}$ and $\mathrm{BCRx}$ treatment and to a lower extent by LPS and BAFF stimulation (Figure 3-10 C). Since various DUSPs have been identified as target genes the expression of DUSP2, DUSP5, DUSP10 and DUSP22 was investigated more detailed. DUSP2 expression is found to be activated marginally by rhIL21 and strongly by BCRx. This is in line with the obtained array data (Figure 3-10 D). It can be observed that DUSP5 expression is induced by BCRx (Figure 3-10 E). Comparable to the effects on DUSP2 expression, DUSP10 expression is activated in response to $\mathrm{BCRx}$ and marginally in response to IL21 stimulation (Figure 3-10 F). For DUSP22 it can be observed that the activation of CD40 and BCR induces a 2 fold higher expression (Figure 3-10 G), whereas IL21 and LPS stimulation induce only a marginal increase of DUSP22 mRNA levels. As previously shown the expression of MYC is found to be inhibited upon BCRx treatment. This is verified by qRT-PCR demonstrating a up to two fold decreased expression of $M Y C$ in response to BCR activation (Figure 3-10 H). Furthermore it is confirmed that this inhibition is a BCRx specific effect, which is not mediated by any of the other utilized stimuli. Additionally the expression of CXCL10 was investigated. CXCL10 expression is found to be prominently activated by IL21 stimulation, but also affected by SCD40L and LPS stimulation. (Figure 3-10 I). BCRx strongly induces the expression of SLAMF7 and RGS1. This consolidates the studies performed by others (Lee; Jamal) (Figure 3-10 J\&K). The results presented here show one representative experiment out of two. As these replicates are highly reproducible and as well comparable to the microarray results only two replicates were performed. 
These analyses show that the effects observed on the expression ID1, ICAM1, CD58, MYC as well as SLAMF7 and RGS1 detected by microarrays analyses can be confirmed in an independent experiment using qRT-PCR analyses. This holds as well true for the observed effects on the expression of the group of DUSPs.
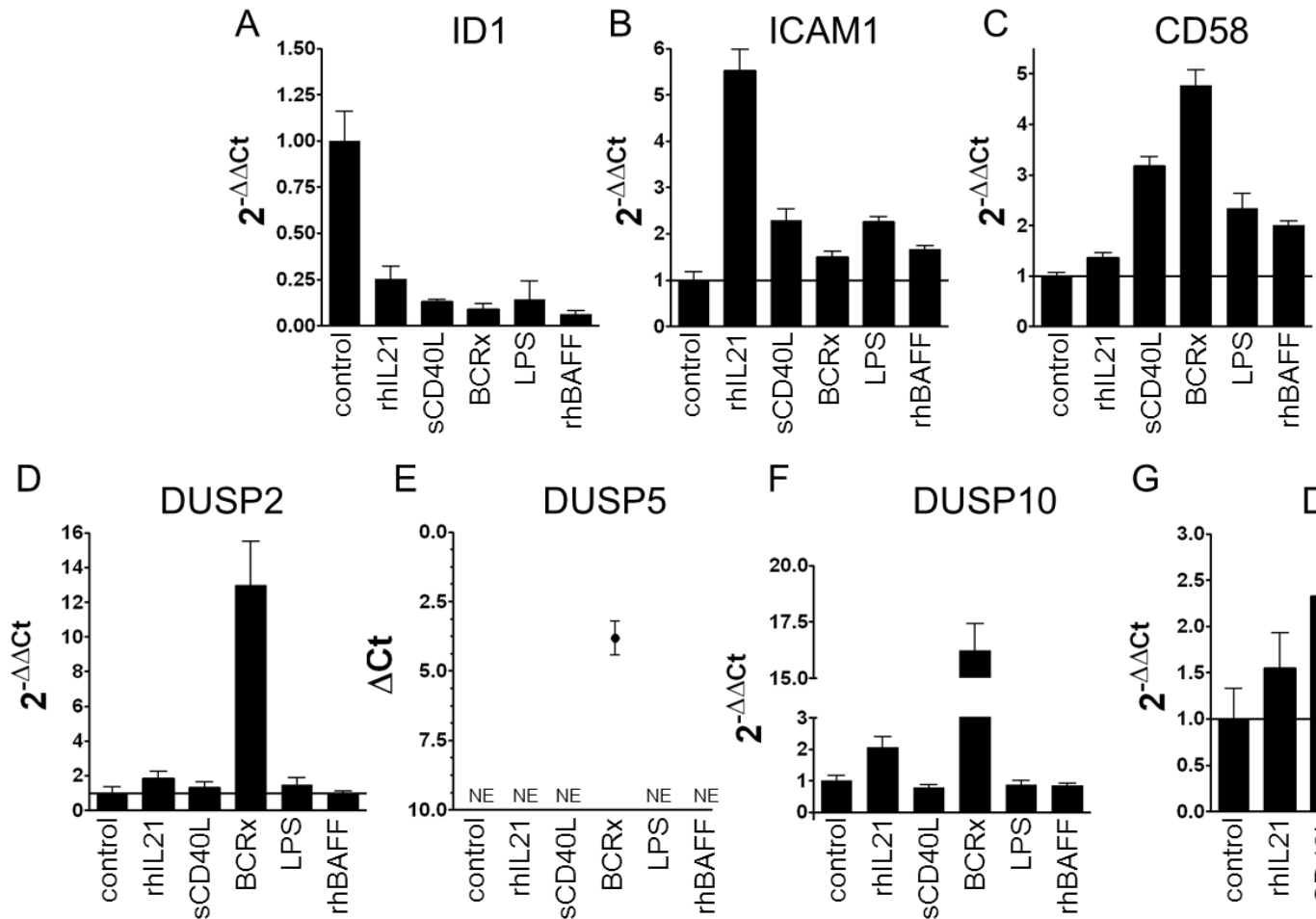

$E$

DUSP5

$\mathrm{F}$

DUSP10

G
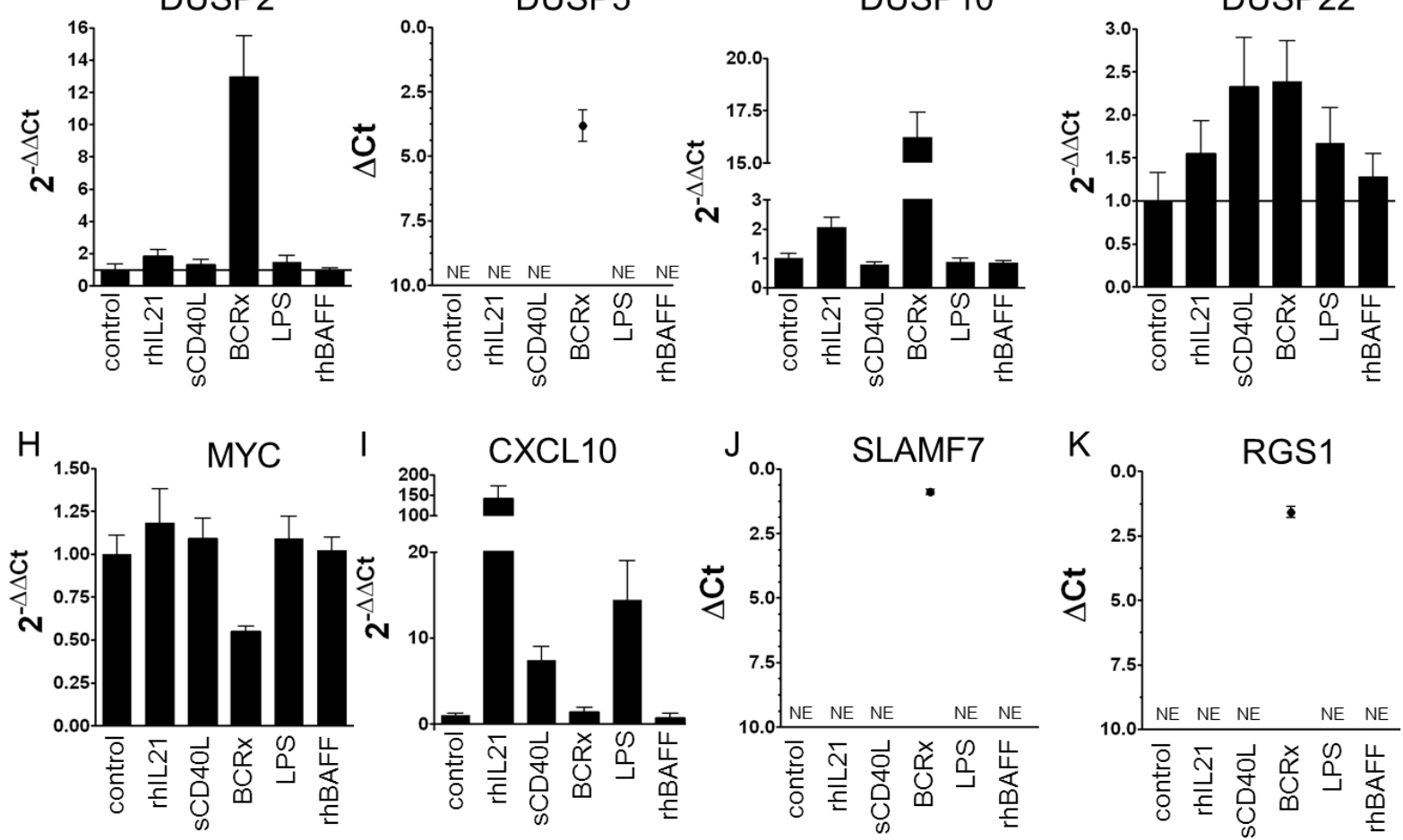

Figure 3-10 qRT-PCR analyses of the expression of a selection of genes after respective stimulation. BL2 cells were stimulated as described in Figure 3-7. One representative experiment out of two is shown. All samples were analysed in triplicates. Results are presented as $2^{-\triangle \Delta C T}$ or $\triangle C T$ values, relative to abl housekeeper expression and compared to unstimulated control. N.E. $=$ Not Expressed $(\triangle \mathrm{Ct}>10) \mathbf{A} I D 1 \mathrm{~B} I C A M 1 \mathrm{C} C D 58$. D DUSP2 E DUSP5 (basal $\triangle \mathrm{Ct}>10$ ) F DUSP10 G DUSP22 H MYC I CXCL10 J SLAMF7 (basal $\triangle \mathrm{Ct}>10$ ) K RGS1 (basal $\Delta \mathrm{Ct}>10)$. 


\subsubsection{Stimulation mediated gene expression changes in lymphoma precursor cells}

So far gene expression changes induced by BCRx, CD40L, IL21, BAFF and LPS have been described in BL2 cells. BL cells are used as B cell model in numerous studies as they are very close to GC B cells with respect to their differentiation status (Basso, Klein et al. 2004; Laskov, Berger et al. 2005; Ci, Polo et al. 2009). Nevertheless BL cells are transformed cells that harbour an aberrant $\mathrm{C}-\mathrm{Myc}$ activity. To test whether BCRx, CD40L, IL21 and BAFF stimulation can mediate the differential expression of selected target genes in a distinct cell system that is close to lymphoma precursor cells, primary human tonsillar CD10+ B cells were used for further stimulation experiments. Effects of CD40 and BCR activation as well as IL21 and BAFF stimulation on the expression of a selected set of were investigated. Primary human tonsillar $\mathrm{CD} 10^{+} \mathrm{B}$ cells were isolated according to Vockerodt and colleagues (Vockerodt, Morgan et al. 2008; Vrzalikova, Vockerodt et al. 2011) from 6 distinct tonsillar specimens of paediatric patients (T96, T97, T98, T99, T101, T102). GC B cells were stimulated with 200ng/ml sCD40L, 1.3 $\mu \mathrm{g} / \mathrm{ml}$ anti-lgM/anti-lgG $\mathrm{F}(\mathrm{ab})_{2}$ fragments, $100 \mathrm{ng} / \mathrm{ml}$ rhlL21 and 100ng/ml rhBAFF for $3 \mathrm{hrs}$.

It was tested for the effects on ICAM1 as dominantly regulated target gene. As only limited information is available so far regarding the regulation of DUSPs in human B cells, the effects of stimulation on DUSP2, DUSP5, DUSP10 and DUSP22 were investigated. Furthermore in BL2 cells BCRx mediates the differential expression of MYC and SLAMF7. It was tested whether the observed effects on the expression of these genes were transferable to non-malignant primary B cells (Figure 3-11).

It can be observed that ICAM1 expression is significantly activated in all investigated biological replicates in response to SCD40L stimulation (Figure 3$11 \mathrm{~A})$. It was found that BCRx has a rather inhibitory effect on ICAM1 expression in 2 of 6 biological replicates. Taking all biological replicates into account, this effect is not significant. The activatory effect of rhIL21 on ICAM1 expression can be significantly shown in $\mathrm{CD} 10^{+} \mathrm{B}$ cells. rhBAFF treatment has no effect on the expression of ICAM1. These results are not directly comparable to the effects 
observed in BL cells, where all stimuli lead to an upregulation of ICAM1 expression. The expression of DUSP2 is activated in response to CD40 and BCR activation in different biological replicates of stimulated $\mathrm{CD} 10^{+} \mathrm{B}$ cells to varying degrees (Figure 3-11 B). Taking into account the high variability between the biological replicates, only the BCR mediated activation of DUSP2 expression is statistically significant. The stimulation with rhIL21 has a small inhibitory effect on the expression of DUSP2, which is consistent over the distinct replicates. The expression of DUSP5 is affected on low levels by BCR crosslink (Figure 3-11 C). DUSP10 expression is reproducibly activated in response to BCRx (Figure 3-11 D). The expression of DUSP22 is highly variable comparing the distinct tonsillar preparations. Two of the samples show an activation of DUSP22 expression in response to CD40 activation (Figure 3-11 E). Nevertheless it can only be observed in some of the biological replicates. It can be shown that MYC expression is significantly activated in response to CD40 and BCR activation (Figure 3-13 F). This observed upregulation of $M Y C$ is opposite to the inhibitory effect of BCRx on MYC expression in BL cells. SLAMF7 expression is activated significantly and solely in response to BCRx (Figure 3-13 G).

In summary it was observed that DUSP10 as well as SLAMF7 are reproducibly activated in response to $\mathrm{BCRx}$, whereas the activation of $M Y C$ or ICAM1 seems to be context depended and therefore different in distinct biological replicates. Overall these results show that some stimulus mediated gene expression changes are indeed transferable to a distinct cell system. These include the regulation of DUSP2, DUSP5, DUSP10 and SLAMF7 in response to BCRx. Nevertheless some effects observed in BL cells in response to stimulation a cell specific. These include for example the inhibition of $M Y C$ expression in response to BCRx. 
A

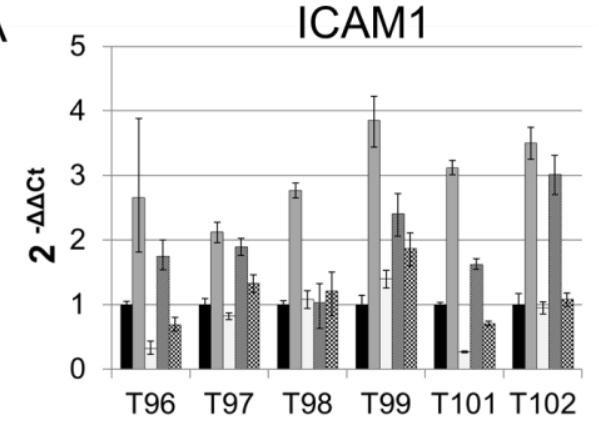

B

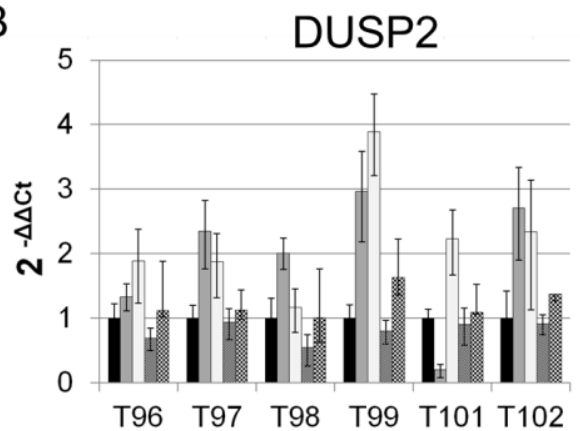

D

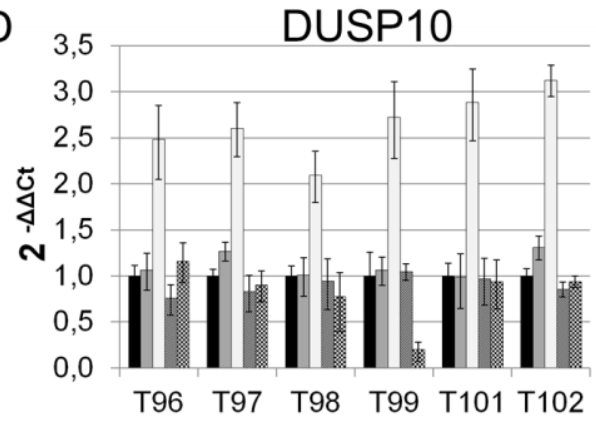

F

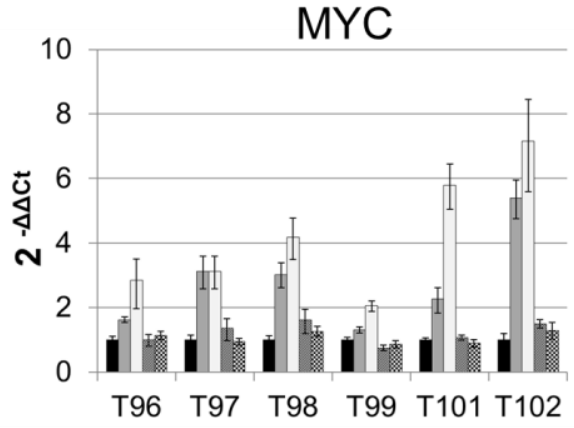

- control

- sCD40L

BCRx

rhIL21

BAFF

C

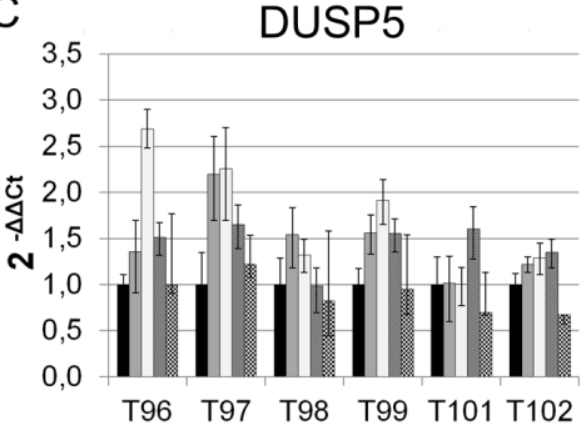

E

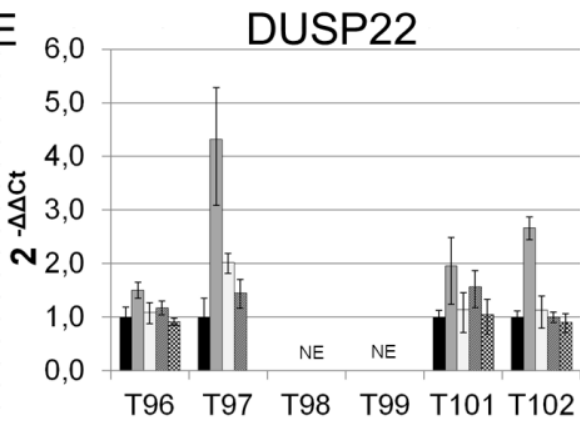

G

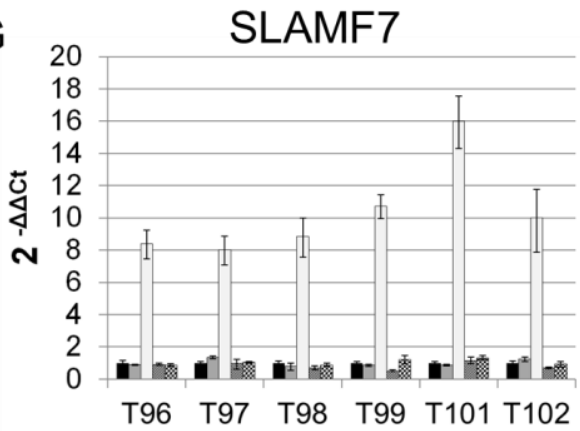

Figure 3-11 Expression of ICAM1, DUSP2, DUSP5, DUSP10, DUSP22 and MYC, SLAMF7 in $\mathrm{CD}^{+} 0^{+}$germinal centre $\mathrm{B}$ cells in response to SCD40L, BCRX, rhIL21 and rhBAFF stimulation CD10+ B cells from distinct tonsillar preparations (T96, T97, T98, T99, T101, T102) were stimulated with $100 \mathrm{ng} / \mathrm{ml} \mathrm{rhlL2} 1,200 \mathrm{ng} / \mathrm{ml} \mathrm{sCD} 40 \mathrm{~L}, 1.3 \mu \mathrm{g} / \mathrm{ml}$ anti $\mathrm{lgM} / \mathrm{anti} \operatorname{lgG} \mathrm{F}(\mathrm{ab})_{2}$ fragments and rhBAFF for $3 \mathrm{hrs}$. Effects are depicted as $\Delta \Delta \mathrm{Ct}$ values normalized to $32 \mathrm{~m}$ expression and relative to the unstimulated control ( $N E=$ not expressed). The statistical significance of the differences in gene expression was calculated for each gene and stimulation separately, using the two paired t-test. A ICAM1 expression in affected by CD40 ( $p=0.0005)$ and IL21 $(p=0.0186)$. B DUSP2 expression is affected by BCRx $(p=0.0209)$ and IL21 $(p=0.0138)$ C DUSP5 expression is affected by BCRx $(p=0.0378)$. D DUSP10 expression is affected by BCRx $(p<0.0001)$. E DUSP22 expression is highly variable and not affected by any stimulation. F MYC expression is affected by BCRx $(p=0.0101)$ and CD40 $(p=0.0306)$. G SLAMF7 expression is affected by BCRx $(p=0.0006)$. 


\subsubsection{Activated expression of DUSP2, DUSP5, DUSP10 and DUSP22}

\section{through BCR is dominantly mediated by ERK activation in contrast to MYC activation that is dominantly involves PI3K}

The genes encoding for DUSP family members are predominantly affected by an activation of the BCR. These effects are in the main observable in BL cells as well as in primary human GC B cells. To elucidate the pathways involved in the regulation of DUSPs in response to BCRx the expression of DUSP2, DUSP5 and DUSP10 was investigated in cells pre-treated with inhibitors targeting specific $\mathrm{BCRx}$ pathways components. As the inhibition of $M Y C$ expression in response to $B C R x$ is a $B L$ cell specific phenomenon that cannot be observed in normal $B$ cells (see Figure 3-10 and 3-11) it would be interesting to investigate the pathway that is involved in the regulation of translocated MYC.

The pathway components that were considered for the NF-kB pathway include TAK1, and IKK2. The following specific chemical inhibitors, well known from the literature, were used: 5Z-7-oxozeaenol (TAK1) (Ninomiya-Tsuji, Kajino et al. 2003) and IKK2 inhibitor VIII (IKK2) (Sanda, lida et al. 2005). To affect MAPKsignalling, SB203580 (p38 MAPK) (Cuenda, Rouse et al. 1995), SP600125 (JNK MAPK) (Bennett, Sasaki et al. 2001) and U0126 (ERK MAPK) (Favata, Horiuchi et al. 1998) were used. It has to be noted that under some conditions TAK1 is also part of MAPK signalling. To inhibit PI3K Ly294002 was used (Vlahos, Matter et al. 1994). To affect $\mathrm{Ca}^{2+} / \mathrm{NFAT}$ a peptide inhibitor (VIVIT) was utilized (Aramburu, Yaffe et al. 1999).

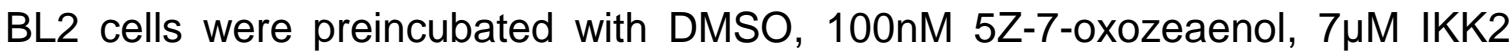

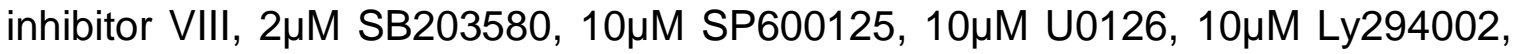
or $2.5 \mu \mathrm{M}$ VIVIT for 3hrs. Subsequently respective amounts of anti-IgM were added for additional 3 hrs. Cells were harvested and RNA was isolated for qRTPCR. One representative experiment out of three is shown in Figure 3-12.

Using this approach was shown that the activation of DUSP2 expression by $\mathrm{BCRx}$ is abolished in cells treated with ERK inhibitor U016 indicating the involvement of the Erk-pathway in this process (Figure 3-12 A). The induction of DUSP5 expression in response to BCRx is diminished in cells treated with TAK1i, 
JNKi and completely abolished in cells treated with ERKi (Figure 3-12 B). Thus the ERK-pathway is dominantly involved, whereas JNK and TAK1 are influencing the induction of DUSP5 only partially. The activation of DUSP10 is reproducibly diminished in cells treated with Pi3Ki and ERKi supporting an involvement of PI3K and ERK signalling in the activation of DUSP10 expression by BCRx (Figure 3-12 C).

These data show that BCRx mediated induction or activation of DUSPS2, DUSP5 or DUSP10 are predominantly conducted via the activation of ERK. However, to regulate DUSP5 and DUSP10 expression through BCR TAK1, JNK or PI3K signalling events have to be taken into account.
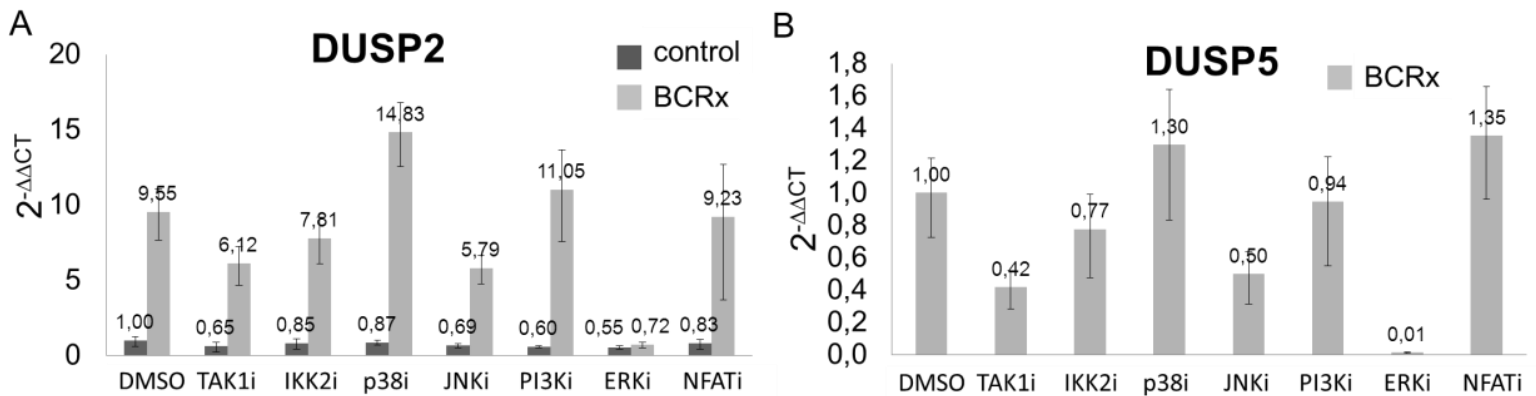

C

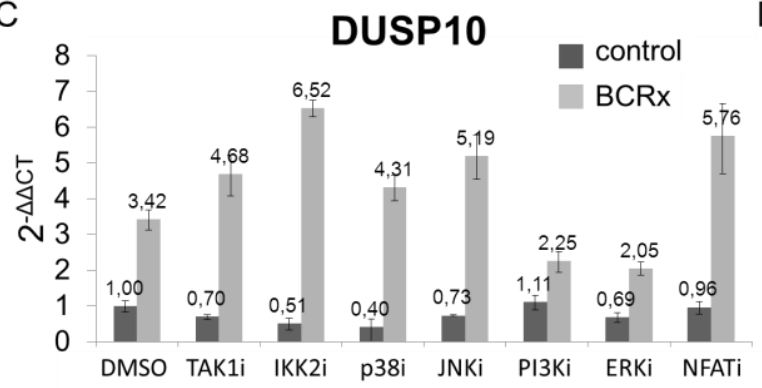

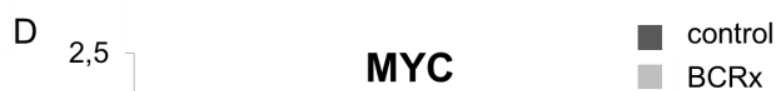

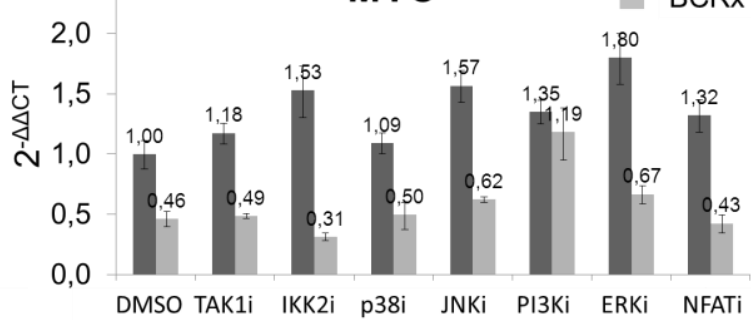

Figure 3-12 Pathways involved in the regulation of DUSP5, DUSP2 and DUSP10 as well as MYC in response to BCRx in BL cells. BL2 cells were pre-incubated with specific pathway inhibitors for 3hrs (for detailed information see Methods section chapter 2.12.6). $1.3 \mu \mathrm{g} / \mathrm{ml}$ anti$\operatorname{lgM~} \mathrm{F}(\mathrm{ab})_{2}$ fragments were added respectively and cells were harvested after additional $3 \mathrm{hrs}$ for qRT-PCR. A-D Expression of DUSP2, DUSP5 and DUSP10 and MYC. Results are presented as $2^{-\triangle \triangle C T}$ values, relative to abl housekeeper expression and compared to unstimulated DMSO control. As DUSP5 expression (B) is below detectable levels in unstimulated probes, only $\triangle \mathrm{Ct}$ values of stimulated probes relative to DMSO control were compared. One representative experiment out of three biological replicates is shown.

The suppression of the aberrant $M Y C$ gene expression in BL cells in response to BCRx is dependent on PI3K activity as demonstrated by the reversal of the BCRx mediated inhibition by the PI3K inhibitor Ly294002 (Figure 3-12 D). In the future additional and alternative inhibitors have to be used to investigate the observed 
involvements of specific kinases for the expression of DUSPS 2,5,10 and MYC. In addition it would be necessary to use RNA-interference to dissect the respective mechanisms in more detail.

From picture 3-12 it becomes obvious that in some cases the inhibitor treatment is associated with an enhanced gene expression after the BCRx. Thus for example the expression of DUPS2 is enhanced comparing cells treated with antiIgM antibody and cells treated together with anti-IgM antibody and SB203580 (p38i). A comparable observation is made for DUSP10, where the inhibition of IKK2 is associated with a two-fold higher expression after BCRx. Whether the observed effects of TAKi, SB203580, SP600125 or VIVIT are significant remains to be elucidated by additional independent analyses in the future. However, the presented data already suggest the existence of tonic signalling in BL cells suppressing the capacity of the BCR activated pathways to regulate a set of genes as shown here for DUSPs and MYC. Perceptively such an approach could be used to clarify networks of pathways that interact and depend on each other. This dependency would be reflected in a combined abolishment of gene regulation in cells treated with distinct pathway inhibitors (e.g. TAK1 and p38 as TAK1 is upstream of p38).

\subsection{7 rhBAFF stimulation induces differential p38 signals in cell lines of distinct lymphoma entities independent of BAFF receptor expression}

As described above it was observed that the stimulation of $B L$ cells with recombinant BAFF induces a predominant activation of $\mathrm{p38}$, rather than a strong activation of the noncanonical NF-KB signalling as previously described ( $(\mathrm{He}$, Chadburn et al. 2004; Mackay, Sierro et al. 2005; Mackay and Leung 2006). Therefore it was tested whether this observed pathway specificity is limited to BL cells or can be observed also in DLBCL cells.

The activation of p38 MAPK signalling was detected using immunoblot analyses to visualize phosphorylation of $\mathrm{p38}$ after short time points of stimulation. It was found that both $B L$ cell lines (Ramos and BL2) respond to BAFF by a respective phosphorylation of p38 (Figure 3-13 A). BL2 and Ramos cells solely differed in the time point of highest p38 phosphorylation (30 min vs. $15 \mathrm{~min}$ respectively). The 
activation of p38 by BL16 was utilized as positive control, as it has been shown previously that these cells are capable of activating p38 in response to BAFF stimulation (He, Chadburn et al. 2004). Compared to the observed effect on p38 in BL cells the DLBCL cell lines SUDHL4 and SUDHL6 show very low levels of basal p38 activity and no induction of p38 phosphorylation upon BAFF stimulation (Figure 3-13 A).

As described in chapter 3.2.1, BAFF stimulation induces a rather weak activation of the noncanonical NF-kB pathway. To investigate the possible differences in the capability of lymphoma cells to activate noncanonical NF-KB signalling BL and DLBCL cell lines were stimulated with BAFF for 9 and 24h. As marker for NF-KB activation the cleavage of p100 (inactive precursor of NFKB2) to p52 was monitored via immunoblot. It can be shown that the DLBCL cell lines SuDHL4 and SuDHL6 show high degradation of p100 to p52 after 9 hrs of stimulation with recombinant human BAFF (Figure 3-13 B). Compared to this effect, BL2 cells show only marginal levels of p52 after 9 hrs and 24 hrs. Ramos cells do not express p100 and therefore cannot activate NF-KB via this pathway (data not shown).

In a next step it was tested whether a variation in BAFF receptor expression might be the reason for the differences in BAFF response. BAFF-R and TACI expression were investigated via flow cytometry using fluorescently labelled antibodies. Unfortunately BCMA expression could not be investigated due to the lack of the availability of appropriate antibodies. It was observed that $\mathrm{BL}$ and DLBCL cell lines are positive for the expression of both receptors (Figure 3-13 $C \& D)$. Additionally the mRNA expression of BAFF receptors was investigated using qRT-PCR. Ct values were related to the expression of the housekeeper beta2m. It was observed that the mRNA levels of BAFF-R are highly comparable in BL2, SuDHL4 and SuDHL6 cells (Figure 3-13 E1). Ramos cells showed lower expression of all three BAFF receptor mRNAs. Nevertheless it can be observed that BL2 and SUDHL6 cells show highly comparable levels of the expression of BAFF-R, TACI and BCMA on mRNA level (Figure 3-13 E). These data show, that differences in BAFF receptor equipment are not the basis for distinct responses to BAFF regarding the activation of $\mathrm{p} 38 \mathrm{MAPK}$. 
To get a better insight into the mechanisms leading to these differences additional comprehensive experiments are necessary. However, we decided not to continue this part of the project within the PhD thesis period. However our group started a series of experiments to answer the question whether these differences in BAFF mediated signals are dependent on the different BAFF protein variants. We ask whether the p38 activation specificity of $B L$ cells is still present using native soluble trimetric, 60mer forms or membrane bound BAFF for the stimulation of lymphoma cells. So far a feeder cell line has been developed by $\mathrm{K}$. Moses, that can be used for the stimulation of lymphoma cells with membrane bound and native soluble BAFF. Furthermore, a number of constitutive active BAFF receptor variants for BAFF-receptor (BR3), TACl or $B C M A$ have been cloned. This was realized by a fusion of the signalling domain of BR3, TACl and BCMA to the transmembrane domain of LMP1 following the example of CD40-LMP1 fusions (Hömig-Hölzel, Hojer et al. 2008). This will allow answering the question which receptor might be responsible for the activation of p38 in BL cells or NF-kB in DLBCL cells or NF-kB in DLBCL cells. To follow this issue it would be essential to clarify the role of BCMA for the activation of $p 38$ in BL cells (Gross, Johnston et al. 2000; Hatzoglou, Roussel et al. 2000). 

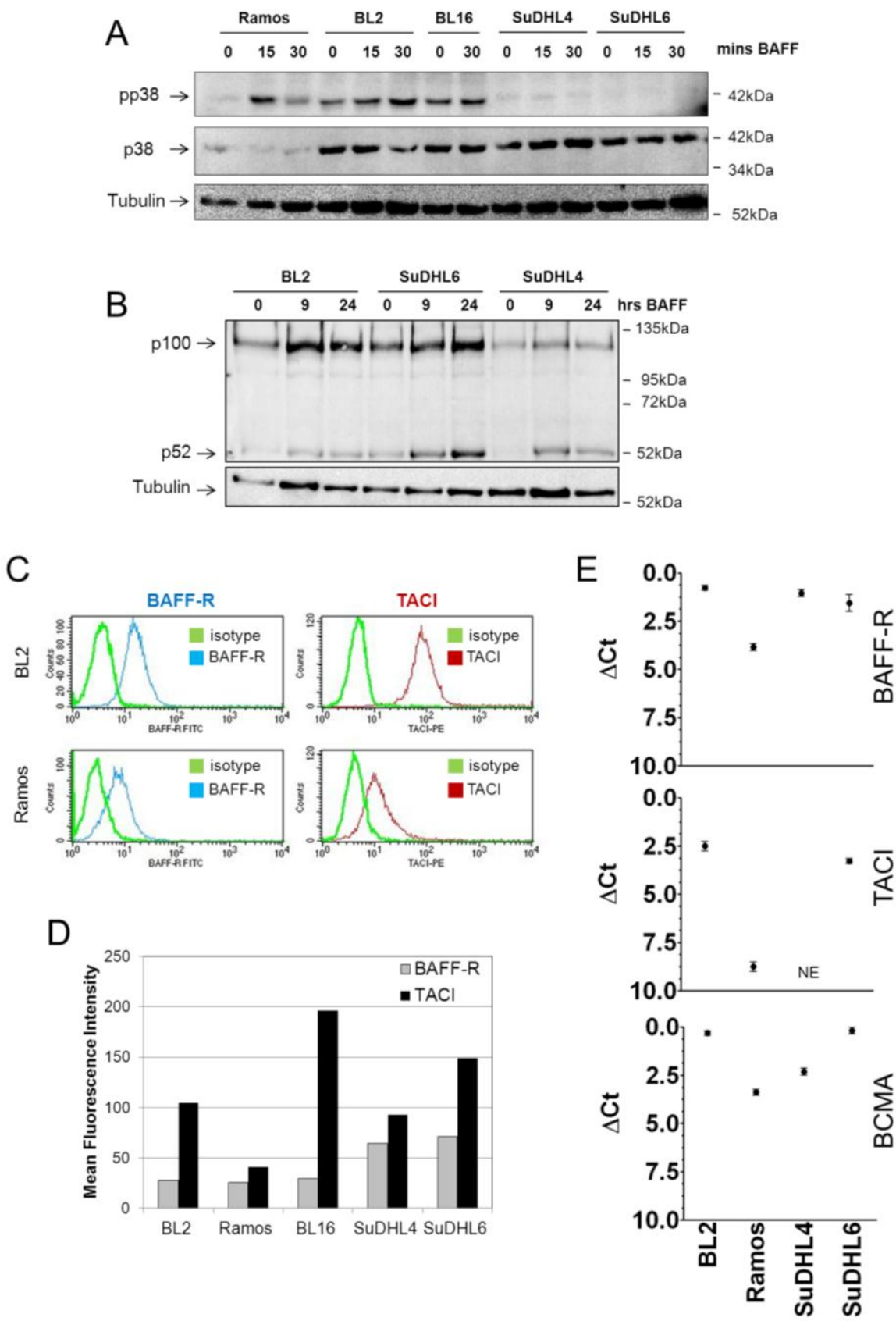

Figure 3-13 rhBAFF stimulation induces differential p38 signals in cell lines of distinct Iymphoma entities despite comparable receptor equipment A BL2, Ramos, BL16, SUDHL4 and SuDHL6 cells were stimulated with $100 \mathrm{ng} / \mathrm{ml}$ rhBAFF for 30 mins. p38 activity was detected using an anti pp38 specific antibody. B BL2, SuDHL4 and SuDHL6 cells were stimulated as described in A for 9 and $24 \mathrm{~h}$ respectively. Activation of the noncanonical NF-KB pathway was detected using an antibody that detects p100/p52 NFKB2. C\&D Surface expression of BAFF-R and TACI was detected on BL2, Ramos, BL16, SuDHL4 and SUDHL6 cells using flow cytometry. $D$ Mean fluorescence intensities of BAFF-R and TACl stained cells are compared. E Expression of BAFF-R, TACl and BCMA mRNA was investigated in BL2, Ramos, SuDHL4 and SUDHL6 cells using qRT-PCR. $\triangle \mathrm{Ct}$ values were calculated using beta2m expression as housekeeper ( $\mathrm{NE}=$ not expressed). 


\subsubsection{Individual aNHL gene expression profiles exhibit a high similarity to the gene expression profiles of in vitro stimulated BL cells, if globally changed genes are considered for this comparison}

To further proof the functional relevance of BCRx, CD40L, BAFF, IL-21 or LPS target genes identified in vitro, it was investigated how the genes, changed with the highest magnitude upon stimulation of $\mathrm{BL}$ cells (see tables $\mathrm{A} 2-\mathrm{A} 6$ in the appendix as well as Figures 3-7, 3-8 and 3-9), are expressed in gene expression profiles of 220 aNHL cases. The expression of these genes in gene expression profiles of aNHL cases is summarized in Figure 3-14. It was tested which subgroup of aNHL patients showed an "activated gene expression profile", meaning an expression of stimulus responsive genes similar to stimulated $\mathrm{BL}$ cells. This analysis reveals a relative similarity to the gene expression of stimulated BL cells for each patient sample. Lymphomas showing a high relative similarity of their gene expression to BL cells stimulated with BCRx, CD40L, BAFF, IL-21 or LPS show a higher evidence of respective pathway activity than those with a lower similarity. A high similarity to the respective stimulated gene expression profile will be simplified in the following as "activated pathway activity".

To analyse the characteristics of aNHL samples in more detail, their affiliation to the $\mathrm{mBL} /$ non-mBL and $\mathrm{ABC} / \mathrm{GCB}$ groups as well as their $M Y C$ status was plotted in a colour coded bar on top of the respective heatmap. A red bar represents a sample identified as $\mathrm{mBL}$, a yellow bar represents a sample identified as intermediate and a green bar on top of the heatmaps represents a non-mBL sample.

The comparison of gene expression profiles of aNHL cases according to the expression of stimulus responsive genes reveals that $\mathrm{mBL}$ cases show a pattern of gene expression that is, as expected, comparable to untreated BL2 (Figure 314 A-E). non-mBL cases however show an expression of these stimulus affected genes that is more or less comparable to the treated, activated BL2 cells. Intermediate cases show a transitional expression of stimulated genes. It can be observed that the expression of these genes changes in a continuous way over the aNHL samples. This gradient of pathway activities can be observed among 
non-mBL and intermediate lymphoma. This observation is in line with the observed presence of a chromosomal MYC-aberration (Figure 3-14 A-E). Lymphomas with a MYC-translocation are depleted in all comparisons from those lymphomas characterised by a high pathway activity. Regarding the affiliation of patients to either $A B C$ or GCB DLBCL subgroups no clear picture can be observed. The expression of all stimulus regulated genes is not correlated with an enrichment of either $\mathrm{ABC}$ or GCB DLBCL cases.

One could conclude from this observation that the stimulation with BAFF, CD40L, anti-IgM $F(a b)_{2}$ fragments, IL21 and LPS shifts the gene expression profile of our $B L$ cell line towards a gene expression detectable in DLBCL cases. To elucidate whether the same cases show an activated gene expression profile disregarding the stimulus used the groups of patients showing an activated gene expression profile (55 cases; right border of the heatmaps) regarding the expression of BCRx, CD40, BAFF and IL21 affected genes were compared (Figure 3-15). Thereby it was observed that $45 \%$ of these cases are present in all compared groups. This means disregarding the stimulus used, about 25 lymphoma samples are characterised by a generalized activated gene expression profile. However this does not correspond to the $A B C / G C B$ subgrouping (Figure 3-14). Thus the categorization of aNHL patients according to the expression of these genes is highly insufficient. As one might notice the heatmaps depicted in Figure 3-14 appear rather noisy. This is a result of the high numbers of genes that are regulated in the cell system, but not differentially expressed among the distinct lymphoma cases. Therefore it would be better to focus on genes which are specifically regulated by only one of the stimuli to avoid redundancy of gene activities and to focus on genes which are on the other hand as well differentially expressed among distinct lymphoma samples. 

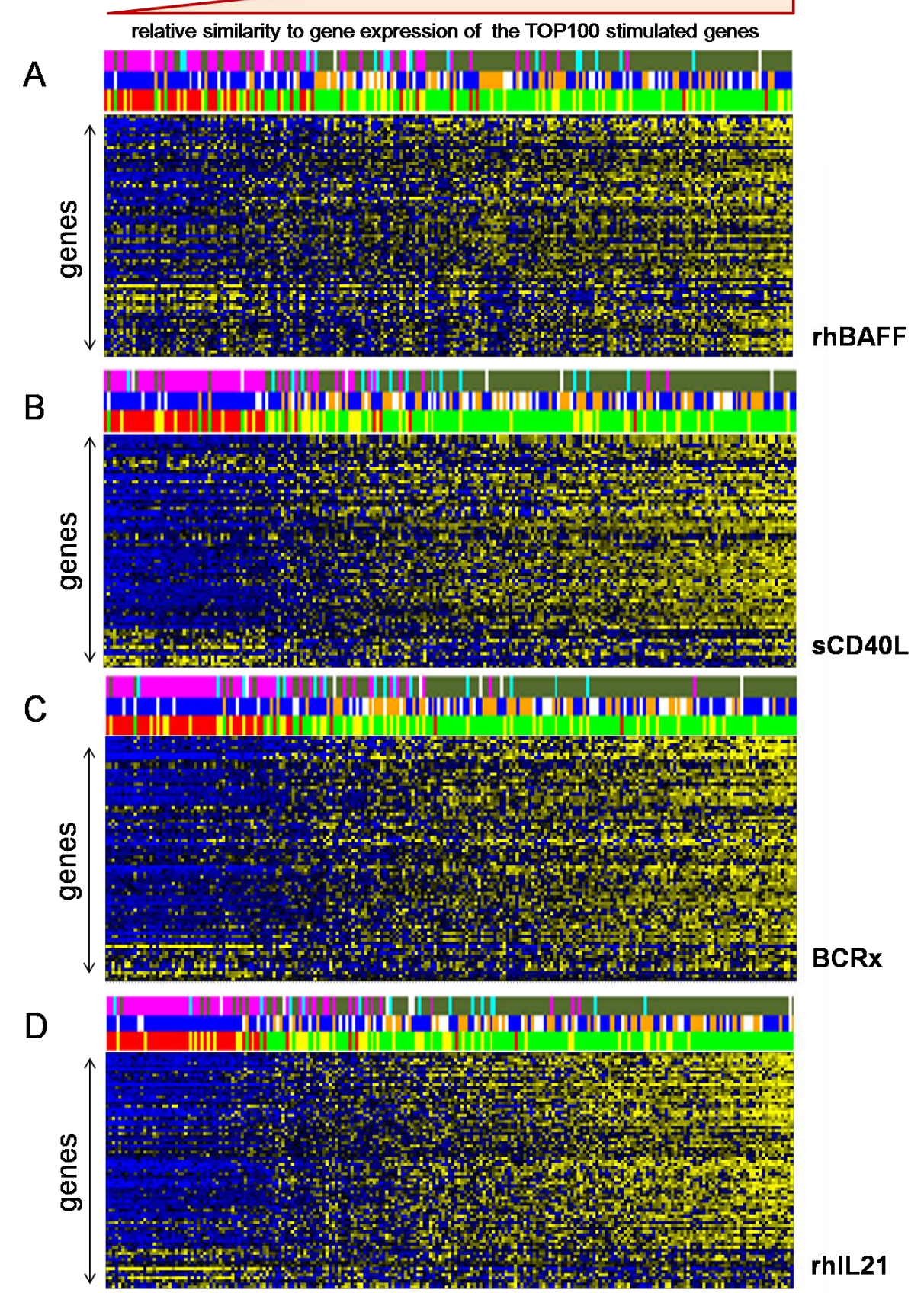
rhlL 21

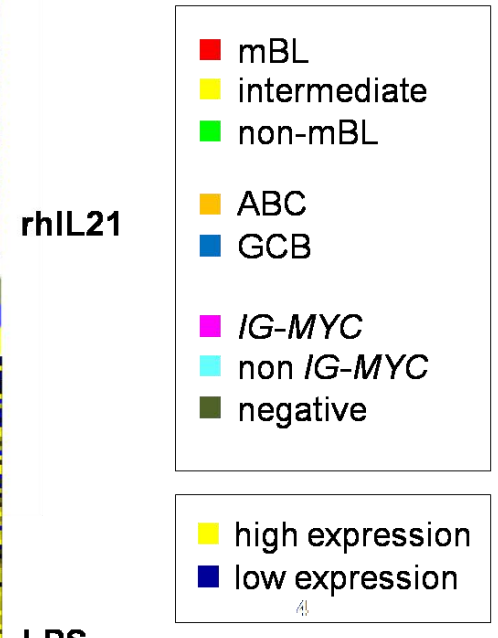

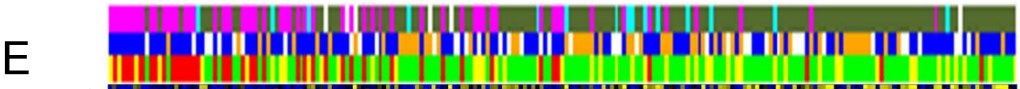

aNHL cases

Figure 3-14 (legend see next page) 
Figure 3-14 Expression of stimulus regulated genes in aNHL. The TOP100 most highly responding genes upon stimulation of BL2 with A rhBAFF, B sCD40L, C anti-lgM F(ab) 2, D rhIL21, fragments, E LPS and (see tables A2-A6 in the appendix) were investigated for their expression in the gene expression profiles of $220 \mathrm{aNHL}$ lymphoma cases (Hummel, Bentink et al. 2006). aNHL cases were ordered from left to right according to the similarity of gene expression to the stimulated status of BL2 cells. The Heatmaps display the expression of target genes (columns) across 220 lymphoma samples (rows). The colour bar above the heatmaps marks mBL in red, non-mBL in green and intermediate lymphoma in yellow. Furthermore the affiliation of samples to $A B C / G C B$ DLBCL subgroups and the presence of an IG-MYC translocation in encoded in a bar on top of the map (see legend for colour coding). Relative gene expression is encoded with yellow (high expression) and blue (low expression).

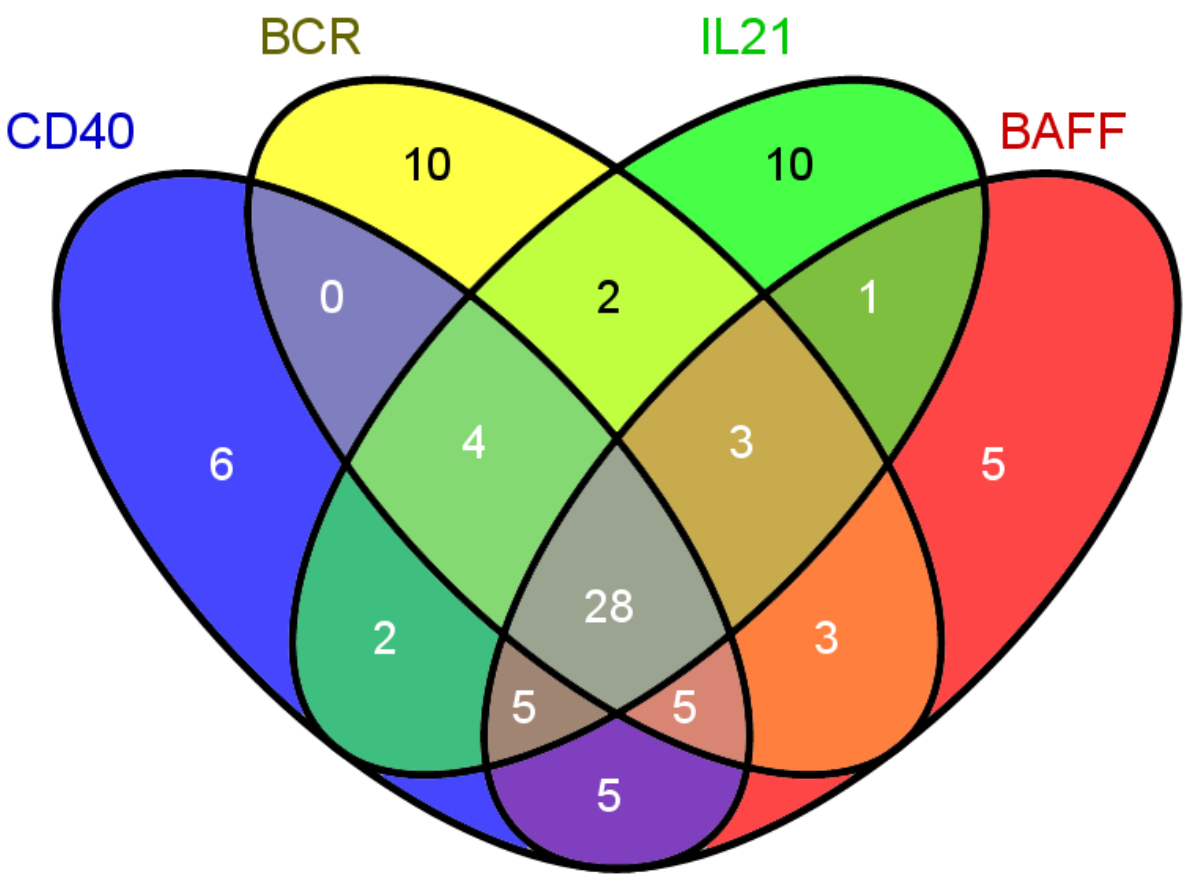

Figure 3-15 Comparison of the patient groups that show a gene expression profile of stimulus effected genes most closely to the activated gene expression profile of BL2 cells $55 \mathrm{aNHL}$ samples that show the highest similarity regarding their gene expression profile to the stimulated BL cells in response to CD40L, BCRx, IL21 and BAFF stimulation were compared using Venn Diagrams as described in Figure 3-8.

It was shown that the activation of BL cells with B cell specific microenvironmental factors triggers different global changes in gene expression patterns to some extend useful in describing pathway activity in individual lymphoma. Thereby a comprehensive repository of gene expression data for CD40L, BCRx, IL21, LPS and BAFF responsive genes in a transformed B cell line is provided. It was observed that anti-lgM treatment has the strongest 
capacity to modify gene expression. CD40L and IL21 show intermediate changes, whereas BAFF and LPS affect gene expression at lower levels.

Using qRT-PCR analyses it was verified that a number of genes are regulated by a combination of the used stimuli (e.g. ICAM1, CD58, ID1) or by specifically one of the utilized stimuli (e.g. MYC, SLAMF7). Furthermore, a selected set of genes involved in the control of negative feedback mechanisms was analysed in more detail (DUSPs). It was observed that the effects of BCRx on DUSPs are in principle transferable to non-malignant $B$ cells and predominantly mediated via ERK.

$\mathrm{BL}$ cells are characterised by an IG-MYC translocation and thus aberrantly express MYC. Interestingly an inhibitory effect of BCRx on MYC expression was observed. This seems to be specific for BL cells and is mediated via PI3K. In contrast, in primary human tonsillar CD10+ B cells CD40L and BCR are activating the expression of c-Myc. The findings presented here characterise the BCRx mediated effects as predominantly ERK and PI3K dependent, rather than NF-kB mediated. This seems to be in contrast to previous studies.

Furthermore, it was shown that upon stimulation highly affected genes are expressed in DLBCL cells with a high relative similarity. The group of lymphomas showing an activated gene expression profile is highly comparable disregarding the stimulus used. However, this generalized activated gene expression profile does not correspond to the $\mathrm{ABC}$ categorization and thus needs further investigations.

\subsection{Identification of pathway activities in aNHL using stimulation mediated gene expression changes detected by guided clustering}

As described above, aNHLs can be distinguished to some extend on molecular level using global gene expression profiling. In the previous paragraphs new insights into potential pathway activities in individual lymphoma have been pointed out. The described c-Myc index was found to be of prognostic significance. The above described relative similarities regarding the global gene expression between in vitro perturbated cells and primary lymphoma indicates 
the existence of a gradient of pathway activities. However, a real quantification of these activities and the explanation of their functional consequence are still missing.

In order to describe new gene clusters functionally associated to specific paracrine signalling factors, the differentially expressed genes in BL2 cells in response to BAFF, CD40L, IL21 and LPS stimulation as well as BCR activation were used. This data set seems to be well suitable as lymphoma cells activate overlapping but also distinguishing pathways in response to each stimulus. For a better understanding of the functional consequence of aberrant pathway activation in individual lymphomas it was decided to investigate subgroups of gene sets defined as dominantly affected by one of the stimulations described above, and at the same time not affected by any of the other stimuli. We believe that this approach is able to further narrow functional important pathway activities

\subsubsection{Guided Clustering}

Together with M. Maneck and R. Spang an approach called "guided clustering" was developed (Maneck, Schrader et al.). This methodology enables the identification of specific gene expression modules (clusters) that are affected by the in vitro cell line perturbation and as well differentially expressed comparing gene expression profiles of tumour samples. Basically this algorithm identifies genes which fulfil two criteria at the same time: (i) affected by the stimulus and (ii) differently expressed across a set of tumour gene expression profiles. Thereby modules are identified that are functionally associated with the activation by a known stimulus useful to identify pathway activities that are exclusive to a defined lymphoma subgroup. In order to "measure" the activity that is predicted by the expression of these genes in tumour gene expression profiles an index value was used. Therefore, the expression levels of the cluster genes are combined to a single value (index) that quantifies the activity of the identified gene cluster in the tumours (Maneck, Schrader et al.) This value was defined as "Pathway Activation Index".

To identify genes specifically regulated by one stimulus a vector based bioinformatical approach was embedded into the guided clustering analysis. 
Briefly: the mean of the control gene expression values was subtracted from the gene expression values of stimulated samples, resulting in values that solely represent the reaction caused by the stimulation. The gene vectors were correlated to a binary vector. This binary vector includes a "1" only for one stimulation that was investigated to solely regulate genes. The genes were ordered according to the calculated absolute Pearson correlation coefficient.

Using this approach combining stimulus specific gene expression changes of stimulated BL2 cells and gene expression profiles of 220 aggressive NHL a number of specific gene clusters for each stimulus could be described. For each perturbation two pathway indices were identified: an activating and an inhibiting. Among these two clusters changed by LPS stimulation (LPS.1, LPS.2), two clusters regulated upon SCD40L stimulation (CD40.1 and CD40.2), two clusters responding to BAFF (BAFF.1 and BAFF.2), two clusters responding to IL21 stimulation (IL21.1, IL21.2) as well as two clusters changed by BCR activation (BCR.1, BCR.2) were identified (see Appendix table A8).

The data obtained from a single stimulation of BL cells with LPS were used in parallel studies to verify an observation concerning a potential influence of BCL6 on TLR signalling. Therefore an additional LPS driven pathway activation index was identified (LPS.2*) (Maneck, Schrader et al. 2011). It was shown that LPS mediated Toll-like receptor signalling and BCL6 targets are coherently expressed in DLBCL. This supports the hypothesis that BCL6 could potentially modulate Toll-like receptor signalling in DLBCL. For further information please refer to the published manuscript.

In the following paragraphs BCR and CD40 regulated gene clusters will be described in detail.

\subsubsection{CD40 and BCR mediated pathway activity is continuously increasing in aggressive NHL samples}

As described above, in order to measure gene cluster activity in the gene expression profiles of aNHL samples the expression of the cluster genes was condensed to one single value: the index. This index value was used as a surrogate marker for the activity of a gene cluster in each single patient sample. 
Two major gene clusters were identified to be regulated in response to BCRx. One of these gene clusters contains genes which are dominantly inhibited upon BCR activation (BCR.1) whereas the other gene cluster is built up by genes that are specifically activated in response to BCR crosslink (BCR.2) in BL2 cells. (Figure 3-16 A, left panel). The BCR.1 cluster is determined by 288 genes, the BCR.2 cluster encompasses 286 genes. It was striking that within the group of genes summarized as BCR.1 cluster genes involved in DNA-damage response and cell cycle control are highly overrepresented. These include for example BRCA1, AURKA, BUB1B, CCNA2, CCNB1, PLK1 and 3, PBKJTOPK, PRC1 and BIRC5/SURVIVIN. The BCR.2 cluster comprises 286 genes. These include for example genes encoding for kinases like SGK1, MAPK6 and MAP2K3 (see Appendix table A8 for detailed information). An expression of these genes according to the stimulated status of the BL cell model will be further referred to as "high index". Corresponding to that an expression of genes similar to the unstimulated status will be referred to as "low index". Please note that in the case of the BCR.1 gene cluster a high index corresponds to a low expression of cluster genes.

In order to focus on the heterogeneity of DLBCL the indices based on the expression of BCR.1 and BCR.2 cluster genes were compared in $175 \mathrm{aNHL}$ cases, that have been described as "non-mBL" (127 cases) and "intermediate" (48 cases) with the index of Burkitt-likeness as published by Hummel and colleagues (Hummel, Bentink et al. 2006). These DLBCL gene expression profiles were analysed according to the expression of the respective cluster genes (Figure 3-16 A, right panel). aNHL samples are ordered from left to right according to the BCR.1 index in both heatmaps. BCR.1 and BCR.2 indices show oppositional activities in aNHL gene expression profiles. Lymphoma which exhibit a low expression of BCR.1 cluster genes (index high) show at the same time a low expression of BCR.2 cluster genes (index low). The information derived from these oppositional activities can as well not be used to group ABC and DLBCL patients.

CD40.1 represents a cluster of 288 genes which are activated by CD40 signalling in BL2 cells (Figure 3-16 B left panel). These genes include for example genes 
encoding for MHC1 and MHC2 molecules as well as CD59, a gene that encodes a cell surface glycoprotein that is involved in lymphocyte signal transduction, CD160, encoding a receptor that shows broad specificity for both classical and non-classical MHC class I molecules, as well as $\mathrm{NOTCH}$, which encodes for a cell surface receptor for membrane bound ligand, and may play a role in developmental processes. CD40.2 comprises 71 genes which are mostly inhibited upon CD40 activation. In Figure 3-16 B (right panel) heatmaps of the expression of the CD40 cluster genes in gene expression data of 175 cases (described in A) are depicted. aNHL samples are ordered from left to right according to the CD40.1 index in both heatmaps. Contrary to the oppositional BCR indices, both CD40 indices are basically coherent in DLBCL. A high CD40.1 index (high gene expression of CD40.1 cluster genes) is in most cases accompanied by a high CD40.2 index (low expression of CD40.2 cluster genes). For the affiliation of patients to ABC and GCB DLBCL subgroups (colour coded bar on top of the heatmap) no clear segmentation of patients by one of the CD40 gene cluster activities can be identified. Nevertheless a trend for a higher prevalence of lymphoma samples with the label $A B C$-like DLBCL can be observed in lymphomas with a high CD40.1 / CD40.2 pathway activation index. 
Results
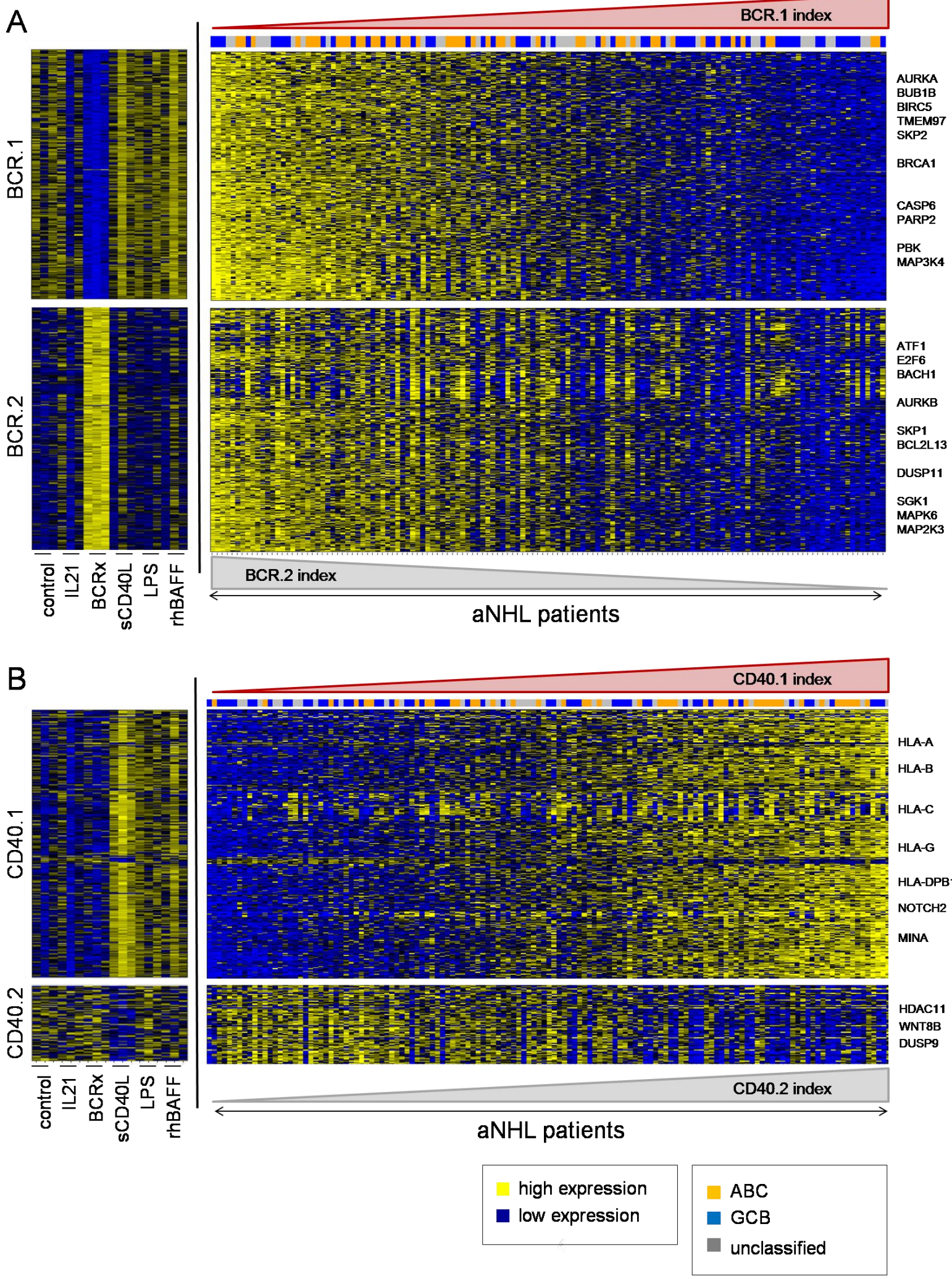

Figure 3-16 (legend see next page) 
Figure 3-16 Guided clustering identifies four major clusters of genes regulated by BCR activation and CD40L stimulation. Each row in the heatmaps represents a gene and each column represents a microarray sample. Yellow and blue indicate high and low expression. left panel: Heatmaps show the gene expression of the respective cluster genes in stimulated BL2 cells compared to control. right panel: Heatmaps show the expression of respective cluster genes in gene expression profiles of tumour samples from 175 intermediate and non-mBL aNHL patients. The patient samples are ordered according to rising BCR.1/CD40.1 index from left to right (symbolized by the red bars). The colour coded bar on top of the heatmaps represents the affiliation of patients to $A B C / G C B$ DLBCL subgroups (orange $=A B C$ tumour sample, blue $=$ GC B tumour sample and grey = unclassifiable sample). A The gene expression of BCR.1 and BCR.2 cluster genes is depicted. B The gene expression of CD40.1 and CD40.2 cluster genes is displayed.

\subsection{3 mBLs are characterised by a missing BCR.1 and a high c-Myc activity}

Next, it was investigated whether there are specific interactions of the identified gene clusters which can be better used to identify specific activities of oncogenic gene modules. These modules could then be used to describe new subgroups of DLBCL patients. Furthermore the activities of these gene modules could be used to identify new targets for an improved therapy. This is of particular interest since the identified gene clusters hold functional information about the signalling pathways that underlie the affected genes. As described in Chapter 3.1, a high c-Myc activity was observed in a number of DLBCL cases and found to be an independent risk factor for these DLBCL patients. Therefore it was first asked whether the activity of one of the newly identified gene clusters shows a correlation with high c-Myc activity in DLBCL patients thus implicating a link between c-Myc activity and respective other pathways.

The c-Myc index and the indices representing the expression of CD40 and BCR gene clusters were investigated in gene expression profiles of $220 \mathrm{aNHL}$ cases (Hummel, Bentink et al. 2006). The interactions of the distinct gene cluster activities were investigated by plotting the indices of C-Myc, CD40.1, CD40.2, BCR.1 and BCR.2 against each other (Figure 3-17 A \& B, page 102). Thereby the information about the activity of two gene clusters in the gene expression profile of one aNHL sample can be assessed. The most interesting interaction is observed for the BCR.1- and c-Myc-index. In Figure 3-17 B1 it is shown that the BCR.1 index inversely correlates with the c-Myc index. The correlation coefficient is -0.76 . That implies that lymphomas which exhibit a high c-Myc activity are characterised by a high expression of BCR.1 genes (low index). mBL cases show 
a high c-Myc index but a low BCR.1 index, whereas DLBCL cases show a respectively lower c-Myc index but high BCR.1 index thus reflecting a stronger inhibition of genes defining the BCR.1 index. Intermediate/mindL cases are characterised by an intermediate activity of the c-Myc index and the BCR.1 index. One explanation of this strong inverse correlation could be that BCR.1 genes are regulated directly or indirectly through c-Myc. There might be mechanisms by which a high c-Myc activity accounts for a low BCR.1 activity or vice versa. This indicated a potential direct connection of c-Myc activity with the expression of BCR.1 cluster genes. The other index interactions have to be analysed in more detail in the future.

\subsubsection{The expression of some BCR.1 cluster genes is decreased upon inhibition of c-Myc in BL cell lines}

As already shown in chapter 3.2 the activation of the BCR is associated with a decreased c-Myc expression. By qRT-PCR it was analysed whether "BCR.1genes" BIRC5/SURVIVIN, AURKA, BUB1B, PBK-TOPK are indeed inhibited by BCRx (validation of microarray data). Furthermore, TMEM97 as a c-Myc index gene, which is also present within the BCR.1 gene cluster, was analysed. To investigate the possible interaction of c-Myc with BCR.1 cluster genes it was tested whether c-Myc inhibition can reduce the expression of BCR.1 genes. In addition, it was tested whether there is an additive effect of BCRx and c-Myc inhibition on the decreased expression of this selected set of BCR.1 cluster genes. Therefore the mRNA levels of selected cluster genes were assessed in response to BCR activation, c-Myc inhibitor treatment and both (BCRx and c-Myci) using qRT-PCR.

BL2 and Ramos cells were preincubated for 3h with $60 \mu \mathrm{M}$ c-Myc inhibitor 10058-F4 (Berg, Cohen et al. 2002; Yin, Giap et al. 2003) or left untreated (DMSO). DMSO control as well as c-Myci treated cells were stimulated using $1.3 \mu \mathrm{g} / \mathrm{ml}$ anti-lgM $\mathrm{F}(\mathrm{ab})_{2}$ fragments or left unstimulated as control. The inhibition of c-Myc by 10058-F4 can be easily controlled since the 10058-F4 treatment leads to a lower expression of $M Y C$ itself via a microRNA mediated mechanism (Sampson, Rong et al. 2007). One representative experiment of three replicates is shown in Figure 3-18 (page 104). 
A

\begin{tabular}{|l|c|c|c|c|c|}
\hline & MYC & BCR.1 & BCR.2 & CD40.1 & CD40.2 \\
\hline MYC & 1,00 & $-0,76$ & 0,25 & 0,67 & 0,44 \\
\hline BCR.1 & & 1,00 & $-0,74$ & $-0,95$ & $-0,67$ \\
\hline BCR.2 & & & 1,00 & 0,82 & 0,57 \\
\hline CD40.1 & & & & 1,00 & 0,61 \\
\hline CD40.2 & & & & & 1,00 \\
\hline
\end{tabular}

B index value
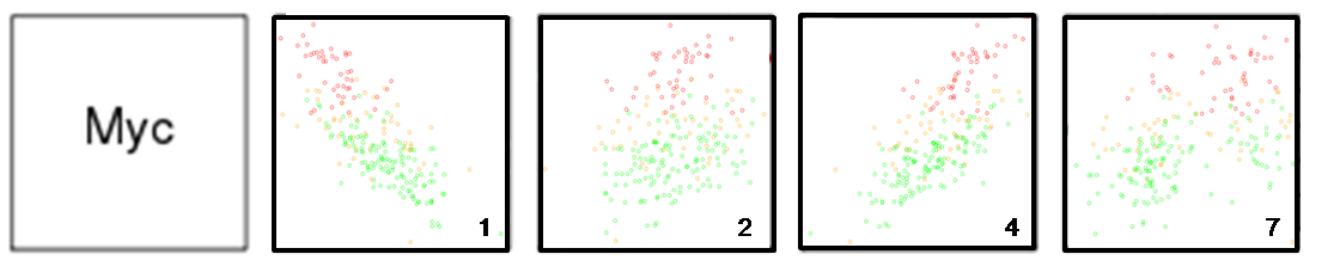

$0 \mathrm{mBL}$

intermediate non-mBL
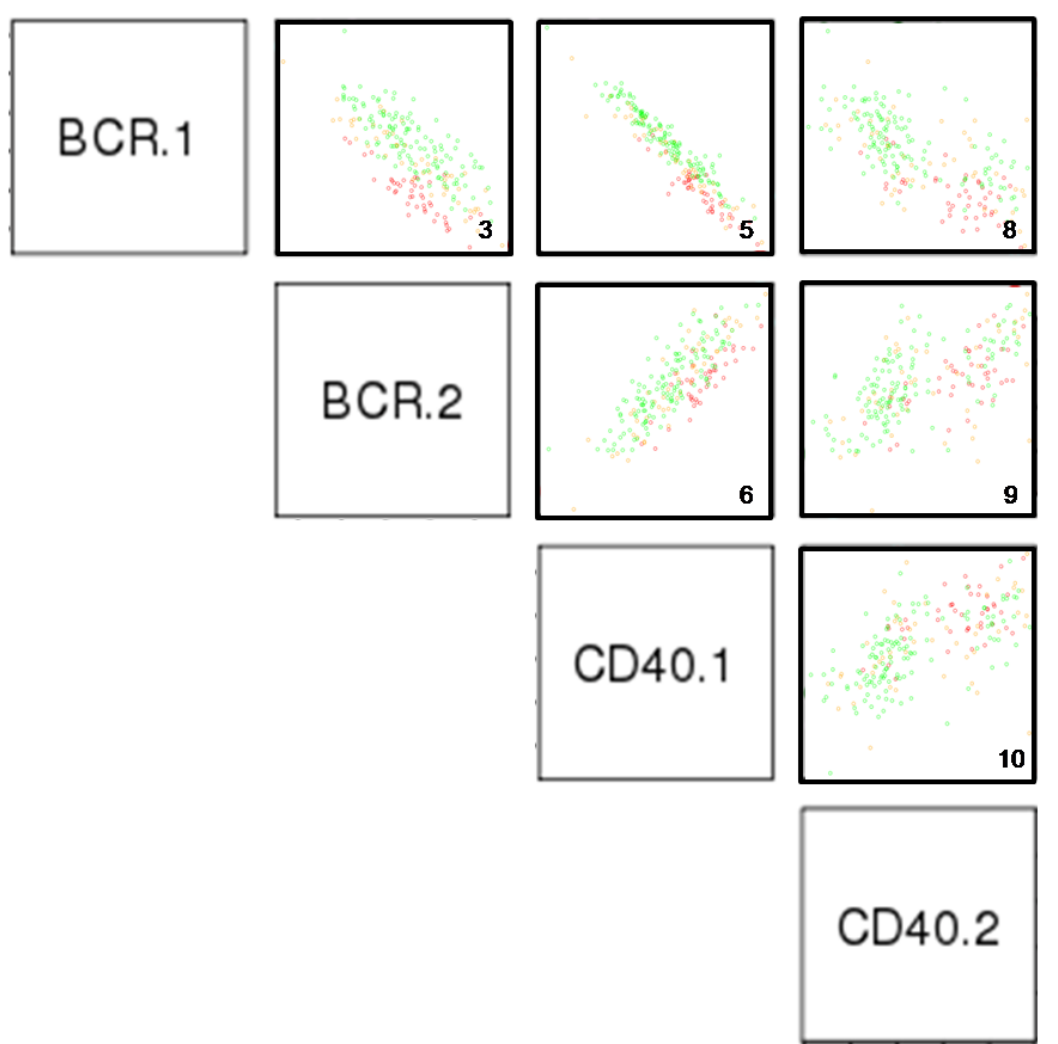

Figure 3-17 The BCR.1 index is inversely correlated with the c-Myc index. A\&B Correlation coefficients of Pathway Activation Indices in a cohort of $220 \mathrm{aNHL}$ cases. C-Myc index genes, BCR.1, BCR.2, CD40.1 and CD40.2 gene clusters were used to calculate the respective PAls in gene expression profiles of $220 \mathrm{aNHL}$ diagnosed as $\mathrm{mBL}$ (red), non-mBL (green) and intermediate lymphoma (yellow) by Hummel and colleagues (Hummel, Bentink et al. 2006). The parallel activity was estimated plotting the indices against each other and calculating the respective correlation coefficient. A coefficient close to one indicates highly correlated index activities and a high number of lymphoma expressing both gene clusters in an activated state. 
As shown in previous experiments microarray data BCRx is associated with a reduced expression of $M Y C$ in BL2 and Ramos cells. The same is observed for BIRC5/SURVIVIN, AURKA, BUB1B, PBK-TOPK and TMEM97 expression. Interestingly, the expression of BIRC5/SURVIVIN, AURKA, BUB1B, PBK-TOPK and TMEM97 is also affected by the c-Myc inhibitor 10058-F4. (Figure 3-18 A-F page 104; see also Figure 3-10). AURKA and BUB1B have been previously described as c-Myc target genes in different cell systems (Menssen, Epanchintsev et al. 2007; den Hollander, Rimpi et al. 2009). Furthermore the BCRx and c-Myc dependent expression of PBK-TOPK is remarkable since it was shown that this kinase could possibly play a role for BL pathogenesis (SimonsEvelyn, Bailey-Dell et al. 2001). This result suggests that the expression of a set of BCR.1 genes is indeed dependent on the aberrant C-Myc activity in BL cells. Combining the inhibition of c-Myc with BCR activation one can observe an additive effect regarding the decreased expression of BCR.1 cluster genes. However, the observed additive effect indicates that there are additional pathways involved by which BCR activation could mediate the inhibition of the investigated BCR.1 cluster genes. One possibility is c-Myc. The second possibility might be mediated by one of the various pathways triggered upon BCR activation but not CD40L, BAFF, IL21 or LPS. Ongoing experiments indicate that ERK and/or PI3K signalling could be involved. However additional experiments are necessary to give a final conclusion on that.

\subsubsection{Changes in BUB1B gene expression in response to BCR crosslink are mediated by altered C-Myc binding to the BUB1B locus}

To follow the question whether BCR.1 genes might be directly regulated by c-Myc upon BCR activation, the direct promoter binding of c-Myc to one BCR.1 cluster gene, namely Bub1B, was investigated. Bub1B was selected as example since E-boxes, which serve as direct C-Myc binding sites, have already been published for this gene (Menssen, Epanchintsev et al. 2007). Using ChIP it was tested whether the binding of $\mathrm{C}-\mathrm{Myc}$ to the E-box containing region in the first intron of the Bub1B is altered upon BCR activation. As seen in Figure 3-19 (page 105) the locus of the Bub1B gene containing the E-box can be enriched by Immunoprecipitation of c-Myc in unstimulated cells (Figure 3-19 lane 5). Upon 
activation of the BCR this enrichment is abolished (Figure 3-19 lane 6). As negative control an IP with an anti IgG antibody was used (Figure 3-19 lane 3\&4). As positive control an IP of acetylated histone $\mathrm{H} 3$ was used as this is a marker for active description (Figure 3-19 lane 7\&8). In a photo with lower exposure time one can observe that $\mathrm{acH} 3$ binding to the BUB1B locus is slightly diminished upon BCR crosslink (Figure 3-19 lane 7\&8 2). This result points to a direct regulation of the BCR.1 genes by C-Myc.
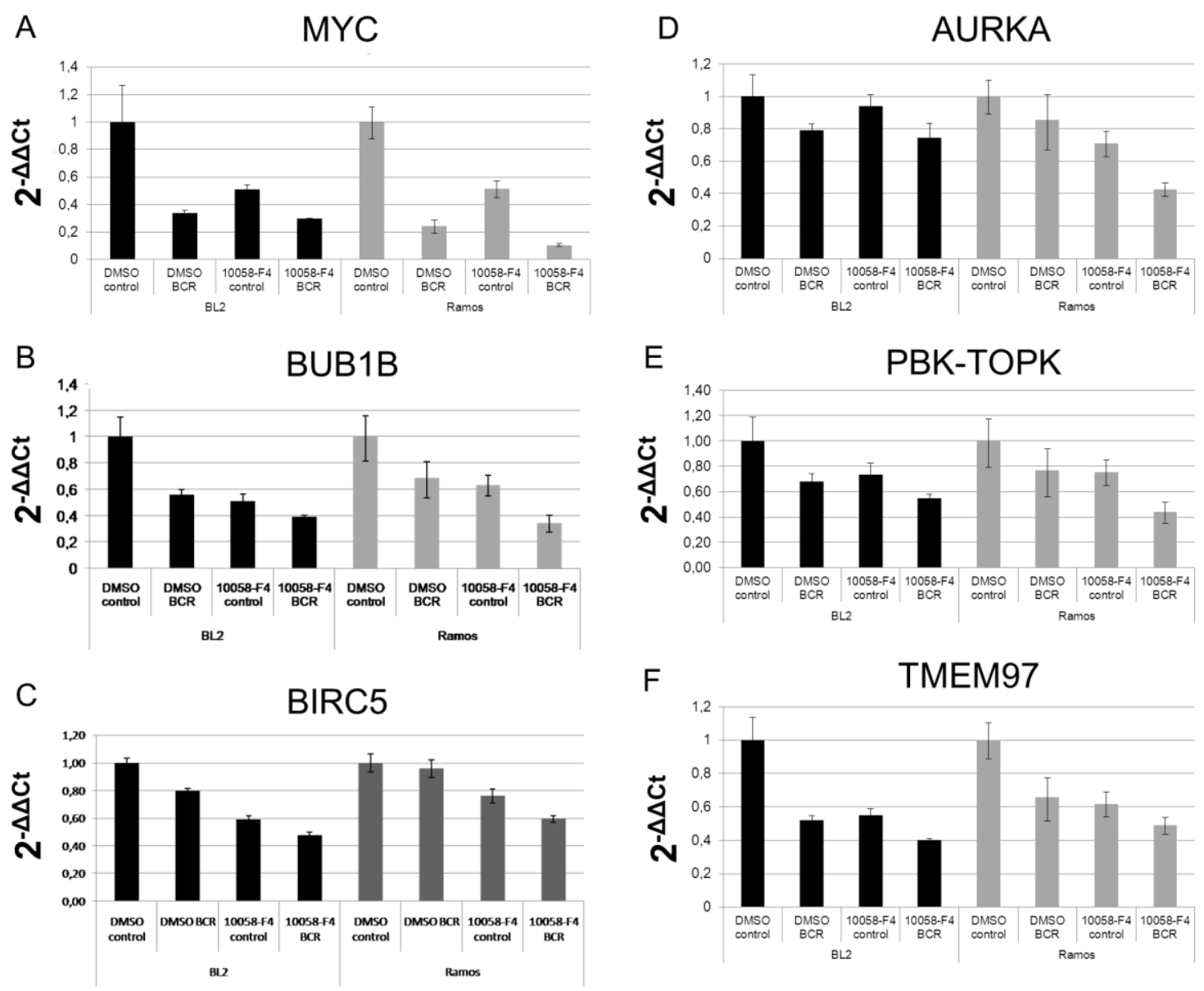

Figure 3-18 Expression of BCR.1 cluster genes is downregulated by BCR activation and c-Myc inhibition in Burkitt Lymphoma cell lines. A-F BL2 and Ramos cell were pretreated for 3h with $60 \mu \mathrm{M}$ 10058-F4 c-Myc inhibitor or left untreated (DMSO). Cells were stimulated for additional $3 \mathrm{~h}$ with anti $\operatorname{lgM} \mathrm{F}(\mathrm{ab}) 2$ fragment $(1.3 \mu \mathrm{g} / \mathrm{ml})$. qRT-PCR analyses were performed using SYBR green. Foldchanges were calculated using the $\Delta \Delta \mathrm{Ct}$ method. One representative experiment of three replicates is shown. 


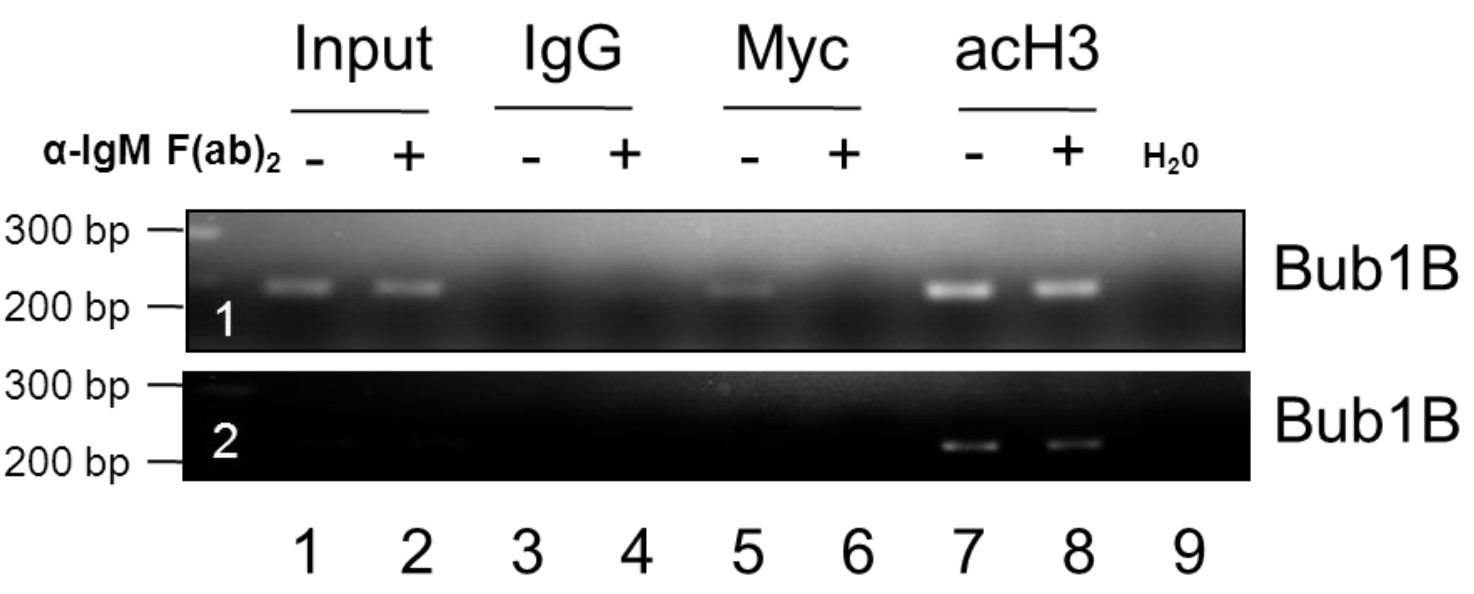

Figure 3-19 ChIP of c-Myc reveals a change in c-Myc abundance at the Bub1B promoter upon BCR activation. Chromatin IPs were performed using antibodies directed against IgG as negative control, against c-Myc and against acetylated histone $\mathrm{H} 3$ as positive control (marker for active transcription). To check for C-Myc binding a fragment was amplified that encompasses the previously described E-box in intron 1 of the Bub1B gene (Menssen, Epanchintsev et al. 2007). The lower lane shows a shorter exposure time to infer on differences in acetyl Histone H3 binding.

\subsubsection{Prolongation of the G2 phase of the cell cycle in BL cells after BCRx}

In parallel to the investigation of a direct C-Myc dependent regulation of BCR.1 gene expression the effect of BCRx on the cell cycle was investigated, as BCR.1 cluster genes are highly enriched in genes associated with $\mathrm{G} 2$ cell cycle processes (see table A 9 in the Appendix). Furthermore it was tested whether an inhibition of C-Myc is associated with a comparable effect on the cell cycle as $B C R$ activation. It was hypothesized that c-Myc inhibition could even enhance this biological effect mediated by BCR activation, when both treatments are utilized at the same time.

BL cell lines BL2 and Ramos were incubated with $60 \mu \mathrm{M}$ of 10058-F4 c-Myc inhibitor and $1.3 \mu \mathrm{g} / \mathrm{ml}$ anti $\operatorname{lgM~} F(a b)_{2}$ fragments over a time course of up to $24 \mathrm{~h}$. The distribution of cells to distinct cell cycle phases was investigated using Nicoletti buffer followed by FACS analyses of nuclei. One representative experiment of 5 is shown in Figure 3-20 A, page 107 . It could be observed that after $6 \mathrm{~h}$ of BCR activation the percentage of cells in G2 phase increases from $22 \%$ to $29 \%$ for Ramos cells and from $20 \%$ to $32 \%$ for BL2 cells. This effect is even enhanced by the inhibition of c-Myc. Here an increase from $25 \%$ to $32 \%$ of 
Ramos cells and from $32 \%$ to $38 \%$ of BL2 cells in the G2 phase can be induced by BCR activation. These results are comparable for both $\mathrm{BL}$ cell lines. Measurements of the $6 \mathrm{~h}$ time point are exemplified in figure 3-20 B.

To obtain a more detailed picture of the BCR effects on the passage of $B L$ cell through the cell cycle, Ramos cells were synchronized at the $S$ to G2 phase border using 2 rounds of thymidine treatment (described in Methods Section Chapter 2.12.11 (Stolz, Ertych et al. 2010)). Using this technique it is possible to follow the cells through all cell cycle passages. To relieve the cell cycle block cells were washed three times. At the same time point of the release from cell cycle arrest the cells were stimulated with anti-lgM $F(a b)_{2}$ fragments $(1.3 \mu \mathrm{g} / \mathrm{ml})$ and treated with $60 \mu \mathrm{M}$ of 10058-F4 c-Myc inhibitor. Thereby one can follow treated compared to control cells over a detailed time course as they re-entry into the cell cycle and pass G2, M, G1 and S phase (Figure 3-20 C). After 8 hours $65 \%$ of control cells achieved the passage from $G 2 / M$ phase to $G 1$. The activation of the BCR decelerates this process. After $8 \mathrm{~h} 48 \%$ of BCR activated cells are still within G2/M phase. This effect is enhanced by the inhibition of c-Myc. Of activated Ramos cells with additionally inhibited c-Myc more than $60 \%$ of cells were still in G2/M phase after 8h. This observation is in line with the additive negative effect of BCR activation and $c-M y c$ inhibition on the mRNA expression the BCR.1 cluster genes BUB1B, PBK-TOPK, AURKA and BIRC5 (see Figure 3-18).

By investigating direct short term effects on the cell cycle it was found that BCR crosslink leads to a prolonged G2-phase in BL cell lines BL2 and Ramos. It can be shown that the already described G1 arrest is only the final outcome of the influences of $B C R$ signals on the cell cycle that follows the primarily induced prolongation of the G2 phase (Figure 3-20 A, B \& C). These results point to the conclusion that the inhibition of G2 phase associated genes represented in the BCR.1 cluster might be indeed the reason for BCR mediated elongation of $\mathrm{G} 2$ cell cycle phase. Since the bioinformatic description suggests that DLBCL cases are characterised by a low c-Myc and a high BCR.1 index it could be postulated that the lower expression levels of BCR.1 genes, as observed in a subgroup of DLBCL patients, might be the reason for the differences in growth behaviours of 
DLBCL and BL, as it is known that DLBCL tumours show lower growth rates compared to $\mathrm{BL}$. It needs to be investigated on primary lymphoma samples whether there is indeed a longer G2/M-cell cycle transition in DLBCLs compared to BLs.

Using "guided clustering" it was possible to identify new clusters of gene which are affected by paracrine and B cell intrinsic stimuli in the BL cell model. The developed indices are able to quantify pathway activity in individual lymphomas. Most importantly one gene cluster was identified that is inhibited upon BCRx in BL2 cells (BCR.1). BCR.1 activity is inversely correlated with c-Myc activity and separates $\mathrm{mBLs}$ from the other analysed aggressive NHLs. The results presented here provide evidence that a lower expression of BCR.1 cluster genes in non-mBLs is probably due to the absence of a strong c-Myc activity or a high activity of paracrine/autocrine signals mimicking BCRx. Furthermore, BCRx leads as short term effect to a prolonged G2 cell cycle phase which could be an explanation for the G1 arrest of the cells observed after longer time points. 
Results

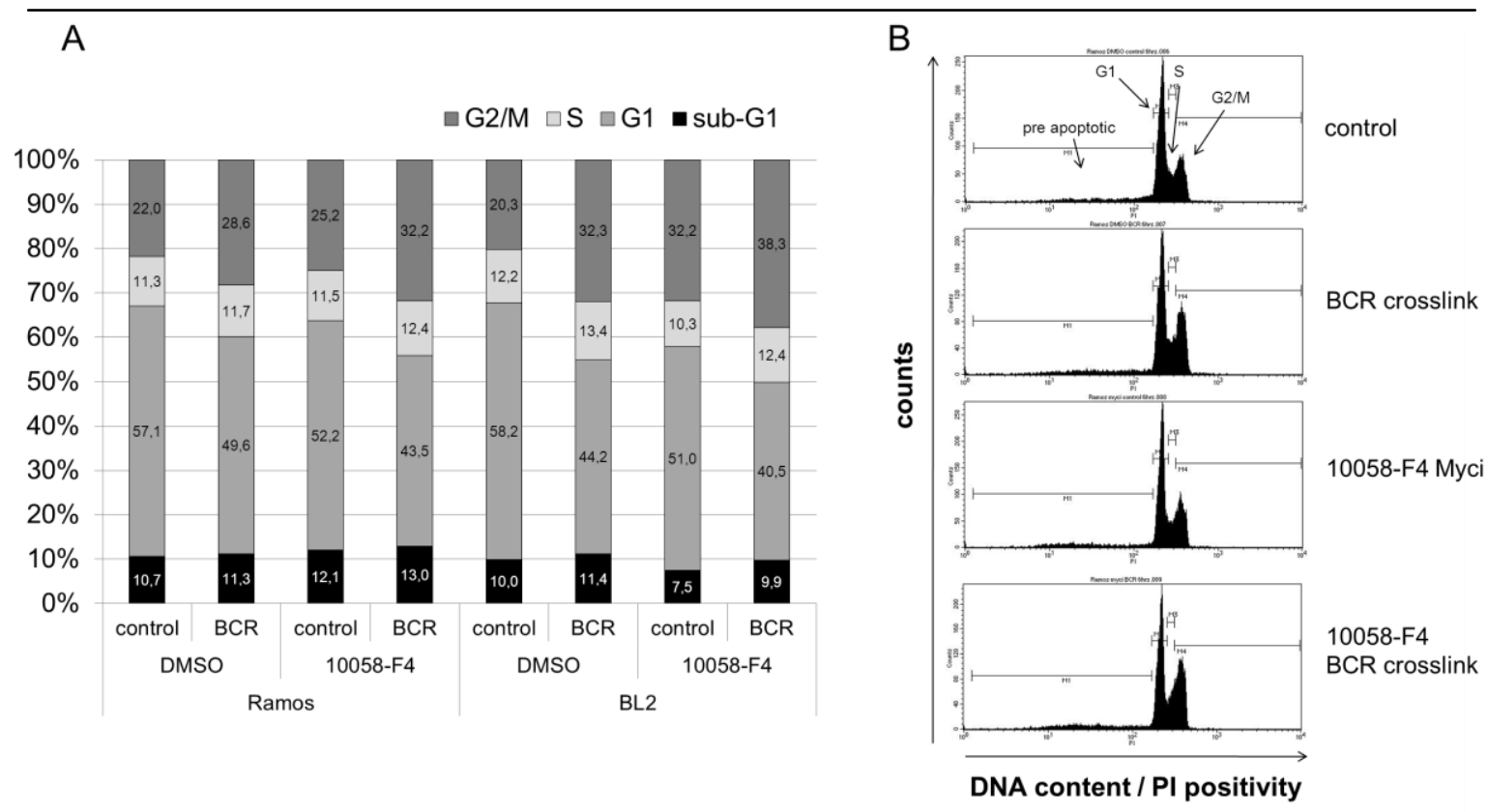

C control

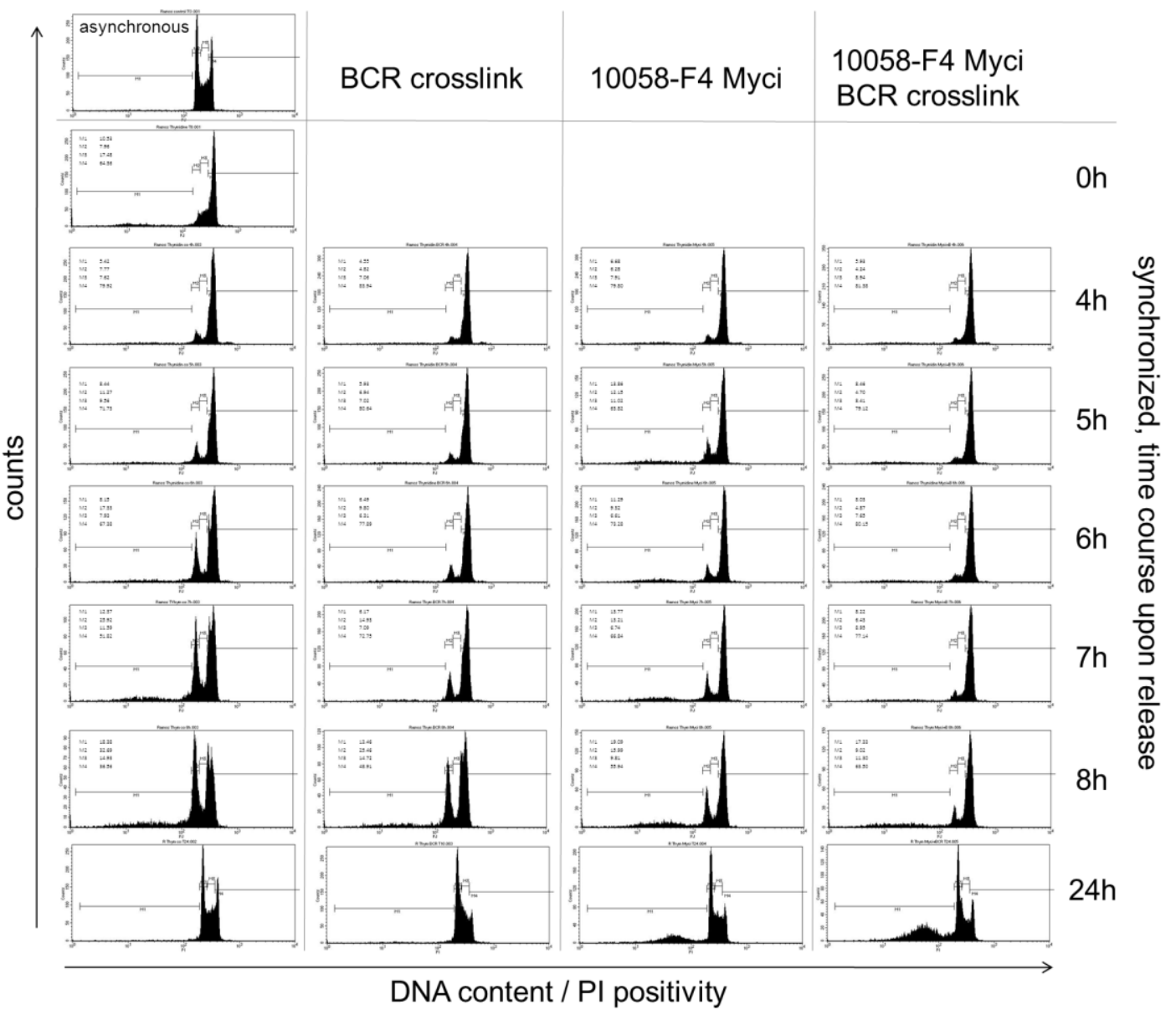

Figure 3-20 (legend see next page) 
Figure 3-20 Activation of the BCR leads to a prolonged G2 phase in BL cell lines A \& B Asynchronous growing $\mathrm{BL} 2$ and Ramos cells were treated with $1.3 \mu \mathrm{g} / \mathrm{ml}$ anti $\operatorname{lgM~} \mathrm{F}(\mathrm{ab})_{2}$ fragments and $60 \mu \mathrm{M} 10058-\mathrm{F} 4 \mathrm{c}-\mathrm{Myc}$ inhibitor for $6 \mathrm{~h}$. Cell cycle distribution of cells was measured using Nicolletti buffer and FACS based analyses of the DNA content of the nuclei. C Ramos cells were synchronised in G2 cell cycle phase using 2 rounds of thymidine (2mM) treatment. After removing the Thymidine (Oh) the cells started to pass through the cell cycle. Cell cycle distributions were measured over a time course of $0 \mathrm{~h}$ up to $8 \mathrm{~h}$ using Nicoletti technique. The $24 \mathrm{hrs}$ time point was measured separately. One out of three representative experiments is shown.

\section{Discussion}

Recently the analysis of gene expression profiles of aNHL samples has allowed an advanced understanding of the molecular heterogeneity of these lymphomas (Alizadeh, Eisen et al. 2000; Monti, Savage et al. 2005; Dave, Fu et al. 2006; Hummel, Bentink et al. 2006; Bentink, Wessendorf et al. 2008; Ci, Polo et al. 2009). A molecular definition of $B L$ was described based on different approaches including cell line perturbation experiments. This molecular definition can be used to differentiate molecular BL from DLBCL and other aggressive $\mathrm{NHL}$ on the basis of their tumour gene expression profiles (Dave, Fu et al. 2006; Hummel, Bentink et al. 2006). In previous investigations two major DLBCL subgroups were defined comparing at a qualitative level global gene expression of $\mathrm{B}$ cells from different differentiation stages with those from primary lymphoma. Thus at the molecular level often a discrimination of the ABC- and GCB-like DLBCLs is performed. The group of $A B C D L B C L$ has been characterised by a worse clinical outcome (Alizadeh, Eisen et al. 2000). However, in a comparable approach a so called OxPhos / BCR-like subgroup was also identified only partially overlapping with ABC- or GCB-like DLBCLs (Monti, Savage et al. 2005). From additional studies on cell lines resembling the $A B C$ - and GCB-like gene expression it is suggested that $A B C$-like DLBCLs are characterised by highly activated NF-KB and JAK-STAT signals (Feuerhake, Kutok et al. 2005; Lam, Davis et al. 2005; Ngo, Davis et al. 2006; Ding, Yu et al. 2008; Lam, Wright et al. 2008; Hailfinger, Lenz et al. 2009; Davis, Ngo et al. 2010; Ngo, Young et al. 2011). In contrast GCB-like DLBCLs are characterised by deregulated Bcl6 function (Iqbal, Greiner et al. 2007; Choi, Weisenburger et al. 2009; Ci, Polo et al. 2009). Nevertheless, the characterisation of aNHL according to their gene expression profiles is so far 
largely descriptive lacking a clear quantitative estimation of pathway activities in individual lymphomas.

In addition, there are a number of open questions, as for example how aberrant c-Myc activity is reflected in non-mBL DLBCL and whether this activity is of functional relevance for these lymphoma. It is not known how the activities of paracrine $B$ cell stimuli contribute to the heterogeneity and the malignant phenotype of DLBCL. It is likely that other oncogenic pathways are involved in the malignancy of DLBCL other than NF-KB and JAK-STAT signalling. However these so far remain elusive for primary lymphoma. Furthermore it is not understood how the differences in proliferative potential and chromosomal complexity of DLBCL and BL, which highly contribute to the heterogeneity of aNHL, can be explained.

Hence, the aim of this study was to use perturbation experiments in primary lymphoma precursor cells or lymphoma cell lines to identify and characterise new gene expression patterns that hold information about relevant oncogenic pathway activities and their quantitative estimation in individual lymphoma samples. Furthermore, understanding the heterogeneity of pathway deregulation is important for a better understanding of the clinical outcome and prediction of treatment responses not only in lymphoma patients. Thus in this study (i) the effect of ectopic expression of the proto-oncogene $M Y C$ in lymphoma precursor cells was investigated and (ii) perturbations of B cell lines by B cell specific paracrine stimuli were used to define new groups of genes in order to obtain novel insights into the functional differences underlying the malignant phenotypes of distinct aNHL.

\subsection{High c-Myc activity is an independent negative prognostic marker for DLBCL}

In this study it was shown that ectopic expression of c-Myc in GC B cells triggers a characteristic expression pattern of c-Myc targets that is also expressed in aNHL. While a very high expression is restricted to Burkitt lymphomas, the expression of c-Myc targets varies on a lower level across non-mBL and 
intermediate lymphomas and constitutes a negative prognostic marker in these lymphomas.

The results presented here consolidate the previous conclusions of recent studies with respect to c-Myc activity in aNHL (Dave, Fu et al. 2006; Bentink, Wessendorf et al. 2008). While Dave and coworkers described expression of C-Myc targets as a hallmark of BL, the results presented in this study predict C-Myc activity also for a subset of DLBCL. Like the pattern from Dave et al., the pattern presented here can be found in the expression profiles of Burkitt lymphomas. However, different to their pattern, the c-Myc-index is also displaying a considerable c-Myc activity in DLBCL. Moreover, its expression is prognostic in DLBCL suggesting that $\mathrm{C}-\mathrm{Myc}$ activity is not limited to BL but exists in some DLBCL and affects their outcome.

Thus, in line with Dave et al., it was demonstrated that sets of c-Myc targets genes can be used to discriminate between BL and DLBCL (Dave, Fu et al. 2006). However oncogenic activity of $\mathrm{c}-\mathrm{Myc}$ is not restricted to BL but can also be found in other aNHL subtypes. It was observed that within the group of non-mBL and intermediate lymphomas, a high c-Myc index was associated with significantly poorer survival, an effect that was independent of established risk factors and importantly the presence of a detectable MYC breakpoint. While recent data suggested genetic aberrations involving $M Y C$ are associated with a poor prognosis in DLBCL, we demonstrate here that a high c-Myc index is also present in cases without a detectable MYC breakpoint (Klapper, Stoecklein et al. 2008; Johnson, Savage et al. 2009; Savage, Johnson et al. 2009) (Barrans, Crouch et al. 2011; Zhang, Chen et al. 2011). Thus, high c-Myc activity is responsible for poor prognosis, irrespective of the nature of the $M Y C$ abnormality. These abnormalities could include for example copy number variations as recently increased copy numbers of $M Y C$ have been identified in DLBCL (Stasik, Nitta et al. 2010). Therefore, the assumption, that only those DLBCLs with an IG$M Y C$ translocation have a poorer prognosis compared to $\mathrm{BL}$ and other types of DLBCL, has to be reconsidered. The c-Myc index gives a more comprehensive risk assessment since it is based on actual c-Myc activity instead of the presence of a $M Y C$ translocation. 
Many of the genes in the c-Myc index have been identified earlier as c-Myc targets in different cellular contexts using different experimental approaches. For example, the GSEA analysis showed a strong enrichment of genes identified by Bild and colleagues, who developed a series of oncogenic signatures based on an analysis of data from c-Myc expression in human primary mammary epithelial cells (Bild, Yao et al. 2006). Also enriched were c-Myc target genes that have been identified in a lymphatic cell line by chromatin immunoprecipitation in combination with human promotor arrays or in inducible c-Myc assays (Schuhmacher, Kohlhuber et al. 2001; Li, Van Calcar et al. 2003). The uniqueness of the c-Myc target list presented here, lies in its focus on genes that are targeted by c-Myc both in GC B cells and in the lymphoma samples. Hence one could conclude that these genes are those most likely to be crucial for the transformation of germinal centre B cells.

It was also observed that CD40 pathway elements are depleted upon c-Myc overexpression. This is mainly reflected by genes that are regulated by NF-kB and fits with previous observations of others groups (Basso, Klein et al. 2004; Hummel, Bentink et al. 2006; Ding, Yu et al. 2008; Lam, Wright et al. 2008; Compagno, Lim et al. 2009; Fan, Zeller et al. 2010). It is also in line with previously reported in vitro studies showing that aberrant c-Myc expression is associated with reduced NF-KB activity and impaired interferon response (Schlee, Holzel et al. 2007; Klapproth, Sander et al. 2009; Keller, Huber et al. 2010). Furthermore, it also supports the observation that NF-KB and JAK/STAT regulated genes can distinguish DLBCL from mBL (Ding, Yu et al. 2008; Lam, Wright et al. 2008; Lee, Herrmann et al. 2009).

FZD7 expression was analysed as an example for one of the index genes. The inverse correlation between MYC and FZD7 expression reflects the described c-Myc index. This is of interest as it allows developing new hypotheses regarding the role of Wnt signalling in germinal centre reaction and lymphomagenesis. Linking the two observations that (i) $\mathrm{BL}$ cell lines barely respond to stimulation with Wnt3a or Wnt5a (unpublished observation) and (ii) that MYC and FZD7 expression seem to be anti-correlated, it can be suggested that BLs are less responsive towards these stimuli due to a downregulation of FZD receptors for 
the Wnt pathways. This is remarkable because the gene encoding the transcription factor Lef-1, as major mediator of B-Catenin signalling, is aberrantly expressed in BLs (Hummel, Bentink et al. 2006). Therefore, a number of new questions arise regarding the role of $F Z D$ receptors in the process of mature $B$ cell homeostasis or B cell transformation. It would be interesting to analyse the functional consequences of the observed c-Myc associated reduction of FZD7 and how this relation might be linked to GC B cell transformation. One hypothesis could be that high c-Myc expression is leading to a disruption of these cell communication pathways and thereby further promote lymphomagenesis. However, this needs more comprehensive experiments in the future.

More recent studies, investigating the time course of c-Myc targets by array based nuclear run-on (ANRO), demonstrated a time-dependent regulation of different pathways by c-Myc (Fan, Zeller et al. 2010). Although the non-viral transient expression assay in primary human GC B cells utilized in the presented study can only picture a small snapshot, this approach demonstrates that c-Myc expression in GC B cells leads to an expression pattern that is still present in fully developed lymphomas. It shall now be extended to study if this gene expression pattern can promote cell survival, reduce spontaneous apoptosis or affect cell proliferation. This observation might open a new discussion about, whether some DLBCL (non-mBL and intermediate lymphomas) have to be treated closer to the scheme used for BL or by modifying the R-CHOP therapy.

\subsection{Identification and characterisation of pathway activities in aNHL}

Descriptions of global gene expression changes after perturbation of murine splenic B cells or transformed human lymphoma cells are increasingly available (Basso, Klein et al. 2004; Zhu, Hart et al. 2004). However so far these data have not been used to identify and characterise pathway activities in individual lymphomas of $B$ cell origin. Therefore, the global effects of the activation of lymphoma cells by BCR-, CD40-, IL21-, BAFF- or LPS activation /stimulation were analysed. First, it was necessary to identify and describe the major patterns of gene expression changes induced by these stimuli. Secondly these data 
repositories were used to identify gene sets allowing to explain differences in cell cycle progression behaviour between BLs and DLBCLs.

It was shown in this study that the BL cell line BL2 is in general responsive to each of the utilized stimuli and that overlapping as well as specific signalling pathways are activated upon stimulation. These include for example the activation of p38 by BCRx and CD40L and the activation of noncanonical NF-KB in response to CD40L and to lesser extent to BAFF stimulation. Pathways that are activated upon BCR crosslink are predominantly characterised by activation of $\mathrm{Ca}^{2+}$, ERK/MAPK and PI3K/AKT signals. This is in line with observations by others characterising the activated pathways in response to these stimuli in $\mathrm{BL}$ cells (An and Knox 1996; Wang, Grand et al. 1996; He, Chadburn et al. 2004; Hristov, Knox et al. 2005; Ogden, Pound et al. 2005). Supporting the presented observation that BCRx predominantly induces ERK MAPK and PI3K/AKT signals it was shown on a selected set of genes (DUSPS/MYC) that the effects of BCR activation are dominantly characterised by the activation of ERK MAPK and $\mathrm{PISK} / \mathrm{AKT}$. The activation of NF-KB by BCRx is rather low but needs to be evaluated in detail in the future (see chapter 3.2.1 and chapter 3.2.6). Such an analysis is in progress and will answer also the question whether the BCR activation reflects indeed an aberrant ERK or PI3K activity and can be used to identify NHLs with high PI3K/ERK-activity. A group of dual specificity phosphatases has been identified as being regulated predominantly by BCRx in $\mathrm{BL}$ as well as in GC B cells. This regulation is probably mediated by an ERK dependent mechanism in BL2 cells. So far nothing is known about the regulation of DUSPs in B cells. It has been described by several groups in distinct cell systems that DUSPs can be upregulated in response to external stimuli like for example LPS stimulation of macrophages or the activation of the $\mathrm{T}$ cell receptor in developing T cells (Jeffrey, Brummer et al. 2006; Lang, Hammer et al. 2006). Interestingly, a deregulation of DUSPs has been described to be relevant for distinct cancer types (reviewed in Keyse 2008). Based on the findings presented here it would be interesting to investigate the levels of DUSPs expression in B cell lymphoma with potential aberrant MAPK activity resulting from constitutive BCR signalling. 
Recently it was shown that ABC-like DLBCL seems to be dependent on a chronic active BCR or related signals as for example TLR mediated processes (Gururajan, Jennings et al. 2006; Ke, Chelvarajan et al. 2009; Davis, Ngo et al. 2010). Until now several studies have linked active BCR signalling in lymphoma solely to an aberrant NF-KB activity. However there is also evidence that aberrant PI3K signalling could be involved (Uddin, Hussain et al. 2006; Baohua, Xiaoyan et al. 2008). The results presented here point to a coexistence of several pathway activities in aNHL as all analysed stimulations support the view that the relative similarity of gene expression changes are mutual jointly (see chapter 3.2.8). In addition BCR mediated activity of ERK and PI3K seems to be coexisting with NFkB activity, as shown by the expression of CD40L stimulated genes. This is consistent with the results obtained recently by Kloo and colleagues. They showed that the activity of the PI3K is essential for some ABC DLBCL cell lines, which have a constitutive BCR signalling mediated by mutations in CD79B (Kloo, Nagel et al. 2011). Kloo and colleagues came to the conclusion, that chronic BCR activity is not only constituted of a constitutive NF-KB activation but that as well other pathways activated by the BCR have a critical function for the sustained proliferation and survival capacity of malignant aNHLs. However Kloo and colleagues were unable to translate their experimental data on cell lines to individual lymphoma.

The conclusion that the constitutive pathway activities in DLBCL are associated with the aberrant expression of NF-KB target genes through BCR, TLR or TNFreceptor signalling is based on the cumulative description of mutations in a number of genes involved in parts of the NF-kB pathways. These are for example genetic alterations in MALT1, MyD88 and CARD11 which have been described for ABC DLBCL (Hailfinger, Lenz et al. 2009; Davis, Ngo et al. 2010). These mutations lead to constitutive activation of NF-kB signalling and have been identified to be essential for the survival of DLCBCL cells (Compagno, Lim et al. 2009; Ngo, Young et al. 2011). The data presented here concerning the comparison of the relative similarity of gene expression changes as described in paragraph 3.2.8 support this view on the presence of a gradient of pathway activities supporting the clinical heterogeneity of aggressive NHLs rather than a sharp discrimination of two or three subgroups. 
Using the newly developed bioinformatical method "guided clustering" it was possible to identify new clusters of genes which are affected by paracrine and $B$ cell intrinsic stimuli in the BL cell model, and as well suitable for the stratification of aNHL samples. Thereby the LPS.2* cluster was identified which was shown to be negatively associated with $\mathrm{Bcl} 6$ function in the gene expression profiles of aNHL (Maneck, Schrader et al. 2011). This supports the hypothesis that BCL6 could potentially modulate Toll-like receptor signalling in DLBCL, which is in line with the data published by Basso and Dalla-Favera who suggest that Bcl6 could possibly modulate TLR4 signalling (Basso, Saito et al. 2010). This finding is of particular importance as recently oncogenic mutations in MyD88, which is part of the TLR4 signalling pathway, have been identifies to be relevant for ABC DLBCL (Ngo, Young et al. 2011). Furthermore the inverse correlation of Bcl6 and TLR4 activity in aNHL represents the main differences in pathway deregulations observed so far between ABC and GCB DLBCL. Our group showed that indeed the Bcl6 activity, detected via the Bcl6 index, is higher in GCB DLBCL than in ABCs. This observation consolidates the findings of $\mathrm{Ci}$ and colleagues $(\mathrm{Ci}$, Polo et al. 2009) and further supports the understanding for the oncogenic events underlying the heterogeneity of DLBCL.

A central result presented in this study is the description of one gene cluster that is inhibited upon BCRx in BL2 cells (BCR.1). It was shown that BCR.1 activity is anti correlated with c-Myc activity in aNHL gene expression profiles, most likely as some of the BCR.1 genes are directly regulated by c-Myc. This negative association has not been observed until now. So far c-Myc and BCR signalling have been implied in the genesis of lymphoma as two synergistically acting factors. These observations include for example the critical utilization of c-Myc for BCR triggered B cell proliferation (Murn, Mlinaric-Rascan et al. 2009) as well as a direct interaction of active BCR signalling and $M Y C$ overexpression for the genesis of B cell lymphoma in a mouse model (Refaeli, Young et al. 2008).

It was shown that the expression of the translocated $M Y C$ itself is inhibited in response to BCR activation in lymphoma cells harbouring an IG-MYC translocation. This is in line with the results published by Kaptein and colleagues (Kaptein, Lin et al. 1996). The study presented here for the first time provides a 
hint how this inhibitory effect is mediated, showing that Pi3K activity is needed for this effect. The BCR.1 cluster represents a group of genes which is expressed on lower levels in a subgroup of DLBCLs compared to BLs. The results presented here imply that the low expression of these genes in aNHL is either mediated by a high constitutive BCR signal or by a missing aberrant c-Myc activity. As shown in chapter 3.3.5 and 3.3.6 a group of BCR.1 genes is expressed dependently of high c-Myc function in BL cells and the expression of one of the BCR.1 cluster genes $(B \cup B 1 B)$ is directly regulated by $c-M y c$ in response to BCR crosslink. The effects observed on the expression of these genes in response to c-Myc inhibition are perfectly in line with previously published findings regarding $A U R K A$ and $B U B 1 B$, which have been identified as c-Myc target genes in different cell systems (Menssen, Epanchintsev et al. 2007; den Hollander, Rimpi et al. 2009). The identification of TMEM97 as being expressed dependently on c-Myc in BL cells in consolidates the c-Myc index described above. PBK-TOPK as well as BIRC5 have so far not been described as target genes of c-Myc.

It was found that BCR activation leads as short term effect to a prolonged G2 cell cycle phase which is accompanied by a downregulated expression of $\mathrm{G} 2$ phase associated genes mainly encoding spindle checkpoint factors (BCR.1). Furthermore it could be observed that after $24 \mathrm{~h}$ of BCR stimulation $\mathrm{BL}$ cells arrest in G1 phase of the cell cycle. So far the effects of BCR activation on cell cycle regulation in lymphoma cells have only been investigated using longer time points of 16-24hrs (Hristov, Knox et al. 2007; Jamal, Ravichandran et al. 2010). These studies found that BCR activation leads to a G1 arrest of BL cells which is consistent with the results presented here. Jamal and colleagues described a complex model of a BCRx induced network involving AKT and ERK, which induces $\mathrm{G} 1$ cell cycle arrest in $\mathrm{CH} 1$ mouse $\mathrm{B}$ cell lymphoma cells. This is in line with the ERK and PI3K dominant effect of BCRx observed in BL2 cells. On top of this, it was shown here that BCR activation leads to a prolonged G2 phase of BL cells cycle in a time frame of 3-9hrs. The findings presented here offer a potential explanation for the $\mathrm{G} 1$ cell cycle arrest observed in response to BCR activation. The prolonged G2 phase accompanied by an inhibited expression of spindle checkpoint genes could be a hint for problems of the cell with proper chromosomal segregation during mitosis. Chromosomal miss-segregation in 
response to BCR activation could activate a safety mechanism which arrests the cells in $\mathrm{G} 1$ phase.

The BCR mediated effect on the G2 phase is enhanced by an additional inhibition of c-Myc. Since several BCR.1 cluster genes e.g. BUB1B and BIRC5 have been identified to be regulated by BCR activation and by c-Myc activity one could conclude that the BCR effect on the cell cycle is, at least in part, mediated by cMyc. The regulation of the G2 cell cycle phase via BUB1B and MAD2 has already been linked to c-Myc by Menssen and colleagues (Menssen, Epanchintsev et al. 2007). In the study presented by Menssen and colleagues it was shown that the activation of c-Myc leads to a prolonged passage of cells through the G2 phase of the cell cycle. This is contradictory to the findings presented here, where it was shown that highly active c-Myc is needed for a fast progression of BL cells through the G2 cell cycle phase. Menssen and colleagues investigated the effects of c-Myc on the cell cycle in a human colon cancer cell line and a mouse mammary carcinoma cell line both genetically modified to contain a tamoxifen inducible MYC allele. Compared to the system presented here, where c-Myc is expressed under the control of an Immunoglobulin enhancer, the cell systems used by Menssen and colleagues are rather inapplicable for the analysis of c-Myc function in lymphoma cells. It has been shown by several groups that the effects of c-Myc are largely context dependent (Dang, O'Donnell et al. 2006). Therefore it is not surprising that the alterations in c-Myc activities have distinct effects in a c-Myc dependent BL cell line compared to a genetically modified colon or mammary carcinoma cell line.

One of the central BCR.1 genes identified here is $B U B 1 B$. It has been shown that a dysfunction of BUB1B is associated with defects in spindle checkpoint function which lead in consequence to chromosomal instability (CIN) and to the development of tumours due to a tumour suppressor gene loss of heterozygosity (Rao, Yang et al. 2005; Baker, Jin et al. 2009; Li, Fang et al. 2009). It has been shown for CML that the activity of the Bcr-abl tyrosine kinase is associated with an inhibited expression of BRCA1, MAD2, Bub1, Bub3 and BUB1B and thereby induces a weakened spindle checkpoint function accompanied with mitotic slippage upon nocodazole treatment (Wolanin, Magalska et al. 2010). Keeping in 
mind that DLBCL lymphoma are characterised by a complex karyotype, one could postulate, that the chronic BCR signal provokes a lower expression of spindle checkpoint regulators like BUB1B in these lymphoma and thereby impairs a proper spindle checkpoint function leading to miss segregation of chromosomes.

Transferred to primary lymphoma one could postulate that the lower expression of the BCR.1 cell cycle genes in the group of DLBCL with high BCR.1 index, could be associated with a longer passage of the lymphoma cells through the G2 phase of the cell cycle. This would be in line with the generally slower growth of DLBCL lymphoma (Ki67 index) compared to BL (Hummel, Bentink et al. 2006) and could serve as explanation for the differences in proliferation rates of $B L$ and DLBCL.

The presented study raises the question how the cell cycle regulation is affected in intermediate lymphoma that have both: active BCR signalling as well as aberrant C-Myc activity. These cases show high BCR.1 index compared to BL, but a lower BCR.1 index compared to DLBCL (lower expression of BCR.1 cluster genes). One could define this group as "Myc high" and "BCR.1 intermediate". Following the presented model these cells would have a rather high proliferation rate accompanied with a fast passage through the G2 phase and additional impairments regarding the proper progress through G2. This could potentially explain why these lymphomas have been identified as those aNHL cases with a poorer prognosis compared to other DLBCL patients (see Chapter 1). Using treatment strategies that are closer to $B L$ together with targeted therapies against the pathways that inhibit the expression of BCR.1 genes (e.g. the Syk inhibitor proposed by Chen and colleagues (Chen, Monti et al. 2008)) might help to overcome the bad prognosis for these patients.

Another BCR.1 index gene that encodes for a factor involved in spindle checkpoint function is PLK1 (Polo-Like Kinase 1). In ongoing analyses it is tested whether PLK1 is as well regulated by C-Myc in response to BCRx. It has been shown that the expression of $P L K 1$ is associated with a high proliferative index of aNHLs and shortened event free survival (Mito, Kashima et al. 2005; Liu, Zhang et al. 2007). As small molecule inhibitors against PLK1 are already tested in 
clinical phase 1 studies (Schoffski 2009), this kinase might be a promising target for individualised therapies for "BCR.1 low" BL and DLBCL cases.

To support the model of BCR induced chromosomal instability, it would be interesting to test whether activated BCR signalling induces chromosomal instability in $\mathrm{BL}$ cells harbouring an otherwise simple karyotype. In order to show that the group of "BCR.1 high" lymphoma indeed harbour a longer passage through the G2 phase one strategy could be to stain G2 phase markers, like CyclinB, in histological specimens of DLBCL. Thereby one could be able to check whether the prolonged duration of the G2 phase can be indeed found in vivo. As c-Myc is likely not the only factor regulating BCR.1 genes, it would be interesting to investigate which pathways could additionally mediate the inhibition of BCR.1 cluster genes and the BCR mediated cell cycle effect in order to infer on the possibly deregulated pathways in "BCR.1 high" lymphoma. Using a recently published dataset of geneexpression profiles of 900 aNHL cases (Salaverria, Philipp et al. 2011), that includes survival analyses as independent dataset; it would be interesting to investigate the impact of BCR.1 cluster activity on the patient outcome. Identifying the oppositional existence of BCR.1 activity and c-Myc activity reflected in the gene expression profiles of aNHL this study enabled to suggest new models explaining the heterogeneity of aNHL.

As pointed out in paragraph 3.3.2 the newly identified gene clusters representing pathway activities induced by $B$ cell stimuli did not discriminate ABC from GCB DLBCL. These DLBCL subgroups have been identified on the basis of global differences in lymphoma gene expression profiles (Alizadeh, Eisen et al. 2000). Alizadeh and colleagues described that genes which are differentially expressed comparing both DLBCL subgroups are as well differentially expressed comparing normal GC B cells with peripheral blood B lymphocytes activated with a combination of CD40L, anti-IgM and IL-4. Based on the similarity of lymphoma gene expression profiles to these different normal B cell gene expression profiles the subgroups were named ABC like and GCB like DLBCL. This approach is different to the strategy followed in this study. Alizadeh and colleagues did not focus on genes that are activated by specifically one single stimulus but rather considered the global effects of B cell activation. Genes considered for the 
discrimination of $A B C$ and $G C B$ lymphoma are expressed in the same way in stimulated peripheral blood cells disregarding the stimulus used and the time point of microarray analysis. Thus this "activated B cell pattern" observed by Alizadeh and collegues is rather mediated by a combination of distinct activated pathways in the peripheral blood cells as well as in the lymphoma. It has been shown by several studies that the group of $A B C D L B C L$ still comprises heterogeneous lymphomas that depend on distinct oncogenic pathways (Bentink, Wessendorf et al. 2008; Kloo, Nagel et al. 2011). To achieve a discrimination of $A B C$ and $G C B$ using the gene modules presented here, it could therefore be promising to utilize a combination of distinct gene cluster activities. Nevertheless this was not the primary focus of this study. 


\section{Conclusion}

The integration of global gene expression data from in vitro perturbation analyses as ectopic expression of c-Myc in GC B cells or stimulation of lymphoma cells provides a robust quantitative measure of oncogenic activity in individual lymphoma. This study offers a comprehensive data repository that enabled the advancement of bioinformatical methods. By providing these gene expression analyses, this study is of high value for lymphoma research in general, as these data open a new scope to signalling events induced by specific $B$ cell stimuli in lymphoma cells. The identification of gene clusters regulated by BCR, CD40, IL21, LPS and BAFF provides new opportunities for the analysis of aberrant signalling in lymphomas.

DLBCLs with high c-Myc activity were identified. It was shown that the c-Myc index is an independent negative prognostic factor for these patients. Furthermore, it was found that the c-Myc index is inversely correlated to a newly identified BCR regulated gene cluster in gene expression profiles of aNHL. This correlation links for the first time active BCR signalling to the growth behaviour differences in aNHL. Furthermore, the results presented in this study propose a new explanation regarding the potential mechanism of the appearance of a higher cytogenetic complexity in DLBCLs: a high BCR signal and low c-Myc activity could be involved in a prolonged G2 phase in some DLBCLs which is followed by defects in spindle checkpoint functions, probably leading to enhanced chromosomal instabilities in these lymphomas. This could have implications for individualized therapies of lymphoma patients regarding the usage of chemotherapeutics targeting G2 phase associated processes.

Integrating the information retrieved from the identified c-Myc index and the BCR.1 cluster it was shown that the effects of a genetic alteration are not per se static, but can be mimicked by external mechanisms as paracrine stimulation of lymphoma cells with micro-environmental factors. 


\section{Bibliography}

Adhikary, S. and M. Eilers (2005). "Transcriptional regulation and transformation by Myc proteins." Nat Rev Mol Cell Biol 6(8): 635-645.

Akamatsu, N., Y. Yamada, et al. (2007). "High IL-21 receptor expression and apoptosis induction by IL-21 in follicular lymphoma." Cancer Lett 256(2): 196-206.

Alizadeh, A. A., M. B. Eisen, et al. (2000). "Distinct types of diffuse large B-cell lymphoma identified by gene expression profiling." Nature 403(6769): 503-511.

An, S. and K. A. Knox (1996). "Ligation of CD40 rescues Ramos-Burkitt lymphoma B cells from calcium ionophore- and antigen receptor-triggered apoptosis by inhibiting activation of the cysteine protease CPP32/Yama and cleavage of its substrate PARP." FEBS Lett 386(2-3): 115-122.

Aramburu, J., M. B. Yaffe, et al. (1999). "Affinity-driven peptide selection of an NFAT inhibitor more selective than cyclosporin A." Science 285(5436): 2129-2133.

Armitage, R. J., W. C. Fanslow, et al. (1992). "Molecular and biological characterization of a murine ligand for CD40." Nature 357(6373): 80-82.

Asao, H., C. Okuyama, et al. (2001). "Cutting edge: the common gamma-chain is an indispensable subunit of the IL-21 receptor complex." J Immunol 167(1): 1-5.

Audette, M., L. Larouche, et al. (2001). "Stimulation of the ICAM-1 gene transcription by the peroxovanadium compound [bpV(Pic)] involves STAT-1 but not NF-kappa B activation in 293 cells." Eur J Biochem 268(6): 1828-1836.

Badr, G., G. Borhis, et al. (2008). "BAFF enhances chemotaxis of primary human B cells: a particular synergy between BAFF and CXCL13 on memory B cells." Blood 111(5): 2744-2754.

Baker, D. J., F. Jin, et al. (2009). "Whole chromosome instability caused by Bub1 insufficiency drives tumorigenesis through tumor suppressor gene loss of heterozygosity." Cancer Cell 16(6): 475-486.

Baker, K. P., B. M. Edwards, et al. (2003). "Generation and characterization of LymphoStat-B, a human monoclonal antibody that antagonizes the bioactivities of $B$ lymphocyte stimulator." Arthritis Rheum 48(11): 3253-3265.

Baldwin, A. S., Jr. (1996). "The NF-kappa B and I kappa B proteins: new discoveries and insights." Annu Rev Immunol 14: 649-683.

Baohua, Y., Z. Xiaoyan, et al. (2008). "Mutations of the PIK3CA gene in diffuse large B cell lymphoma." Diagn Mol Pathol 17(3): 159-165.

Baron, B. W., G. Nucifora, et al. (1993). "Identification of the gene associated with the recurring chromosomal translocations $t(3 ; 14)(q 27 ; q 32)$ and $t(3 ; 22)(q 27 ; q 11)$ in B-cell lymphomas." Proc Natl Acad Sci U S A 90(11): 5262-5266.

Barrans, S., S. Crouch, et al. (2011). "Rearrangement of MYC is associated with poor prognosis in patients with diffuse large B-cell lymphoma treated in the era of rituximab." $\underline{\mathrm{J}}$ Clin Oncol 28(20): 3360-3365.

Basso, K., U. Klein, et al. (2004). "Tracking CD40 signaling during germinal center development." Blood 104(13): 4088-4096.

Basso, K., M. Saito, et al. (2010). "Integrated biochemical and computational approach identifies BCL6 direct target genes controlling multiple pathways in normal germinal center B cells." Blood 115(5): 975-984. 
Beckwith, M., D. L. Longo, et al. (1990). "Phorbol ester-induced, cell-cycle-specific, growth inhibition of human B-lymphoma cell lines." J Natl Cancer Inst 82(6): 501-509.

Ben-Bassat, H., N. Goldblum, et al. (1977). "Establishment in continuous culture of a new type of lymphocyte from a "Burkitt like" malignant lymphoma (line D.G.-75)." Int J Cancer 19(1): 27-33.

Bennett, B. L., D. T. Sasaki, et al. (2001). "SP600125, an anthrapyrazolone inhibitor of Jun N-terminal kinase." Proc Natl Acad Sci U S A 98(24): 13681-13686.

Bentink, S., S. Wessendorf, et al. (2008). "Pathway activation patterns in diffuse large Bcell lymphomas." Leukemia 22(9): 1746-1754.

Berg, T., S. B. Cohen, et al. (2002). "Small-molecule antagonists of Myc/Max dimerization inhibit Myc-induced transformation of chicken embryo fibroblasts." Proc Natl Acad Sci U S A 99(6): 3830-3835.

Bernheim, A., R. Berger, et al. (1983). "Cytogenetic studies on Burkitt's lymphoma cell lines." Cancer Genet Cytogenet 8(3): 223-229.

Bidere, N., V. N. Ngo, et al. (2009). "Casein kinase 1alpha governs antigen-receptorinduced NF-kappaB activation and human lymphoma cell survival." Nature 458(7234): 92-96.

Bild, A. H., G. Yao, et al. (2006). "Oncogenic pathway signatures in human cancers as a guide to targeted therapies." Nature 439(7074): 353-357.

Blackwell, T. K., L. Kretzner, et al. (1990). "Sequence-specific DNA binding by the c-Myc protein." Science 250(4984): 1149-1151.

Blumer, K. J. (2004). "Vision: the need for speed." Nature 427(6969): 20-21.

Bossen, C. and P. Schneider (2006). "BAFF, APRIL and their receptors: structure, function and signaling." Semin Immunol 18(5): 263-275.

Boveri, T. (1907). "Zellenstudien. VI. Eine für die erste Orientierung geeignete Darstellung dieser und anderer Chromosomenprobleme findet sich in meiner Schrift: Ergebnisse über die Konstitution der chromatischen Substanz des Zellkerns." Jena 1904.

Boveri, T. (2008). "Concerning the origin of malignant tumours by Theodor Boveri. Translated and annotated by Henry Harris." J Cell Sci 121 Suppl 1: 1-84.

Bradford, M. M. (1976). "A rapid and sensitive method for the quantitation of microgram quantities of protein utilizing the principle of protein-dye binding." Anal Biochem 72: 248254.

Briones, J., J. M. Timmerman, et al. (2002). "BLyS and BLyS receptor expression in nonHodgkin's lymphoma." Exp Hematol 30(2): 135-141.

Burkitt, D. (1958). "A sarcoma involving the jaws in African children." Br J Surg 46(197): 218-223.

Cambier, J. C. (1995). "New nomenclature for the Reth motif (or ARH1/TAM/ARAM/YXXL)." Immunol Today 16(2): 110.

Chang, H., J. A. Blondal, et al. (1995). "p53 mutations, c-myc and bcl-2 rearrangements in human non-Hodgkin's lymphoma cell lines." Leuk Lymphoma 19(1-2): 165-171.

Chen, L., S. Monti, et al. (2008). "SYK-dependent tonic B-cell receptor signaling is a rational treatment target in diffuse large B-cell lymphoma." Blood 111(4): 2230-2237.

Cheng, G., A. M. Cleary, et al. (1995). "Involvement of CRAF1, a relative of TRAF, in CD40 signaling." Science 267(5203): 1494-1498. 
Choi, W. W., D. D. Weisenburger, et al. (2009). "A new immunostain algorithm classifies diffuse large B-cell lymphoma into molecular subtypes with high accuracy." Clin Cancer Res 15(17): 5494-5502.

Ci, W., J. M. Polo, et al. (2009). "The BCL6 transcriptional program features repression of multiple oncogenes in primary B cells and is deregulated in DLBCL." Blood 113(22): 5536-5548.

Claudio, E., K. Brown, et al. (2002). "BAFF-induced NEMO-independent processing of NF-kappa B2 in maturing B cells." Nat Immunol 3(10): 958-965.

Coiffier, B. (2005). "Current strategies for the treatment of diffuse large B cell lymphoma." Curr Opin Hematol 12(4): 259-265.

Compagno, M., W. K. Lim, et al. (2009). "Mutations of multiple genes cause deregulation of NF-kappaB in diffuse large B-cell lymphoma." Nature 459(7247): 717-721.

Coquet, J. M., K. Kyparissoudis, et al. (2007). "IL-21 is produced by NKT cells and modulates NKT cell activation and cytokine production." $\mathrm{J}$ Immunol 178(5): 2827-2834.

Cuenda, A., J. Rouse, et al. (1995). "SB 203580 is a specific inhibitor of a MAP kinase homologue which is stimulated by cellular stresses and interleukin-1." FEBS Lett 364(2): 229-233.

D'Orlando, O., G. Gri, et al. (2007). "Outside inside signalling in CD40-mediated B cell activation." J Biol Regul Homeost Agents 21(3-4): 49-62.

Dalla-Favera, R., M. Bregni, et al. (1982). "Human c-myc onc gene is located on the region of chromosome 8 that is translocated in Burkitt lymphoma cells." Proc Natl Acad Sci U S A 79(24): 7824-7827.

Dang, C. V., K. A. O'Donnell, et al. (2006). "The c-Myc target gene network." Semin Cancer Biol 16(4): 253-264.

Dave, B. J., M. Nelson, et al. (2002). "Cytogenetic characterization of diffuse large cell lymphoma using multi-color fluorescence in situ hybridization." Cancer Genet Cytogenet 132(2): 125-132.

Dave, S. S., K. Fu, et al. (2006). "Molecular diagnosis of Burkitt's lymphoma." N Engl J Med 354(23): 2431-2442.

Davis, I. D., K. Skak, et al. (2007). "Interleukin-21 signaling: functions in cancer and autoimmunity." Clin Cancer Res 13(23): 6926-6932.

Davis, R. E., K. D. Brown, et al. (2001). "Constitutive nuclear factor kappaB activity is required for survival of activated $B$ cell-like diffuse large B cell lymphoma cells." $\underline{J}$ Exp Med 194(12): 1861-1874.

Davis, R. E., V. N. Ngo, et al. (2010). "Chronic active B-cell-receptor signalling in diffuse large B-cell lymphoma." Nature 463(7277): 88-92.

de Jong, D. and O. Balague Ponz (2011). "The molecular background of aggressive B cell lymphomas as a basis for targeted therapy." J Pathol 223(2): 274-282.

den Hollander, J., S. Rimpi, et al. (2009). "Aurora kinases A and B are up-regulated by Myc and are essential for maintenance of the malignant state." Blood 116(9): 1498-1505.

Dent, A. L., A. L. Shaffer, et al. (1997). "Control of inflammation, cytokine expression, and germinal center formation by BCL-6." Science 276(5312): 589-592.

Dillon, S. R., J. A. Gross, et al. (2006). "An APRIL to remember: novel TNF ligands as therapeutic targets." Nat Rev Drug Discov 5(3): 235-246. 
Ding, B. B., J. J. Yu, et al. (2008). "Constitutively activated STAT3 promotes cell proliferation and survival in the activated B-cell subtype of diffuse large B-cell lymphomas." Blood 111(3): 1515-1523.

Ding, C. and G. Jones (2006). "Belimumab Human Genome Sciences/Cambridge Antibody Technology/GlaxoSmithKline." Curr Opin Investig Drugs 7(5): 464-472.

Doyle, S. L. and L. A. O'Neill (2006). "Toll-like receptors: from the discovery of NFkappaB to new insights into transcriptional regulations in innate immunity." Biochem Pharmacol 72(9): 1102-1113.

Egawa, T., B. Albrecht, et al. (2003). "Requirement for CARMA1 in antigen receptorinduced NF-kappa B activation and lymphocyte proliferation." Curr Biol 13(14): 12521258.

Eick, D. and G. W. Bornkamm (1989). "Expression of normal and translocated c-myc alleles in Burkitt's lymphoma cells: evidence for different regulation." EMBO J 8(7): 19651972.

Epstein, A. L., M. M. Herman, et al. (1976). "Biology of the human malignant lymphomas. III. Intracranial heterotransplantation in the nude, athymic mouse." Cancer 37(5): 21582176.

Epstein, A. L., R. Levy, et al. (1978). "Biology of the human malignant lymphomas. IV. Functional characterization of ten diffuse histiocytic lymphoma cell lines." Cancer 42(5): 2379-2391.

Ettinger, R., S. Kuchen, et al. (2008). "The role of IL-21 in regulating B-cell function in health and disease." Immunol Rev 223: 60-86.

Ettinger, R., G. P. Sims, et al. (2005). "IL-21 induces differentiation of human naive and memory B cells into antibody-secreting plasma cells." J Immunol 175(12): 7867-7879.

Fan, J., K. Zeller, et al. (2010). "Time-dependent c-Myc transactomes mapped by Arraybased nuclear run-on reveal transcriptional modules in human B cells." PLoS One 5(3): e9691.

Farinha, P. and R. D. Gascoyne (2005). "Molecular pathogenesis of mucosa-associated lymphoid tissue lymphoma." J Clin Oncol 23(26): 6370-6378.

Favata, M. F., K. Y. Horiuchi, et al. (1998). "Identification of a novel inhibitor of mitogenactivated protein kinase kinase." J Biol Chem 273(29): 18623-18632.

Ferlay J, S. H., Bray F, Forman D, Mathers C and Parkin DM. (2010). "GLOBOCAN 2008 v1.2, Cancer Incidence and Mortality Worldwide: IARC CancerBase No. 10 [Internet].", from http://globocan.iarc.fr

Feuerhake, F., J. L. Kutok, et al. (2005). "NFkappaB activity, function, and target-gene signatures in primary mediastinal large B-cell lymphoma and diffuse large B-cell lymphoma subtypes." Blood 106(4): 1392-1399.

Fox (1980). "A model for the computer analysis of synchronous DNA distributions obtained by flow cytometry." Cytometry 1: 71-77.

Foy, T. M., J. D. Laman, et al. (1994). "gp39-CD40 interactions are essential for germinal center formation and the development of B cell memory." J Exp Med 180(1): 157-163.

Foy, T. M., D. M. Shepherd, et al. (1993). "In vivo CD40-gp39 interactions are essential for thymus-dependent humoral immunity. II. Prolonged suppression of the humoral immune response by an antibody to the ligand for CD40, gp39." J Exp Med 178(5): 1567-1575. 
Friedberg, J. W. and R. I. Fisher (2008). "Diffuse large B-cell lymphoma." Hematol Oncol Clin North Am 22(5): 941-952, ix.

Fukuda, T., T. Yoshida, et al. (1997). "Disruption of the Bcl6 gene results in an impaired germinal center formation." J Exp Med 186(3): 439-448.

Fuqua, C. F., R. Akomeah, et al. (2008). "Involvement of ERK-1/2 in IL-21-induced cytokine production in leukemia cells and human monocytes." Cytokine 44(1): 101-107.

Gardam, S., F. Sierro, et al. (2008). "TRAF2 and TRAF3 signal adapters act cooperatively to control the maturation and survival signals delivered to $B$ cells by the BAFF receptor." Immunity 28(3): 391-401.

Good, D. J. and R. D. Gascoyne (2008). "Classification of non-Hodgkin's lymphoma." Hematol Oncol Clin North Am 22(5): 781-805, vii.

Graf, D., U. Korthauer, et al. (1992). "Cloning of TRAP, a ligand for CD40 on human T cells." Eur J Immunol 22(12): 3191-3194.

Gross, J. A., J. Johnston, et al. (2000). "TACI and BCMA are receptors for a TNF homologue implicated in B-cell autoimmune disease." Nature 404(6781): 995-999.

Gururajan, M., C. D. Jennings, et al. (2006). "Cutting edge: constitutive B cell receptor signaling is critical for basal growth of B lymphoma." J Immunol 176(10): 5715-5719.

Hailfinger, S., G. Lenz, et al. (2009). "Essential role of MALT1 protease activity in activated B cell-like diffuse large B-cell lymphoma." Proc Natl Acad Sci U S A 106(47): 19946-19951.

Hanahan, D. and R. A. Weinberg (2011). "Hallmarks of cancer: the next generation." Cell 144(5): 646-674.

Harada, M., K. Magara-Koyanagi, et al. (2006). "IL-21-induced Bepsilon cell apoptosis

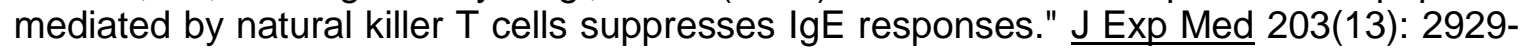
2937.

Hatzoglou, A., J. Roussel, et al. (2000). "TNF receptor family member BCMA (B cell maturation) associates with TNF receptor-associated factor (TRAF) 1, TRAF2, and TRAF3 and activates NF-kappa B, elk-1, c-Jun N-terminal kinase, and p38 mitogenactivated protein kinase." J Immunol 165(3): 1322-1330.

He, B., A. Chadburn, et al. (2004). "Lymphoma B cells evade apoptosis through the TNF family members BAFF/BLyS and APRIL." J Immunol 172(5): 3268-3279.

Hollenbaugh, D., L. S. Grosmaire, et al. (1992). "The human T cell antigen gp39, a member of the TNF gene family, is a ligand for the CD40 receptor: expression of a soluble form of gp39 with B cell co-stimulatory activity." EMBO J 11(12): 4313-4321.

Hömig-Hölzel, C., C. Hojer, et al. (2008). "Constitutive CD40 signaling in B cells selectively activates the noncanonical NF-kappaB pathway and promotes lymphomagenesis." J Exp Med 205(6): 1317-1329.

Hörtnagel, K., J. Mautner, et al. (1995). "The role of immunoglobulin kappa elements in c-myc activation." Oncogene 10(7): 1393-1401.

Hoshino, K., O. Takeuchi, et al. (1999). "Cutting edge: Toll-like receptor 4 (TLR4)deficient mice are hyporesponsive to lipopolysaccharide: evidence for TLR4 as the Lps gene product." $\mathrm{J}$ Immunol 162(7): 3749-3752.

Hristov, K. K., K. A. Knox, et al. (2005). "Regulation of tyrosine phosphorylation during the CD40-mediated rescue of Ramos-BL B cells from BCR-triggered apoptosis." Int J Mol Med 16(5): 937-941. 
Hristov, K. K., K. A. Knox, et al. (2007). "Vanadate-induced inhibition of BCR-triggered apoptosis is coupled with tyrosine phosphorylation and induction of G2M growth arrest in Ramos-BL B cells." Immunol Invest 36(3): 293-306.

Hu, H. M., K. O'Rourke, et al. (1994). "A novel RING finger protein interacts with the cytoplasmic domain of CD40." J Biol Chem 269(48): 30069-30072.

Huber, W., A. von Heydebreck, et al. (2002). "Variance stabilization applied to microarray data calibration and to the quantification of differential expression." Bioinformatics 18 Suppl 1: S96-104.

Hummel, M., S. Bentink, et al. (2006). "A biologic definition of Burkitt's lymphoma from transcriptional and genomic profiling." N Engl J Med 354(23): 2419-2430.

lqbal, J., T. C. Greiner, et al. (2007). "Distinctive patterns of BCL6 molecular alterations and their functional consequences in different subgroups of diffuse large B-cell lymphoma." Leukemia 21(11): 2332-2343.

lqbal, J., S. Gupta, et al. (2007). "Diffuse large B-cell lymphoma with a novel translocation involving BCL6." Cancer Genet Cytogenet 178(1): 73-76.

Irizarry, R. A., B. Hobbs, et al. (2003). "Exploration, normalization, and summaries of high density oligonucleotide array probe level data." Biostatistics 4(2): 249-264.

Ishida, T., S. Mizushima, et al. (1996). "Identification of TRAF6, a novel tumor necrosis factor receptor-associated factor protein that mediates signaling from an amino-terminal domain of the CD40 cytoplasmic region." J Biol Chem 271(46): 28745-28748.

Ishida, T. K., T. Tojo, et al. (1996). "TRAF5, a novel tumor necrosis factor receptorassociated factor family protein, mediates CD40 signaling." Proc Natl Acad Sci U S A 93(18): 9437-9442.

Jaffe, E. S., N. L. Harris, et al. (1998). "World Health Organization Classification of lymphomas: a work in progress." Ann Oncol 9 Suppl 5: S25-30.

Jamal, M. S., S. Ravichandran, et al. (2010). "Defining the antigen receptor-dependent regulatory network that induces arrest of cycling immature B-lymphocytes." BMC Syst Biol 4: 169.

Jeffrey, K. L., T. Brummer, et al. (2006). "Positive regulation of immune cell function and inflammatory responses by phosphatase PAC-1." Nat Immunol 7(3): 274-283.

Johnson, N. A., K. J. Savage, et al. (2009). "Lymphomas with concurrent BCL2 and MYC translocations: the critical factors associated with survival." Blood 114(11): 2273-2279.

Kahl, B. (2008). "Chemotherapy combinations with monoclonal antibodies in nonHodgkin's lymphoma." Semin Hematol 45(2): 90-94.

Kaptein, J. S., C. K. Lin, et al. (1996). "Anti-lgM-mediated regulation of c-myc and its possible relationship to apoptosis." J Biol Chem 271(31): 18875-18884.

Karin, M. and Y. Ben-Neriah (2000). "Phosphorylation meets ubiquitination: the control of NF-[kappa]B activity." Annu Rev Immunol 18: 621-663.

Kawai, T., O. Adachi, et al. (1999). "Unresponsiveness of MyD88-deficient mice to endotoxin." Immunity 11(1): 115-122.

Ke, J., R. L. Chelvarajan, et al. (2009). "Anomalous constitutive Src kinase activity promotes B lymphoma survival and growth." Mol Cancer 8: 132.

Keller, U., J. Huber, et al. (2010). "Myc suppression of Nfkb2 accelerates lymphomagenesis." BMC Cancer 10: 348. 
Keyse, S. M. (2000). "Protein phosphatases and the regulation of mitogen-activated protein kinase signalling." Curr Opin Cell Biol 12(2): 186-192.

Keyse, S. M. (2008). "Dual-specificity MAP kinase phosphatases (MKPs) and cancer." Cancer Metastasis Rev 27(2): 253-261.

Khan, W. N. (2009). "B cell receptor and BAFF receptor signaling regulation of B cell homeostasis." J Immunol 183(6): 3561-3567.

Klapper, W., H. Stoecklein, et al. (2008). "Structural aberrations affecting the MYC locus indicate a poor prognosis independent of clinical risk factors in diffuse large B-cell lymphomas treated within randomized trials of the German High-Grade Non-Hodgkin's Lymphoma Study Group (DSHNHL)." Leukemia 22(12): 2226-2229.

Klapproth, K., S. Sander, et al. (2009). "The IKK2/NF-\{kappa\}B pathway suppresses MYC-induced lymphomagenesis." Blood 114(12): 2448-2458.

Klein, G., B. Giovanella, et al. (1975). "An EBV-genome-negative cell line established from an American Burkitt lymphoma; receptor characteristics. EBV infectibility and permanent conversion into EBV-positive sublines by in vitro infection." Intervirology 5(6): 319-334.

Klein, U. and R. Dalla-Favera (2008). "Germinal centres: role in B-cell physiology and malignancy." Nat Rev Immunol 8(1): 22-33.

Klein, U., Y. Tu, et al. (2003). "Transcriptional analysis of the B cell germinal center reaction." Proc Natl Acad Sci U S A 100(5): 2639-2644.

Kloo, B., D. Nagel, et al. (2011). "Critical role of PI3K signaling for NF-kappaB-dependent survival in a subset of activated B-cell-like diffuse large B-cell lymphoma cells." Proc Natl Acad Sci U S A 108(1): 272-277.

Konforte, D., N. Simard, et al. (2009). "IL-21: an executor of B cell fate." J Immunol 182(4): 1781-1787.

Kube, D., C. Platzer, et al. (1995). "Isolation of the human interleukin 10 promoter. Characterization of the promoter activity in Burkitt's lymphoma cell lines." Cytokine 7(1): 1-7.

Kube, D. and M. Vockerodt (2001). "Transient gene expression and MACS enrichment." Methods Mol Biol 174: 155-164.

Küppers, R. (2005). "Mechanisms of B-cell lymphoma pathogenesis." Nat Rev Cancer 5(4): 251-262.

Küppers, R. and R. Dalla-Favera (2001). "Mechanisms of chromosomal translocations in B cell lymphomas." Oncogene 20(40): 5580-5594.

Kutz, H., G. Reisbach, et al. (2008). "The c-Jun N-terminal kinase pathway is critical for cell transformation by the latent membrane protein 1 of Epstein-Barr virus." Virology 371(2): 246-256.

Ladanyi, M., K. Offit, et al. (1991). "MYC rearrangement and translocations involving band 8q24 in diffuse large cell lymphomas." Blood 77(5): 1057-1063.

Lam, L. T., R. E. Davis, et al. (2005). "Small molecule inhibitors of IkappaB kinase are selectively toxic for subgroups of diffuse large B-cell lymphoma defined by gene expression profiling." Clin Cancer Res 11(1): 28-40.

Lam, L. T., G. Wright, et al. (2008). "Cooperative signaling through the signal transducer and activator of transcription 3 and nuclear factor-\{kappa\}B pathways in subtypes of diffuse large B-cell lymphoma." Blood 111(7): 3701-3713. 
Lang, R., M. Hammer, et al. (2006). "DUSP meet immunology: dual specificity MAPK phosphatases in control of the inflammatory response." J Immunol 177(11): 7497-7504.

Laskov, R., N. Berger, et al. (2005). "Differential effects of tumor necrosis factor-alpha and CD40L on NF-kappa B inhibitory proteins I kappa B alpha, beta and epsilon and on the induction of the Jun amino-terminal kinase pathway in Ramos Burkitt lymphoma cells." Eur Cytokine Netw 16(4): 267-276.

Lederman, S., M. J. Yellin, et al. (1992). "Identification of a novel surface protein on activated CD4+ T cells that induces contact-dependent B cell differentiation (help)." $\underline{J}$ Exp Med 175(4): 1091-1101.

Lee, H., A. Herrmann, et al. (2009). "Persistently activated Stat3 maintains constitutive NF-kappaB activity in tumors." Cancer Cell 15(4): 283-293.

Lee, J. K., S. O. Mathew, et al. (2007). "CS1 (CRACC, CD319) induces proliferation and autocrine cytokine expression on human B lymphocytes." J Immunol 179(7): 4672-4678.

Lenoir, G. M., M. Vuillaume, et al. (1985). "The use of lymphomatous and lymphoblastoid cell lines in the study of Burkitt's lymphoma." IARC Sci PubI(60): 309-318.

Lenz, G., R. E. Davis, et al. (2008). "Oncogenic CARD11 mutations in human diffuse large B cell lymphoma." Science 319(5870): 1676-1679.

Li, M., X. Fang, et al. (2009). "Loss of spindle assembly checkpoint-mediated inhibition of Cdc20 promotes tumorigenesis in mice." J Cell Biol 185(6): 983-994.

Li, Z., S. Van Calcar, et al. (2003). "A global transcriptional regulatory role for c-Myc in Burkitt's lymphoma cells." Proc Natl Acad Sci U S A 100(14): 8164-8169.

Liu, L., M. Zhang, et al. (2007). "Expression of PLK1 and survivin in diffuse large B-cell lymphoma." Leuk Lymphoma 48(11): 2179-2183.

Liu, Y., X. Hong, et al. (2003). "Ligand-receptor binding revealed by the TNF family member TALL-1." Nature 423(6935): 49-56.

Locksley, R. M., N. Killeen, et al. (2001). "The TNF and TNF receptor superfamilies: integrating mammalian biology." Cell 104(4): 487-501.

Loken, M. R., D. R. Parks, et al. (1977). "Two-color immunofluorescence using a fluorescence-activated cell sorter." J Histochem Cytochem 25(7): 899-907.

Mackay, F. and H. Leung (2006). "The role of the BAFF/APRIL system on T cell function." Semin Immunol 18(5): 284-289.

Mackay, F., F. Sierro, et al. (2005). "The BAFF/APRIL system: an important player in systemic rheumatic diseases." Curr Dir Autoimmun 8: 243-265.

Mackus, W. J., S. M. Lens, et al. (2002). "Prevention of B cell antigen receptor-induced apoptosis by ligation of CD40 occurs downstream of cell cycle regulation." Int Immunol 14(9): 973-982.

Magrath, I. T., C. B. Freeman, et al. (1980). "Characterization of lymphoma-derived cell lines: comparison of cell lines positive and negative for Epstein-Barr virus nuclear antigen. II. Surface markers." J Natl Cancer Inst 64(3): 477-483.

Maneck, M., A. Schrader, et al. (2011). "Genomic data integration using guided clustering." Bioinformatics.

Matsuzawa, A., P. H. Tseng, et al. (2008). "Essential cytoplasmic translocation of a cytokine receptor-assembled signaling complex." Science 321 (5889): 663-668.

McNally, R. J. and L. Parker (2006). "Environmental factors and childhood acute leukemias and lymphomas." Leuk Lymphoma 47(4): 583-598. 
Medzhitov, R., P. Preston-Hurlburt, et al. (1997). "A human homologue of the Drosophila Toll protein signals activation of adaptive immunity." Nature 388(6640): 394-397.

Menssen, A., A. Epanchintsev, et al. (2007). "C-MYC delays prometaphase by direct transactivation of MAD2 and BubR1: identification of mechanisms underlying C-MYCinduced DNA damage and chromosomal instability." Cell Cycle 6(3): 339-352.

Mito, K., K. Kashima, et al. (2005). "Expression of Polo-Like Kinase (PLK1) in nonHodgkin's lymphomas." Leuk Lymphoma 46(2): 225-231.

Monti, S., K. J. Savage, et al. (2005). "Molecular profiling of diffuse large B-cell lymphoma identifies robust subtypes including one characterized by host inflammatory response." Blood 105(5): 1851-1861.

Moore, P. A., O. Belvedere, et al. (1999). "BLyS: member of the tumor necrosis factor family and B lymphocyte stimulator." Science 285(5425): 260-263.

Muramatsu, M., K. Kinoshita, et al. (2000). "Class switch recombination and hypermutation require activation-induced cytidine deaminase (AID), a potential RNA editing enzyme." Cell 102(5): 553-563.

Murn, J., I. Mlinaric-Rascan, et al. (2009). "A Myc-regulated transcriptional network controls B-cell fate in response to BCR triggering." BMC Genomics 10: 323.

Ngo, V. N., R. E. Davis, et al. (2006). "A loss-of-function RNA interference screen for molecular targets in cancer." Nature 441(7089): 106-110.

Ngo, V. N., R. M. Young, et al. (2011). "Oncogenically active MYD88 mutations in human lymphoma." Nature 470(7332): 115-119.

Nicoletti, I., G. Migliorati, et al. (1991). "A rapid and simple method for measuring thymocyte apoptosis by propidium iodide staining and flow cytometry." J Immunol Methods 139(2): 271-279.

Nilsson, K. and J. Ponten (1975). "Classification and biological nature of established human hematopoietic cell lines." Int J Cancer 15(2): 321-341.

Ninomiya-Tsuji, J., T. Kajino, et al. (2003). "A resorcylic acid lactone, 5Z-7-oxozeaenol, prevents inflammation by inhibiting the catalytic activity of TAK1 MAPK kinase kinase." $\underline{\mathrm{J}}$ Biol Chem 278(20): 18485-18490.

Novak, A. J., J. R. Darce, et al. (2004). "Expression of BCMA, TACI, and BAFF-R in multiple myeloma: a mechanism for growth and survival." Blood 103(2): 689-694.

Novak, A. J., D. M. Grote, et al. (2004). "Expression of BLyS and its receptors in B-cell non-Hodgkin lymphoma: correlation with disease activity and patient outcome." Blood 104(8): 2247-2253.

O'Conor, G. T., H. Rappaport, et al. (1965). "Childhood Lymphoma Resembling "Burkitt Tumor" in the United States." Cancer 18: 411-417.

O'Dea, E. and A. Hoffmann "The regulatory logic of the NF-kappaB signaling system." Cold Spring Harb Perspect Biol 2(1): a000216.

Ogden, C. A., J. D. Pound, et al. (2005). "Enhanced apoptotic cell clearance capacity and $B$ cell survival factor production by IL-10-activated macrophages: implications for Burkitt's lymphoma." J Immunol 174(5): 3015-3023.

Oliveros, J. C. (2007). "VENNY." Retrieved 18/11/2011, 20011, from http://bioinfogp.cnb.csic.es/tools/venny/index.html.

Osmond, D. G. (1990). "B cell development in the bone marrow." Semin Immunol 2(3): 173-180. 
Palsson-McDermott, E. M. and L. A. O'Neill (2004). "Signal transduction by the lipopolysaccharide receptor, Toll-like receptor-4." Immunology 113(2): 153-162.

Parrish-Novak, J., S. R. Dillon, et al. (2000). "Interleukin 21 and its receptor are involved in NK cell expansion and regulation of lymphocyte function." Nature 408(6808): 57-63.

Pelengaris, S., M. Khan, et al. (2002). "c-MYC: more than just a matter of life and death." Nat Rev Cancer 2(10): 764-776.

Perkins, A. S. and J. W. Friedberg (2008). "Burkitt lymphoma in adults." Hematology Am Soc Hematol Educ Program: 341-348.

Pham, L. V., A. T. Tamayo, et al. (2005). "Constitutive NF-kappaB and NFAT activation in aggressive B-cell lymphomas synergistically activates the CD154 gene and maintains lymphoma cell survival." Blood 106(12): 3940-3947.

Poltorak, A., X. He, et al. (1998). "Defective LPS signaling in C3H/HeJ and C57BL/10ScCr mice: mutations in Tlr4 gene." Science 282(5396): 2085-2088.

Puskas, L. G., A. Zvara, et al. (2002). "RNA amplification results in reproducible microarray data with slight ratio bias." Biotechniques 32(6): 1330-1334, 1336, 1338, 1340.

Rajewsky, K. (1996). "Clonal selection and learning in the antibody system." Nature 381(6585): 751-758.

Rao, C. V., Y. M. Yang, et al. (2005). "Colonic tumorigenesis in BubR1+/-ApcMin/+ compound mutant mice is linked to premature separation of sister chromatids and enhanced genomic instability." Proc Natl Acad Sci U S A 102(12): 4365-4370.

Rasti, N., K. I. Falk, et al. (2005). "Circulating epstein-barr virus in children living in malaria-endemic areas." Scand J Immunol 61(5): 461-465.

Refaeli, Y., R. M. Young, et al. (2008). "The B cell antigen receptor and overexpression of MYC can cooperate in the genesis of B cell lymphomas." PLoS Biol 6(6): e152.

Reth, M. (1989). "Antigen receptor tail clue." Nature 338(6214): 383-384.

Rodig, S. J., A. Shahsafaei, et al. (2005). "BAFF-R, the major B cell-activating factor receptor, is expressed on most mature B cells and B-cell lymphoproliferative disorders." Hum Pathol 36(10): 1113-1119.

Rothe, M., V. Sarma, et al. (1995). "TRAF2-mediated activation of NF-kappa B by TNF receptor 2 and CD40." Science 269(5229): 1424-1427.

Ruland, J., G. S. Duncan, et al. (2001). "Bcl10 is a positive regulator of antigen receptorinduced activation of NF-kappaB and neural tube closure." Cell 104(1): 33-42.

Ruland, J., G. S. Duncan, et al. (2003). "Differential requirement for Malt1 in T and B cell antigen receptor signaling." Immunity 19(5): 749-758.

Saito, Y., Y. Miyagawa, et al. (2008). "B-cell-activating factor inhibits CD20-mediated and B-cell receptor-mediated apoptosis in human B cells." Immunology 125(4): 570-590.

Salaverria, I., C. Philipp, et al. (2011). "Translocations activating IRF4 identify a subtype of germinal center-derived B-cell lymphoma affecting predominantly children and young adults." Blood 118(1): 139-147.

Sampson, V. B., N. H. Rong, et al. (2007). "MicroRNA let-7a down-regulates MYC and reverts MYC-induced growth in Burkitt lymphoma cells." Cancer Res 67(20): 9762-9770.

Sanchez, M., Z. Misulovin, et al. (1993). "Signal transduction by immunoglobulin is mediated through Ig alpha and Ig beta." J Exp Med 178(3): 1049-1055. 
Sanda, T., S. lida, et al. (2005). "Growth inhibition of multiple myeloma cells by a novel IkappaB kinase inhibitor." Clin Cancer Res 11(5): 1974-1982.

Santos-Argumedo, L., J. Gordon, et al. (1994). "Antibodies to murine CD40 protect normal and malignant B cells from induced growth arrest." Cell Immunol 156(2): 272285.

Sato, T., S. Irie, et al. (1995). "A novel member of the TRAF family of putative signal transducing proteins binds to the cytosolic domain of CD40." FEBS Lett 358(2): 113-118.

Savage, K. J., N. A. Johnson, et al. (2009). "MYC gene rearrangements are associated with a poor prognosis in diffuse large B-cell lymphoma patients treated with R-CHOP chemotherapy." Blood 114(17): 3533-3537.

Saxena, M. and T. Mustelin (2000). "Extracellular signals and scores of phosphatases: all roads lead to MAP kinase." Semin Immunol 12(4): 387-396.

Schiemann, B., J. L. Gommerman, et al. (2001). "An essential role for BAFF in the normal development of B cells through a BCMA-independent pathway." Science 293(5537): 2111-2114.

Schlee, M., M. Holzel, et al. (2007). "C-myc activation impairs the NF-kappaB and the interferon response: implications for the pathogenesis of Burkitt's lymphoma." Int J Cancer 120(7): 1387-1395.

Schoffski, P. (2009). "Polo-like kinase (PLK) inhibitors in preclinical and early clinical development in oncology." Oncologist 14(6): 559-570.

Schrader, A., S. Bentink, et al. (2011). "High myc activity is an independent negative prognostic factor for diffuse large B cell lymphomas." Int J Cancer.

Schuhmacher, M., F. Kohlhuber, et al. (2001). "The transcriptional program of a human B cell line in response to Myc." Nucleic Acids Res 29(2): 397-406.

Shu, H. B., W. H. Hu, et al. (1999). "TALL-1 is a novel member of the TNF family that is down-regulated by mitogens." J Leukoc Biol 65(5): 680-683.

Simons-Evelyn, M., K. Bailey-Dell, et al. (2001). "PBK/TOPK is a novel mitotic kinase which is upregulated in Burkitt's lymphoma and other highly proliferative malignant cells." Blood Cells Mol Dis 27(5): 825-829.

Spolski, R. and W. J. Leonard (2008). "Interleukin-21: basic biology and implications for cancer and autoimmunity." Annu Rev Immunol 26: 57-79.

Stadanlick, J. E., M. Kaileh, et al. (2008). "Tonic B cell antigen receptor signals supply an NF-kappaB substrate for prosurvival BLyS signaling." Nat Immunol 9(12): 1379-1387.

Stasik, C. J., H. Nitta, et al. (2010). "Increased MYC gene copy number correlates with increased mRNA levels in diffuse large B-cell lymphoma." Haematologica 95(4): 597603.

Stolz, A., N. Ertych, et al. (2010). "The CHK2-BRCA1 tumour suppressor pathway ensures chromosomal stability in human somatic cells." Nat Cell Biol 12(5): 492-499.

Subramanian, A., P. Tamayo, et al. (2005). "Gene set enrichment analysis: a knowledgebased approach for interpreting genome-wide expression profiles." Proc Natl Acad Sci U S A 102(43): 15545-15550.

Taub, R., I. Kirsch, et al. (1982). "Translocation of the c-myc gene into the immunoglobulin heavy chain locus in human Burkitt lymphoma and murine plasmacytoma cells." Proc Natl Acad Sci U S A 79(24): 7837-7841.

Thomas, R. K., C. Wickenhauser, et al. (2004). "Mutational analysis of the lkappaBalpha gene in activated B cell-like diffuse large B-cell lymphoma." Br J Haematol 126(1): 50-54. 
Tweeddale, M., N. Jamal, et al. (1989). "Production of growth factors by malignant lymphoma cell lines." Blood 74(2): 572-578.

Uddin, S., A. R. Hussain, et al. (2006). "Role of phosphatidylinositol 3'-kinase/AKT pathway in diffuse large B-cell lymphoma survival." Blood 108(13): 4178-4186.

Vallabhapurapu, S., A. Matsuzawa, et al. (2008). "Nonredundant and complementary functions of TRAF2 and TRAF3 in a ubiquitination cascade that activates NIK-dependent alternative NF-kappaB signaling." Nat Immunol 9(12): 1364-1370.

Van den Eertwegh, A. J., R. J. Noelle, et al. (1993). "In vivo CD40-gp39 interactions are essential for thymus-dependent humoral immunity. I. In vivo expression of CD40 ligand, cytokines, and antibody production delineates sites of cognate T-B cell interactions." $\underline{\mathrm{J}}$ Exp Med 178(5): 1555-1565.

Vlahos, C. J., W. F. Matter, et al. (1994). "A specific inhibitor of phosphatidylinositol 3kinase, 2-(4-morpholinyl)-8-phenyl-4H-1-benzopyran-4-one (LY294002)." J Biol Chem 269(7): 5241-5248.

Vockerodt, M., S. L. Morgan, et al. (2008). "The Epstein-Barr virus oncoprotein, latent membrane protein-1, reprograms germinal centre B cells towards a Hodgkin's ReedSternberg-like phenotype." J Pathol 216(1): 83-92.

Vrzalikova, K., M. Vockerodt, et al. (2011). "Down-regulation of BLIMP1\{alpha\} by the EBV oncogene, LMP-1, disrupts the plasma cell differentiation program and prevents viral replication in B cells: implications for the pathogenesis of EBV-associated B-cell lymphomas." Blood 117(22): 5907-5917.

Wang, D., Y. You, et al. (2002). "A requirement for CARMA1 in TCR-induced NF-kappa B activation." Nat Immunol 3(9): 830-835.

Wang, H., R. J. Grand, et al. (1996). "Repression of apoptosis in human B-lymphoma cells by CD40-ligand and Bcl-2: relationship to the cell-cycle and role of the retinoblastoma protein." Oncogene 13(2): 373-379.

Wang, L. D. and M. R. Clark (2003). "B-cell antigen-receptor signalling in lymphocyte development." Immunology 110(4): 411-420.

Weiss, L. M., R. A. Warnke, et al. (1987). "Molecular analysis of the $t(14 ; 18)$ chromosomal translocation in malignant lymphomas." N Engl J Med 317(19): 1185-1189.

Wendel, M., I. E. Galani, et al. (2008). "Natural killer cell accumulation in tumors is dependent on IFN-gamma and CXCR3 ligands." Cancer Res 68(20): 8437-8445.

Wolanin, K., A. Magalska, et al. (2010). "Expression of oncogenic kinase Bcr-Abl impairs mitotic checkpoint and promotes aberrant divisions and resistance to microtubuletargeting agents." Mol Cancer Ther 9(5): 1328-1338.

Yang, J. and M. Reth (2010). "The dissociation activation model of B cell antigen receptor triggering." FEBS Lett 584(24): 4872-4877.

Ye, B. H., G. Cattoretti, et al. (1997). "The BCL-6 proto-oncogene controls germinalcentre formation and Th2-type inflammation." Nat Genet 16(2): 161-170.

Ye, B. H., P. H. Rao, et al. (1993). "Cloning of bcl-6, the locus involved in chromosome translocations affecting band 3q27 in B-cell lymphoma." Cancer Res 53(12): 2732-2735.

Yin, X., C. Giap, et al. (2003). "Low molecular weight inhibitors of Myc-Max interaction and function." Oncogene 22(40): 6151-6159.

Yustein, J. T. and C. V. Dang (2007). "Biology and treatment of Burkitt's lymphoma." Curr Opin Hematol 14(4): 375-381. 
Zeng, R., R. Spolski, et al. (2007). "The molecular basis of IL-21-mediated proliferation." Blood 109(10): 4135-4142.

Zhang, H. W., Z. W. Chen, et al. (2011). "Clinical significance and prognosis of MYC translocation in diffuse large B-cell lymphoma." Hematol Oncol.

Zhang, Q., J. A. Didonato, et al. (1994). "BCL3 encodes a nuclear protein which can alter the subcellular location of NF-kappa B proteins." Mol Cell Biol 14(6): 3915-3926.

Zhu, X., R. Hart, et al. (2004). "Analysis of the major patterns of B cell gene expression changes in response to short-term stimulation with 33 single ligands." $\underline{\mathrm{J} \text { Immunol }}$ 173(12): 7141-7149.

Zipper, H., H. Brunner, et al. (2004). "Investigations on DNA intercalation and surface binding by SYBR Green I, its structure determination and methodological implications." Nucleic Acids Res 32(12): e103.

Zucca, E., F. Bertoni, et al. (1998). "Molecular analysis of the progression from Helicobacter pylori-associated chronic gastritis to mucosa-associated lymphoid-tissue lymphoma of the stomach." $\mathrm{N}$ Engl J Med 338(12): 804-810. 
Danksagung

Zunächst gilt mein Dank Prof. Dieter Kube, der mich in den letzten drei Jahren kompromisslos unterstützt hat. Sein Engagement und seine Ideen haben diese Arbeit essentiell geprägt. Vielen Dank, dass Du diese Arbeit ermöglicht hast!

Ich möchte mich besonders bei Frederike von Bonin und Neele Walther bedanken. Ihre gute Arbeit und zuverlässige Unterstützung hat entscheidend zur Form dieser Arbeit beigetragen! Dankeschön! Mein ganz besonderer Dank gilt Dr. Martina Vockerodt. Ihre enthusiastische Art und ihre überaus umfassende Betreuung haben mir sehr geholfen. Liebe Martina, die Zusammenarbeit mit dir hat mit immer unglaublich viel Spaß gemacht! (:) Danke dass Du mir so viel beigebracht hast und danke für den quietschenden LKW in der Zellkultur... Die Zeit in Brum werde ich nie vergessen! At this point I would like to thank Prof. Paul Murray for giving me the possibility to be his guest in his group in Birmingham! Special thanks go to Eszter Nagy, Kate Vrzalikova and all people from the laboratory in Birmingham for their support.

Ich möchte mich ganz herzlich bei Prof. Rainer Spang, Matthias Maneck, Katharina Meyer und der gesamten computational diagnostics group in Regensburg bedanken. Ohne die Kooperation mit Euch und Eure bioinformatische Expertise wäre vieles nicht möglich gewesen. Liebe Katharina, vielen Dank dass Du Dich für unsere Zusammenarbeit so eingesetzt hast und immer ein offenes Ohr für meine nicht enden wollenden Fragen hattest! Außerdem möchte ich mich bei Dr. Stefan Bentink bedanken. Seine Ideen waren essentiell für das Weiterkommen im MYC-Projekt. Lieber Stefan, danke dass Du auch jetzt neben deiner Arbeit so viel investiert hast!

Ich bedanke mich herzlich bei Prof. Michael Hummel und seiner AG, die im Rahmen des MMML Verbundes die Hybridisierung der microarrays durchgeführt haben. Außerdem möchte ich mich bei Prof. Georg Bornkamm bedanken, dafür, dass er das MYC Expressionsplasmid zur Verfügung gestellt hat. Ein großes Dankeschön geht auch an Prof. Arnd Kieser und seine AG, die uns mit dem JNK-Kinase Assay unterstützt haben. An dieser Stelle möchte ich mich ganz besonders bei Antje Ulrich bedanken, dafür dass sie nach München gefahren ist um den Kinase Assay durchzuführen. :)

Christina Heemann danke ich speziell für Ihre Hilfe mit den CHIPs. Außerdem möchte ich mich bei Kamila Matulewicz bedanken die mit Ihren Vorarbeiten zu CD40 einen entscheidenden Anstoß zur Weiterentwicklung meines Projekts gegeben hat. Außerdem danke ich Katrin Moses und Katja Hüttner für die gute Zusammenarbeit im 
BAFF-Projekt. Ich danke allen meinen Kollegen in der AG Kube für unsere unglaublich tolle Arbeitsatmosphäre und besonders Frederike für jeden Freitags-Witz!

Des Weiteren möchte ich mir bei Prof. Heidi Hahn und Prof. Martin Oppermann bedanken. Ihre Diskussionsbereitschaft und Ihr Interesse in den Thesis Committees haben mich immer wieder auf ein Neues motiviert. Ich danke allen Mitgliedern des GRK1043, insbesonere Prof. Brockmöller und Sven Müller

Ganz besonders möchte ich mich bedanken bei den Mädels aus dem OST-Büro (incl. aller ehemaligen). Bei Euch habe ich gelernt, dass die Wanderung auf dem Grad zum Wahnsinn auch ein lustiger und ausgelassener Tanz sein kann! :) Alles wir einfacher wenn man darüber lacht... Insbesondere herzlich danken möchte ich Betty und Julia, die beim Korrekturlesen der Arbeit geholfen haben und Sandra, die immer einen konstruktiven Vorschlag parat hatte!

Für meine Familie und meine Freunde möchte ich an dieser Stelle ein Zitat von Goethe aufgreifen: „Leider lässt sich eine wahrhaftige Dankbarkeit mit Worten nicht ausdrücken.“ (Goethe 1749-1832). Dennoch möchte ich diese Gelegenheit nutzen um einfach mal allen danke zu sagen, die mich bisher, auch im Verlauf der Doktorarbeit, begleitet haben. Ich danke meinen Eltern und meinen Großeltern für Ihre bedingungslose Unterstützung in jeglicher Hinsicht. Frederik danke ich dafür, dass er einfach da ist. Meinen Mädels aus Soest danke ich dafür dass wir es tatsächlich geschafft haben noch immer unser Leben miteinander zu teilen. Gruppe Dino möchte ich danken für eine unvergessliche Studienzeit, insbesondere Julia dafür, dass sie unser zu Hause zu dem gemacht hat was es ist!

This work was supported by the DFG (GRK1034), the German Cancer Aid organisation (MMML), the BMBF (HaematoSys), the "Stiftung der Georg-August-Universität aus Mitteln der Kubeschka/Stricker/Wirth-Stiftung" and the UICC. 


\section{Appendix}

\section{Chapter 1 The c-Myc index}

Table A 1 Gene Set Enrichment Analysis of c-Myc responsive genes. Gene set enrichment analysis (GSEA) of the resulting ranked gene list was performed using the Java implementation of GSEA obtained from http://www.broadinstitute.org/gsea/. The ES (Enrichment Score) is given, which is the primary result of the gene set enrichment analysis and reflects the degree to which a gene set is overrepresented in a ranked list of genes. Gene sets are displayed in the order of the NES (Normalized Enrichment Score) which accounts for differences in gene set sizes and correlations between the gene set and the expression dataset. The NOM p-value (Nominal pvalue) is a statistical measure for the significance of the enrichment of one single gene set. The FDR q-value (False Discovery Rate) is adjusted for multiple testing.

\begin{tabular}{|c|c|c|c|c|c|}
\hline \multicolumn{6}{|l|}{$\begin{array}{l}\text { Gene sets enriched in c-Myc negatively } \\
\text { correlated genes }\end{array}$} \\
\hline Name & $\begin{array}{l}\text { Size of } \\
\text { Geneset }\end{array}$ & ES & NES & $\begin{array}{l}\text { NOM } \\
\text { p-val }\end{array}$ & $\begin{array}{l}\text { FDR } \\
\text { q-val }\end{array}$ \\
\hline WIELAND_HEPATITIS_B_INDUCED & 106 & $-0,44$ & $-2,07$ & 0,000 & 0,033 \\
\hline BASSO_GERMINAL_CENTER_CD40_UP & 97 & $-0,43$ & $-2,16$ & 0,000 & 0,026 \\
\hline NO2IL12PATHWAY & 15 & $-0,65$ & $-2,07$ & 0,000 & 0,043 \\
\hline TAKEDA_NUP8_HOXA9_8D_UP & 121 & $-0,40$ & $-2,06$ & 0,000 & 0,035 \\
\hline IGF_VS_PDGF_DN & 34 & $-0,52$ & $-2,04$ & 0,004 & 0,033 \\
\hline P53_BRCA1_UP & 28 & $-0,53$ & $-1,97$ & 0,000 & 0,058 \\
\hline LINDSTEDT_DEND_8H_VS_48H_UP & 64 & $-0,41$ & $-1,90$ & 0,000 & 0,086 \\
\hline IFNA_UV-CMV_COMMON_HCMV_6HRS_UP & 29 & $-0,49$ & $-1,90$ & 0,003 & 0,077 \\
\hline SANA_IFNG_ENDOTHELIAL_UP & 60 & $-0,42$ & $-1,90$ & 0,000 & 0,071 \\
\hline TNFA_NFKB_DEP_UP & 18 & $-0,57$ & $-1,89$ & 0,000 & 0,064 \\
\hline VERHAAK_AML_NPM1_MUT_VS_WT_UP & 189 & $-0,34$ & $-1,86$ & 0,000 & 0,074 \\
\hline STAEGE_EFTS_UP & 21 & $-0,53$ & $-1,86$ & 0,000 & 0,072 \\
\hline DAC_IFN_BLADDER_UP & 16 & $-0,58$ & $-1,85$ & 0,009 & 0,067 \\
\hline YANG_OSTECLASTS_SIG & 38 & $-0,46$ & $-1,85$ & 0,000 & 0,065 \\
\hline TAKEDA_NUP8_HOXA9_3D_UP & 150 & $-0,35$ & $-1,85$ & 0,000 & 0,063 \\
\hline IFNA_HCMV_6HRS_UP & 53 & $-0,42$ & $-1,84$ & 0,000 & 0,062 \\
\hline PHOTOSYNTHESIS & 20 & $-0,54$ & $-1,83$ & 0,003 & 0,062 \\
\hline CMV_HCMV_TIMECOURSE_12HRS_UP & 26 & $-0,50$ & $-1,83$ & 0,006 & 0,060 \\
\hline $\begin{array}{l}\text { HSA04060_CYTOKINE_CYTOKINE_RECEPTOR } \\
\text { _INTERACTION }\end{array}$ & 226 & $-0,32$ & $-1,83$ & 0,000 & 0,057 \\
\hline TAKEDA_NUP8_HOXA9_16D_UP & 135 & $-0,35$ & $-1,82$ & 0,000 & 0,058 \\
\hline $\begin{array}{l}\text { Gene sets enriched in c-Myc positively } \\
\text { correlated genes }\end{array}$ & & & & & \\
\hline Name & $\begin{array}{l}\text { Size of } \\
\text { Geneset }\end{array}$ & ES & NES & $\begin{array}{l}\text { NOM } \\
\text { p-val }\end{array}$ & $\begin{array}{l}\text { FDR } \\
\text { q-val }\end{array}$ \\
\hline PENG_GLUTAMINE_DN & 248 & 0,56 & 2,61 & 0,000 & 0,000 \\
\hline
\end{tabular}


Appendix

\begin{tabular}{|c|c|c|c|c|c|}
\hline BLEO_MOUSE_LYMPH_HIGH_24HRS_DN & 34 & 0,74 & 2,52 & 0,000 & 0,000 \\
\hline MRNA_PROCESSING_REACTOME & 102 & 0,58 & 2,44 & 0,000 & 0,000 \\
\hline MENSSEN_MYC_UP & 31 & 0,71 & 2,41 & 0,000 & 0,000 \\
\hline MANALO_HYPOXIA_DN & 78 & 0,59 & 2,40 & 0,000 & 0,000 \\
\hline MRNA_PROCESSING & 41 & 0,67 & 2,38 & 0,000 & 0,000 \\
\hline PENG_RAPAMYCIN_DN & 188 & 0,52 & 2,38 & 0,000 & 0,000 \\
\hline PENG_LEUCINE_DN & 139 & 0,54 & 2,35 & 0,000 & 0,000 \\
\hline MYC_TARGETS & 39 & 0,64 & 2,25 & 0,000 & 0,000 \\
\hline CANCER_NEOPLASTIC_META_UP & 60 & 0,57 & 2,21 & 0,000 & 0,000 \\
\hline TRANSLATION_FACTORS & 45 & 0,61 & 2,20 & 0,000 & 0,000 \\
\hline SCHUMACHER_MYC_UP & 50 & 0,59 & 2,19 & 0,000 & 0,002 \\
\hline COLLER_MYC_UP & 17 & 0,75 & 2,18 & 0,000 & 0,003 \\
\hline MTORPATHWAY & 23 & 0,70 & 2,16 & 0,000 & 0,004 \\
\hline BRCA1_OVEREXP_DN & 109 & 0,51 & 2,16 & 0,000 & 0,004 \\
\hline CANTHARIDIN_DN & 49 & 0,58 & 2,15 & 0,000 & 0,004 \\
\hline TARTE_PLASMA_BLASTIC & 305 & 0,45 & 2,13 & 0,000 & 0,006 \\
\hline MYC_ONCOGENIC_SIGNATURE & 173 & 0,47 & 2,11 & 0,000 & 0,006 \\
\hline MRNA_SPLICING & 47 & 0,58 & 2,09 & 0,000 & 0,009 \\
\hline ET743_SARCOMA_DN & 246 & 0,45 & 2,09 & 0,000 & 0,010 \\
\hline
\end{tabular}

\section{Chapter 2 Global gene expression changes}

Table A 2 IL21 responsive genes. This table shows the effects of rhIL21 on the most variable genes. 100 probesets with the highest differential expression were selected from all significantly regulated genes. Probesets that were array specific and not spotted on the HG U133 plus, which was used for the evaluation of aNHL samples, were discarded and excluded from further analysis.

\begin{tabular}{|c|c|c|c|c|c|c|c|}
\hline & GenSymbols & Probeset-ID & $\log F C$ & AveExpr & $t$ & P.Value & adj.P.Val \\
\hline 1 & IRF9 & 203882_at & $-3,16$ & 7,46 & $-39,06$ & 0,00 & 0,00 \\
\hline 2 & ICAM1 & 202638_s_at & $-2,92$ & 8,06 & $-31,38$ & 0,00 & 0,00 \\
\hline 3 & SGK1 & 201739_at & $-2,80$ & 9,00 & $-20,13$ & 0,00 & 0,00 \\
\hline 4 & CD83 & 204440_at & $-2,71$ & 10,60 & $-34,67$ & 0,00 & 0,00 \\
\hline 5 & ICAM1 & 202637_s_at & $-2,70$ & 8,39 & $-28,47$ & 0,00 & 0,00 \\
\hline 6 & BATF & 205965_at & $-2,30$ & 9,42 & $-34,76$ & 0,00 & 0,00 \\
\hline 7 & IFIT1 & 203153_at & $-2,19$ & 6,35 & $-23,58$ & 0,00 & 0,00 \\
\hline 8 & IRF4 & 204562_at & $-2,17$ & 11,00 & $-24,84$ & 0,00 & 0,00 \\
\hline 9 & SLC30A1 & 212907_at & $-1,97$ & 7,68 & $-13,67$ & 0,00 & 0,00 \\
\hline 10 & IRF1 & 202531_at & $-1,97$ & 7,67 & $-19,28$ & 0,00 & 0,00 \\
\hline 11 & BCL2A1 & 205681_at & $-1,94$ & 8,84 & $-16,07$ & 0,00 & 0,00 \\
\hline 12 & IFIT5 & 203595_s_at & $-1,91$ & 6,74 & $-28,08$ & 0,00 & 0,00 \\
\hline 13 & NFKBIE & 203927_at & $-1,77$ & 8,62 & $-19,14$ & 0,00 & 0,00 \\
\hline 14 & EGR2 & 205249_at & $-1,69$ & 7,44 & $-15,60$ & 0,00 & 0,00 \\
\hline 15 & BIRC3 & 210538_s_at & $-1,66$ & 9,84 & $-16,54$ & 0,00 & 0,00 \\
\hline 16 & STAT1 & 200887_s_at & $-1,66$ & 8,89 & $-15,00$ & 0,00 & 0,00 \\
\hline 17 & ICAM1 & $215485 \mathrm{~s}$ at & $-1,65$ & 7,35 & $-15,69$ & 0,00 & 0,00 \\
\hline
\end{tabular}




\begin{tabular}{|c|c|c|c|c|c|c|c|}
\hline 18 & MX1 & 202086_at & $-1,64$ & 8,68 & $-17,78$ & 0,00 & 0,00 \\
\hline 19 & TNFAIP3 & 202644_s_at & $-1,64$ & 9,15 & $-11,68$ & 0,00 & 0,00 \\
\hline 20 & CXCL10 & 204533_at & $-1,62$ & 6,58 & $-25,63$ & 0,00 & 0,00 \\
\hline 21 & PTGER4 & 204897_at & $-1,56$ & 9,00 & $-13,41$ & 0,00 & 0,00 \\
\hline 22 & GADD45B & 207574_s_at & $-1,48$ & 8,85 & $-10,05$ & 0,00 & 0,00 \\
\hline 23 & TNFAIP3 & 202643 ss_at & $-1,44$ & 8,43 & $-10,77$ & 0,00 & 0,00 \\
\hline 24 & STAT1 & $\begin{array}{l}\text { AFFX- } \\
\text { HUMISGF3A/ } \\
\text { M97935_3_at }\end{array}$ & $-1,44$ & 8,22 & $-15,70$ & 0,00 & 0,00 \\
\hline 25 & RGS16 & 209324_s_at & $-1,44$ & 8,68 & $-8,34$ & 0,00 & 0,00 \\
\hline 26 & NFKBIA & 201502_s_at & $-1,44$ & 10,84 & $-10,37$ & 0,00 & 0,00 \\
\hline 27 & RGS16 & 209325_s_at & $-1,42$ & 8,68 & $-10,26$ & 0,00 & 0,00 \\
\hline 28 & IRF4 & 216986_s_at & $-1,40$ & 7,81 & $-17,95$ & 0,00 & 0,00 \\
\hline 29 & $\mathrm{ZC} 3 \mathrm{H} 12 \mathrm{~A}$ & 218810_at & $-1,38$ & 8,31 & $-14,00$ & 0,00 & 0,00 \\
\hline 30 & GADD45B & 209304_x_at & $-1,35$ & 8,74 & $-11,66$ & 0,00 & 0,00 \\
\hline 31 & MAP3K8 & 205027_s_at & $-1,33$ & 6,67 & $-12,96$ & 0,00 & 0,00 \\
\hline 32 & IFIT3 & 204747_at & $-1,27$ & 6,84 & $-13,18$ & 0,00 & 0,00 \\
\hline 33 & GADD45B & 209305_s_at & $-1,27$ & 8,27 & $-11,49$ & 0,00 & 0,00 \\
\hline 34 & USP18 & 219211_at & $-1,23$ & 7,20 & $-18,06$ & 0,00 & 0,00 \\
\hline 35 & IL2RA & 206341_at & $-1,21$ & 7,03 & $-14,85$ & 0,00 & 0,00 \\
\hline 36 & STAT1 & $\begin{array}{l}\text { AFFX- } \\
\text { HUMISGF3A/ } \\
\text { M97935_MB_at }\end{array}$ & $-1,19$ & 7,27 & $-12,32$ & 0,00 & 0,00 \\
\hline 37 & SAMSN1 & 220330 s_at & $-1,18$ & 8,15 & $-9,38$ & 0,00 & 0,00 \\
\hline 38 & BCL3 & 204908_s_at & $-1,16$ & 8,08 & $-12,80$ & 0,00 & 0,00 \\
\hline 39 & IER5 & 218611_at & $-1,16$ & 10,32 & $-11,09$ & 0,00 & 0,00 \\
\hline 40 & CXCR5 & 206126_at & $-1,16$ & 8,08 & $-17,16$ & 0,00 & 0,00 \\
\hline 41 & NUDT4 & 212183_at & $-1,14$ & 8,27 & $-16,19$ & 0,00 & 0,00 \\
\hline 42 & DUSP2 & 204794_at & $-1,13$ & 9,06 & $-9,07$ & 0,00 & 0,00 \\
\hline 43 & MARCKS & 201670_s_at & $-1,11$ & 8,85 & $-8,80$ & 0,00 & 0,00 \\
\hline 44 & STAT1 & 209969_s_at & $-1,11$ & 7,13 & $-13,11$ & 0,00 & 0,00 \\
\hline 45 & NA & 212181_s_at & $-1,10$ & 9,81 & $-18,49$ & 0,00 & 0,00 \\
\hline 46 & LRRC32 & 203835_at & $-1,10$ & 6,78 & $-12,56$ & 0,00 & 0,00 \\
\hline 47 & JUNB & 201473_at & $-1,09$ & 8,44 & $-10,31$ & 0,00 & 0,00 \\
\hline 48 & IL2RA & 211269_s_at & $-1,09$ & 6,92 & $-14,14$ & 0,00 & 0,00 \\
\hline 49 & TAP1 & 202307_s_at & $-1,09$ & 8,34 & $-17,64$ & 0,00 & 0,00 \\
\hline 50 & SNX11 & 220140_s_at & $-1,08$ & 9,08 & $-13,80$ & 0,00 & 0,00 \\
\hline 51 & ZFP36L1 & 211962_s_at & $-1,07$ & 9,16 & $-7,60$ & 0,00 & 0,00 \\
\hline 52 & IER2 & 202081_at & $-1,07$ & 10,04 & $-13,61$ & 0,00 & 0,00 \\
\hline 53 & STAT1 & $\begin{array}{l}\text { AFFX- } \\
\text { HUMISGF3A/ } \\
\text { M97935_MA_at }\end{array}$ & $-1,07$ & 7,89 & $-11,38$ & 0,00 & 0,00 \\
\hline 54 & PIM2 & 204269_at & $-1,06$ & 9,28 & $-14,10$ & 0,00 & 0,00 \\
\hline 55 & MCL1 & 200798 x at & $-1,04$ & 11,19 & $-11,97$ & 0,00 & 0,00 \\
\hline 56 & TLR7 & 220146_at & $-1,04$ & 7,21 & $-13,25$ & 0,00 & 0,00 \\
\hline 57 & MARCKS & 201669_s_at & $-1,00$ & 10,41 & $-8,34$ & 0,00 & 0,00 \\
\hline 58 & SRSF5 & 203380_x_at & $-1,00$ & 9,98 & $-9,39$ & 0,00 & 0,00 \\
\hline 59 & NA & 206302_s_at & $-0,98$ & 9,92 & $-10,54$ & 0,00 & 0,00 \\
\hline 60 & ZFP36L1 & 211965_at & $-0,97$ & 7,53 & $-4,11$ & 0,00 & 0,02 \\
\hline 61 & SOCS1 & 210001_s_at & $-0,96$ & 7,38 & $-13,37$ & 0,00 & 0,00 \\
\hline 62 & CD40 & 215346_at & $-0,93$ & 8,82 & $-16,45$ & 0,00 & 0,00 \\
\hline 63 & BCL2L1 & 215037_s_at & $-0,92$ & 7,76 & $-10,96$ & 0,00 & 0,00 \\
\hline 64 & CYTIP & 209606_at & 0,93 & 8,04 & 13,75 & 0,00 & 0,00 \\
\hline 65 & HEY2 & 219743_at & 0,95 & 7,26 & 9,33 & 0,00 & 0,00 \\
\hline 66 & GADD45A & 203725_at & 0,98 & 8,54 & 12,98 & 0,00 & 0,00 \\
\hline 67 & VEGFA & 210512_s_at & 1,12 & 7,35 & 9,77 & 0,00 & 0,00 \\
\hline 68 & IL7R & 205798_at & 1,15 & 9,65 & 9,17 & 0,00 & 0,00 \\
\hline 69 & SOX2 & 213721_at & 1,16 & 7,96 & 10,16 & 0,00 & 0,00 \\
\hline 70 & DNAJB4 & 203811_s_at & 1,21 & 8,18 & 13,88 & 0,00 & 0,00 \\
\hline 71 & C13orf15 & 218723_s_at & 1,24 & 10,81 & 10,29 & 0,00 & 0,00 \\
\hline
\end{tabular}


Appendix

\begin{tabular}{|r|l|l|r|r|r|r|r|}
\hline 72 & ID1 & 208937_s_at & 1,49 & 7,73 & 14,36 & 0,00 & 0,00 \\
\hline 73 & DDIT4 & 202887_s_at & 1,51 & 9,39 & 8,53 & 0,00 & 0,00 \\
\hline 74 & ID3 & 207826_s_at & 1,53 & 11,03 & 17,50 & 0,00 & 0,00 \\
\hline 75 & DNAJB4 & 203810_at & 1,59 & 8,11 & 17,18 & 0,00 & 0,00 \\
\hline 76 & BCL6 & 215990_s_at & 1,67 & 8,88 & 20,75 & 0,00 & 0,00 \\
\hline 77 & BCL6 & 203140_at & 1,90 & 10,60 & 20,01 & 0,00 & 0,00 \\
\hline
\end{tabular}

Table A 3 CD40 responsive genes This table shows the effects of $\mathrm{SCD} 40 \mathrm{~L}$ on the most variable genes. 100 probesets with the highest differential expression were selected from all significantly regulated genes. Probesets that were array specific and not spotted on the HG U133 plus, which was used for the evaluation of aNHL samples, were discarded and excluded from further analysis.

\begin{tabular}{|c|c|c|c|c|c|c|c|}
\hline & GenSymbols & Probeset-ID & $\log \mathrm{FC}$ & AveExpr & $t$ & P.Value & adj.P.Val \\
\hline 1 & CD58 & 205173_x_at & $-1,62$ & 9,22 & $-12,40$ & 0,00 & 0,00 \\
\hline 2 & CD58 & 216942_s_at & $-1,51$ & 8,52 & $-11,46$ & 0,00 & 0,00 \\
\hline 3 & CD58 & 211744_s_at & $-1,49$ & 8,40 & $-10,79$ & 0,00 & 0,00 \\
\hline 4 & NA & 221491_x_at & $-1,26$ & 9,31 & $-12,92$ & 0,00 & 0,00 \\
\hline 5 & BTN2A2 & 205298_s_at & $-1,25$ & 7,59 & $-20,54$ & 0,00 & 0,00 \\
\hline 6 & DOCK10 & 219279_at & $-1,20$ & 7,79 & $-14,55$ & 0,00 & 0,00 \\
\hline 7 & HLA-DPA1 & 213537_at & $-1,11$ & 8,83 & $-8,45$ & 0,00 & 0,00 \\
\hline 8 & DENND4A & 214787_at & $-1,10$ & 8,48 & $-11,41$ & 0,00 & 0,00 \\
\hline 9 & CUX2 & 213920_at & $-1,09$ & 7,81 & $-12,65$ & 0,00 & 0,00 \\
\hline 10 & MAN1A1 & 208116_s_at & $-1,08$ & 8,57 & $-7,74$ & 0,00 & 0,00 \\
\hline 11 & HLA-DQA1 & 213831_at & $-1,07$ & 9,34 & $-9,35$ & 0,00 & 0,00 \\
\hline 12 & CCDC28B & 221912_s_at & $-1,07$ & 9,28 & $-16,04$ & 0,00 & 0,00 \\
\hline 13 & BATF & 205965_at & $-1,06$ & 9,42 & $-16,03$ & 0,00 & 0,00 \\
\hline 14 & FNBP1 & 212288_at & $-1,04$ & 9,68 & $-9,28$ & 0,00 & 0,00 \\
\hline 15 & MAN1A1 & 221760_at & $-1,04$ & 10,19 & $-8,59$ & 0,00 & 0,00 \\
\hline 16 & NFKB2 & 207535_s_at & $-1,01$ & 8,23 & $-11,68$ & 0,00 & 0,00 \\
\hline 17 & ICAM1 & 202638_s_at & $-1,01$ & 8,06 & $-10,81$ & 0,00 & 0,00 \\
\hline 18 & HLA-DQA1 & 203290_at & $-1,01$ & 10,45 & $-12,99$ & 0,00 & 0,00 \\
\hline 19 & ICAM1 & 202637_s_at & $-1,00$ & 8,39 & $-10,51$ & 0,00 & 0,00 \\
\hline 20 & HLA-DQB1 & 212998_x_at & $-0,99$ & 10,38 & $-9,23$ & 0,00 & 0,00 \\
\hline 21 & OLFML2A & 213075_at & $-0,99$ & 8,81 & $-12,76$ & 0,00 & 0,00 \\
\hline 22 & $\mathrm{IFIH1}$ & 219209_at & $-0,99$ & 7,97 & $-8,76$ & 0,00 & 0,00 \\
\hline 23 & HLA-DQB1 & 209480_at & $-0,99$ & 9,25 & $-7,13$ & 0,00 & 0,00 \\
\hline 24 & NA & 212671_s_at & $-0,98$ & 11,06 & $-10,00$ & 0,00 & 0,00 \\
\hline 25 & HLA-DQB1 & 209823_x_at & $-0,97$ & 8,75 & $-9,46$ & 0,00 & 0,00 \\
\hline 26 & RPS6KA1 & 203379_at & $-0,96$ & 9,11 & $-8,94$ & 0,00 & 0,00 \\
\hline 27 & PLEKHO1 & 218223_s_at & $-0,94$ & 7,90 & $-13,22$ & 0,00 & 0,00 \\
\hline 28 & $\mathrm{CTSH}$ & 202295_s_at & $-0,94$ & 8,65 & $-12,51$ & 0,00 & 0,00 \\
\hline 29 & RUNX3 & 204198_s_at & $-0,93$ & 9,45 & $-6,30$ & 0,00 & 0,00 \\
\hline 30 & BMP2K & 59644_at & $-0,93$ & 8,17 & $-8,17$ & 0,00 & 0,00 \\
\hline 31 & WNT5A & 213425_at & $-0,92$ & 7,27 & $-9,15$ & 0,00 & 0,00 \\
\hline 32 & WNT5A & 205990_s_at & $-0,92$ & 7,76 & $-13,23$ & 0,00 & 0,00 \\
\hline 33 & FNBP1 & 213940_s_at & $-0,91$ & 9,19 & $-10,06$ & 0,00 & 0,00 \\
\hline 34 & ALCAM & 201951_at & $-0,91$ & 7,59 & $-10,42$ & 0,00 & 0,00 \\
\hline 35 & NFKB2 & 209636_at & $-0,90$ & 7,42 & $-12,07$ & 0,00 & 0,00 \\
\hline 36 & SYNGR2 & 201079_at & $-0,90$ & 9,78 & $-10,25$ & 0,00 & 0,00 \\
\hline 37 & HLA-DQB1 & 211656_x_at & $-0,89$ & 9,69 & $-9,65$ & 0,00 & 0,00 \\
\hline 38 & NA & 206302_s_at & $-0,89$ & 9,92 & $-9,54$ & 0,00 & 0,00 \\
\hline 39 & HCP5 & 206082_at & $-0,88$ & 7,10 & $-10,00$ & 0,00 & 0,00 \\
\hline 40 & LAT2 & 221581_s_at & $-0,87$ & 8,32 & $-9,75$ & 0,00 & 0,00 \\
\hline 41 & PIK3CD & 203879_at & $-0,86$ & 9,99 & $-13,68$ & 0,00 & 0,00 \\
\hline 42 & HLA-DQB1 & 211654_x_at & $-0,85$ & 10,22 & $-10,13$ & 0,00 & 0,00 \\
\hline 43 & ANXA7 & 201366_at & $-0,85$ & 9,87 & $-9,67$ & 0,00 & 0,00 \\
\hline 44 & RUNX3 & 204197_s_at & $-0,85$ & 9,10 & $-11,13$ & 0,00 & 0,00 \\
\hline
\end{tabular}




\begin{tabular}{|c|c|c|c|c|c|c|c|}
\hline 45 & HLA-DQB1 & 212999_x_at & $-0,85$ & 8,04 & $-6,96$ & 0,00 & 0,00 \\
\hline 46 & BIRC3 & 210538_s_at & $-0,85$ & 9,84 & $-8,42$ & 0,00 & 0,00 \\
\hline 47 & HLA-E & 200905_x_at & $-0,84$ & 9,77 & $-8,96$ & 0,00 & 0,00 \\
\hline 48 & RASSF2 & 203185_at & $-0,84$ & 9,62 & $-8,32$ & 0,00 & 0,00 \\
\hline 49 & ELL2 & 214446_at & $-0,83$ & 7,16 & $-9,92$ & 0,00 & 0,00 \\
\hline 50 & HLA-B & 211911_x_at & $-0,83$ & 12,27 & $-13,69$ & 0,00 & 0,00 \\
\hline 51 & LOXL2 & 202998_s_at & $-0,83$ & 9,28 & $-9,55$ & 0,00 & 0,00 \\
\hline 52 & NFKBIE & 203927_at & $-0,83$ & 8,62 & $-8,97$ & 0,00 & 0,00 \\
\hline 53 & BMP2K & 219546_at & $-0,82$ & 8,19 & $-7,14$ & 0,00 & 0,00 \\
\hline 54 & FDXR & 207813_s_at & $-0,81$ & 7,77 & $-13,11$ & 0,00 & 0,00 \\
\hline 55 & RFX5 & 202963_at & $-0,81$ & 11,31 & $-13,10$ & 0,00 & 0,00 \\
\hline 56 & HLA-B & 208729_x_at & $-0,80$ & 12,06 & $-12,47$ & 0,00 & 0,00 \\
\hline 57 & TAP1 & 202307_s_at & $-0,79$ & 8,34 & $-12,81$ & 0,00 & 0,00 \\
\hline 58 & CIITA & 205101_at & $-0,79$ & 7,26 & $-6,73$ & 0,00 & 0,00 \\
\hline 59 & FAS & 215719_x_at & $-0,79$ & 6,67 & $-11,09$ & 0,00 & 0,00 \\
\hline 60 & PDZRN4 & 220595_at & 0,81 & 7,33 & 12,02 & 0,00 & 0,00 \\
\hline 61 & ID4 & 209291_at & 0,84 & 8,89 & 10,82 & 0,00 & 0,00 \\
\hline 62 & GPER & 210640_s_at & 0,85 & 7,11 & 6,27 & 0,00 & 0,00 \\
\hline 63 & AICDA & 219841_at & 0,86 & 10,06 & 10,10 & 0,00 & 0,00 \\
\hline 64 & IRF8 & 204057_at & 0,92 & 10,84 & 12,60 & 0,00 & 0,00 \\
\hline 65 & ID3 & 207826_s_at & 0,98 & 11,03 & 11,22 & 0,00 & 0,00 \\
\hline 66 & METTL7A & 207761_s_at & 1,01 & 9,60 & 13,40 & 0,00 & 0,00 \\
\hline 67 & CD83 & 204440_at & 1,02 & 10,60 & 13,04 & 0,00 & 0,00 \\
\hline 68 & SMAD1 & 210993_s_at & 1,13 & 9,31 & 11,49 & 0,00 & 0,00 \\
\hline 69 & DEPTOR & 218858_at & 1,16 & 9,52 & 18,56 & 0,00 & 0,00 \\
\hline 70 & C3orf37 & 201678_s_at & 1,43 & 9,54 & 11,46 & 0,00 & 0,00 \\
\hline 71 & ID1 & 208937_s_at & 2,01 & 7,73 & 19,30 & 0,00 & 0,00 \\
\hline
\end{tabular}

Table A 4 BCR responsive genes. This table shows the effects of BCRx on the most variable genes. 100 probesets with the highest differential expression were selected from all significantly regulated genes. Probesets that were array specific and not spotted on the HG U133 plus, which was used for the evaluation of aNHL samples, were discarded and excluded from further analysis.

\begin{tabular}{|c|c|c|c|c|c|c|c|}
\hline & GenSymbols & Probeset-ID & $\log F C$ & AveExpr & $t$ & P.Value & adj.P.Val \\
\hline 1 & RGS1 & 216834_at & $-5,48$ & 7,65 & $-19,42$ & 0,00 & 0,00 \\
\hline 2 & DUSP5 & 209457_at & $-5,01$ & 7,22 & $-32,60$ & 0,00 & 0,00 \\
\hline 3 & SGK1 & 201739_at & $-4,84$ & 9,00 & $-34,82$ & 0,00 & 0,00 \\
\hline 4 & RGS1 & 202988_s_at & $-4,75$ & 7,11 & $-24,85$ & 0,00 & 0,00 \\
\hline 5 & EGR2 & 205249_at & $-4,52$ & 7,44 & $-41,72$ & 0,00 & 0,00 \\
\hline 6 & BCL2A1 & 205681_at & $-4,30$ & 8,84 & $-35,53$ & 0,00 & 0,00 \\
\hline 7 & CCR7 & 206337_at & $-3,57$ & 8,24 & $-29,24$ & 0,00 & 0,00 \\
\hline 8 & EGR1 & 201694_s_at & $-3,23$ & 7,12 & $-21,01$ & 0,00 & 0,00 \\
\hline 9 & LY9 & 210370_s_at & $-3,19$ & 7,38 & $-48,30$ & 0,00 & 0,00 \\
\hline 10 & LY9 & 215967_s_at & $-3,17$ & 7,68 & $-50,09$ & 0,00 & 0,00 \\
\hline 11 & BHLHE40 & 201170_s_at & $-3,14$ & 7,62 & $-23,47$ & 0,00 & 0,00 \\
\hline 12 & PHLDA1 & 217996_at & $-3,05$ & 6,92 & $-17,97$ & 0,00 & 0,00 \\
\hline 13 & SQSTM1 & 201471_s_at & $-3,04$ & 9,39 & $-29,95$ & 0,00 & 0,00 \\
\hline 14 & DUSP2 & 204794_at & $-3,00$ & 9,06 & $-24,03$ & 0,00 & 0,00 \\
\hline 15 & DDIT3 & 209383_at & $-2,98$ & 7,47 & $-43,01$ & 0,00 & 0,00 \\
\hline 16 & CD83 & 204440_at & $-2,97$ & 10,60 & $-38,10$ & 0,00 & 0,00 \\
\hline 17 & PLEK & 203471_s_at & $-2,72$ & 9,22 & $-31,78$ & 0,00 & 0,00 \\
\hline 18 & CD1C & 205987_at & $-2,66$ & 8,15 & $-23,42$ & 0,00 & 0,00 \\
\hline 19 & TNFAIP3 & 202644_s_at & $-2,61$ & 9,15 & $-18,65$ & 0,00 & 0,00 \\
\hline 20 & TNFAIP3 & 202643_s_at & $-2,56$ & 8,43 & $-19,11$ & 0,00 & 0,00 \\
\hline 21 & PLEK & 203470_s_at & $-2,43$ & 9,27 & $-33,86$ & 0,00 & 0,00 \\
\hline 22 & PHACTR1 & 213638_at & $-2,42$ & 8,74 & $-23,64$ & 0,00 & 0,00 \\
\hline 23 & TRIB3 & 218145 at & $-2,35$ & 9,54 & $-27,70$ & 0,00 & 0,00 \\
\hline
\end{tabular}


Appendix

\begin{tabular}{|c|c|c|c|c|c|c|c|}
\hline 24 & FAM46C & 220306_at & $-2,34$ & 7,03 & $-15,34$ & 0,00 & 0,00 \\
\hline 25 & ZFP36L1 & 211962_s_at & $-2,33$ & 9,16 & $-16,52$ & 0,00 & 0,00 \\
\hline 26 & RGS16 & 209325_s_at & $-2,32$ & 8,68 & $-16,80$ & 0,00 & 0,00 \\
\hline 27 & TSC22D3 & 208763_s_at & $-2,29$ & 7,68 & $-25,00$ & 0,00 & 0,00 \\
\hline 28 & CD69 & 209795_at & $-2,28$ & 7,15 & $-18,06$ & 0,00 & 0,00 \\
\hline 29 & SLC7A11 & 217678_at & $-2,22$ & 6,89 & $-35,76$ & 0,00 & 0,00 \\
\hline 30 & ARAP2 & 213618_at & $-2,21$ & 7,49 & $-32,28$ & 0,00 & 0,00 \\
\hline 31 & NA & 205114_s_at & $-2,21$ & 6,61 & $-21,03$ & 0,00 & 0,00 \\
\hline 32 & HLA-DQB1 & 209480_at & $-2,21$ & 9,25 & $-15,94$ & 0,00 & 0,00 \\
\hline 33 & PTGER4 & 204897_at & $-2,20$ & 9,00 & $-18,91$ & 0,00 & 0,00 \\
\hline 34 & FAM102A & 212400_at & $-2,20$ & 9,06 & $-23,26$ & 0,00 & 0,00 \\
\hline 35 & SLC7A11 & 209921_at & $-2,18$ & 7,13 & $-30,99$ & 0,00 & 0,00 \\
\hline 36 & DUSP10 & 221563_at & $-2,14$ & 7,76 & $-22,26$ & 0,00 & 0,00 \\
\hline 37 & IER2 & 202081_at & $-2,14$ & 10,04 & $-27,27$ & 0,00 & 0,00 \\
\hline 38 & RGS16 & 209324_s_at & $-2,10$ & 8,68 & $-12,18$ & 0,00 & 0,00 \\
\hline 39 & PHLDA1 & 217997_at & $-2,09$ & 6,45 & $-15,00$ & 0,00 & 0,00 \\
\hline 40 & MDFIC & 211675_s_at & $-2,09$ & 8,34 & $-31,76$ & 0,00 & 0,00 \\
\hline 41 & IL21R & 221658_s_at & $-2,08$ & 7,91 & $-28,63$ & 0,00 & 0,00 \\
\hline 42 & SLAMF7 & 219159_s_at & $-2,04$ & 6,28 & $-20,32$ & 0,00 & 0,00 \\
\hline 43 & CDKN1A & 202284_s_at & $-2,03$ & 8,85 & $-25,53$ & 0,00 & 0,00 \\
\hline 44 & UPP1 & 203234_at & $-2,03$ & 7,61 & $-21,74$ & 0,00 & 0,00 \\
\hline 45 & ARL4C & 202207_at & $-2,03$ & 6,64 & $-20,93$ & 0,00 & 0,00 \\
\hline 46 & JUND & 203752_s_at & $-2,02$ & 9,35 & $-14,05$ & 0,00 & 0,00 \\
\hline 47 & NAB2 & 212803_at & $-1,98$ & 7,26 & $-12,70$ & 0,00 & 0,00 \\
\hline 48 & KLF6 & 208961_s_at & $-1,97$ & 7,95 & $-15,99$ & 0,00 & 0,00 \\
\hline 49 & NFKBIE & 203927_at & $-1,96$ & 8,62 & $-21,23$ & 0,00 & 0,00 \\
\hline 50 & RAB8B & 219210_s_at & $-1,95$ & 7,83 & $-24,01$ & 0,00 & 0,00 \\
\hline 51 & CD58 & 205173_x_at & $-1,95$ & 9,22 & $-14,90$ & 0,00 & 0,00 \\
\hline 52 & NFKB1 & 209239_at & $-1,94$ & 9,97 & $-20,66$ & 0,00 & 0,00 \\
\hline 53 & АРОВЕСЗВ & 206632_s_at & $-1,93$ & 7,66 & $-15,05$ & 0,00 & 0,00 \\
\hline 54 & CTH & 217127_at & $-1,91$ & 7,99 & $-30,66$ & 0,00 & 0,00 \\
\hline 55 & TNF & 207113_s_at & $-1,91$ & 6,74 & $-13,67$ & 0,00 & 0,00 \\
\hline 56 & SLC30A1 & 212907_at & $-1,89$ & 7,68 & $-13,09$ & 0,00 & 0,00 \\
\hline 57 & DUSP10 & 215501_s_at & $-1,86$ & 7,34 & $-30,90$ & 0,00 & 0,00 \\
\hline 58 & NA & 221491_x_at & $-1,86$ & 9,31 & $-18,99$ & 0,00 & 0,00 \\
\hline 59 & TOR3A & 218459_at & $-1,85$ & 9,65 & $-25,87$ & 0,00 & 0,00 \\
\hline 60 & ARHGAP25 & 38149_at & $-1,85$ & 8,99 & $-30,42$ & 0,00 & 0,00 \\
\hline 61 & DENND4A & 214787_at & $-1,85$ & 8,48 & $-19,14$ & 0,00 & 0,00 \\
\hline 62 & ARHGAP25 & 204882_at & $-1,85$ & 8,60 & $-23,06$ & 0,00 & 0,00 \\
\hline 63 & NCKAP1 & 207738_s_at & 1,86 & 9,04 & 18,13 & 0,00 & 0,00 \\
\hline 64 & C13orf15 & 218723_s_at & 1,95 & 10,81 & 16,16 & 0,00 & 0,00 \\
\hline 65 & $\mathrm{RHOH}$ & 204951_at & 2,01 & 9,74 & 27,10 & 0,00 & 0,00 \\
\hline 66 & BCL6 & 203140_at & 2,04 & 10,60 & 21,41 & 0,00 & 0,00 \\
\hline 67 & ID1 & 208937_s_at & 2,09 & 7,73 & 20,12 & 0,00 & 0,00 \\
\hline 68 & DNAJB4 & 203810_at & 2,16 & 8,11 & 23,32 & 0,00 & 0,00 \\
\hline 69 & SOX4 & 201416_at & 2,27 & 9,20 & 24,61 & 0,00 & 0,00 \\
\hline 70 & SOX4 & 201417_at & 2,34 & 10,89 & 33,59 & 0,00 & 0,00 \\
\hline 71 & IL7R & 205798_at & 2,37 & 9,65 & 18,88 & 0,00 & 0,00 \\
\hline 72 & BMP7 & 209590_at & 2,37 & 9,07 & 27,89 & 0,00 & 0,00 \\
\hline 73 & ID4 & 209291_at & 2,69 & 8,89 & 34,82 & 0,00 & 0,00 \\
\hline 74 & CYP26A1 & 206424_at & 2,75 & 10,75 & 24,85 & 0,00 & 0,00 \\
\hline
\end{tabular}


Table A 5 LPS responsive genes This table shows the effects of LPS on the most variable genes. 100 probesets with the highest differential expression were selected from all significantly regulated genes. Probesets that were array specific and not spotted on the HG U133 plus, which was used for the evaluation of aNHL samples, were discarded and excluded from further analysis.

\begin{tabular}{|c|c|c|c|c|c|c|c|}
\hline & GenSymbols & Probeset-ID & $\log F C$ & AveExpr & $t$ & P.Value & adj.P.Val \\
\hline 1 & NA & 221491_x_at & $-0,95$ & 9,31 & $-9,75$ & 0,00 & 0,00 \\
\hline 2 & CD58 & 205173_x_at & $-0,83$ & 9,22 & $-6,39$ & 0,00 & 0,00 \\
\hline 3 & HLA-DPA1 & 213537_at & $-0,82$ & 8,83 & $-6,24$ & 0,00 & 0,00 \\
\hline 4 & MAN1A1 & 221760_at & $-0,78$ & 10,19 & $-6,48$ & 0,00 & 0,00 \\
\hline 5 & MAN1A1 & 208116_s_at & $-0,76$ & 8,57 & $-5,46$ & 0,00 & 0,00 \\
\hline 6 & CD58 & 216942_s_at & $-0,76$ & 8,52 & $-5,77$ & 0,00 & 0,00 \\
\hline 7 & CD58 & 211744_s_at & $-0,75$ & 8,40 & $-5,43$ & 0,00 & 0,01 \\
\hline 8 & IKBKE & 204549_at & $-0,72$ & 8,38 & $-11,41$ & 0,00 & 0,00 \\
\hline 9 & HLA-DQB1 & 212998 x at & $-0,72$ & 10,38 & $-6,71$ & 0,00 & 0,00 \\
\hline 10 & HLA-DQB1 & 209480_at & $-0,72$ & 9,25 & $-5,18$ & 0,00 & 0,01 \\
\hline 11 & OLFML2A & 213075_at & $-0,71$ & 8,81 & $-9,16$ & 0,00 & 0,00 \\
\hline 12 & CALR & 214315_x_at & $-0,70$ & 9,56 & $-3,99$ & 0,00 & 0,05 \\
\hline 13 & BATF & 205965_at & $-0,70$ & 9,42 & $-10,61$ & 0,00 & 0,00 \\
\hline 14 & HLA-DQB1 & 212999_x_at & $-0,70$ & 8,04 & $-5,77$ & 0,00 & 0,00 \\
\hline 15 & MT1X & 204326_x_at & $-0,67$ & 7,84 & $-7,42$ & 0,00 & 0,00 \\
\hline 16 & HLA-DQB1 & 211656_x_at & $-0,66$ & 9,69 & $-7,19$ & 0,00 & 0,00 \\
\hline 17 & HLA-DQB1 & 209823_x_at & $-0,65$ & 8,75 & $-6,27$ & 0,00 & 0,00 \\
\hline 18 & ANXA7 & 201366_at & $-0,64$ & 9,87 & $-7,30$ & 0,00 & 0,00 \\
\hline 19 & IKBKE & 214398_s_at & $-0,64$ & 8,07 & $-10,88$ & 0,00 & 0,00 \\
\hline 20 & HLA-DQB1 & 211654_x_at & $-0,62$ & 10,22 & $-7,39$ & 0,00 & 0,00 \\
\hline 21 & HLA-DQA1 & 213831_at & $-0,62$ & 9,34 & $-5,43$ & 0,00 & 0,01 \\
\hline 22 & FNBP1 & 212288_at & $-0,62$ & 9,68 & $-5,50$ & 0,00 & 0,00 \\
\hline 23 & NA & 206302 s at & $-0,60$ & 9,92 & $-6,49$ & 0,00 & 0,00 \\
\hline 24 & NA & 212671_s_at & $-0,60$ & 11,06 & $-6,14$ & 0,00 & 0,00 \\
\hline 25 & HLA-DQA1 & 203290_at & $-0,59$ & 10,45 & $-7,61$ & 0,00 & 0,00 \\
\hline 26 & IRF4 & 204562_at & $-0,58$ & 11,00 & $-6,59$ & 0,00 & 0,00 \\
\hline 27 & CREBZF & 202979_s_at & $-0,57$ & 8,23 & $-4,43$ & 0,00 & 0,02 \\
\hline 28 & IGLL1 & 206660_at & $-0,55$ & 9,38 & $-8,98$ & 0,00 & 0,00 \\
\hline 29 & DNAJB1 & 200664_s_at & $-0,54$ & 9,39 & $-4,63$ & 0,00 & 0,02 \\
\hline 30 & IFIT3 & 204747_at & $-0,54$ & 6,84 & $-5,59$ & 0,00 & 0,00 \\
\hline 31 & HLA-E & 200905_x_at & $-0,54$ & 9,77 & $-5,72$ & 0,00 & 0,00 \\
\hline 32 & PDLIM3 & 209621_s_at & $-0,54$ & 8,96 & $-7,13$ & 0,00 & 0,00 \\
\hline 33 & DNAJB1 & 200666_s_at & $-0,54$ & 10,02 & $-4,76$ & 0,00 & 0,01 \\
\hline 34 & DENND4A & 214787_at & $-0,54$ & 8,48 & $-5,54$ & 0,00 & 0,00 \\
\hline 35 & NARF & 219862_s_at & 0,54 & 9,37 & 6,32 & 0,00 & 0,00 \\
\hline 36 & SPG11 & 203513_at & 0,54 & 8,80 & 7,68 & 0,00 & 0,00 \\
\hline 37 & GPM6A & 209469_at & 0,55 & 8,34 & 4,73 & 0,00 & 0,02 \\
\hline 38 & MYBL1 & 213906_at & 0,56 & 8,08 & 5,44 & 0,00 & 0,00 \\
\hline 39 & BNIP3L & 221478_at & 0,56 & 9,54 & 5,51 & 0,00 & 0,00 \\
\hline 40 & STAP1 & 220059_at & 0,56 & 10,36 & 7,50 & 0,00 & 0,00 \\
\hline 41 & TRIM22 & 213293_s_at & 0,57 & 9,60 & 5,87 & 0,00 & 0,00 \\
\hline 42 & PIK3C2B & 204484_at & 0,57 & 8,90 & 7,36 & 0,00 & 0,00 \\
\hline 43 & GPER & 210640_s_at & 0,59 & 7,11 & 4,33 & 0,00 & 0,03 \\
\hline 44 & KLRC3 & 207723_s_at & 0,59 & 8,27 & 7,68 & 0,00 & 0,00 \\
\hline 45 & VEGFA & 210512_s_at & 0,59 & 7,35 & 5,19 & 0,00 & 0,01 \\
\hline 46 & P4HA1 & 207543_s_at & 0,59 & 9,01 & 4,38 & 0,00 & 0,03 \\
\hline 47 & SMAD1 & 210993_s at & 0,59 & 9,31 & 6,05 & 0,00 & 0,00 \\
\hline 48 & C7orf68 & 218507 at & 0,60 & 9,48 & 4,31 & 0,00 & 0,03 \\
\hline 49 & ID4 & 209292_at & 0,61 & 7,10 & 8,77 & 0,00 & 0,00 \\
\hline 50 & TXNIP & 201009_s_at & 0,62 & 8,21 & 4,68 & 0,00 & 0,02 \\
\hline 51 & TXNIP & 201008_s_at & 0,63 & 8,13 & 4,23 & 0,00 & 0,03 \\
\hline 52 & PTPRC & 212587_s_at & 0,64 & 9,74 & 6,77 & 0,00 & 0,00 \\
\hline 53 & PTPRC & 207238_s_at & 0,67 & 9,49 & 8,88 & 0,00 & 0,00 \\
\hline
\end{tabular}


Appendix

\begin{tabular}{|c|c|c|c|c|c|c|c|}
\hline 54 & CCNG2 & 211559_s_at & 0,69 & 8,54 & 6,98 & 0,00 & 0,00 \\
\hline 55 & KDM3A & 212689_s_at & 0,69 & 8,67 & 6,16 & 0,00 & 0,00 \\
\hline 56 & CCNG2 & 202769_at & 0,70 & 9,09 & 7,25 & 0,00 & 0,00 \\
\hline 57 & CCNG2 & 202770_s_at & 0,72 & 8,64 & 7,03 & 0,00 & 0,00 \\
\hline 58 & BNIP3 & 201848_s_at & 0,75 & 8,40 & 5,67 & 0,00 & 0,00 \\
\hline 59 & BNIP3 & 201849_at & 0,78 & 9,75 & 5,60 & 0,00 & 0,00 \\
\hline 60 & ID4 & 209291_at & 0,78 & 8,89 & 10,06 & 0,00 & 0,00 \\
\hline 61 & TXNIP & 201010_s_at & 0,79 & 8,40 & 5,59 & 0,00 & 0,00 \\
\hline 62 & METTL7A & 207761_s_at & 0,80 & 9,60 & 10,66 & 0,00 & 0,00 \\
\hline 63 & ID3 & 207826_s_at & 0,81 & 11,03 & 9,25 & 0,00 & 0,00 \\
\hline 64 & DDIT4 & 202887_s_at & 0,83 & 9,39 & 4,68 & 0,00 & 0,02 \\
\hline 65 & C3orf37 & 201678_s_at & 0,85 & 9,54 & 6,80 & 0,00 & 0,00 \\
\hline 66 & ID1 & 208937_s_at & 1,90 & 7,73 & 18,27 & 0,00 & 0,00 \\
\hline
\end{tabular}

Table A 6 BAFF responsive genes This table shows the effects of rhBAFF on the most variable genes. 100 probesets with the highest differential expression were selected from all significantly regulated genes. Probesets that were array specific and not spotted on the HG U133 plus, which was used for the evaluation of aNHL samples, were discarded and excluded from further analysis.

\begin{tabular}{|c|c|c|c|c|c|c|c|}
\hline & GenSymbols & ID & $\log \mathrm{FC}$ & AveExpr & $t$ & P.Value & adj.P.Val \\
\hline 1 & TCOF1 & 202384_s_at & $-0,74$ & \begin{tabular}{|r|}
8,23 \\
\end{tabular} & $-4,42$ & $\begin{array}{r}0,00 \\
\end{array}$ & 0,03 \\
\hline 2 & HLA-DQA1 & 203290_at & $-0,73$ & 10,45 & $-9,46$ & 0,00 & 0,00 \\
\hline 3 & HLA-DQB1 & 209823_x_at & $-0,73$ & 8,75 & $-7,06$ & 0,00 & 0,00 \\
\hline 4 & HLA-DQB1 & 212998 x_at & $-0,71$ & 10,38 & $-6,57$ & 0,00 & 0,00 \\
\hline 5 & NA & 221491_x_at & $-0,70$ & 9,31 & $-7,21$ & 0,00 & 0,00 \\
\hline 6 & RUNX3 & 204198_s_at & $-0,70$ & 9,45 & $-4,74$ & 0,00 & 0,02 \\
\hline 7 & EIF5B & 214314_s_at & $-0,68$ & 7,93 & $-4,23$ & 0,00 & 0,04 \\
\hline 8 & NA & 212671_s_at & $-0,65$ & 11,06 & $-6,64$ & 0,00 & 0,00 \\
\hline 9 & C1orf63 & 209006_s_at & $-0,65$ & 6,99 & $-5,29$ & 0,00 & 0,01 \\
\hline 10 & EIF5B & 201024_x_at & $-0,63$ & 10,17 & $-4,20$ & 0,00 & 0,04 \\
\hline 11 & IGLL1 & 206660_at & $-0,61$ & 9,38 & $-10,13$ & 0,00 & 0,00 \\
\hline 12 & HLA-DQB1 & 211656 x_at & $-0,61$ & 9,69 & $-6,67$ & 0,00 & 0,00 \\
\hline 13 & DENND4A & 214787_at & $-0,60$ & 8,48 & $-6,20$ & 0,00 & 0,00 \\
\hline 14 & LRRFIP1 & 201862_s_at & $-0,59$ & 10,36 & $-4,08$ & 0,00 & 0,05 \\
\hline 15 & OLFML2A & 213075_at & $-0,59$ & 8,81 & $-7,54$ & 0,00 & 0,00 \\
\hline 16 & SLC23A2 & 209236 at & $-0,59$ & 8,56 & $-6,87$ & 0,00 & 0,00 \\
\hline 17 & RUNX3 & 204197_s_at & $-0,59$ & 9,10 & $-7,67$ & 0,00 & 0,00 \\
\hline 18 & NCOR2 & 207760_s_at & $-0,58$ & 8,95 & $-4,23$ & 0,00 & 0,04 \\
\hline 19 & CD58 & 205173_x at & $-0,57$ & 9,22 & $-4,35$ & 0,00 & 0,03 \\
\hline 20 & ICAM1 & 202638_s_at & $-0,57$ & 8,06 & $-6,09$ & 0,00 & 0,00 \\
\hline 21 & HLA-DQB1 & 211654_x_at & $-0,56$ & 10,22 & $-6,59$ & 0,00 & 0,00 \\
\hline 22 & DNAJB1 & 200664_s_at & $-0,54$ & 9,39 & $-4,65$ & 0,00 & 0,02 \\
\hline 23 & MAN1A1 & 221760_at & $-0,54$ & 10,19 & $-4,47$ & 0,00 & 0,03 \\
\hline 24 & MT1X & 204326 x_at & $-0,53$ & 7,84 & $-5,91$ & 0,00 & 0,00 \\
\hline 25 & ICAM1 & 202637_s_at & $-0,53$ & 8,39 & $-5,61$ & 0,00 & 0,01 \\
\hline 26 & PEA15 & 200787_s_at & $-0,53$ & 8,75 & $-5,10$ & 0,00 & 0,01 \\
\hline 27 & HLA-DQA1 & 213831_at & $-0,53$ & 9,34 & $-4,61$ & 0,00 & 0,02 \\
\hline 28 & HSP90B1 & 200598_s_at & $-0,52$ & 10,33 & $-5,14$ & 0,00 & 0,01 \\
\hline 29 & HLA-B & 211911_x_at & $-0,52$ & 12,27 & $-8,55$ & 0,00 & 0,00 \\
\hline 30 & DNAJB1 & 200666_s_at & $-0,52$ & 10,02 & $-4,61$ & 0,00 & 0,02 \\
\hline 31 & CCDC28B & 221912_s_at & $-0,51$ & 9,28 & $-7,72$ & 0,00 & 0,00 \\
\hline 32 & LRP8 & 205282_at & $-0,51$ & 7,58 & $-6,07$ & 0,00 & 0,00 \\
\hline 33 & BIRC3 & 210538_s_at & $-0,51$ & 9,84 & $-5,06$ & 0,00 & 0,01 \\
\hline 34 & NFKB2 & 207535_s_at & $-0,50$ & 8,23 & $-5,79$ & 0,00 & 0,01 \\
\hline 35 & HSP90B1 & 200599_s_at & $-0,50$ & 11,68 & $-5,63$ & 0,00 & 0,01 \\
\hline 36 & ILF3 & 208931_s_at & $-0,50$ & 9,33 & $-4,48$ & 0,00 & 0,03 \\
\hline 37 & TOMM40 & 202264_s_at & $-0,50$ & 10,13 & $-5,13$ & 0,00 & 0,01 \\
\hline 38 & $\mathrm{ClZ1}$ & 213977_s_at & $-0,50$ & 8,51 & $-4,23$ & 0,00 & 0,04 \\
\hline 39 & FNBP1 & 212288_at & $-0,49$ & 9,68 & $-4,41$ & 0,00 & 0,03 \\
\hline
\end{tabular}




\begin{tabular}{|c|c|c|c|c|c|c|c|}
\hline 40 & SRRT & 201680_x_at & $-0,49$ & 10,85 & $-8,41$ & 0,00 & 0,00 \\
\hline 41 & NAA16 & 219378 at & $-0,49$ & 8,62 & $-4,78$ & 0,00 & 0,02 \\
\hline 42 & PEA15 & 200788_s_at & $-0,49$ & 8,91 & $-5,23$ & 0,00 & 0,01 \\
\hline 43 & HLA-B & $208729 \times$ at & $-0,49$ & 12,06 & $-7,62$ & 0,00 & 0,00 \\
\hline 44 & MYBBP1A & 219098_at & $-0,48$ & 8,89 & $-4,36$ & 0,00 & 0,03 \\
\hline 45 & CSF2RB & 205159_at & $-0,48$ & 8,77 & $-5,12$ & 0,00 & 0,01 \\
\hline 46 & HSP90B1 & $216449 \times$ at & $-0,48$ & 9,88 & $-6,29$ & 0,00 & 0,00 \\
\hline 47 & TAF1D & 218750_at & $-0,48$ & 7,51 & $-4,29$ & 0,00 & 0,04 \\
\hline 48 & KPNB1 & 208975_s_at & $-0,48$ & 10,45 & $-4,16$ & 0,00 & 0,04 \\
\hline 49 & HBP1 & 209102 s at & 0,48 & 8,16 & 5,22 & 0,00 & 0,01 \\
\hline 50 & POLD4 & 202996 at & 0,49 & 8,28 & 8,74 & 0,00 & 0,00 \\
\hline 51 & CD83 & 204440_at & 0,51 & 10,60 & 6,52 & 0,00 & 0,00 \\
\hline 52 & CCNG2 & 202770_s_at & 0,52 & 8,64 & 5,02 & 0,00 & 0,01 \\
\hline 53 & ALDOC & 202022_at & 0,52 & 8,26 & 6,89 & 0,00 & 0,00 \\
\hline 54 & BBOX1 & 205363_at & 0,52 & 6,82 & 5,33 & 0,00 & 0,01 \\
\hline 55 & CD24 & $216379 \times$ at & 0,53 & 12,11 & 8,03 & 0,00 & 0,00 \\
\hline 56 & ID4 & 209293_x_at & 0,53 & 7,79 & 7,23 & 0,00 & 0,00 \\
\hline 57 & GPR18 & 210279_at & 0,54 & 9,43 & 5,98 & 0,00 & 0,00 \\
\hline 58 & C3orf37 & 201678_s_at & 0,56 & 9,54 & 4,48 & 0,00 & 0,03 \\
\hline 59 & ID3 & 207826_s_at & 0,56 & 11,03 & 6,44 & 0,00 & 0,00 \\
\hline 60 & ID4 & 209292_at & 0,57 & 7,10 & 8,21 & 0,00 & 0,00 \\
\hline 61 & CCNG2 & 202769_at & 0,57 & 9,09 & 5,95 & 0,00 & 0,00 \\
\hline 62 & CD24 & 209772 s_at & 0,58 & 10,39 & 7,39 & 0,00 & 0,00 \\
\hline 63 & ID2 & 201565_s_at & 0,59 & 10,27 & 4,98 & 0,00 & 0,01 \\
\hline 64 & TXNIP & 201009_s_at & 0,62 & 8,21 & 4,71 & 0,00 & 0,02 \\
\hline 65 & C7orf68 & 218507_at & 0,63 & 9,48 & 4,55 & 0,00 & 0,03 \\
\hline 66 & CCNG2 & 211559_s_at & 0,64 & 8,54 & 6,48 & 0,00 & 0,00 \\
\hline 67 & BNIP3L & 221479_s_at & 0,64 & 9,06 & 7,57 & 0,00 & 0,00 \\
\hline 68 & P4HA1 & 207543_s_at & 0,65 & 9,01 & 4,83 & 0,00 & 0,02 \\
\hline 69 & PNOC & 205901_at & 0,67 & 11,84 & 10,66 & 0,00 & 0,00 \\
\hline 70 & GPER & 210640_s_at & 0,68 & 7,11 & 5,03 & 0,00 & 0,01 \\
\hline 71 & TXNIP & 201008_s_at & 0,70 & 8,13 & 4,67 & 0,00 & 0,02 \\
\hline 72 & BNIP3 & 201848_s_at & 0,72 & 8,40 & 5,47 & 0,00 & 0,01 \\
\hline 73 & BNIP3L & 221478_at & 0,73 & 9,54 & 7,19 & 0,00 & 0,00 \\
\hline 74 & TXNIP & 201010 s_at & 0,75 & 8,40 & 5,31 & 0,00 & 0,01 \\
\hline 75 & BNIP3 & 201849_at & 0,80 & 9,75 & 5,75 & 0,00 & 0,01 \\
\hline 76 & ID4 & 209291_at & 0,92 & 8,89 & 11,97 & 0,00 & 0,00 \\
\hline 77 & ID1 & 208937_s_at & 2,08 & 7,73 & 19,95 & 0,00 & 0,00 \\
\hline
\end{tabular}

\section{Chapter 3 Guided Clustering}

Table A 7 Cluster genes identified by guided clustering

\begin{tabular}{|c|c|c|c|c|c|c|c|c|c|c|}
\hline & IL21.1 & IL21.2 & CD40.1 & CD40.2 & BCR.1 & BCR.2 & LPS.1 & LPS.2 & BAFF.1 & BAFF.2 \\
\hline 1 & SEC24B & STAT1 & SFRS2 & PICK1 & XPO1 & MAPKSP1 & LAMA1 & GRIN2B & KPNB1 & EPHB4 \\
\hline 2 & RSRC2 & IRF1 & MRPL46 & SOX15 & PMS1 & ATF1 & VNN3 & POU2AF1 & SLTM & AGRN \\
\hline 3 & DYNC1LI1 & IFIT3 & MUS81 & HP & RNASEN & CCDC59 & ELAVL3 & NRD1 & REV1 & VCX2 \\
\hline 4 & USP8 & CXCL10 & TOE1 & TRIM17 & LBR & RSL24D1 & TSHZ2 & FAF1 & EIF3A & TBKBP1 \\
\hline 5 & RABGGTB & APOL6 & FARSA & CYP2A13 & CETN3 & BZW1 & MEGF8 & TRBV10-2 & LSM14A & DNAJC28 \\
\hline 6 & FAM178A & OASL & EIF4A3 & SLC9A3R2 & DCK & BNIP2 & FOXO4 & PDGFB & CKAP5 & GPR110 \\
\hline 7 & NOC3L & IFI44L & MCM3 & SDK2 & GPN3 & ETF1 & GRK1 & SLC34A1 & CENPE & ALDOAP2 \\
\hline 8 & MTERFD1 & IFIT1 & NOC3L & APOC4 & SLBP & TAF9 & ADAMTSL2 & NR2E3 & ORC6L & SLC18A3 \\
\hline 9 & ANKRD27 & RSAD2 & ANKRD27 & DCLK2 & RHOT1 & POMP & TMEM179B & CRTAC1 & KIF18B & MLXIPL \\
\hline 10 & ZDHHC6 & MX1 & DNAJA2 & CELA2B & CAND1 & GNAI3 & $\mathrm{DOHH}$ & GABRD & ATAD2 & DLG4 \\
\hline 11 & METAP1 & IFI44 & GPN2 & CNPY4 & RACGAP1 & ARF6 & PSD & PDIA2 & TOP2A & OSGIN1 \\
\hline 12 & C2orf49 & IFITM1 & C16orf80 & LTB4R2 & KIF20A & YWHAZ & SNAPC2 & ZNF205 & ASPM & ENPP3 \\
\hline 13 & TRA2B & IFITM3 & VRK1 & GPATCH2 & AURKA & GABPB1 & NIN & POU4F3 & WHSC1 & ALPI \\
\hline 14 & SFRS1 & & NDUFV2 & KCNQ1 & HMMR & CEBPG & FOXE1 & ADORA1 & SMC2 & SOX15 \\
\hline 15 & KRR1 & & COX4NB & SULT4A1 & NDC80 & MAPK6 & ZNF646 & KCNJ5 & $\mathrm{MSH} 2$ & CADM4 \\
\hline 16 & RBM25 & & SHQ1 & IGF2AS & CDC20 & RBM22 & C1orf183 & IGF2AS & CACYBP & STBD1 \\
\hline 17 & NUP50 & & MCAT & IGFBP5 & CENPA & C6orf62 & GJA8 & $\mathrm{ABO}$ & WBP4 & SCNN1A \\
\hline 18 & ZNHIT6 & & PRPF4 & STMN3 & PLK1 & ERBB2IP & SIX5 & TRGV5 & $\mathrm{ZC} 3 \mathrm{H} 13$ & PFKFB4 \\
\hline 19 & GNL2 & & LCMT1 & PYY2 & NEK2 & UBE2B & PTPRS & STMN3 & SFRS1 & MATN4 \\
\hline 20 & СCT6A & & RFC2 & SLC9A3 & CCNA2 & CSNK1A1 & TEX11 & PKLR & NASP & PCYT1B \\
\hline
\end{tabular}


Appendix

\begin{tabular}{|c|c|c|c|c|c|c|c|c|c|}
\hline 21 & POLR3E & RAD51C & ADRA2C & KIF18A & NFE2L2 & FOXC2 & WFDC8 & ACYP1 & LRAT \\
\hline 22 & RPL23AP7 & FEN1 & NRXN2 & RMI1 & PLEKHB2 & SLC2A4 & NRXN2 & SDCCAG1 & OPRD1 \\
\hline 23 & APIP & TRIP13 & AKAP4 & PBK & MTMR6 & C2orf72 & SPTB & LUC7L3 & NBR2 \\
\hline 24 & PSMC6 & TRA2B & FAM179B & PRC1 & TRIP12 & NFKBIL2 & OPRL1 & KIF20B & NPTXR \\
\hline 25 & ZC3H15 & SFRS1 & $\mathrm{PLCH} 2$ & BUB1B & TM9SF3 & EPO & CEMP1 & SUCLA2 & KRT16 \\
\hline 26 & SART3 & HNRNPR & ANKRD2 & PLK4 & DDX5 & GPR32 & SLC9A3R2 & SPAG5 & TNXB \\
\hline 27 & CHORDC1 & PEF1 & UCP3 & CDCA8 & YIPF4 & PRDM8 & TLX2 & MKI67 & TUBB4Q \\
\hline 28 & C14orf104 & C2orf47 & ALOX12B & $\mathrm{NCAPH}$ & CEP57 & PLEKHA4 & SYT5 & PLK4 & SH2D4A \\
\hline 29 & WDR3 & DLD & HIST1H2AK & TMEM48 & MIS12 & CYP11B2 & NFIX & NCAPH & TGFB2 \\
\hline 30 & FUBP3 & SFRS3 & MYCN & OIP5 & ZNF330 & BARX1 & MMP16 & PRDX3 & WIF1 \\
\hline 31 & TAF2 & DDX19A & SCN2B & CEP55 & LARP7 & KRT3 & SNCA & ADK & MYH15 \\
\hline 32 & ZMYM4 & CIAPIN1 & ZNF205 & KIF14 & NUP88 & CEBPE & MAP1LC3C & PAICS & HOXD10 \\
\hline 33 & ZBTB11 & CYC1 & EPB41L1 & ESPL1 & WAPAL & CDKN2B & APCS & EIF2B3 & GDF2 \\
\hline 34 & PRPF38B & PEX14 & SLC34A1 & POLA2 & VPS26A & $\mathrm{ZCCHC4}$ & PSPN & NUDC & CCL27 \\
\hline 35 & BTAF1 & GCDH & NHEJ1 & FEN1 & UBE2D3 & MTHFR & & KIN & MAPT \\
\hline 36 & TNFAIP8 & EXOSC4 & HDAC11 & BRCA1 & RBM15 & LRIT1 & & C12orf48 & CRYBB2 \\
\hline 37 & KIAA0406 & PUF60 & FKBP6 & TUBG1 & PITPNB & & & SSB & TPPP3 \\
\hline 38 & TM9SF3 & REEP4 & PCYT1B & MRPL16 & TARS & & & SMC3 & FGF20 \\
\hline 39 & PPWD1 & SF4 & SNCG & TACC3 & MAK16 & & & KIF14 & PCDHB17 \\
\hline 40 & UBXN2B & UBTF & OR3A2 & SAC3D1 & MTHFD2 & & & POLD1 & ADAMTS7 \\
\hline 41 & LUC7L3 & ABCF3 & PTCRA & ASPM & SNX5 & & & SCRIB & CABP2 \\
\hline 42 & GTF2H1 & RRP9 & ROM1 & WDHD1 & PDXDC1 & & & REXO4 & PRB3 \\
\hline 43 & PCNP & STX4 & NPHS1 & BIRC5 & DHX15 & & & $\mathrm{MSH} 3$ & UBTD1 \\
\hline 44 & ANAPC10 & CTCF & SIRT5 & CCNB1 & DENR & & & MPHOSPH10 & HSPB2 \\
\hline 45 & RECQL & SMARCAL1 & CATSPERB & ASF1B & ZNF410 & & & FASTKD3 & PDGFB \\
\hline 46 & KLHL2 & NOC4L & TCL6 & ORC1L & DERL2 & & & ARL6IP4 & NR2E3 \\
\hline 47 & TIMM17A & WDR18 & HGFAC & KIF2C & HNRNPK & & & SAFB2 & CRTAC1 \\
\hline 48 & CEP170 & PDCD5 & CCNJL & CDCA3 & C5orf28 & & & CHERP & C14orf115 \\
\hline 49 & RRS1 & MAT2A & $\mathrm{HOXC13}$ & FOXM1 & DIMT1L & & & SRRM1 & GPR37L1 \\
\hline 50 & LARP4 & AIMP2 & ADCY10 & RFC3 & CDK7 & & & ZNF146 & LCN1 \\
\hline 51 & DNAJB14 & MTIF2 & ACAP2 & ECT2 & RAP2C & & & SUPT16H & NDST1 \\
\hline 52 & SERBP1 & HEATR3 & HTR5A & DSCC1 & SSFA2 & & & KIAA0406 & TRPV6 \\
\hline 53 & RBM28 & DDRGK1 & TBL2 & C12orf48 & JMJD1C & & & UPF2 & HOXA3 \\
\hline 54 & SSB & THOC1 & SLC38A3 & WRAP53 & EIF1B & & & LUC7L2 & TP53TG5 \\
\hline 55 & MPHOSPH 10 & MTHFS & ATP6V1B1 & PARP2 & ZC3H15 & & & BMS1 & TSKS \\
\hline 56 & C1orf109 & TBL3 & PAX3 & TRIP13 & SAR1A & & & CHAF1A & KRT19P2 \\
\hline 57 & NOL7 & PPP3CA & RBP3 & KIF11 & BCAS2 & & & TCOF1 & RNLS \\
\hline 58 & TCEB1 & RPS6KA1 & C8orf30A & AASDHPPT & ETFDH & & & SAFB & XPNPEP3 \\
\hline 59 & MAGOH & TYMS & PBOV1 & FARSA & MMADHC & & & TOPBP1 & DDX25 \\
\hline 60 & $\mathrm{RCHY} 1$ & RASSF2 & GNG7 & CTCF & MRPS30 & & & SSRP1 & HSD3B2 \\
\hline 61 & C9orf82 & MRPL12 & NPPA & RNASEH2A & MRPL39 & & & SFRS12 & ACCN2 \\
\hline 62 & FBXW2 & HSPA14 & CLCN7 & NEIL3 & GMFB & & & BAZ1A & RGS7 \\
\hline 63 & ENOPH1 & BRMS1 & PDGFRA & STIL & TSG101 & & & DAZAP1 & TACR2 \\
\hline 64 & RARS & COPS7B & TASP1 & TARDBP & CSNK1D & & & RPAP3 & PSG3 \\
\hline 65 & TAF1A & PIK3CD & EXOSC1 & ARMC1 & GDI2 & & & $\mathrm{HSPH} 1$ & OR7C1 \\
\hline 66 & VEZF1 & $A C O X 3$ & WNT8B & MRPL35 & LASP1 & & & RSF1 & $\mathrm{BICC} 1$ \\
\hline 67 & CEBPZ & IMPDH1 & ADORA1 & WDR67 & CSGALNACT2 & & & TOP1 & SYN2 \\
\hline 68 & AGPAT5 & SARS2 & DHX29 & NUP37 & ZBTB1 & & & PPWD1 & CAMKV \\
\hline 69 & EIF3J & SPIB & TLX2 & MRPL12 & SLC2A3P1 & & & KTN1 & AMBN \\
\hline 70 & $\mathrm{ZCCHC8}$ & SH3BP5 & DUSP9 & RAD54L & ZNF217 & & & CENPF & EPB41L1 \\
\hline 71 & $\mathrm{CNIH}$ & DOCK10 & KCNJ5 & C16orf53 & CAPZA 1 & & & IARS2 & AP3D1 \\
\hline 72 & UNC50 & ARHGAP17 & & ALG6 & HMGCR & & & BRAP & SPAG9 \\
\hline 73 & SGMS1 & RAB7L1 & & TROAP & ATP2C1 & & & ACTR6 & OR11A1 \\
\hline 74 & MLX & EIF2B5 & & CDC7 & HSPA5 & & & FABP5 & PKLR \\
\hline 75 & AHCTF1 & MICALL1 & & RFC4 & PPP6C & & & POLR2F & SHB \\
\hline 76 & CEP57 & POP4 & & UNG & TOR1A & & & ITGB1BP1 & ADCY10 \\
\hline 77 & PIBF1 & TTC35 & & PPAT & JOSD1 & & & GNB1 & TGFBRAP1 \\
\hline 78 & PSMD12 & UAP1 & & FASTKD1 & PTBP1 & & & NUP107 & TRIM49 \\
\hline 79 & SDHAF1 & ICT1 & & KIF15 & YBX1 & & & TCP1 & $\mathrm{PCDH} 1$ \\
\hline 80 & C12orf44 & TACO1 & & ANP32A & EPRS & & & ССТ6A & ATP2B3 \\
\hline 81 & MFSD1 & MRPL34 & & SRRD & SDCBP & & & PRPF38B & RAX \\
\hline 82 & NPTN & C8orf33 & & LRRC47 & RNF4 & & & CPSF6 & CDHR5 \\
\hline 83 & SOAT1 & UCK2 & & PREB & CAB39 & & & AHSA1 & WNT8B \\
\hline 84 & SLC35A1 & TOMM70A & & $\mathrm{ZC} 3 \mathrm{H} 14$ & YAF2 & & & ERCC3 & $\mathrm{RHO}$ \\
\hline 85 & MTO1 & AGFG1 & & TTK & TMEM123 & & & YY1 & KRT15 \\
\hline 86 & GSPT1 & LSM12 & & EFTUD1 & TMEM222 & & & $\mathrm{CHD} 8$ & CACNA1E \\
\hline 87 & UTP6 & G3BP1 & & OSBPL11 & TFAM & & & PPIG & LMAN1L \\
\hline 88 & ANKRD40 & ANXA7 & & MYCBP & CDK17 & & & DUT & GUCA1B \\
\hline 89 & BANP & EXOC1 & & DYNLL1 & USP16 & & & CHORDC1 & DNAH9 \\
\hline 90 & TMEM33 & SLC25A46 & & NIF3L1 & GARS & & & DDX23 & NGFR \\
\hline 91 & TMED5 & TRPM3 & & MRFAP1L1 & $\mathrm{CNIH}$ & & & RUVBL1 & GJA3 \\
\hline 92 & SLC30A5 & DDX50 & & NARG2 & RAN & & & EXO1 & MYL10 \\
\hline 93 & SNW1 & EIF4E & & SPAST & C11orf57 & & & EIF5B & NR0B1 \\
\hline 94 & C14orf135 & $\mathrm{ZC} 3 \mathrm{H} 14$ & & ZW10 & LYRM1 & & & PABPN1 & GRAP2 \\
\hline 95 & POP1 & HEATR2 & & ELF2 & SARS & & & NDUFS8 & IFT140 \\
\hline 96 & $\mathrm{ZDHHC13}$ & GTF3C2 & & $\mathrm{ADH} 5$ & CLIC1 & & & TAF2 & LOC645961 \\
\hline 97 & KIAA1704 & TIMM23 & & ORC4L & MAPRE1 & & & BUB1B & PTPRU \\
\hline
\end{tabular}




\section{Appendix}

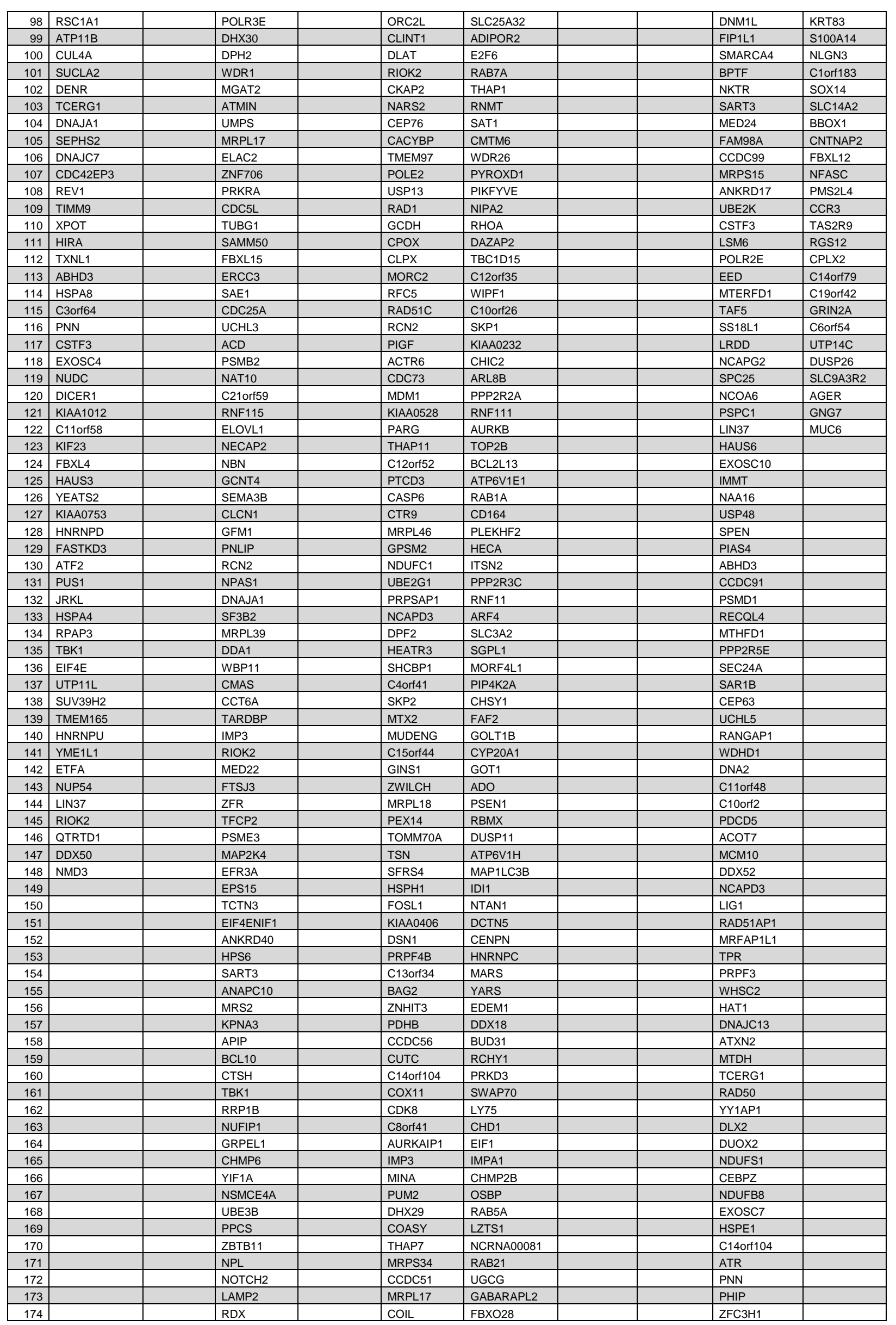


Appendix

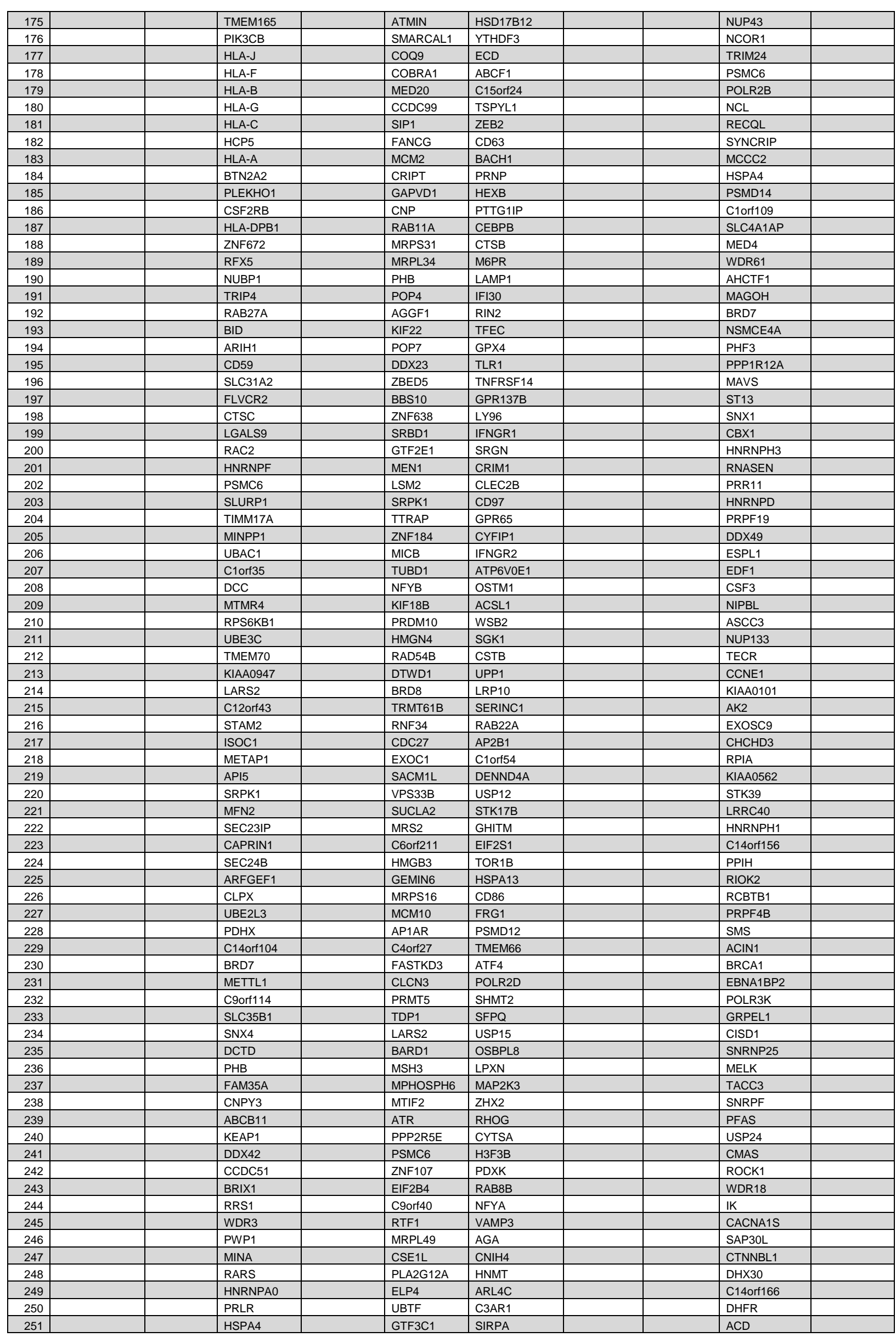




\section{Appendix}

\begin{tabular}{|c|c|c|c|c|}
\hline 252 & SIX3 & $\mathrm{BCOR}$ & EMP3 & GPN3 \\
\hline 253 & ADRA1D & C5orf22 & MKLN1 & PDHB \\
\hline 254 & WDR41 & TTC33 & ITM2B & PIBF1 \\
\hline 255 & ALCAM & PSME4 & CCPG1 & E4F1 \\
\hline 256 & PALB2 & PPM1B & CDC42 & \\
\hline 257 & SYNGR2 & PIAS4 & KIAA0430 & \\
\hline 258 & PSMC4 & WBP4 & TNPO1 & \\
\hline 259 & RAP2B & ACAP2 & TXNDC9 & \\
\hline 260 & TAF1B & GRSF1 & ElF2S2 & \\
\hline 261 & NUDT21 & $\begin{array}{l}\text { GADD45GIP } \\
1\end{array}$ & WARS & \\
\hline 262 & YARS2 & $\mathrm{MSH} 2$ & CCL4 & \\
\hline 263 & DCLRE1B & DTYMK & NINJ1 & \\
\hline 264 & CINP & FRAT2 & LGALS8 & \\
\hline 265 & IFRD2 & STAMBP & RRAGD & \\
\hline 266 & SERBP1 & C17orf75 & ACP5 & \\
\hline 267 & TTC4 & FANCL & C6orf145 & \\
\hline 268 & C16orf88 & SFRS2B & IL32 & \\
\hline 269 & PSMA7 & HMBS & $\mathrm{MARCH} 7$ & \\
\hline 270 & MCCC2 & PAAF1 & KLF10 & \\
\hline 271 & TESC & NAA40 & SMURF2 & \\
\hline 272 & LMNB2 & NDUFS3 & SFT2D2 & \\
\hline 273 & THAP11 & DUT & FAM18B & \\
\hline 274 & FNBP1 & STRA13 & UBL3 & \\
\hline 275 & EIF4H & HADH & MAFF & \\
\hline 276 & CD160 & SEPHS1 & TMEM30A & \\
\hline 277 & TRAPPC3 & ABHD10 & TMBIM6 & \\
\hline 278 & FASTKD3 & SLC4A1AP & MON1B & \\
\hline 279 & CTR9 & STRADA & DOCK2 & \\
\hline 280 & $\mathrm{HCK}$ & $\mathrm{CBX} 1$ & $\mathrm{NR} 3 \mathrm{C} 1$ & \\
\hline 281 & C3orf37 & MRPS27 & $\mathrm{GCH} 1$ & \\
\hline 282 & PHF16 & WRB & SAP30BP & \\
\hline 283 & TRIM44 & DERA & MATR3 & \\
\hline 284 & KCNJ1 & SAR1B & GCC2 & \\
\hline 285 & NOL11 & MAP3K4 & PLXNC1 & \\
\hline 286 & CPSF4 & KIAA1279 & HEXA & \\
\hline 287 & C7orf23 & PPCS & & \\
\hline 288 & RSRC2 & C5orf15 & & \\
\hline
\end{tabular}

Table A 8 Gene Set Enrichment Analyses (GO) Gene Set Enrichment for BCR.1 genes was performed using the Geneset annotations implemented in the GO database. The TOP100 most significantly enriched genesets corresponding to biological processes are shown below

\begin{tabular}{|r|l|l|l|}
\hline \multicolumn{2}{|l|}{ Biological Process } & $\begin{array}{l}\text { downreg. } \mathbf{p} \text { - } \\
\text { value }\end{array}$ \\
\hline & GO ID & GO Term & $6,00 \mathrm{E}-16$ \\
\hline $\mathbf{1}$ & GO:0007017 & microtubule-based process & $7,00 \mathrm{E}-15$ \\
\hline $\mathbf{2}$ & GO:0000278 & mitotic cell cycle & $5,00 \mathrm{E}-14$ \\
\hline $\mathbf{3}$ & GO:0006996 & organelle organization & $1,00 \mathrm{E}-13$ \\
\hline $\mathbf{4}$ & GO:0000226 & microtubule cytoskeleton organization & $2,00 \mathrm{E}-13$ \\
\hline $\mathbf{6}$ & GO:0051301 & cell division & $3,00 \mathrm{E}-13$ \\
\hline $\mathbf{7}$ & GO:0007059 & chromosome segregation & $5,00 \mathrm{E}-12$ \\
\hline $\mathbf{8}$ & GO:0006974 & DNA repair & $2,00 \mathrm{E}-11$ \\
\hline $\mathbf{9}$ & GO:0007051 & spindle organization & $4,00 \mathrm{E}-09$ \\
\hline $\mathbf{1 0}$ & GO:0000070 & mitotic sister chromatid segregation & $8,00 \mathrm{E}-09$ \\
\hline $\mathbf{1 1}$ & GO:0006260 & DNA replication & $8,00 \mathrm{E}-09$ \\
\hline $\mathbf{1 2}$ & GO:0000819 & sister chromatid segregation & $1,00 \mathrm{E}-08$ \\
\hline $\mathbf{1 3}$ & GO:0090304 & nucleic acid metabolic process & $3,00 \mathrm{E}-08$ \\
\hline $\mathbf{1 4}$ & GO:0010564 & regulation of cell cycle process & $9,00 \mathrm{E}-08$ \\
\hline $\mathbf{1 5}$ & GO:0044260 & cellular macromolecule metabolic process & $9,00 \mathrm{E}-08$ \\
\hline $\mathbf{1 6}$ & GO:0033554 & cellular response to stress & $2,00 \mathrm{E}-07$ \\
\hline $\mathbf{1 7}$ & GO:0051276 & chromosome organization & $2,00 \mathrm{E}-07$ \\
\hline $\mathbf{1 8}$ & GO:0006139 & nucleobase, nucleoside, nucleotide and nucleic acid metabolic process & $4,00 \mathrm{E}-07$ \\
\hline $\mathbf{1 9}$ & GO:0007098 & centrosome cycle & $7,00 \mathrm{E}-07$ \\
\hline $\mathbf{2 0}$ & GO:0000075 & cell cycle checkpoint & $8,00 \mathrm{E}-07$ \\
\hline $\mathbf{2 1}$ & GO:0051640 & organelle localization & $1,00 \mathrm{E}-06$ \\
\hline $\mathbf{2 2}$ & GO:0040001 & establishment of mitotic spindle localization & $1,00 \mathrm{E}-06$ \\
\hline $\mathbf{2 3}$ & GO:0051293 & establishment of spindle localization & $2,00 \mathrm{E}-06$ \\
\hline $\mathbf{2 4}$ & GO:0051653 & spindle localization & $2,00 \mathrm{E}-06$ \\
\hline
\end{tabular}


Appendix

\begin{tabular}{|c|c|c|c|}
\hline 25 & GO:0051726 & regulation of cell cycle & $2,00 \mathrm{E}-06$ \\
\hline 26 & GO:0016043 & cellular component organization & $3,00 \mathrm{E}-06$ \\
\hline 27 & GO:0034641 & cellular nitrogen compound metabolic process & $4,00 \mathrm{E}-06$ \\
\hline 28 & GO:0006261 & DNA-dependent DNA replication & $5,00 \mathrm{E}-06$ \\
\hline 29 & GO:0007052 & mitotic spindle organization & $9,00 \mathrm{E}-06$ \\
\hline 30 & GO:0006302 & double-strand break repair & $1,00 \mathrm{E}-05$ \\
\hline 31 & GO:0051297 & centrosome organization & $1,00 \mathrm{E}-05$ \\
\hline 32 & GO:0000132 & establishment of mitotic spindle orientation & $1,00 \mathrm{E}-05$ \\
\hline 33 & GO:0051294 & establishment of spindle orientation & $1,00 \mathrm{E}-05$ \\
\hline 34 & GO:0007010 & cytoskeleton organization & $1,00 \mathrm{E}-05$ \\
\hline 35 & GO:0009987 & cellular process & $1,00 \mathrm{E}-05$ \\
\hline 36 & GO:0006310 & DNA recombination & $2,00 \mathrm{E}-05$ \\
\hline 37 & GO:0006807 & nitrogen compound metabolic process & $2,00 \mathrm{E}-05$ \\
\hline 38 & GO:0031023 & microtubule organizing center organization & $2,00 \mathrm{E}-05$ \\
\hline 39 & GO:0046599 & regulation of centriole replication & $2,00 \mathrm{E}-05$ \\
\hline 40 & GO:0050000 & chromosome localization & $2,00 \mathrm{E}-05$ \\
\hline 41 & GO:0051303 & establishment of chromosome localization & $2,00 \mathrm{E}-05$ \\
\hline 42 & GO:0043170 & macromolecule metabolic process & $2,00 \mathrm{E}-05$ \\
\hline 43 & GO:0051656 & establishment of organelle localization & $3,00 \mathrm{E}-05$ \\
\hline 44 & GO:0007080 & mitotic metaphase plate congression & $4,00 \mathrm{E}-05$ \\
\hline 45 & GO:0051321 & meiotic cell cycle & $5,00 \mathrm{E}-05$ \\
\hline 46 & GO:0051983 & regulation of chromosome segregation & $7,00 \mathrm{E}-05$ \\
\hline 47 & GO:0007018 & microtubule-based movement & $7,00 \mathrm{E}-05$ \\
\hline 48 & GO:0006271 & DNA strand elongation involved in DNA replication & $1,00 \mathrm{E}-04$ \\
\hline 49 & GO:0034501 & protein localization to kinetochore & $1,00 \mathrm{E}-04$ \\
\hline 50 & GO:0007346 & regulation of mitotic cell cycle & $1,00 \mathrm{E}-04$ \\
\hline 51 & GO:0000910 & cytokinesis & $1,00 \mathrm{E}-04$ \\
\hline 52 & GO:0051310 & metaphase plate congression & $1,00 \mathrm{E}-04$ \\
\hline 53 & GO:0006397 & mRNA processing & $2,00 \mathrm{E}-04$ \\
\hline 54 & GO:0007126 & meiosis & $2,00 \mathrm{E}-04$ \\
\hline 55 & GO:0051327 & M phase of meiotic cell cycle & $2,00 \mathrm{E}-04$ \\
\hline 56 & GO:0044237 & cellular metabolic process & $3,00 \mathrm{E}-04$ \\
\hline 57 & GO:0010824 & regulation of centrosome duplication & $3,00 \mathrm{E}-04$ \\
\hline 58 & GO:0006270 & DNA-dependent DNA replication initiation & $3,00 \mathrm{E}-04$ \\
\hline 59 & GO:0010212 & response to ionizing radiation & $4,00 \mathrm{E}-04$ \\
\hline 60 & GO:0051298 & centrosome duplication & $4,00 \mathrm{E}-04$ \\
\hline 61 & GO:0033044 & regulation of chromosome organization & $4,00 \mathrm{E}-04$ \\
\hline 62 & GO:0032886 & regulation of microtubule-based process & $5,00 \mathrm{E}-04$ \\
\hline 63 & GO:0046605 & regulation of centrosome cycle & $5,00 \mathrm{E}-04$ \\
\hline 64 & GO:0000236 & mitotic prometaphase & $6,00 \mathrm{E}-04$ \\
\hline 65 & GO:0051299 & centrosome separation & $6,00 \mathrm{E}-04$ \\
\hline 66 & GO:0006297 & nucleotide-excision repair, DNA gap filling & $7,00 \mathrm{E}-04$ \\
\hline 67 & GO:0007062 & sister chromatid cohesion & $7,00 \mathrm{E}-04$ \\
\hline 68 & GO:0007099 & centriole replication & $8,00 \mathrm{E}-04$ \\
\hline 69 & GO:0022616 & DNA strand elongation & $8,00 \mathrm{E}-04$ \\
\hline 70 & GO:0031124 & mRNA 3'-end processing & $9,00 \mathrm{E}-04$ \\
\hline 71 & GO:0033043 & regulation of organelle organization & $1,00 \mathrm{E}-03$ \\
\hline 72 & GO:0006259 & DNA metabolic process & $<2 \mathrm{e}-16$ \\
\hline$\overline{73}$ & GO:0048285 & organelle fission & $<2 e-16$ \\
\hline 74 & GO:0022403 & cell cycle phase & $<2 e-16$ \\
\hline 75 & GO:0000280 & nuclear division & $<2 \mathrm{e}-16$ \\
\hline 76 & GO:0007067 & mitosis & $<2 e-16$ \\
\hline 77 & GO:0000087 & M phase of mitotic cell cycle & $<2 \mathrm{e}-16$ \\
\hline 78 & GO:0007049 & cell cycle & $<2 e-16$ \\
\hline 79 & GO:0000279 & M phase & $<2 \mathrm{e}-16$ \\
\hline 80 & GO:0022402 & cell cycle process & $<2 e-16$ \\
\hline 81 & GO:0007127 & meiosis I & 0.001 \\
\hline 82 & GO:0006412 & translation & 0.001 \\
\hline 83 & GO:0000724 & double-strand break repair via homologous recombination & 0.001 \\
\hline 84 & GO:0000725 & recombinational repair & 0.001 \\
\hline 85 & GO:0030010 & establishment of cell polarity & 0.001 \\
\hline 86 & GO:0051716 & cellular response to stimulus & 0.001 \\
\hline 87 & GO:0007143 & female meiosis & 0.001 \\
\hline 88 & GO:0007093 & mitotic cell cycle checkpoint & 0.001 \\
\hline 89 & GO:0000375 & RNA splicing, via transesterification reactions & 0.002 \\
\hline 90 & GO:0006289 & nucleotide-excision repair & 0.002 \\
\hline 91 & GO:0007088 & regulation of mitosis & 0.002 \\
\hline
\end{tabular}


Appendix

\begin{tabular}{|r|l|l|l|}
\hline $\mathbf{9 2}$ & GO:0051783 & regulation of nuclear division & 0.002 \\
\hline $\mathbf{9 3}$ & GO:0070507 & regulation of microtubule cytoskeleton organization & 0.002 \\
\hline $\mathbf{9 4}$ & GO:0000077 & DNA damage checkpoint & 0.002 \\
\hline $\mathbf{9 5}$ & GO:0016071 & mRNA metabolic process & 0.002 \\
\hline $\mathbf{9 6}$ & GO:0045132 & meiotic chromosome segregation & 0.002 \\
\hline $\mathbf{9 7}$ & GO:0045292 & nuclear mRNA cis splicing, via spliceosome & 0.002 \\
\hline $\mathbf{9 8}$ & GO:0006396 & RNA processing & 0.002 \\
\hline $\mathbf{9 9}$ & GO:0034621 & cellular macromolecular complex subunit organization & 0.003 \\
\hline $\mathbf{1 0 0}$ & GO:0044238 & primary metabolic process & 0.003 \\
\hline
\end{tabular}




\section{Curriculum vitae}

\section{Personal data}

Alexandra Schrader

Born:

Soest, Germany

Marital Status: unmarried

\section{Profession since April 2008}

Ph.D. student in the Department of Haematology and Oncology, Lymphoma-AG Prof Dr. Dieter Kube (GRK1034 fellowship of the DFG)

\section{Tertiary education}

$12 / 2003-08 / 2006$

Studies:

Degree:

Topic Bachelorthesis:

$10 / 2006-04 / 2008$

Studies:

Degree:

Topic Masterthesis:

\section{Language skills}

German:

native language

English:

French:

first language during studies, internet-based TOEFL (Test of English as a Foreign Language)

5 year classes

\section{Extended qualifications}

EDV skills in Microsoft Office (Word, Excel, Power Point), Endnote, $\mathrm{R}$ 


\section{Publications:}

High Myc activity is an independent negative prognostic factor for diffuse large B cell lymphomas

A. Schrader, S. Bentink, R. Spang, D. Lenze, M. Hummel, M. Kuo, J.R. Arrand, P.G. Murray, L. Trümper, D. Kube and M. Vockerodt

International Journal of Cancer. 2011 Sep 12. doi: 10.1002/ijc.26423 Epub ahead of print; PMID: 21913186

\section{Genomic data integration using guided clustering}

M. Maneck, A. Schrader, D. Kube, R. Spang

Bioinformatics. 2011 Jun 17.; PMID: 21685050

Down-regulation of BLIMP1a by the EBV oncogene, LMP-1, disrupts the plasma cell differentiation program and prevents viral replication in B cells: implications for the pathogenesis of EBV-associated B-cell lymphomas.

K. Vrzalikova, M. Vockerodt, S. Leonard, A. Bell, W. Wei, A. Schrader, K.L. Wright, D. Kube, M. Rowe, C.B. Woodman, P.G. Murray

Blood. 2011 Jun 2;117(22):5907-17. Epub 2011 Mar 16.; PMID: 21411757

Comparison of major gene expression patterns activated by B cell specific paracrine stimuli

A. Schrader, K. Meyer, N. Walther, M. Vockerodt, E. Hand, A. Ulrich, K. Matulewicz, D. Lenze, M. Hummel, A. Kieser, M. Engelke, M. Kuo, L.Trümper, R. Spang and D. Kube

in preparation

\section{LEF1 is a pro-proliferative factor in Burkitt lymphoma.}

A. Ulrich, N. Walther, M. Vockerodt, F. von Bonin, W. Klapper, K. Meyer, A. Schrader, R. Spang, T. Pukrop, P.G. Murray, L. Trümper and D. Kube

in preparation

\section{Congress Participation:}

\section{$14^{\text {th }}$ STS Meeting 2010 Weimar (Germany)}

Poster: "Aberrant expression of the prooncogene c-Myc in normal human germinal centre B cells triggers a tumor like expression pattern that is expressed in Burkitt lymphomas but also some DLBCL"; A. Schrader, S. Bentink, R. Spang, D. Lenze, M. Hummel, M. Kuo, J.R. Arrand, P.G. Murray, L. Trümper, D. Kube and M. Vockerodt

$4^{\text {th }}$ Poster Prize

\section{EACR21 Meeting 2010 Oslo (Norway)}

Poster: "A c-Myc induced gene expression signature in human germinal center B cells predicts subtypes of aggressive non-Hodgkin Lymphoma."; Schrader A, Bentink S, Spang R, Lenze D, Hummel M, Kuo M, Arrand JR, Murray P, Trümper L, Kube D, Vockerodt

\section{FOR942 Workshop 2009 Göttingen (Germany)}

Poster: "Dissecting the molecular events in Burkitt's Lymphoma by expressing Myc in lymphoma precursor cells"; A. Schrader, S. Bentink, R. Spang, D. Lenze, M. Hummel, M. Kuo, J.R. Arrand, P.G. Murray, L. Trümper, D. Kube, M. Vockerodt 